\title{
Untersuchungen über das Extremitätenskelett des Chinesen.
}

\author{
ron \\ Prof. Dr. E. Kurz, \\ Abtelunsworsteher an anatum. Institat der Universitat Müster. \\ Nit 14 Textabbildurgen.
}

(Eingegungen an 20. Jumi 19:2.)

Vorhegende Tntersuchungen über das Extremitätenskelett des Chinesen bilden einen Teil einer größeren Reihe von Arbeiten, die ich während meines mehrjährigen Aufenthaltes in China als Lehrer an der deutschen Medizinschule für Chinesen in Shanghai fertigstellen konnte. Selbst an Ort und Stelle ist es schwierig, osteologisches Material oder gar frische Leichen zu erhalten, da der Chinese den Verstorbenen mit besonderer Ehrfurcht betrachtet. Das von mir im Laufe mehrerer Jahre gesammelte Material stammt samt und sonders aus Shanghai. Für besonders wichtig halte ich es, daß ich wenigstens in einem Falle die gesamte Leiche einer 25 jahrigen, ca $145 \mathrm{~cm}$ großen, an Tuberkulose im Paulunhospital in Shanghai vexstorbenen Chinesin bearbeiten konnte und ich stellte hierbei nicht nur altertümliche Merkmale hinsichtlich des Skeletts, sondern auch in bezug auf die Muskulatur und das Gehirn fest. So fand ich eine geringe Schädelkapazität $(1180 \mathrm{ccm})$, sehr dicke Schädelknochen, einen stark prognathen Oberkiefer mit kxäftigen Zähnen, eine Schmelzrunzelung am dritten Molar, einen massiven, plumpen Unterliefer mit geringem Kinnvorsprung und einem breiten niederen Ast, der eine wenig tiefe Incisura semilunaris aufwies. Hinsichtich des Extremitätenskelettes ergab sich, daß namentlich die unteren Extremitaten einen primitiveren Typus als beim Europäer aufwiesen, daß insbesondere das Fußskelett die Merkmale der ehemaligen Kletterfunktion nicht ganz abgelegt hatte. Von großem Interesse ist es nun, daß ich in meinen Untersuchungen über die Muskulatur sowohl beim Neugeborenen als auch beim Erwachsenen auch hinsichtlich dieses Systemes primitive Befunde nachwies, wie auch japanische Autoren für eine Anzahl fon Muskeln dasselbe für den Japaner feststellten. Diese Tatsache gewinnt an Bedeutung, wenn wir sehen, daß nach Adachi die Russen hinsichtlich der Häufigkeit der Yuskelvarietäten den Mongoloiden näher stehen als den westlichen weißen Völkern. Fasse ich meine Untersuchungen über die Muskulatur der 25 jährigen Chinesin, deren Skelett hier abgehandolt wird, zusammen, so ergeben sich folgende primitiven Befunde:

Andeutung einer tiefen Schichte des Platysmas, ein beiderseits vorhandener M. sternalis, ein sehniger, vom M. latissimus dorsi ausgehender, gegen den Proc. corac. ausstrahlender Achselbogen, ein gut entwickelter M. occipitalis und $M$. palmaris brevis. Beide Anteile des M. sternocleidomast. sind völlig voneinander getrennt. Stemohyoidens mit Inscriptio tendinea, Omohyoideus mit akzessori- 
schem Kopf von der Clavicula. Kaunuskulatur bäftiger als beim Europäer: dbenso ist der X. biventer breiter als bei letzterem und vom medialen Rande des vorderen Bauches lösen sich Nuskelbündel zur anderen Seite los. Dor Biceps brachi war dreiköpfig, der Coracobrachialis and Pronator teres der Länge nach gespalten; letzterer reichte weiter distal als beim Europäer. In allen montersuchten fallen fand sich ein gut entwickelter W. palm. longus. Flexor digitorum subl. und prof. standen dureh Wushelbundel im Zusmmenhang, dit Zeigefingerportion res Profundus war beiderseits gesondert und der M. promotor quadratus ctstreckte wich weites proximal als beim Enropaer. Adductor pollitis in vior Kopfe getremt. Der M. glut. max. war proximal mit dem Medius verschmoluen, pyrifomis zweiköpfig nit durchtretendem $\mathrm{N}$. peronaeus, Psoas minor beiderseits gut entwickelt. Der Adductor magnus war beiderseits wie bei Altweltaffen (Macacous, Inuus, Cynocephalus) in zwei gleichgroße, von verschiedenen Nerven versorgte Portionen geschieden. Das Caput breve des Biceps reichte bis zum unteren Teil aes Trochanter major empor, was Testut auch für Feuerländer angibt. Klantsch ist geneigt, auf Grund verglejohend anatomischer und ontogenetischer Untersuchungen diesen weit proximal reichenden Ursprung des kurzen Kopfes für einen primitiven Befund zu halten. Dex M. plantaris war beiderseits gut entwickelt, ein Peronaeus parvus, den ich bei einem geringen Leichenmaterial dreimal feststellte, fehlte hier. In der Planta pedis zeigte der M. flexor digit. brevis wie bei den Affen einen tiefen Kopf. Er war $20 \mathrm{~mm}$ lang und $4 \mathrm{~mm}$ breit und nahm seinen Crsprung von der Unterflïche der gemeinschaftlichen Sehne des Flexor digitorum longus. Die Sehne des oberflächlichen Kopfes zur fünften Zehe fehlte. Am Gehirn war die Insel unbedeckt und beiderseits war eine sehr starke laterale Affenspalte vorhanden. Das Gehirngewicht betrug mit. Pia 1140 g. Uber den Kehlkopf, das Zungenbein, den Unterkiefer, das Sternum und die Rippen dieser Chinesin habe ich im Arch. f. Anat. u. Physiol. 1919, anat. Abteilung, berichtet. Ubber die Wirbelsänle im anat. Anz. Muskulatur and Gehirn werden demnächst ausführlich erscheinen. Die zahlreichen primitiven Befunde an den verschiedenen. Organen ließen es wünschenswert erscheinen, auch das Extremitatenskelett dieser Chinesin genau zu messen und zu beschreiben; ich konnte aber im Verlaufe meiner Untersuchungen noch anderes osteologisches Material in Shanghai sammeln, das teils aus im Freien aufgestellten chinesischen Särgen, teils aus dem Paulun. hospital in Shanghai stammt, so daB ich im ganzen über folgendes Material verfügte: 4 Scapulae, 3 Claviculae, 20 Humeri, 12 Radii, 9 Ulnae, 3 Handskelette, ein vollstundiges oberes Extremitatenskelett eines Neugeborenen, 4 Becken, 25 Femora, 4 Patellae, 5 Tibiae, 5 Fibulae, 4 Fubskelette von Erwachsenen, sowie das Becken, 2 Femora und eine Tibia eines Neugeborenen. Die Anordnung der Maßtabellen und die. Messungen selbst sind nach Martin, ,Lehrbuch der Anthropologie" ausgefuhrt. Ebendort findet sich auch ein reichhaltiges Literaturverzeichnis hinsichtlich des Extremitätenskelettes. Bezüglich des deformierten Fußes verweise ich auf $H$. Firchow: ,Abhdlg. der Preuß. Akad. d. Wiss.". Die Arbeit von $K$. A. Haberer ,Schädel und Skeletteile aus Peking, ein Beitrag zur somatischen Ethnologie der Mongolen" behandelt hauptsächlich den Schädel, während das Extremitätenskelett nur wenige Seiten umfaßt. Außerdem ist mein Waterial namentlich hinsichtlich des Hand- und FuBskelettes, da ich es selbst 
makerieren konnte, Follständiger und habe den Vorteil einer genauen Herkunt. In der Arbeit von Haberer ist anch an das in Deutschland befindliche chinesische osteologische Material verwiesen. Die Resultate meiner Cntersuchungen habe ich zusammengefaßt in meiner Arbeit, Ergebuisse rassenanatomischer Untersuchungen über das Extremitätenszelett des Chinesen", erschienen im Arch. $f$. Anat. u. Physiol. 1919. Anat. Abtlg. Ich verweise auf die Abbildungen 1-20 in dieser Arbeit: R. Scapula einer 25 jährigen Chinesin, $r$. Scapula eines 30 jahrigen Chinesen, 1. Clavicula einer 25 jährigen Chinesin. Humerus und Cuteramknochen eines 30 jährigen Chinesen und einer 25 jährigen Chinesin, Handskelet eines 30 jähligen Chinesen, Becken einer 25 jährigen Chinesin und eines 30 jährigen Chinesen, Femur und Cnterschenkelknohen eines 30 jährigen (hinesen and einer 25 jah rigen Chinesin. Fußskelett eines 30 jährigen Chinesen und einer 25 jährigen Chinesin. Bezüglich weiterer Abbildungen sei verwiesen auf Haberer, Abb. 95-107.

\section{Obere Extremität.}

Serpulat.

\section{Untersuchtes Material.}

1. Linke und rechte Seapula einer an Phthise verstorbenen 25jahrigen Chinesin (Präpariersaalleiche): Nr. 1 und 2.

2. Scapula eines an Gangraena pedum rerstorbenen 30 jährigen Chinesen (Priptipariersalleiche); Nr. 3.

3. Ausgegrabene Scapula eines Chinesen aus Schanghai; Nr. 4. Claviculae.

1. Die beiden Clavioulae dex 25jährigen Chinesin.

2. Laterale Halfte einer Clavicula des 30 jahrigen Chinesen.

Humeri.

1. Die beiden Humeri der 25jährigen thinesin.

2. Die beiden Humeri des 30 jährigen Chinesen.

3. Bruchstücke von 16 auggegrabenen Humeri (aus dem Cartenklub in Shanghai).

Radii.

1. Die beiden Radii der 25 jährigen Chinesin.

2. Ein Radius des 30 jährigen Chinesen.

3. Bruchstücke von nem ausgegrabenen Radii (Shanghid).

Ilnae.

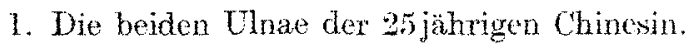

2. Die Ulna des 30 jährigen Chincsen.

3. Bruchstücke von 6 Uhae.

Handskelete.

1. Die beiden Handskelette der 25jährigen Chinesin.

2. Das Handskelett des 30 jahrigen Chinesen.

Gesamtskelett

der oberen Extremität eines neugeborenen ausgetragenen männichen Chinesenkindes. 


\section{Seapula.}

Die absoluten Dimensionen der Scapula der 25 jährigen Chinesin $\mathrm{Nr}, 1$ sind sehr gering. Die morphologische Breite beträgt links 128,5, rechts $130 \mathrm{~mm}$, während dieselbe für den Europäer im Mittel $160 \mathrm{~mm}$ beträgt (Broca). Die morphologische Länge beträgt 83,5 und $81,5 \mathrm{~mm}$; beim Europäer beläuft sie sich im Wittel auf $105 \mathrm{~mm}$. Aber auch die männliche Scapula Nr. 2 zeigt geringere Dimensionen als die europäische. Am kräftigsten ist die dritte Scapula, die aber immerhin die europäischen mittleren Dimensionen nicht erreicht. Die morphologische Breite schwankt an den vier vorliegenden chinesischen Scapulae zwischen 128,5 und $157 \mathrm{~mm}$. Der japanische Mann besitzt nach Koganei eine mittlere morphologische Breite von $142 \mathrm{~mm}$, die japanische Frau eine solche von $137 \mathrm{~mm}$. Die Flächenausdehnung sämtlicher chinesischer Scapulae ist geringer als die der mir vorliegenden deutschen Scapulae. Besonders klein ist die Flächenausdehnung der Scapula Nr. 1; sie deckt noch nicht einmal die Infraspinalgrube einer kräftigen deutsehen Scapula. Die beiden Scapulae Nr. I sind außerordentlich dünn und leicht. Die linke Scapula Nr. 1 wiegt nur $32 \mathrm{~g}$, während eine mir rorliegende deutsche Scapula $83,5 \mathrm{~g}$ wiegt. Die letztere ist immer noch um $21,5 \mathrm{~g}$ schwerer als die mir vorliegende kräftigste dritte Scapula eines chinesischen Mannes. -

Das Verhältnis der morphologischen Länge zur morphologischen Breite, der sog. Scapularindex, schwankt beim Chinesen zwischen 62,7 und 69,2. Bei den anthropomorphen Affen ist der Scapularindex etwas größer, 70 - 77 betragend (Flower). Für den Europäer gibt ihn der letztgenannte Autor zu 65,2, für den Neger zu 69,7 an. Für eine Rassendifferenz kann demnach der Scapularindex nicht verwertet werden.

An dem vorliegenden kleinen Material ist die sexuelle Differenz sehr in die Augen springend, was sich auch aus den Photographien ergibt, die alle auf eine Platte aufgenommen wurden, so daß sie die relativen Größenverhältnisse wiedergeben. Eine sexuelle Differenz besteht hinsichtlich des Gewichtes, der morphologischen Breite, der morphologischen Lange sowie des Muskelretiefs, das besonders an der Scapula Nr. 3 ausgeprägt ist.

Die morphologische Breite der Fossa infraspinala schwankt beim Chinesen zwischen 99,0 und 126,5, während sie beim Europäer im Mittel 120 beträgt (Broca). Der Spinalgrubenindex (b) schwankt zwischen 36,6 und 47,1; es herrschen also typisch mensehliche Verhälnisse; die Fossa supraspinata ist im Verhätnis zur Fossa infraspinata sehr klein, während bei den Anthropomorphen die crstere sich sehr ausdehnt, so daB der Spinalgrubenindex sehr hoch wird. Derselbe beträgt nach Schïck für den Schimpanse 92 und für den Gorilla 97. Am geringsten ist der Spinalgrubenindex bei Nr. 3; er beträgt 36,6, während er für den Europäer im Mittel zu 46,6 angegeben wird. Infolge des geringen Spinalgrubenindex bei Nr. 3 steht die Spina scapulae hier viel mehr horizontal als an der deutschen Scapula; demgemäß ist hier auch der Scapulospinalwinkel an größten (87 Grad), während er an der Scapula Nr. 2 nur 73 Grad beträgt. Bei den meisten Anthropomorphen ist dagegen dieser Winkel viel kleiner.

Die Scapulae der Chinesin weisen eine bilaterale Asymmetrie auf, indem die morphologische Länge der Scapula links 83,5 , rechts $81,5 \mathrm{~mm}$ beträgt; die rechte 
Scapula ist um $2,0 \mathrm{~mm}$ kürzer als die linke; das gibt sich aus dem Scapularindex zu erkennen, der links 64,9 und rechts 63,7 beträgt.

Gestalt der Ränder. Bei der linken Scapula von Nr. 1 verlüuft der Margo vertebr. vom Ursprung der unteren Lippe der Spina scapulae eine Strecke von $60,0 \mathrm{~mm}$ gerade nach abwärts. Dann biegt er mach lateral gegen den Angulus inferior, was noch stakker an der rechten weiblichen Scapula ansgeprägt ist. Am Ursprung der oberen Lippe der Spina geht der Margo vertebralis in einem leicht konvexen Bogen in die Spitze des Angulus medialis uber. Der Margo vertebralis ist auf der linken Seite am Ursprung der oberen Spinallippe stärker abgeknickt als anf der rechten Seite, wo er abgerundet gegen den Angulus medialis zieht. An der männlichen Scapula Nr. 2 beschreibt der Nargo vertebralis in seinem der Fossa supraspinata angehörigen Abschnitt einen starken konvexen Bogen, während der Infraspinalteil schwächer konvex gekrümmt verläuft. Nr. 3 besitzt in der Mitte des Vertebralrandes der Basis spinae einen Vorsprung (in der Abb. nicht zu sehen), von dem aus der Vertebralrand nach oben und unten verlaut, einen Winkel ron 165 Grad bildend.

Der Margo superior ist, namentlich an den Scapulae der Chinesin, sehr scharf und medial dicker als lateral. Die männliche Scapula $\mathrm{Nr}$. 3 besitzt keine Incisura scapulae und verhält sich somit wie das Schulterblatt der Anthropomorphen, z. B. des Gorilla. Aber auch an der übrigen Scapulae sind die Incisuren breiter und weniger vertieft als beim Europäer, ein Verhalten, wie es Martin für den Senoi beschreibt. Die rechte Incisura scapulae in $\mathrm{Nr}, 1$ ist sehr breit $(9,0 \mathrm{~mm})$ und niedrig ( $4 \mathrm{~mm})$. Aber auch die männliche Scapula Nr. 2 besitzt eine breite Incisura scapulae.

Am Margo axillaris ist bei $\mathrm{Nr} .1$ die Ursprungsstelle des Caput longum des M. triceps in Gestalt einer $13-15,0$ mm langen Leiste gut entwickelt. An den beiden männlichen Scapulae ist jene Leiste noch stärker ausgebildet. An den Sehulterblätern von $\mathrm{Nr} .1$ ist das Crsprungsfeld des $\mathrm{M}$. teres major nach medial und oben wenig abgegrenzt. Die mämliche Scapula Nr. 2 besitzt dagegen gegen die Fossa infraspinata zu eine kräftige gerade verlaufende Leiste, die noch mehr an der Scapula Nr. 3 hervortritt. Diese gegen die Fossa infraspinata zu stark abfallende Muskelleiste ist stärker ausgeprägt als an einer im $\dot{U}$ brigen viel stärkeren deutschen männlichen Scapula. Dureh die starke Entwicklung des M. teres major entsteht obcrhalb und lateral vom Angulus inferior ein vinklicher Knochenvorsprung, der dem Weibe fehlt. Das Ursprungsfeld des M. teres major besitzt in Nr. 3 die Form eines Rechteckes, dessen lange Seite 45 und dessen kurze Seite $22,0 \mathrm{~mm}$ milt. Lateral und oben ist das Lrsprungsfeld des Teres major von dem des Teres minr deutlich getrennt (in Nr. 3); das letztere besitzt die Form eines gestreckten Ovals, dessen größte Breite $9,0 \mathrm{~mm}$ beträgt. So scheint auch der Teres minor in $\mathrm{Nr} .3$ ein kräftiger Muskel zu sein. In diesem Verhalten der scharf markierten Crsprungsfelder ron $M$. teres major und minor düfte ein altertümliches Merkmal zu erblicken sein.

Dis Akromion ist bei allen viex Scapulae unregelmäBig viereckig. Am dicksten ist es im Bereich der Art. acromioclavucularis (bei Nr. $39 \mathrm{~mm}$ ). Bei Nr. 1 ist es in seiner Mitte 18, bei Nr. 221 , bei Nr. $324 \mathrm{~mm}$ breit. An der Scapula des Weibes sind die Processzus coracoidei klein. Aber auch an den Scapulae der Chinesen sind sie bedeutend kleiner als an vorliegenden deutschen Scapulae. 
Die Fossa glenoidalis der rechten Scapula Nr. 1 besitzt ein ziemlich gleichmäßBiges längliches Oval; an der linken Scapula ist die Fossa leicht birnförmig. Die beiden männlichen Scapulae dagegen besitzen eine ausgesprochene Birnenform der Cavitas glenoidalis. Besonders flach ist die linke Fossa glenoidalis von Nr. 1 . Der Längenbreitenindex der Fossa glenoidalis schwankt zwischen 60 beim 5 und 74 beim 3 ; er ist bei Nr. I noch geringer wie ibn Martin für das Senoiweib angibt (links 61, rechts 62,1 ).

Die Fossae subscapulares sind an der Scapula des Weihes flach und zeigen nur 1 bzw. 2 undeutliche Lineae musculares. Auch an der Scapula Nr. 2 sind diese Muskellinien nur als drei ganz kurze Leisten nahe dem Margo vertebralis vorhanden. Dagegen zeigt das Schnlterblatt Nr. 3 zwei kräftige Lineat musculares.

Die Fossa supraspinata ist beim Weibe (Nx.1) im Verhältnis zu der eines deut. schen Schulterblattes sehr flach; auch bei Nr. 2 zeigt sich dieses, which die dritte Scapula eine größere Tiefe dieser Grube aufweist.

\section{Clavieula.}

Ich konnte nur die beiden Claviculae einer 25jährigen Chinesin untersuchen (Präpariersaalleiche), ferner die laterale Hälfte einer Clavicula eines 30 jährigen Chinesen (Präpariersaalleiche). Zurn Vergleiche gebe ich noch die Mal3e einer kräftigen deutschen Clavicula (Nr. 3).

Tabelle der Gröfenterhältnisło der Scapula in Millimetern.

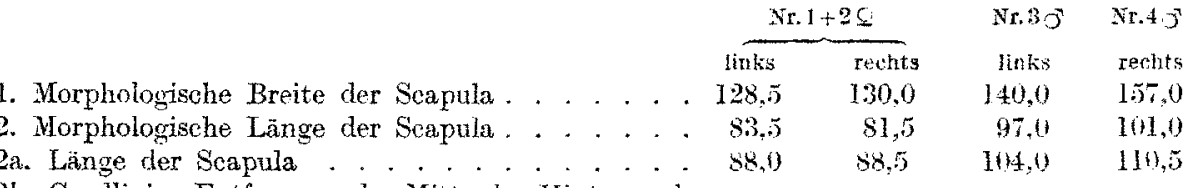

2b. Gradlinige Entfernung der Mitte des Hinterrandes der Fossa glenoidalis von einem Punkte des Vertebrairandes, der in der Mitte zwischen den boiken Lippen der Spina scapulae gelegen ist . . . . . \$ 83,0

3. Länge des Margo axillaris . . . . . . . . . . 103,4

4. Länge des Margo superior . . . . . . . . . . 65,0

5. Projektivische Breite der Fossa infraspinata . . 96,

5a. Morphologisohe Breite der Fossa infraspinata , 99,0

6. Projektivische Breite der Fossa supraspinata . . 333.0

6a. Morphologische Breite der Fossa supraspinata 42,0

7. Länge der Spina scapulae. . . . . . . . . 112.5

8. Länge der Basis spinae. . . . . . . . . . . . . . . $\frac{-}{34,0}$

10. Länge des Akromion . . . . . . . . . . . 26,5

11. Größte Länge des Processus coracoidens . . . 31.0

12. Lange der Caritas glenoidalis . . . . . . . . 30,0

13. Breite der Cavitas glenoidalis . . . . . . . . . 18.0

14. Tiefe der Cavita glenoidalis . . . . . . . . 3,5

15. Breitenlängenwinkel der Scapala. . . . . . . . 93

La. Scapulospinalwinkel . . . . . . . . . . . .

15b. Winkel, den der Vertebralrand mit der Spinalachse bildet

16. Axillospinalwinkel

17. Axilloglenoidalwinkel . . . . . . . . . $140^{\circ}$ $95^{\circ}$
$53^{\circ}$
$14)^{\circ}$
$8.3,5$

104,9

65,0

96,5

99,0

34,0

41,0

113,0

32,5

28,0

32,0

30,0

18.0

4,0

$80^{\circ}$

$86^{\circ}$

98,13

108,5

124.0 $\quad 126,0$

$74.0 \quad 79,0$

$103,5 \quad 123,5$

$106,0126,5$

$39,0 \quad 35,0$

$30,0 \quad 46,00$

$132,5 \quad 133.0$

$100^{\circ}$

41,0

49,0

$23,0 \quad 42,0$

$41,5 \quad 39,5$

$38,0 \quad 38,5$

$25,0 \quad 28.5$

$0,0 \quad 5,11$

$87^{\circ} \quad 96$

$73^{\circ} \quad 87^{\circ}$

$51^{\circ} \quad 44^{\circ} \quad 54^{\circ}$

$142^{\circ} \quad 138^{\circ} \quad 137^{\circ}$ 


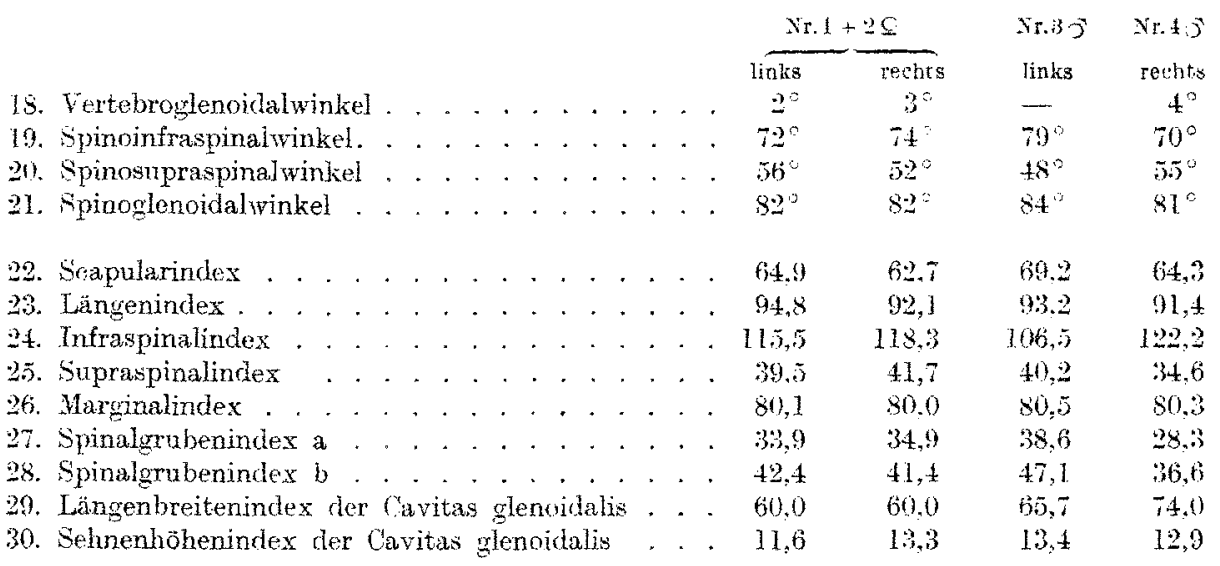

Ich füge noch einige Maße bei (in nm):

31. Dicke des Margo axillaris in seiner Mitte

.. 7
32. Dicke des Marro vertebralis in semer Mitte. . 3,5
33. Dicke des Marso superior in seiner Mitte . . I I.9
34. Dicke des Angulus inferior . . . . . . . . . . 6.2
35 . Breite der Incisura scapulae . . . . . . . . . 6,5
36. Tiefe der Incisura seapulae . . . . . . . . . . 5,4

37. Gewicht der Scapula in Grammen . . . . . . 33

0,5
3,0
1,3
6.1
9,0
4,0

9.5

Die rechte Clavicula der Chinesin zeigt die Spuren einer abgelaufenen Periostitis. Die Leiche besaß in der rechten Hals-und Schultergegend mehrere tuber. kulöse Fisteln. Die Extremitas acromialis des Chinesen gehörte einer linksseitigen Clacivula an und ist $81,0 \mathrm{~mm}$ lang. Teh schicke eine Tabelle iber Gewichts und Größenverhältnisse voraus.

\section{Das lewioht der (laviculito}

1. (kwicht der L. Claricula des Chinesenweibes Xr. l . . . . . . . . . . $12200 \mathrm{mg}$

2. Gewiebt der r. Clavieula des Chinesenweibes Xr. 1 . . . . . . . 14200 "

3. Gewicht der lateralon Häfte der Clavienla eines Chinesen $\mathrm{Nr}, 2$. . . . 10700 "

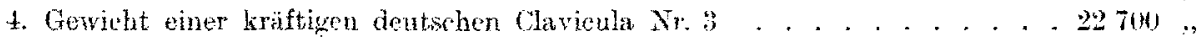

Waße der Claticula in Mitlimelern whd lotdices.

\begin{tabular}{|c|c|c|c|c|}
\hline \multicolumn{3}{|l|}{ 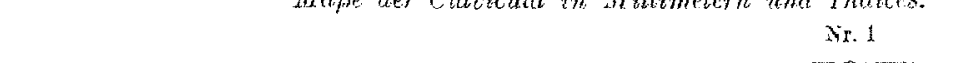 } & \multirow{2}{*}{$\begin{array}{l}\text { Nr. } 2 \\
\text { links }\end{array}$} & \multirow{2}{*}{$\begin{array}{r}N_{\Gamma} \cdot 3 \\
\text { deutsen } \\
\text { wehts }\end{array}$} \\
\hline & links & rechts & & \\
\hline 1. Cröbte Länge der Clavicula. . & $1 \geq 1$ & 121 & - & 164 \\
\hline 2. Höhe der Diaphysenkrümmung & 21,5 & 23,5 & - & 31,0 \\
\hline 3. Länge der Sehne der Diaphysenkriimmung & 77,0 & $\$ 0,0$ & - & 116.0 \\
\hline 4. Vertikaler Durchmesser der Mitte . . . & 8,0 & 11.8 & - & 13,0 \\
\hline 5. Sagittaler Durchmesser der Mitte & 0,0 & 12,0 & - & 12,8 \\
\hline 6. Limfang der Kitte . . . . . & 27,0 & $38,1)$ & - & 39.0 \\
\hline 7. Längendickenindex der Clavicula & 32,3 & 31,4 & -- & 23,7 \\
\hline 8. Krümmungsindex der Clavicula ... & 27,9 & 29,3 & - & 26,7 \\
\hline 0. Qtuerdurchsehnittsindex der Clavieula & 88,8 & 98.3 & - & 101,5 \\
\hline 10. Gaviculo-Fumeralindex . . . . & 45,1 & 44,8 & - & - \\
\hline
\end{tabular}


Die linke Clavicula der Chinesin (Nr. 1) ist kurz und gracil; die rechte dagegen ist durch einen periostitischen Prozeß verdickt, so daß sich, wie die Tabelle zeigt, ein höherer vertikaler und sagittaler Durchmesser in der Mitte sowie ein bedeutenderer Umfang ergibt. Der Umfang der rechten Clavicula der Chinesin ist infolgedessen, trotz ihrer geringen Länge, fast so groß wie der Umfang der $164 \mathrm{~mm}$ langen deutschen kräftigen Clavicula. Durch diesen periostitischen abgelaufenen Proce $B$ ist auch der Längendickenindex ein pathologisch hoher. Eine ähnlich schwache Entwicklung der Clavicula wie bei der Chinesin findet sich bei den Senoi, Semang and Australiern.

Die größte Länge der Clavicula von Nr. 1 ist auf beiden Seiten $121 \mathrm{~mm}$. Martin fand dieselbe bei den Senoi und Semang im Mittel ebenfalls zu 121 (116-124). Die Kürze der Clavicula fällt gegenüber der vorliegenden deutschen Clavicula ( $164 \mathrm{~mm}$ ) besonders auf. Für die Bajuvaren wird die gröBte Länge der Clavicula im Mittel auf $143 \mathrm{~mm}$ angegeben. Der Claviculohumpralindex beträgt 44,8 und 45,1 ; er verhält sich also ähnlich wie beim Europäer, wo er zu 45,0 für das Weib angegeben wird. Die Höhe der Diaphysenkrümmung beträgt 21,5 und 23,5, die der deutschen Clavicula $31,0 \mathrm{~mm}$. Diese größere Krümmung ist aber teilweise dadurch bedingt, daß am deutschen Schlüsselbein die Extremitas sternalis nach hinten einen starken Fortsatz aussendet und durch die bedeutendere größte Länge. Der Umfang der ersten normalen Clavicula von $\mathrm{Nr}$. 1 beträgt $27 \mathrm{~mm}$, der der deutsehen $39 \mathrm{~mm}$. Doch ist der Längendickenindex für die Chinesin und die Clavicula des Deutschen nicht sehr verschieden; ex beträgt 22,3 und 23,7. Der sagittale Durchmesser der Mitte ist gröler als der vertikale; dadurch wird die Clavicula etwas abgeplattet von oben nach unten. Dies gilt selbst für die periostitisch veränderte Clavicula. Bei der deutschen Clavicula ist der vertikale Durchmesser etwas größer als der sagittale.

An der Clavicula $\mathrm{Nr}$. I findet sich unten beiderseits eine deutliche Rinne zum Ursprung des M. subclavius. Die Tuberositates coracoideae sind an den drei chinesischen Scapulae sehr deutlich ausgeprägt, am auffalligsten an der linken Clavicula von Nr. 1. Diese Rauhigkeit ist hier größer als an der krätigen deutschen Clavicula. Auch die Tuberositas costalis ist überall gut sichtbar.

\section{Untersuchtes Material. III. Humerus.}

1. Linker und rechter Hunerus einer 25jährigen Chinesin (Präpariersalleiche). Humeri völlig intakt.

2. Linker und rechter Humerus eines 30jahrigen Chinesen (Präpariersad. leiche). Gestorben an Gangraena pedum.

Humeri völlig intakt.

Die übrigen 16 Humeri stammen aus Chinesengräbern des Gebietes des deutschen Gartenklubs in Shanghai und wurden mir vom Vorstand dieses Klubs äberwiesen. Es handelt sich um Bruchstücke, die, wie folgt, erhalten sind.

3. ein $77,0 \mathrm{~cm}$ langes Bruchstück, dem die proximale Epiphyse fehlt.

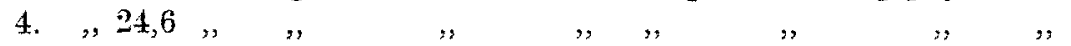

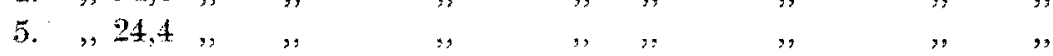

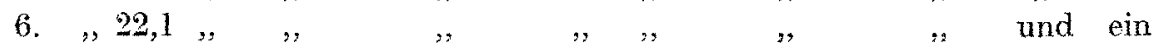

kurzer Abschnitt des proximalen Teiles der Diaphyse fehlen. 
7. Ein $19,6 \mathrm{~cm}$ langes Bruchstück, dem die proximale Epiphyse und ein Teil des proximalen Abschnittes der Diaphyse fehlen.

8. Ein $19,5 \mathrm{~cm}$ langes Bruchstück, dem die proximale Epiphyse und ein Teil des proximalen Abschnittes der Diaphyse fehlen.

9. $14,7 \mathrm{~cm}$ langes Bruchstück (distale Hälfte).

10. $12,9 \mathrm{~cm}$ langes Bruchstück (distale Hälfte).

11. $10,6 \mathrm{~cm}$ langes Bruchstück (distales Drittel).

12. $10,4 \mathrm{~cm}$ langes Bruchstïck (distales Drittel).

Den folgenden 4 Bruchstucken fehlen die proximalen und distalen Epiphysen:

13. 24,4 cm langes Diaphysenstück.

14. 23,4 , ", ,

15. $22,5, ", \quad$,

16. 20,7 , , ,

Die beiden letzten Bruchstücke sind untere Diaphysenhälften, denen die distalen Epiphysen fehlen.

17. $15,1 \mathrm{~cm}$ langes Stück.

18. 12,5, , , ",

Die beiden chinesischen Humeri sind kürzer und schlanker als ein deutscher Humerus; auch weisen sie, namentlich der des Weibes, eine geringere Reliefbildung auf. Besonders fällt an dem Humerus des Chinesen die Schlankheit der Diaphyse gegenüber den Epiphysen auf, so.daB die letzteren gegen die Diaphysen sehr scharf abgehoben sind. Beim Chinesen (Nr. 2) ist der Querschnitt der Diaphysenmitte unregelmäBig dreieckig, was durch die starke Ausprägung cler Crista tuberculi majoris zustande kommt; dasselbe Verhalten findet sich bei den Humeri Nr. 3,4,5, 6, 7 und 8. Am Humerus des Chinesenweibes dagegen (Nr. 1) jst der Querschnitt infolge der geringen Entwicklung der Crista tuberculi majoris mehr rund. Auffallend lang ist dieselbe bei $\mathrm{Nr} .2$ : ihre Länge beträgt links 11,5 , rechts $12,4 \mathrm{~cm}$. Sie ist beim Manne ( $\mathrm{Nr}^{2}$ ) scharf ausgeprägt, beginnt niedrig am vorderen medialen Rand des Tuberculum majus humeri, zieht dann, von medial nach lateral abgeplattet und sich als hohe Leiste erhebend, in einem sebr ausgeprägten nach medial konvexen Bogen nach abwärts, um in threr unteren Hälfte ziemlich gerade auf der Vorderfläche des Humerus zu vertaufen. An deutschen Humeri finde ich die Crista tuberculi majoris weder so lang noch so scharflantig, noch so stark convex nach einwärts gebogen. Bezuglich der langen Crista erinnert der Humerus des Chinesen (Nr. 2) an den Humerus des Neandertalmenschen. Mit der Krümmung der Crista tub. maj. bogenförmig nach innen verläuft auch der Sulcus intertubereularis sehr stark nach immen geLrümmt, ein Verhalten, das, wie Klatatsch zeigte, am Gorillahumerus sich findet. Beim Chinesenweib ist die Christa tub. maj. gering ausgebildet, links etwas stärker als rechts. Der Sulcus intertubercularis ist eine flache, breite, gerade nach abwärts verlaufende Rinne. In Nr. 3, dem Humerus eines Nannes, reicht die Crista tub. maj. als stumpfe, rauhe Kante bis zur Mitte des Humerus herab; sie ist in ihrem oberen Teil ebenfalls, aber nicht so stark, nach medial gewandt. Eine kräf. tige, aber abgestumpfte $\mathrm{Kante}$ ist die Crista bei $\mathrm{Nr} .13$ und 14 ; sie nimmt aber nur das obere Drittel des Humerus ein and ist ebenfalls nach innen konvex. 
Das Verhalten der Crista tub. maj. bei Nr. 1 düfte ein alt ererbtes sein, kein bloB individuelles, ein Residuum der alten Kletterfunktion. Die Tubrositas: deltoidea ist beim Chinesen (Nr. 2) ziemlich gering ausgeprägt, rechts $3,5 \mathrm{~cm}$ lang und stärker entwickelt als links. Bei Nr. 3 ist sie dagegen ein starker rauher Wulst, der schief von oben hinten nach unten vorne zieht; er besitzt einc Länge son $4,5 \mathrm{~cm}$ und ist $7,0 \mathrm{~mm}$ breit. Beim Weibe (Nr. 1) ist diese Rauhigheit sehr gering entwickelt. Ein sehr starker Wulst ( $4 \mathrm{~cm}$ lang und $0,7 \mathrm{~cm}$ breit) ist sie bei $\mathrm{Nr}$. 13, etwas geringer bei $\mathrm{Nr}$. 16. Die Muskelmarken für das Caput laterale des Y. triceps sind gering entwickelt. Der Sulcus spiralis zeigt keine Besonderheiten; besonders ausgeprägt ist er bei Nr. 13, weil der laterale Teil des caput mediale des Y. triceps eine dentliche Leiste hervorruft, die den Sulcus spiralis medial und hinten begrenzt. Auch ist hier die Rauhigkeit für das Caput laterale des Triceps gut ausgeprägt.

Gering entwickelt ist die Crista tuh. min. Am Humerus des Mannes (Nr. 2) ist sie links eine 2,0 , rechts eine $2,5 \mathrm{~cm}$ lange Rauhigkeit, die deutlicher bei $\mathrm{Nr} .3$ ist, wo sie $3,2 \mathrm{~cm}$ lang ist. Am Humerus des Weibew Nr. 1 ist sie sehr schwach, links etwas stärker als rechts. Ein Foramen nutricium findet sich bei $\mathrm{Nr} .1$ und 2 etwas unterhalb der Mitte des medialen Randes der Diaphyse.

An der disfalen Epiphyse ist der Epicondylus lateralis geringer entwickelt, wie an deutschen Humeri; besonders gering ausgebildet ist er bei $\mathrm{Nr} .4,5,7$ und 12. Auch der Epicondylus mediatis ist stärker am deutschen Humerus entwickelt als am chinesischen. Sehr gering, im Verhältnis zum deutschen ist er bei Nr. 1, 5. 6 u. 7. Am Humerus Nr. 2 (3) ist die Eossa coronoida wenig tief, am Grunde siebartig durchlöchert, ron spongiosaähnlichem Bau; doch ist kein Durchbruch in die Fossa olecrani vorhanden. Breite der Fossa coronoidea links 12, rechts $10 \mathrm{~mm}$. Beim Weibe (Nr. 1) ist die Fossa coronoidea etwas tiefer, aber weniger breit (links 10 , rechts $9,0 \mathrm{~mm}$ ). Sehr gering ausgebildet ist sie bej $\mathrm{Nr} . t, 7$ und 8 . Bei Nr. 5 und 18 ist sie durchbrochen (Foramen supratrochleare).

Die Fossa radialis ist bei $\mathrm{Nr}, 2$ (j) ungefahr dreieckig und grobler und flacher als die Fossa coronoidea. Beim deutschen Humerus besteht jedoch zwischen den beiden Gruben eine größere Differenz. Auch in Nr. 1 (c) ist dic Fossa radialis deutlich ausgeprägt und von dreieckiger Form. Der kräftige Humerus Nr. 3 besitzt eine fast ebenso große und tiefe Fossa radialis als Fossa coronoidea. Bei 4 sind beide Gruben gleich groß und fast gleich flach. Nr. 5 zeigt eine deutliche. Fossa radialis und daneben eine durchbohrte Fossa coronoidea. Nr. 6 besitzt zwei gleich große und fast gleich tiefe Fossae und zeigt ein von deutschen Humeri typisch verschiedenes Verhalten. In $\mathrm{Nr} .7$ und 8 sind beide Gruben gleich gro $B$ und gleich seicht. In $\mathrm{Nr} .9,10,11$ und 12 sind die Fossae coronoidene etwas tiefer als die gleich großen Fossae radiales. Bei Nr. 3 und 6 sind die Fossae coronoideae stark ulnarwärts geschoben. Im allgemeinen kann man sagen, daß die Fossa radialis größer, tiefer und ausgeprägter ist als beim Deutschen. Der zwischen Fossa radialis und Fossa coronoidea liegende Knochenkamm liegt nicht in der Richtung der Diaphysenachse, sondern biegt etwas nach radial ab.

Die Fossa olecrani ist unter 20 Humeri zweimal durchbohrt bei $\mathrm{Nr}$. 5 und 18): Foramen supratrochleare. Dasselbe ist in $\mathrm{Nr} .58 \mathrm{~mm}$ breit und $5,5 \mathrm{~mm}$ boch, in Nr. 187,0 und $4,5 \mathrm{~mm}$. Die Humeri, an denen das Foramen supratrochleare 
wich findet, gehören zwei verschiedenen Individuen an. Der Humerus Nir. 5 (ein rechter) ist besonders schlank, wenig massig und mit wenig ausgeprägter distaler Epiphyse versehen. Der Humems Nr. 18 ist dagegen kräftiger. In 10 Fin. len ist das die Fossa coronoidea von der Fossa olecrani trennende Knochenseptum nicht durchscheinend. In Nr. 1 ist dasselbe sehr dünn. In Nr. 2 ist es durchwheinend und besteht aus einem spongiosen Balkenwerk. Beim Orang und Gerilla ist das furamen supratrochleare eine häufige Erscheinum.

Legt man den Humerus mit seiner Vorderfläche auf eine Horizontale so daß Tuberculum minus und Troehlea dieselbe allein berühren, so sieht man beim Humerus $\mathrm{Nr}$. 2 (weniger bei $\mathrm{Nr}$. 1), daB die oberhalb (kranial) der Fossa olecrani befindliche hintere distale Flache des Humerus staiker nach medial (uinarwäts) geneigt ist, als an deutschen Humerus, wo dieselbe fast horizontal steht. Der Epicondylus medialis steht dabei bei den meisten chinesischen Humeri mehr horizontal als bei den Deutschen, bei denen er meistens etwas mehr nach hinten gebogen ist.

Die Furche zwischen Capitulum und Trochlea ist bei fast allen chinesischen Humeri weniger ausgeprägt als bei deutschen. In Nr. 5 und 8 ist diese Crenze fast verwischt. Die mittlere Vertiefung der Trochlea selbst ist nur bei Nr. 1 (c) ähnlich tief wie an deutschen Humeri bei fast allen andern Humeri ist sie sehr flach (besonders bei Nr. 4, 5, 6, 7 u. 8), so daß eine an die Oberfläche der Trochlea angelegte Tangente eine viel geringere Entfernung von der Gelenkoberfluche besitzt als am deutschen Humerus. So erscheint die Trochlea, ja die distale Epiphyse überhaupt, im Ganzen weniger differenziert als diejenige des Europäers. Eine Crista paratrochleasis fehlt, ebenso eine Foramen supraconyloideum und ein. Processus supraconyloideus.

Beifolgende Tabelle (S.476), deren Anordnung dem Lehrbuch der Anthropologie Fon Martin entnommen ist, gibt über GröBenbeziehungen, Winkel, Indices und Gewicht Aufschluß.

Die größle Länge des Humerus schwankt bei den chinesischen Individuen zwischen 272 und $322 \mathrm{~mm}$. Der rechte Humerus ist beim Weibe um : beim Nanne um $4,0 \mathrm{~mm}$ länger als der linke. Auch ist in beiden Fullen der rechte Humerus dicker als der linke. Hinsichtlich der Länge, der Dicke und der Ausprägung der Muskelwarken herrscht zwischen Mann und Weib eine deutliche sexuelle Differenz. Der Lägendickenindex schwankt zwischen 16,9 und 17,7 , bei den Bajuvaren beträgt er in Nittel 20,8 , bei La-Chapelle aux-Saints 23,0 . Die Massigkeit des Humerus ist also eine geringe, ähnliwe Werte besitzend wit bei den Massai (16,3 für das Weib, 18,2 für den Mann).

Die Gelenkfläche des Humeruskopfes ist beim Manne größer als beim Weibe (Nr. 2 und 1). Der sagittale Durchmesser des Humeruskopfes ist größer als der transversale. Der transversale Durchmesser ist beim Manne (Nr. 2) größer als der größte sagittale des Weibes (Nr. 1). Beim Chinesen ist die Gelenkfläche des Caput humeri kleiner als bei einem gleich langen deutschen Humerus. Der Index des Caputquerschnittes schwankt zwischen 86,3 und 91,8. Das Caput humeri bildet den Abschnitt eines Ellipsoides und nicht den einer Fugel wie bei den Anthropoiden. Der von oben und unten betrachtete Humeruskopf erscheint etwas länglicher als beim Deutschen. Gegen das Tuberoulum majus zu ist die Gelenkfläche des 


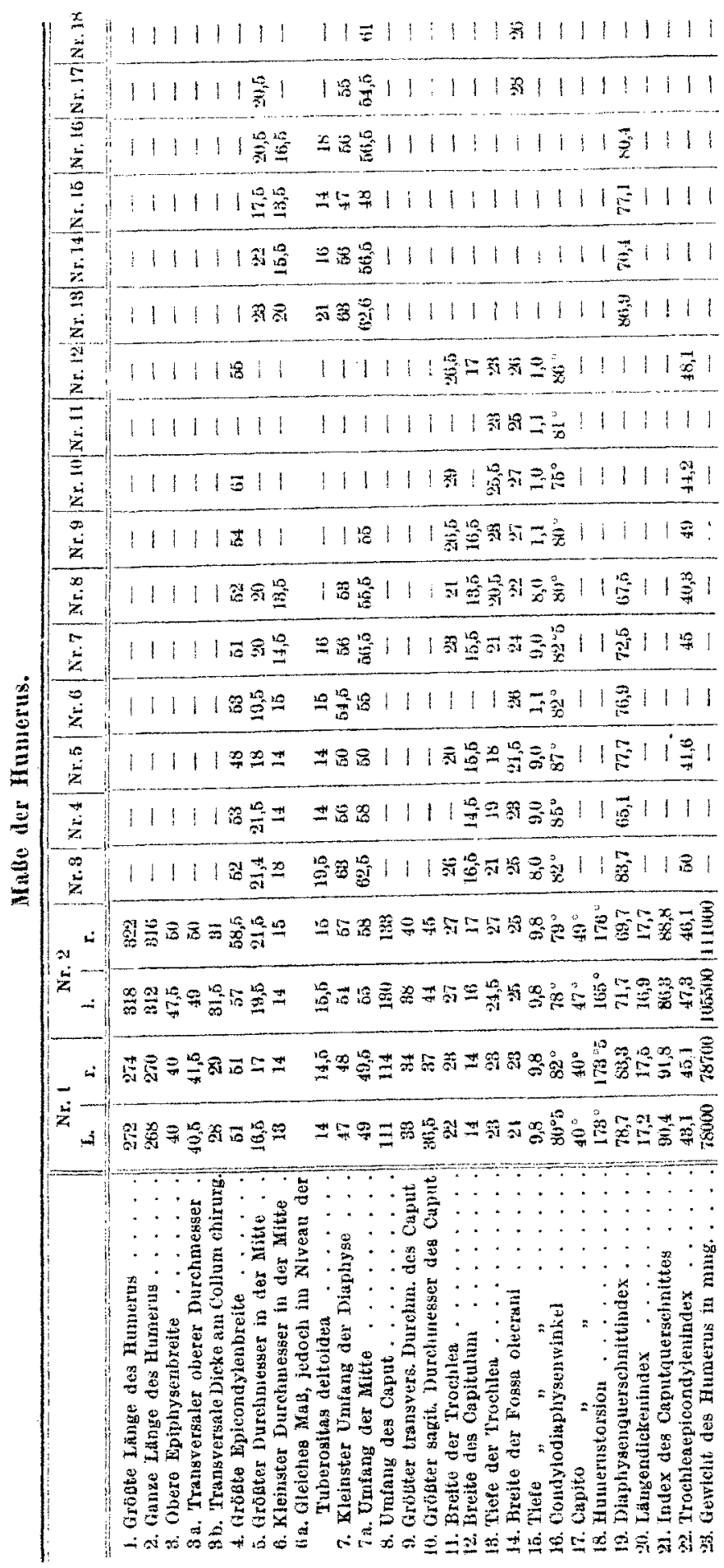

Caput weniger abgegrenzt als bein deut. schen Humerus, auch ragt boim letzteren dieser Huskelhöcker et. was mehr wach oben. Beim Weibe Nr. 1 setzt sich das Tuberculuru majus tast ohne Grenze nach oben und medial in die Knorpelflache des Caput humeri fort. Auf ein ähnliches Verhalten weist Martin bei den Senoi und anderen primitiven Völkern sowie bei den europäischen Neolithikern hin.

Der Querschnitt der Diaphysenmitte ist in den meisten Fällen annähernd dreieckig, wobei die der hinteren Humerusfiäche entsprechende Seite stark gewölbt ist. Der Humerus des Weibes (Nr. 1) ist auf dem Querschnitt ein ron innen nach auBen zusammengepreßtes 0 val. Die Humeri Nr. 4, 8 und 14 zeigen eine sehr starke medio-laterale Abplattung. Der geringste Diaphysenmittenquerschnittsindex beträgt 65,1 , ist also geringer als bei den steinzeitlichen $\mathrm{Ai}$ nos $(66,8)$. Der Index der Diaphysenmitte beträgt bei Bajuvaren 80,7 , bei Japanern 79,9. Wenn wir mit 
Lehmann-Nitsche die Grenze zwischen Platybrachie und Eurybrachie zu 76,5 annehmen, so zeigen unter 14 chinesischen Humeri 6 einen ausgesprochenen platybrachen Typus (siehe Tabelle); zwischen 48 und 62,5 . Bei einem kräftigen deutschen Humerus beträgt er 6.r. Jedoch herrsehen beim Chinesen die geringen Umfange bedeutend vor.

Die obere Epiphysenbreite schwankt zwischen 40 und 50 , die untere (gröBte) Epiphysenbreite zwischen 48 u. $61 \mathrm{~mm}$. Der Epicondylus nedialis ist in den meisten Fallen gat ausgebildet.

Der Capitodiaphysenwinkel beträgt bei der Chinesin 40, beim Manne (Nr. 2) 47 and $49^{\circ}$. Für Schwaben, Alamanmen und Bajuvaren schwankt er zwischen $45^{\circ} 4^{\prime}$ und $49^{\circ} 7^{\prime}$. Eine rassologische Bedeutung läbt sich nicht rekennen.

Der Condylodiaphysenumkel schwankt zwischen 75 und $87^{\circ}$. Die letztere Zahl erreicht er bei dem sehr sehlanken Humerus Nr. 5 , der zugleich die geringste Epicondylenbreite, eine tiefe Fossa radialis und ein Foramen supratrochleare besitzt. Es nähert sich hier der Winkel zwischen der Trochleartangente und der Diaphysenachse einem rechten, ein Verhalten, wie es sich am Humerus des Neandertalmensehen findet. Tch gebe hier einige Zahlen des Condylodiaphysenwinkels aus Martin, Lehrbuch der Anthropologie:

Der Condylodiaphysenwinkel beträgt:

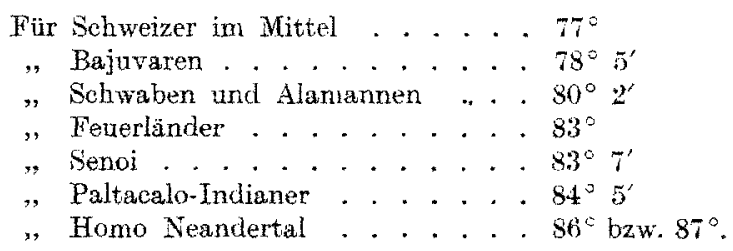

Bei 7 von 14 chinesischen Humeri betrug der Condylodiaphysenwinkel $82^{\circ}$, und von da nach aufwärts, so kaß in der Hälfte der Tälle die Trochlea eine sehr geringe Neigung von oben außen nach unten innen besitzt. Am Europäerhumerus ist diese Neigung sehr ausgeprägt.

Untersuchtes Material.

\section{Radins.}

1. Linker und rechter Radins einer 25 jährigen Chinesin (Präpariersaalleiche). Radii vollständig erhalten.

2. Linker Radius einer Präpariersalleiche (30 jähriger Chinese, an Gangraena pedum gestorben). Am rechten Radius fehit ein etwa $5,0 \mathrm{~cm}$ langes distales Stück, da aus dem distalen Teil der Extremität ein Nervenpräparat angefertigt wurde. Das zur Untersuchung gelangte Stiick des rechten Radius ist $17,4 \mathrm{~cm}$. lang. Die acht übrigen Radii stammen, wie beim Humerus näher angegeben, aus Chinesengräbern. Fs sind:

3. Ein nahezu vollständig erhaltener Radius, an dem nur die Circumferentia articularis radii oberflächlich etwas arrodiert ist.

4. Ein $20,0 \mathrm{~cm}$ langer Radius, der das Capitulum radii fehlt.

5. Ein $14,6 \mathrm{~cm}$ langes Bruchstück, dem das distale Drittel fehlt.

6. Fin $13,3 \mathrm{~cm}$ langes Bruchstück, dem das distale Drittel fehlt. 
7. Ein $7.4 \mathrm{~cm}$ langes proximales Stück.

8 . Ein $13,7 \mathrm{~cm}$ langes distales Stück.

9. Ein $13,1 \mathrm{~cm}$ langes distales Stück.

10. Ein $12,6 \mathrm{~cm}$ langes distales Stück.

Die größte Länge des Radius schwankt zwisehen 207 und $22 \pm$ mm. Das Weib (Nr. 1) besitzt einen küreren Radius als der Mann; der rechte Radius ist bei $\mathrm{Nr} .1 \mathrm{~mm} 3 \mathrm{~mm}$ länger als der 1 . Radius. Bei Deutschen schwankt die gröBte Länge im Mittelwert zwischen 254 und $251 \mathrm{~mm}$ (Math, Lehrbuch der Anthropologie), bei den Paltacalo-Indianern zwiseben 208 mil $207 \mathrm{~mm}$, so daB, wenn bei dem geringen Material ein Vergleich exlaubt ist, eine Amniherung bezüglich der größsten Länge an diese letzteren gegeben ist. Die physiologion Liange schwankt zwischen 194 (beim \& links) und $21+\mathrm{mm}$ (beim Mame Nr. 2). Bei Deutschen bewegt sie sich in Mittel zwischen 2935 und $239 \mathrm{~mm}$.

Der kleinste Umfang des Radius (unterhalb der Mitte gemessen) schwankt zwischen 31 und $38 \mathrm{~mm}$; hei einem allerdings sehr kräftigen deutschen Radius beträgt er $50 \mathrm{~mm}$. Der Umfang des Collum radii in seiner Mitte beträgt 35,5 bis $44,5 \mathrm{~mm}$. Die Massigket des Knochens ergibt sich aus dem Umfang, dem transversalen und sagittalen Durchmesser der Diaphyse. Der transversale Durchmesser der Diaphyse beträgt $19,5-16,5 \mathrm{~mm}$, der sagittale $8,5-10,5 \mathrm{~mm}$. Der aus der physiologischen Länge berechnete Längendickenindex weist Werte zwischen 15,9 und 17,0 auf. Die Massigkeit der Radien ist mithin eine geringe, nähert sich der des Radius der Neger (mit einem mittleren Längendickenindex von 16,7$)$, der Velanesier $(15,7)$ und Negrito $(17,0$ nach $F i s c h e r)$. Die aus der grö(sten Länge berechneten Längendickeninäices betragen 14,9 (für Nr. 11), 15,4 (für $\mathrm{Nr}$. 1 rechts), 15,6 (für $\mathrm{Nr}$. 23) und 16,1 (für $\mathrm{Nr}$. 3); sind also kleiner als bei Deutschen. Bei Weddas und Australiern belaufen sie sich auf 14,5 und 14,3 ; noch niedriger sind sie beim Orang-Utan $(12,8)$ und bei Hylobates $\{8,1$ nach Wartin). Gemäß ihrer geringen Massigkeit zeigen alle Radien beim Chinesen eine sehr schlanke Gestalt, die gegenüber der derbeu bei Deutschen sehr in die Augen springt.

Die Quer-und Lïngsdurchmesser der Capitula radiontm sind im allgemeinen gering; besonders groß sind sie am Radius des Mannes (Nr. 2); das rechte Capitulum ist hier gröber als das linke und beide sind beträchtlich größer als beim Weibe.

DerQuerdurchmesser der distalen Epiphyse schwankt zwischen 25 und $30,7 \mathrm{~mm}$, doch sind die kleineren Durchmesser die häufigeren. Bei einem mir vorliegenden dentschen Radius beträgt er $35 \mathrm{~mm}$.

DerCollodiaphysenwinkel beträgt $160-170^{\circ}$; er ist geringer als bei Deutschen $\left(165-177^{\circ}\right.$ bei Badenem) and nïhert sich dem der Ozeanier und Australier (160-170). Nur in einem Fall ist er 170 und in einem andern 165. Auch bei den Feuerländern ist dieser Winkel gering (160 $\left.4^{\prime}\right)$.

Die Krümmung des Radius nach auben ist bei chinesischen Radien etwas stärker als bei Dentschen. Das gilt namentlich für den 1. Radius des Mannes (Nr. 2). Aber auch der linke Radius des Weibes (Nr. 2) und die Radien Nr. 3 und 4 sind stärker gelrümmt als deutsche Radien. Diese stärkere Krümmung entspricht etwa der des Padius eines Neumecklenburger, wie er sich in Martin. "Lehrluch der Anthropologie: S. 994 abgebildet findet. 
Mafe des Radius.

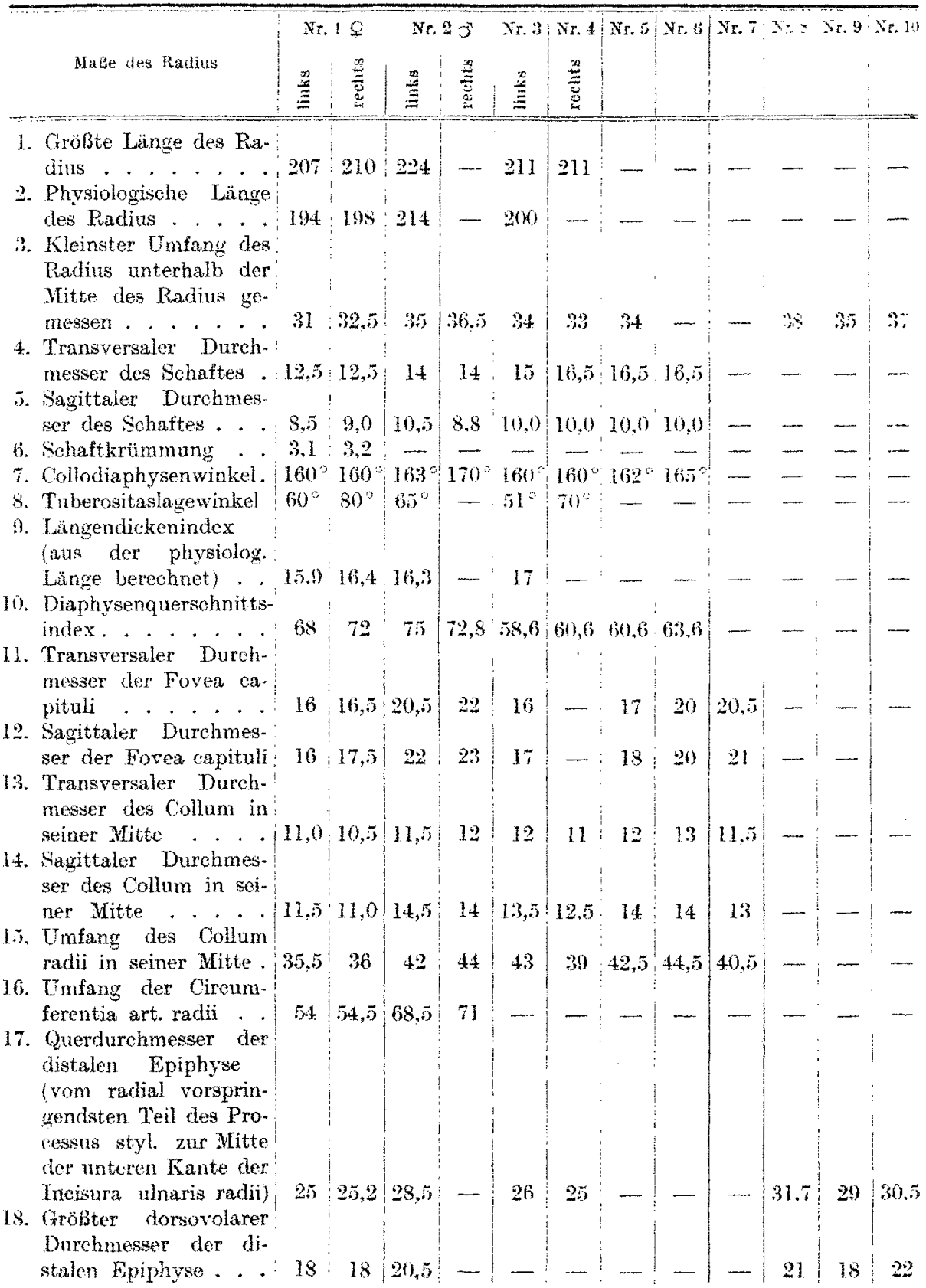

Die Tuberositas bicipitalis radiz ist bei fast allen Radien geringer cntwickelt als bei kräftigen deutschen Radien. Nur in Nr. 7 stellt sie einen scharfkantigen Hïgel dar, der proximal steil abfallt. In den übrigen Fällen ist die Tuberositas 
bicip. radii ein ovaler fast glatter Hügel. Bei dem Weibe (Nr. 1) hesitzt er eine Länge von 16 und eine Breite ron $11 \mathrm{~mm}$. Auch an den abrigen Radien ist er nieht wesentich grober. An einem mit vorliegenden deutsehen Radius erseheint ar fast noch einmal so groß. Seine glatte Beschaffenheit fiillt besonders bei den Radien Nr. 1, 2, 3, 5 und 6 auf. Steht der Padius in voller Supination oder legt man ihn anf seine Dorsalseite, so findet man, daß die Tuberositas bicip. beim Jeutschen mehr volarwärts und radialwarts gewandt ist als bei fast allen chinesisehen Radien, wo dieselbe fast rein wharwarts steht, der Volarseite abgekehrt. Will man daher dis Tuberositas bicip. radii in ihrer ganzen Flachenausdehnung sthen, so muB man den chinesischen Radius aw seiner Supinationsstellung vielmehr um seine Längsachse nach auBen drehen als den deutschen. Bei fast allen Radien liegt daher die Tuherositas bicip. in der prosimalen Fortsetrung der Crista intorossea. Hier haben wir es zweifellos mit einem neandertaloiden Verhalten zu tun, das Fischer anch bei Negern und Australiem fand. Der Tuberositaslagewinkel schwankt zwischen 50 und $80^{\circ}$. Dieser hohe Winkel findet sich am rechten Radius des Weibes (Nr. 1). Hier steht die Ebene der Basis der Tuberositas bicip, an dem in Supination lefindlichen Radius fast vertikal. Soll die Tuberositas aus ihrer nharwärts gerichteten Lage nach oben schen, so muB der Radins am 80 $)^{\circ}$ gedreht werden. Dieses Verhalten weist auf cine längere Bicepssehne, wie sio sich bei den Anthropomorphen findet.

An fast allen Radien sind die Muskelleisten auffälig schwach ausgeprägt. Die Crista interossea ist eine scharfe, aber in allen Fallen nur kurze Leiste; ron der. Witte der Diaphyse an wird sie niedrig und ist distal nur mehr als eine schafe Linie erhalten, whnlich wie es Murtin für den Senoi beschreibt. Beim deutschen Radius dagegen erstreckt sich die Crista interossea weit nach abwärts gegen die distale Epiphyse. Beim Weibe (Nr. 1) ist am besten, aber immer noch gering, die Rinne für den M. extensor pollieis longus ausgeprägt. Bei Nr. 1 ist die Insertionsstelle des M. pronator teres und die Ursprungsstelle für den radialen Kopf des M. flexor digitorum sublimis eben erkennbar; am Padius des Mannes (Nr. 2) sind etwas größere rauhe Stellen vorhanden. Gewicht des Radius beim Weibe (Nr. 1) links 26500, rechts $27500 \mathrm{mmg}$, beim Yanne links (Nr. 2) $37500 \mathrm{mmg}$. Fin sehr kräftiger deutscher Radius wog $48000 \mathrm{mmg}$.

\section{Dlna.}

\section{Untersuchtes Material.}

1. Linke und rechte Uha einer 25jahrigen Chinesin (Präpariersalleiche). Beicle Ulnae intakt.

2. Una eines 30 jührigen Chinesen (Präpariersalleiche). An Gangraena pedum gestorben. Die 1 . Una ist volsstandig erhalten; an der rechten Ulna ist der distale Teil abgesägt. Ths zur Tntressichung zur Verfügung stehende Stück ist $19,2 \mathrm{~cm}$ lang.

Die übrigen Ylnae sind Bruchstücke und entstammen demselben Fundort wic heim Radius und Humerus angegeben ist. Fs sind:

3. Eine $27,0 \mathrm{~cm}$ lange Ulma, weleher der grobte Teil der proximalen Epiphyse fehlt. 
4. Eine 18,1 cm lange rechte Ulna, an welcher der distale Teil und Teile der proximalen Epiphyse fehlen.

5. Proximale Hälfte einer sehr kräftigen Clna. Länge des Bruchstuckes $14,7 \mathrm{~cm}$.

Make der Vlna.

1. Gröbte Länge der Clna. . .

2. Physiologische Länge der 6 Ina

3. Umfang der Ulna

4. Breite des Oleoranon

7. Tiefe des Olecranon . . .

6. Hohe des Oleeranon . . .

7. Vorlere Breite der radialen Gelenkhaifte auf dem Processus coronoideus

8. Hintere Breite der radialen Celenkhalfte anf llom Processus coronoileus.

9. Dorso-volarer Durchmesser dor Elna . . . . . . . .

1ha. Größter dorso- volarer Durchmesser (ron dor höhsten Stelle der Crista zur hin. tren Kante). . . . . . . .

10. 'Transversaler Durchmesser der Ulna. . . . . . . . . .

11. Oberer transversaler Durehmesser ler Llna.

12. Oberer dorso-volarer Durchmesser der Ulna.

13. Gröpte Breite des spatiun interosseum . . . . . . . .

14. Iängendickenindex (aus der physiolog. Lange berechnet)

15. Lüngendickenindex (aus der gröbten Länge berechnet). .

16. Olecranontiefenindex ....

17. Olecranonhohenindex , . .

18. Index der radialen Gelenkhälte an dem Processus coronoidens . . . . . .

19. Diaphysenquersehnittsindex .

20. Index der Platolenie . . .

21. Breitenindex des Spatium interossenm . . . . . . . .

22. Gewieht in ming

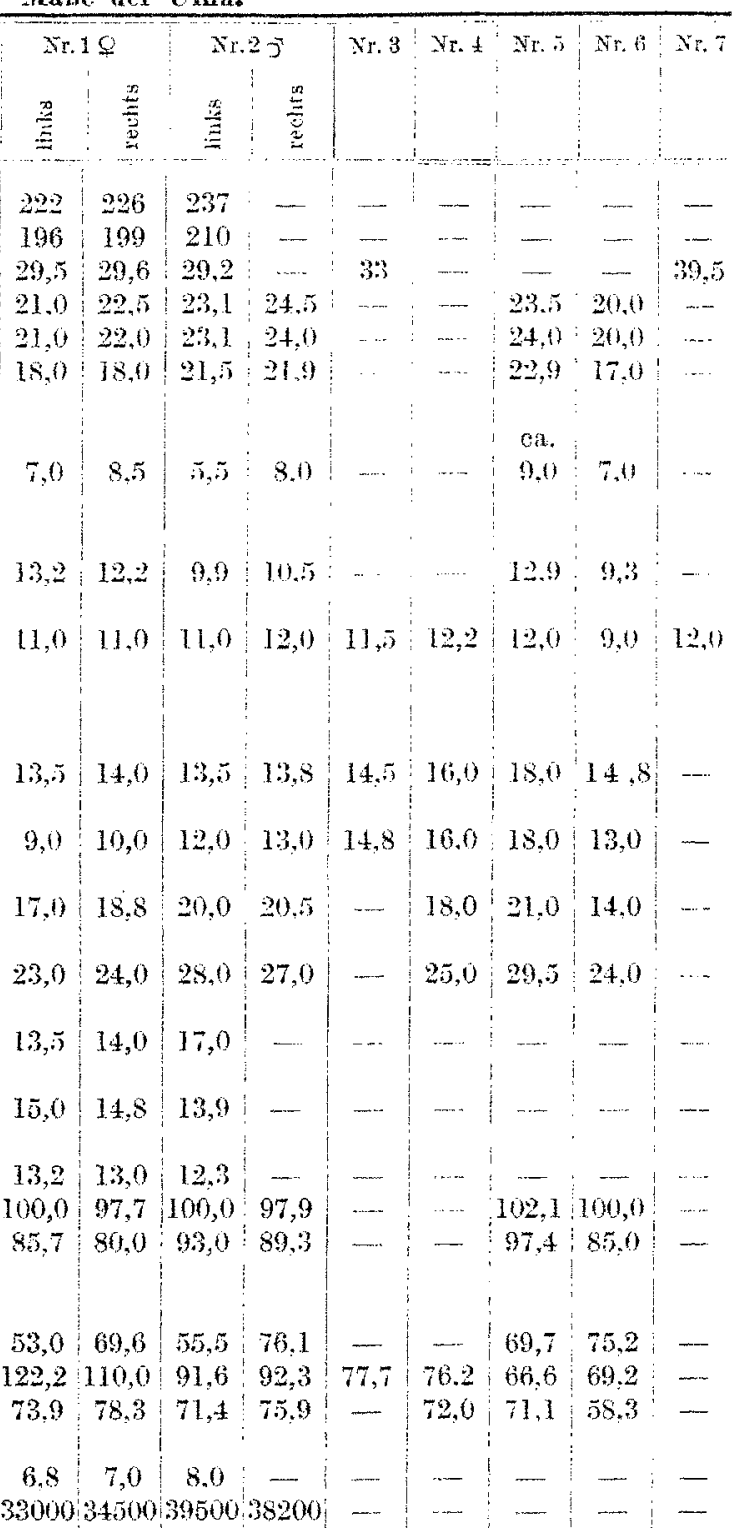

6. Die proximale Hälfte einer linken Ulna. Länge des Bruchstückes $13,6 \mathrm{~cm}$.

7. Die distale $12,5 \mathrm{~cm}$ lange Halfte einer Tlna.

Die gröBte Länge der Vlna beträgt 229 bezw. $226 \mathrm{~mm}$ beim Weibe ( $\mathrm{Ar}, 1$ ), $237 \mathrm{~mm}$ heim Mann (Nr.2); die physiologische Länge beträgt $196-210 \mathrm{~mm}$. 
(Siehe umstehende Tabelle.) Beide Längenmaße sind erheblich kleiner als bei Deutschen, bei denen die größsten Längen zwischen 257 und $269 \mathrm{~mm}$ sich bewegen. Die Differenz zwischen der größten Länge und der physiologischen Länge beträgt 26 und $27 \mathrm{~mm}$.

Der Kleinste Umfang nahe dem distalen Ende des Knochens schwankt zwischen 29,2 und $39,5 \mathrm{~mm}$; bei einer kräftigen deutschen Ulna beträgt er $42 \mathrm{~mm}$. Alle Clnae sind im Verhältnis zu der deutschen sehr schlank: sie besitzen sowohl bezüglich der Diaphysen wie der proximalen Epiphysen eine geringe Massigkeit. Der aus der physiologischen Länge berechnete Längendickenindex beträgt 13,9-15,0 und nähert sich im Mittel dem der Negrito (14,6 Fischer). Bei Badenern beläuft sich der Längendickenindex im Mittel auf 16,8 (Fischer). Die größere Sohlankheit der Ulna ist als primitives Merkmal aufzufassen. Der aus der größten Länge berechnete Längendickenindex ist etwas kleiner $(12,3-13,3)$.

Die dorsale Konvexität ist bei allen chinesischen Unae größer als bei Deutschen. Die stärkste Krümmung zeigt die linke Ulna des Mannes (Nr. 2); die höchste Erhebung derselben befindet sich am distalen Ende des proximalen Drittels. Das distale Ende der konvexen Krümmung liegt am proximalen Ende des distalen Drittels der T7na. Beim Weibe (Nr. 1) ist diese dorsale Krümmung weniger ausgeprägt; sie ist ebenfalls als primitives Zeichen aufzufassen. Sie findet sich bei einigen neolithischen Skeletten und den Anthropomorphen. Der Margo dorsalis ist im mittleren Drittel der Chna am sehärfsten; er besitzt eine leicht $\$$-förmige Krümmung, die an deutschen Ulnae viel ansgesprochener ist.

Die proximale Epiphyse der Ulna ist nach medial abgeknickt; der Clnargelenkswinkel sehwankt zwischen 84 und 920. Der hohe Wert dieses Winkek findet sich nur in einem. Fall.

Die proximale Epiphyse ist nicht nach hinten abgeknickt, wie es bei den Australiern und Anthropomorphen sich findet; infolgedessen sieht die überknorpelte Gclenkfache mehr nach vorne als nach oben.

Die Olecranonkuppe ist schwach entwickelt und besitzt keine an den Neandertalmenschen oder niedere Simiiden erinnernde Morkmale. Der Index der Höhe der Olecranonkuppe beträgt beim Manne links 0,9 ; beim Weibe (Nr. 1) ist er höher $(1,5$ and 2,0). Relativ am bedeutendsten ist die Vorwölbung der Olecranonkuppe über das Niveau des Schnabels an der rechten Ulna des Weibes (Nr. 1).

Das Verhältnis der Tiefe des Olecranon zur Breite, der Olecranontiefenindex, heträgt $97,7-102$. Breite und Tiefe des Olecranon sind einander fast gleich, während bei den niederen Simiiden (mit einem Olecranonhöhenindex von 154) das Olecranon viel höher als breit ist.

Die durch den Knorpelmangel ausgezeichnete Querfurche der Incisura semilunaris ist an der linken Ulna des Weibes $\left(\mathrm{N}_{2} .1\right)$ kaum angedentet; besser entwickelt ist sie an der rechten Ulna, wo sie als ein in der Mitte der Incisura semilunaris befindlicher, $7 \mathrm{~mm}$ langer und $2 \mathrm{~mm}$ breiter Querstreif mit spongiösem Bau auftritt. Beim Manne (Nr.2) ist links ein deutlicher Querstreif vorhanden; rechts ist er noch stärker ausgeprägt und stellt eine nach lateral (radial) und etwas vome gegen die Incisura radialis ulnae verlaufonde Pinne dar. Am radialen und ulnaren Rande ist diese Rinne besonders tief; sie bewirkt eine völlige Trennumg der Gelenkfläche in eine vordere und hintere Halfte. An der kräftigen Ulna 
Nr. 5 ist disse Rinne nur medial ein ganz kurzes Stück rorhanden. In Nr. 6 fehlt diese Rinne und die Gelenkfläche erscheint einheitlich.

Die Incisura radialis ulnae ist an deutschen Ulnae schmäler und steiler gestellt als an chinesischen. Besonders ausgebildet und scharfkantig umgrenzt ist die Incisura radialis beim Manne (Nr. 2). Sie übertrifft an Breite die medial von ihr betindliche Gelenkflächenhälfte des Processus coronoideus. Beim Weibe (Nr. 1) sind die Incisurae radiales nicht so breit. Der Index der radialen Gelenk. hälfte auf dem Processus coronoideus beträgt in Mittel 66,5 ; er ist also kleiner als beim Europäer, bei dem er 72 beträgt. Wit diesem kleineren Index ist beim Chinesen die Incisura radialis mehr volarwärts gestellt als beim Europäer.

Die Diaphyse ist in allen Fällen auf dem Querschnitt prismatisch. Die Crista interossea ist schwächer ausgebildet als an deutschen Uhae. Sehr scharfkantig ist sie bei $\mathrm{Ni}$. 2. Der Index des Diaphysenquerschnitts schwankt zwischen 66,6 und 122,2 .

Der Index des oberen Diaphysenquerschmittes beträgt $58,3-78,3$; bei Europäern 89. Der obere Abschnitt der Ulna zeigt Platolenie, die am deutlichsten bei $\mathrm{Nr} .6$ sich findet. Der Breitenindex des Spatium interosseum zeigt typisch mensehliche Verhältnisse (Index 6,8-8).

\section{Handskelett.}

\section{Untersuchtes Material.}

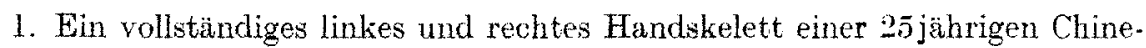
$\sin$ (Präpariersaalleiche).

2. L. Handskelett eines 30 jährigen kräftigen Chinesen, dessen Beruf Koch war (Präpariersaalleiche).

An der wieder zusammengesetzten prosimalen Karpalreihe beträgt die Bogenbreite, gemessen mit dem Faden über die Mitte der Dorsalfläche, beim Manne 62 rum, beim Weibe links 54 , rechts 55 mm. An einem deutsohen Handskelett miBt sie $60,0 \mathrm{~mm}$. Die gradlinige Entfernung der volaren, radialen, stumpfen Spitze des Naviculare von der ulnaren, volaren, stumpfen Ecke des Triquetrum betragt beim Chinesen $40 \mathrm{~mm}$, bei der Chinesin $37 \mathrm{~mm}$ links, $35 \mathrm{~mm}$ rechts, an deutschen Handskelett $45 \mathrm{~mm}$. Uber die Bogenbreite der distalen Karpalreihe, gemessen mit dem Faden über der Nitte der Dorsalfläche, geben folgende Zahlen Auskunft:

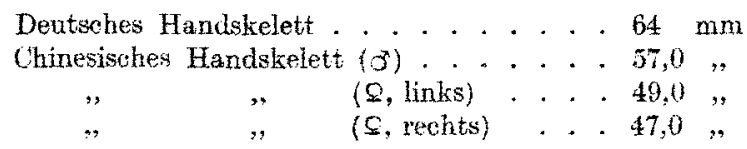

Die gradlinige Entfernung der Mitte des dorsalen radialen Pandes der distalen Karpalreihe von der dorsalen ulnaren Ecke des Hamatum, gemessen nit der Schublehre, beträgt:

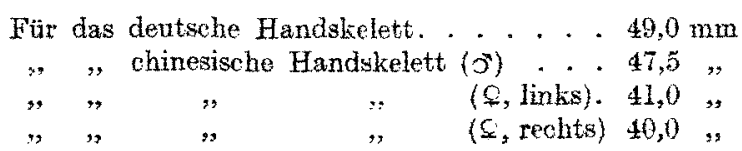


Ther Gewichts- und Gröbenverhälnisse der Komponenten des Habdsketetts gibt beilicgende Tabelle ausfïhrlichen Aufschlub. In folgenden solen einige Bemerkungen über die Formverhältnisse der Karpalknochen gegeben werden.

Das Radiale (Naviculare) its beim Mamne (Nr. 2), von dorsal gesehen, in seiner. Mitte am proximalen und distalen Rand eingeschnärt, sodal es eine hantelformige Gestalt besitzt; beim Weibe ist die distale dorsale Einschnürung sehr gering ausgebildet. Der größte Durchmesser des Radiale beträgt 23-25 mm, während er beim Europäer durchschnittlich sich auf $28-30 \mathrm{~mm}$ beläuft. Dic: dorsalwärts sehonde konvexe ulnare Gelenkflächenhälfte ist in ihren dorsalen Abschnit abgeplattet, in ihrem volaren Teil dagegen viel stanker gelsummt als an vinem deutschen Handskelett. Die beiden Radialia des Weibes hingegen zeigen eine ziemlich gleichmäßige, sanfte Krümmung der ulnaren dorsalen Gelenkfläehenhälfte. Proximal and volar von dieser befindet sich die beim Manze stark gehöhlte und oral gestaltete Gelenkflache zur Aufnahme des radialen Teiles des Kopfehen des Capitatum. Beim Weibe ist diese Gelenkflache annahernd kreisrund und viel flacher. Doral und uhat von der Gelenkflache für das Capitatum liegt eine bein Manne kleinere, bein Weibe größere halbmondförmige Gelenkflache für eine ghlehgrestaltete des Intermedium. Die proximale, nhare Gelenkflache ist von der rablalen, listalen durch wine deutlich ausgeprägte,

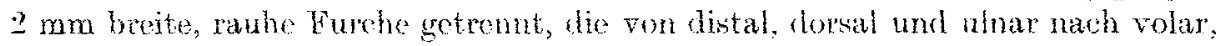
proximal und radial verläuft; an den Radialia des Weibes ist sie noch schärfer ausgeprägt. Die radiale, distale Gelenkhälfte ist beim Mame stark konvex gekrümmt, sowohl radio-ulnar wie proximo-distal. Beim Weibe ist die Krümmung eine geringere. Die distale Gelenkfliche verbindet sich mit dem Os multangulum majus et minus. Vom proximalen Teil dex radialen Hajfte geht als kurzer, glatter, stumpfer Höcker volarwärts das Tuberculum. Ulnar und dorsal von demselben verlauft eine beim Manne $6 \mathrm{~mm}$ breite lache Rinne, die beim Weibe seitlich weniger abgegrenzt ist.

Das Intermedium (Lunatum) besitzt 6 Flächen, die beim Manne besonders deutlich duroh Fanten voutinander abgesetzt sind. Die dorsale, rauhe Fläche ist am kleinsten, besonders am 1 . Intermedium des Weibes. Die radiale Eläche zeigt Halbmondform. Die distale Fläche ist konkav und zwar bein Weibe stärker als beim Manne; dementsprechend ist die Sehnenbreite bei letzterem größer $(12,8 \mathrm{~mm})$ als bei ersterem $(11,5 \mathrm{~mm}$ links). Die Volarfläche erscheint flacher als beim Deutschen und ist distal breiter. Die proximalo Gelenkflüche ist in ihrem ulnaren Abschnitt stark gewölbt, während bein Weibe sowie am deutschen Handskelett die Wolbung eine geringere und gleichmäBige ist. Die mit dem Ulnare sich verbindende Gelenkflache ist eben und riereckig; beim Manne hesitzt sie distal eine konkave Seite. Der zwischen der ulnaren und distalen Gelcnkfläche befindliche Teil für den proximalen, radialen Abschnitt des Hamatum ist höchst unvollständig als Gelenkfläche gesondert. Die lateralen Flächen sind gegen die distale konvergent.

Das Ulnare (Triquetrum) ist eine dreiseitige Pyramide, deren Spitze ulnar und volar gewandt ist. Der größte Durchmesser beträgt beim Weibe 16,5, beim Manne $17,6 \mathrm{~mm}$. Die radiale Gelenkfläche ist beim Manne fast eben, beim Weibe ganz leicht konkav; die Form der Gelenkfläche ist viereckig. Dio proximodorsalt 
Fläche ist radiounar und proximodistal konvex; sic ist rauh und besitzt in ihrer Mitte einen von radial nach uhar verlaufenden, stumpten Knochengrat, vor und hinter welchem der Knochen eine Impression besitzt. Die auf der Volarflache ulnarwäts angebrachte Gelenkflitche für das Os pisiforme ist ein den Kreis sich näherndes Oval, dessen längster Durchmesser beim Mame proximodistal, beim Weibe radio-ulnar gerichtet ist. Radial von der Gelenkflache für das Os pisiforme zeigt die volare Flüche eine rauhe Vertiefung, an die sich distal cin abgerundeter, fast glatter Enochenhöeker anschlieBt. Die distale Gelenkfläche ist grob und Jeicht sattelförmig gewölbt. Boim Weibe ist die Sattelform ausgesprochener als beim Manne.

Das Os pasiforme ist radio-ulnar komprimicrt und trägt dursal eine beim Manne ovale, bein Weibe fast kreisrunde Gelenkfläche, was auch an den Durchmessem zum Ausdruck kommt.

Das Karpale 1. (Os multangulum majus) besitat distal tine grofo, sattelfömige Gelenkfläche für das Vetakarpalo des Daumens. Der Unuil der Gelenkflache ist herzfömig und beim Manne vid breiter als beim Weibe; die Spitze der Her\%form ist volarwarts gewandt. Beim Weibe ist die dorso-volare Konvexitat stärker ausgesprochen als beim Manne, bei dem die radio-ulnase Konvexitat im volaren Abschnitt der distalen Gelenkfläehe äberwirgt. Die dotsale Fhicho des 1. Karpalknochens zeigt beim Manne unar und radial je sinen deutlich abgerundeten Höcker, die durch eine talartige Vertiefung voneinander getrennt sind. Beim Weibe sind diese Höcker sowie die dazwischen liegende Vertiefung selir gering entwickelt. Dio proximale, mit dem radialen Peil des Navicularo sich verbindende Gelonkflache ist kleiner als die distale und beim Vanne viop. eckig; nur die dorsale Ecke ist abgerundet. Beim Weibe konvergieren die ulnare und radiale Seite der proximalen Gelenkfläche nach dorsalwärts zu und gehen bogenförmig ineinander über. Die ulnare Fläche des Karpale 1. besitzt eine proxi. male größere, dorso-volar und proximodistal gering cntfaltete und tine dorsale, distale, kleine Gelenkflüche. Die proximoulnare Gelenkflähe ist von aler proximalen und dorsalen Fläche durch eine scharfe Knoohenkante getrent. Die proxiwale Gelenkfläche der unaren Knochenflache ist beim Mame dorsal und volar zugespitzt, so dab sie anmahernd die Form eines elliptischen schlanken Blattes besitzt. Beim Weibe ist diese Gelenkfläche, namentlich rechts, in proximodistaler. Richtung verbreiturt und hesitzt die Form eines verschobenen Rechtecks. Die dorsale, distale Gelenkflühe der uharen Knochenflache lagert sich dem radialen 'Teil der Basis des 2. Metarkarpale an und ist eben und beim Manne viel stärker proximodistal entwickelt als beim Weibe. Der Umrib dieser Gelenkfliche ist dreiekig, wobei die dorsale Seite konrex ist. Volat von der distalon Gelenkfläche (der unaren Knochenflache) befindet sich beim Manne ein 5,5 mm breiter Häcker, der beim Weibe kleinox int. Volar von demselben liegt eine viereckige kleine, nicht überknorpelte Knochenflache. Die Volarflüche des Karpale l. ist dreieckig und besitzt radial die Eminentia carpi radialis inferior, die beim Manne $12 \mathrm{~mm}$ lang und $3 \mathrm{~mm}$ breit ist. Beim Weibe ist dieselbe sehr niedrig und proximudistal wenig ausgedehnt; ebenso ist die ulnar von ihr liegende Rinne für den Flexor carpi radialis sehr flach und wenig ausgeprägt, während sie beim Manne sehr kräftig ist. 
Das Karpale 2. (Os multangulum minus) ist durso-volar entfaltet. Die kleine, proximale, leicht gehöhlte Flache ist rechteckig, ihr dorsaler Rand ist etwas breiter als ihr volarer. Die radiale Crelenkflache besitzt eine ähnliche Form wie die ulnare, proximale des Karpale 1. Der dorsale und proximale Rand der radialen Gelenkfläche sind in einem distalwärts offenen Winkel abgeknickt, der ungefähr $1: 0^{\circ}$ beträgt. Der distale Rand der radialen Gelenkfläche ist leicht S-förmig gebogen. Beim Weibe nähert sich der Winkel zwischen dem dorsalen und proximalen Rand der radialen Gelenkfläche vielmehr einem rechten als beim Mann; auch ist der Dorsalrand viel kürzer. Distal von der radialen Gelenkflache, die letztere ron der distalen Gelenkfläche scheidend, befindet sich eine dorso-volar ausgedehnte, dorsal sich zuspitzende, volar verbreiterte und in die Volarflache übergehende, rauhe Vertiefung, die von den gewulsteten Rändern der radialen und distalen Gelenkfläche scharf abgegrenzt wird. Die ulnare Gelenkfläche des Karpale 2. ist beim Manne einheitlich und stell ein Rechteck dar, mit der längeren Seite dorso-volar gerichtet. Beim Weibe besteht die ulnarc Gelenkflache aus 2 in einem stumpfen Winkel zueinander geneigten Fazetten, so daß hier eine größ3ere dorso-volare Ausdehnung zustande kommt als beim Nanne. Dir ulnare Gelenkfläche ist beim Manne durch eine stumpfe, dorso-rolar verlaufende Kante von der distalen Gelenkfläche gesehieden; beim Weibe gehen beide Gelenkflächen mehr abgerundet ineinander über. Die distale Gelenkfläche ist am größten; sie hat annähernd Keulenform, wobei der Griff der Keule volarwärts gewandt ist. Die distale, ganz überknorpelte Fläche ist beim Manne dorso-volar stark konkav, radioulnar-konvex; beim Weibe ist die dorso-volare Konkavität sehr gering ausgeprägt. In der Mitte des dorsalen Teiles der distalen Gelenkfläche ist ein beim Weibe stärkerer, beim Manne schwächerer Vorsprung, der sich am rechten Karpale 2. des Weibes als feine, kaum erkennbare Leiste nach volar orstreckt, so undeutlich die distale Gelenkfläche in eine kleinere radiale und gröBere ulnare Hälfte zerlegend. Der Vorsprung entspricht einer Vertiefung an der proximalen Fläche des Metakarpale 2. Die dorsale Flache des Karpale 2. fallt beim Manne ron ulnar und distal ziemlich steil nach radial und proximal ab; beim Weibe ist die dorsale Fläche nicht so steil gestellt. Nahe dem proximalen Rand zeigt die Dorsalfläche eine rauhe, radio-ulnar verlaufende und radial sich verjüngende Vertiefung. Die Volarflüche ist eben und viel kleiner als am deutschen Handskelett. Sie hat die Gestalt eines spitzwinkligen Dreiecks, dessen Basis radio-distal gewandt ist und das sioh kontinuierlich nach dorsal als rauhe Knochenfläche zwischen radialer und distaler Gelenkfläche fortsetzt.

Das Karpale 3. (Capitatum) ist der größ3te Knochen der Hardwurzel. Sein proximodistaler Durchmesser beträgt beim Weibe 19,0, beim Manne $21,0 \mathrm{~mm}$, während er beim Europäer im Vittel $25,0 \mathrm{~mm}$ beträgt. Auf der clorsalen Fläche ist der proximale Teil getrennt durch eine nach hinten leicht konvex von dorsal und ulnar nach volar und radial verlaufende, breite Pinne, die beim Weibe nur in Gestalt einer flachen Grube vorhanden ist. Die proximale Gelenkflache ist konvex. Gegen die Dorsalfläche und die Ulnarfläche ist sie scharf abgegrenzt: auf dis Volarfläche setzt sie sich eine kurze Strecke weit fort. Auf der radialen Seite dagegen nimmt das Capitatum, nach distal sich zuspitzend, mit einer überknorpelten 
dreieckigen Fliche dic proximalen Zweidrittel ein. Brim Weibe ist der ulnare Abschnitt der proximalen Fläche des Capitatum durch eine abgerundete KnochenLinte vom radialen Abschnitt (des Capitatum) deutlich getrennt; beim Manne besitzt das Capitatum dorsal und rolar, radial und ulnar je einen spitzeren und stumpfercn Höcker, sodaß das Capitatum, von groximal gesehen, eine rhombenartige Umgrenzung besitzt, während diese beim Weibe rundlich ist. Die Unarfläche ist beim Manne gegen die übrigen Flächen, aukgenommen volar, schanf abgegrenzt, was beim Weibe nur telweise der Fall ist. Beim Manne sind auf der Clnarfläche 2 getrennte Celenlifacetten vorhanden, eine große proximale und eine kleine distale und dorsale. Beide Gelenkfacetten sind durch eine seichte, $3 \mathrm{~mm}$ breite, sehief yon distal und volar nach proximal und dorsal verlanfende, rauhe Pinne voneinander geschieden. An diese 2 Gelenkfacetten lagem sich dic ebenfalls durch eine breite rauhe Rinne geschiedenen radialen Gelenkflächen des Hamatum. Dio beiden ulnaren Gelenkflachen sinel fast eben. Beim Woibe fohlt die Pinne zwischen der ulnaren proximalen und distalen Gelenkflache, so dab beirlerseits cine einheitliche, uhare Gelenkfläche vorhanden ist. Diesel ty besitzt im proximalen Teil sinen langen, im distalen Toil einen kurzen, dorso-volaren Durehmesser. Beim Weibe setzt wich die ulnare Gelenkfliche fast ohne Grenzc in den volaren, nicht überknorpelten Teil des Knochens fort. Beim Manne hingegen besitzt der colare Rand der beiden Gelenkfacetten eine scharfe Kante, die sich über das Yiveau der nicht überknorpelten uharen Partic des Capitatum erhebt. Der volare distale Teil der ulnaren Flache endet mit einer stumpfen Spitze. Die radiale, Fläche des Capitatum besitzt in ihrem distalen Teil zwei übereinander gelagerte Facetten: beim Mann eine dorsale größere und volare kleinere, die ohne Grenze in die Volarfläche übergeht. Diese Gelenkflächen zeigen eine geringe dorso-volare Ausdehnung; sie lagern sich an das Os inultangulum minus an. Beim Weibe dagegen sind diese äbereinander dorso-volar liegenden Gelenkfacetten leximodistal vielmehr verkürzt und stark dorsovolar ansgedehnt. Dic dorsale Facette ist von der volaren durch einen proximu-distal verlaufenken Knochengrat getrent, der sich in eine entsprechende Vertiefung der uharen Flache des Os multangulum minus legt. Die distale Gelenkflache des Capitatum besitzt drei Facetten, von denen die größte mittlere zur Anlagerung an das Metakarpale 3. (lient. Die mittlere Facette ist fast eben, dorsal breit, volar sich zuspitzend. Die radiale Facette ist besonders beim Manne krâftig ausgeböhlt; sie lagert sich an dis Metakarpale 2. Die ulnare und dorsale Facette ist am kleinsten; sie ist eluen und beim Nanne deutlich durch cine dorso-volare Leiste von dor mittleren Facette getrennt; beim Weibe geht sie ohne Grenze in die letztere über. Die ulnare Facette lagert sich an den radialen Teil des Metakarpale 4. Die dorsale Seite des Capitatum ist in ihrew distalen Ahsehnitt breit. Radial- und Ulnarseite konvergieren stark volarwäts, so daß eine deutliche Keilform des Knochens zustande kommt. Die Volartlache zoigt cino geringere radio-uhare Entfaltung als an deatschen Handskelett.

Das Karpale 4. und 5. (Hamatum) stellt eine vienseitige Pyramide dar mit proximal gerichteter Spitze und distal gestellter Basis. Letztere trägt beim Nanne cino imbeitliche Gelenkflache für das Metakarpale 4. und 5. Eine Trennungt in zwei Wlichen ist baum angedeutet. Etwas besser ausgeprägt ist dio Trennang 
am rechten Hamatum des Weibes im volaren Teil der distalen Gelenkfläche. Die Gelenkflïche ist beim. Manne ziemlich eben, beim Weibe dagegen radial und ulnar je mit einer Konkavität versehen. Die radiale Fläche des Hamatum besitzt beim Manne zwei Facetten, eine große proximale und eine kleine distale und dorsale. Beide Flächen sind fast eben und durch eine 4,0 $\mathrm{mm}$ breite, clorso-volare Rinne voneinander getrennt. Die proximale Facette ist oval und der lange Durchmesser verläuft proximodistal. Am Hamatum des Weibes geht dic proximale, radiale Gelenkfläche im dorsalen Teil kontinuierlich in die distale, radialo Gelenkfläche über; volar von der letzteren liegt ein viereckiges rauhes Feld. Beim Weibe ist die radiale, proximale Gelenkfacette proximodistal stark verkürzt und im dorso-volaren Durchmesser ausgedehnt. An Stelle einer Rinne ist nur eine kleine Grube vorhanden. Die dorsale Fläche des Hamatum ist uneben und besitzt eine dreieckige Form: die distale und radiale Seite treffen unter einem rechten Winkel zusammen. Die ulnare Fläche des Hamatum ist konvex gekrümmt und ist beim Manne meh" proximo-distal entwickelt als heirn Weibe. Der Hamulus ossis hamati ist überall kräftig entwickelt; seine ulnare Fläche ist konvex gekrümmt, seine radiale leicht konver.

Gewicht der Komponenten des Handskeletts in Milligrammen.

\begin{tabular}{|c|c|c|c|c|c|c|c|c|c|c|c|c|c|}
\hline & & & & & & & & & $\begin{array}{l}\text { Tr. } 1 \\
\text { links }\end{array}$ & reents & Differenz & $\begin{array}{l}\text { Nr. } 2 \\
\text { links }\end{array}$ & $\begin{array}{l}\text { Different } \\
\text { zwischen Nr. } 2 \\
\text { whd 1. links }\end{array}$ \\
\hline Radiale. . & & . & & & . & . & . & · & 1150 & 1200 & 50 & 1720 & 571 \\
\hline Intermediun & . & . & • & & . & . & . & . & 750 & 850 & 100 & 1110 & $364)$ \\
\hline Uluare . . & . & . & . & & . & . & . & . & 550 & 630 & 80 & 907 & 357 \\
\hline Os pisiforme & . & : & & & . & . & . & . & 255 & 265 & 10 & \pm 50 & 195 \\
\hline Mrultangulum & & bjus & & & . & . & . & . & 650 & 705 & $5 \overline{5}$ & $1: 36$ & 665 \\
\hline Nultanguiram & $\mathrm{mi}$ & nus & & & . & . & . & . & 500 & 570 & 70 & 785 & $18: \pi$ \\
\hline Capitatum . & . & . & * & & . & . & . & • & 1135 & 1305 & 170 & 1000 & 925 \\
\hline Hamatum & & . & . & & . & . & . & . & 1155 & 1200 & 45 & 1510 & 855 \\
\hline Hetartasus & & . & • & & . & . & . & • & 2630 & 2690 & 60 & 3470 & 840 \\
\hline ; & & . & . & & . & . & . & . & 4300 & 4555 & 255 & 5685 & 1385 \\
\hline , & & . & . & & . & . & . & - & 3450 & 4025 & 575 & 5230 & 1780 \\
\hline 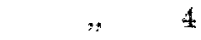 & & . & • & & . & . & . & • & $\geq 050$ & 2300 & 250 & 3310 & 1200 \\
\hline , 5 & & , & . & & . & . & . & . & 1955 & 2110 & 155 & 2740 & 785 \\
\hline Grundphalang & e. & . & . & & . & . & . & . & 1340 & 1450 & 110 & 1020 & 580 \\
\hline , & & 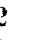 & & & . & . & . & . & 2135 & 2140 & 5 & 2870 & 73.5 \\
\hline 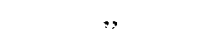 & & 3 & " & & . & - & . & · & 2000 & 2555 & 55 & 3505 & 1005 \\
\hline$\because$ & & $t$ & & & . & . & . & . & 1820 & 1955 & 135 & 2640 & $8 \geqslant 0$ \\
\hline . & & 5 & . & & . & . & . & . & 1060 & 1330 & 270 & 1565 & 505 \\
\hline Mittelphalange & & 2 & & & . & ${ }^{\circ}$ & . & . & 710 & 715 & 5 & 895 & 185 \\
\hline$\because$ & & ; & • & & . & . & . & . & 1000 & $1000)$ & 0 & 1355 & 355 \\
\hline$\therefore$ & & 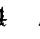 & & & . & . & . & . & 715 & 755 & 40 & 1020 & $3 0 \longdiv { 5 }$ \\
\hline 5 & & 5 & . & & . & . & . & . & 365 & 410 & 45 & 505 & 140 \\
\hline Endphalange & 1 & . & • & & . & " & . & . & 410 & 430 & 20 & 610 & 200 \\
\hline , $\quad 2$ & 2 & . & . & & . & . & . & - & $21 \tilde{5}$ & 215 & 0 & 270 & 55 \\
\hline ", & 3 & . & " & & $\cdot$ & • & $\cdot$ & . & 250 & 250 & 0) & 400 & 150 \\
\hline , & 4 & . & • & & . & • & . & . & 210 & 235 & 25 & 320 & 110 \\
\hline$\because$ & 5 & . & . & & . & - & . & . & . $\quad 150$ & 160 & 10 & 215 & 65 \\
\hline Gesamtgewich & & . & . & & . & • & . & . & $.33 \pm 10$ & 36005 & 2595 & 48382 & 14972 \\
\hline
\end{tabular}


Maße der Komponenten des Handskelettes in Millimetern.

2. Karpalknochen.

(i) Naviculare.

1. GroBter Durchmesser des Nariculare

2. Größter dorso-volarer Durchmesser der ulnaren Hälfte des Naviculare

3. Dono-volarer Durchmesser an der Grenze der ulnaren und radialen Hülte . . . . . . . . . . . . . . . . . . .

4. Crößter dorso-volarer Durchnesser ler radialen Hälfte des Siavculare

5. Prozimo-distaler Durchmesser (Dieke) der alnaren Halfte an dorsalen Teil

6. Prosimo-distaler Durchmesser (Dicke) der anaren Halfte dos Naviculare am rolaren Teil . . . . . . . . . . . . . .

7. Proximo-distaler Durchmesser (Dicke) in der Witte der ulnaren Hälfte

9. Proximo-distaler Durchmesser (Dicke) in der Witte der madialen Hälfte . . . . . . . . . . . . . . . . . .

9. Größter proximo-distaler Durchmesser (Dicke) des Naviculare in der Mitte . . . . . . . . . . . . . . . . . .

10. Radio-1narer Durchmesser (Entfernums der Vitte des unaren Dorsalrandes von der Mitte des radialen Volarrandes . . . . . . . .

11. Größte Sehnenbreite der distalen konkaven Gelenkflächle . . . .

12. Sehnenbreite der distalen konkaven Gelenkflähe senkrecht zur vorigen

b) Lanaium,

1. Größter Durchinesser des Lunatum . . . . . . . . . . . . .

2. Gröbter dorso-volarer Durchmesser (geradlinige Entfermung der radialen dorsalen Ecke von der radialen volaren) . . . . . . .

3. Proximo-distaler Durchmesser (geradlinige Entfernung der Mitte der distalen Flüche von der Witte der proximalen Fläche) . . . . .

4. Radio-nharer Durobmesser (geradlinige Entfernung der Mitte der radialen Fläche von der Mitte der ulnaren Fläche)

5. Radio-ulnarer Durchnesser der distalen konkaven Flache, dorsal . .

6. Padio-ulnaver Durehmesser der distalen konkaven Fläche, nabe der volaren Kante . . . . . . . . . . . . . . . . . . . . . . .

7. Dorsovolarer Durehnesser der distalen konkaven Fläobe (geradlinige Entternung der Mitte des Dorsalmandes ron der Mitte des Volarrandes der distalen Fläche) . . . . . . . . . . . . . . .

8. Größter proximo-distaler Durchmesser der radialen Flähe . . .

9. Größter proximo-distaler Durchmesser der ulnaren Fläche. . .

10. Dorso-volarer Durchmesser der ulnaren Gelenkfläche . . . . .

11. Länge der distalen Kante der dorsalen Wläche . . . . . . . . .

12. Länge der proximalen Kante der dowalen Fläche . . . . . . .

13. Länge der radialen Kante der dorsalen Flache. . . . . . . . .

14. Tänge der ulnaren Kante rer dorsalen Flache. . . . . . . . .

15. Proximo-distaler Durchmesser der Volarfläche (geradinige Ent. fernung der Mitte der proximalen Kante von der Mitte der distale1 Kante der Volarfläche), . . . . . . . . . . . . . . . .

16. Radio-ulnarer Durchmesser der Volarflache (ueradlinige Entfemung der Mitte der radialen Kante ron der Mitte der ulnaren Kante der Volarfläche

17. Länge der Dorsalkante der proximalen Flache . . . . . . . .

15. Lange der Volurkante der proximalen Finche . . . . . . .

\begin{tabular}{crc}
\multicolumn{2}{c}{ Nr. 1 } & Ni. 2 \\
23,9 & 23,0 & 25,0 \\
12,1 & 13,0 & 15,1 \\
12,0 & 12,0 & 11,0 \\
14,0 & 11,0 & 15,3 \\
4,0 & 4,0 & 4,0 \\
6,8 & 6,0 & 7,0 \\
7,0 & 6,0 & 9,5 \\
8,0 & 9,0 & 10,0 \\
10,8 & 10,0 & 12,5 \\
21,7 & 22,0 & $2,3,0$ \\
11,5 & 11,5 & 14,0 \\
11,0 & 11,0 & 9,9
\end{tabular}

$16.9 \quad 17,1 \quad 18,0$

$14,1 \quad 14,0 \quad 15,5$

$8,9 \quad 9,5 \quad 9,0$

$10,0 \quad 10.5 \quad 12,1$

$4,5 \quad 4,1 \quad 4,4$

$7,0 \quad 7,0 \quad 0.0$

$11,1 \quad 11,2 \quad 12,6$

$6,1 \quad 6,1 \quad 6,9$

$9,2 \quad 10,0 \quad 7,5$

$7,2 \quad 8,0 \quad 8,0$

$\pm, 1 \quad 4,5 \quad 5,0$

$9,8 \quad 8,5 \quad 8,0$

$3,0 \quad 6,5 \quad 6,2$

$8,7 \quad 10,0 \quad 8,0$

$10, \bar{j} \quad 11,1 \quad 12,0$

$9,0 \quad 10,0 \quad 12,0$

$11,0 \quad 8,0 \quad 8,0$

$12,0 \quad 13,0 \quad 13,0$ 
19. Länge der Ulnarkante der proximalen Fläche . . . . . .

20. Länge der Padialkante der proxinalen Fläche . . . . . . . .

21. Radio-ulnarer Durchmesser der proximalen Fläche (geradlinige Entfernung des Mittelpunktes der radialen Kante von dem der ulnaren Kante) . . . . . . . . . . . . . . . . . . . . .

22. Dorso-volarer Durchmesuer def proximalen Fläche (geradlinge Entfernung des Yittelpunktes der dorsalen Kante von dem der voluren Kante)

$\overbrace{\text { inks reithts }}^{\text {Yr. }}$ link

$7.0 \quad 6,0 \quad 6,5$

$1 \pm, 0 \quad 12,5 \quad 13,0$

$9,9 \quad 11,0 \quad 13,0$

$11,4 \quad 10,0 \quad 11,1$

c) Triquetrum.

1. Größter Durchmesser des Triquetrum . . . . . . . . . .

16,6) $\quad 16,5 \quad 17,6$

$11.4 \quad 12.4 \quad 12,9$

2. Gröb ter dorso-volarer Durchmesser (im Bereich des radialen Teiles)

$\begin{array}{llllllll}\text { 3. Proximo-distaler Durchmesser (in der Mitte) . . . . . . . . . . . . . . . . } & 8,9 & 9,0 & 10,0 \\ \text { 4. CröBter radio-alnarer Durchmesser . . . . . . . . . . . . . . } & 13,5 & 14,2 & 10,5\end{array}$

5. Radio-ulnarer Durchmesser der dikfitlen Celenkfläche . . . . . $10.8 \quad 11,8 \quad 13,0$

b. Größtex dorso-volarer Durchmesser der distalen Gelenkfläche . . 11,0 11,2 10,0

7. Größter proximo-distaler Durchmesser der radialen Gelenk-

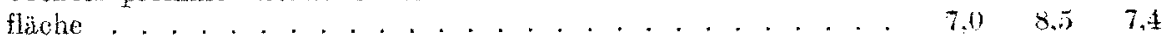

8. Größter dorso-volarer Durchmessser der rudialen Celenkflächo . . $\quad 9,0 \quad 8,1 \quad 8,1$

9. GröBter Durchmesser der rolaren Geleuktlache ........... 7,0 7.5 10,0

$$
\text { d) Pisiforme. }
$$

1. Crröbter Durchmesser des Pisiforme 2. . . . . . . . . . . 12,1 12,8 14,0

2. Größter dorso-volarer Durchmesser . . . . . . . . . . . . . . . . . . $\quad \begin{array}{rrrr}9,9 & 9.8 & 10,8\end{array}$

3. GröBter proximo-distaler Durchnesser. . . . . . . . . . . . . $11.2 \quad 11,0$ 13,0

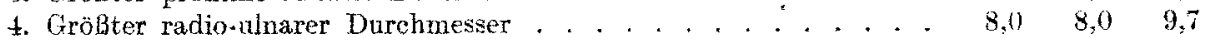

5. Proximo-distaler Durchmesser der dorsalen Gelenkfläche . . . . $\quad 7.0 \quad 7,5 \quad 9,0$

B. Radio-ulnarer Durchmesser der dorsalen Cielenkfläche . . . . . $7,0 \quad 7,0 \quad 7,0$

e) Os multangulum majus.

1. GröBter Durchmesser des Os multangulum majus . . . . .

2. GröBter dorso-volarer Durchmesser (an der radialen Flache des Fnochens mit Einschluß der Eminentia carpi radialis inf). . .

3. Größter dorso-volarer Durchmesser (Entfernung der Witte der Dorsalfläche von der Mitte der Volarflăche ulnarwärts von iler Ementia carpi rad. inf.) . . . . . . . . . . . . . .

4. Proximo-distaler Durchmesser (Entfernung der Mitte der distalen Gelenkfläche von der Mitte der proximalen Gelenkfläche) . . . .

5. Crößter proximo-distaler Durchmesser (nahe der proximo-distalen Halbierungslinie der dorsalen Fläche) . . . . . . . . .

6. Kleinster proximo-distaler Durchmesser (im Volarabschnitt) . .

7. Radio-uharer Durchmesser (Entfernung der Mitte der radialen Flache von der Mitte der alnaren Fläche) . . . . . . . .

8. Größter radio-ulnarer Durchmeswer (radio-ulnare Halbierungslinie der dorsalen Fläche des Os multangulum majus) . . . . . . . .

9. Kleinster radio-nlnarer Durchmesser (im volaren Abschnitt des

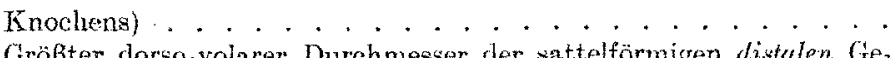

10. Größter dorso-volarer Durchmesser der sattelförmigen distalen Ge-

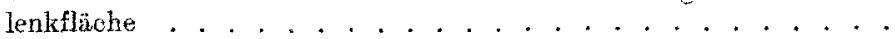

11. Größter radio-alnarer Durchmesser der sattelförmigen distalen Celenkllache ..................

$19,0 \quad 19,1 \quad 23,0$

13.0 $\quad 14,0 \quad 16,2$

$11,0 \quad 11,0 \quad 13,0$

$9,9 \quad 10,0 \quad 11,5$

$11,0 \quad 11,2 \quad 12,2$

$6,5 \quad 7,0 \quad 9,0$

$11,0 \quad 10,3 \quad 13,0$

$13,5 \quad 13,1 \quad 18,0$

$9,9 \quad 9,3 \quad 11,0$

$10,0 \quad 10,5 \quad 11,6$

$11,0 \quad 10,5 \quad 14,0$

12. Dorso-volarer Durchmesser der proximalen Gelenkfläche . . . $8,5 \quad 8,0 \quad 9,5$

13. Racio-ulnarer Durchmesser der proximalen Gelenkfläche . . . . $\quad 6,8 \quad 8,0 \quad 8,5$

14. Dorso-volarer Durchmesser der Mitte der rudialen Fläche . . . $13,0 \quad 14,0$ 16,2

15. Proximo-distaler Durchmesser der Witte der Radialfläche . . . $\quad \begin{array}{lll}9,6 & 9,8 & \mathbf{1 2 , 0}\end{array}$ 
16. GröBter dorso-volarer Durchmesser der wharen Fläche . . . .

17. Proximo-distaler Durchmesser der Yitte der ulnaren Fläche. . .

18. GröBter proximo-distaler Durchmesser der proximalen Gelenkfacette der ulnaren Fläche . . . . . . . . . . . . . . .

19. Dorso-volarer Durchmesser der proximalen Gelenkfacette der ulnaren Fläche. . . . . . . . . . . . . . . . . .

20. Proximo-distaler Durchmesser der distalen dorsalen Gelenkfacette der nlnaren Flache . . . . . . . . . . . . . . . . . . . .

21. Croßbter dorso-5olarer Durchmesser der distalen dorsalen Gelenkfacette der ulnaren Fläche

2*. Gerade Länge der proximo-distalen Habierngstinie der torsalen Fläthe. . . . . . . . . . . . . . . . . . .

f) Os maltangulam winus.

1. Größter Durehmesser des Os multangulum minus . . . . . .

2. Dorso-volarer Durchmesser (geradliniue Entfernung der Mitte cler Volarflache von der Mitte der Dorsalflache) . . . . . . . . . .

3. Proximo-distaler Durchmesser (geradlinige Entfernung der Mitte der distalen Flähe rom Wittelpunkt des dorsalen Randes der proxi. malen Gelenkfläche) . . . . . . . . . . . . . . . . .

4. Proximo-distaler Durchmesser im Bereich der Vorlarfläche . .

5. Radio-ulnarer Durchmesser (Entfernung der Mitte der Ulnarfläche von (ler Mitte der Radialflache) . . . . . . . . . . . . . .

6. GroBter dorso-volarer Durchmessen der distnten Gelenkflähe -

7. GröBter radio-volarer Durchmesser der distalen Gelenkfliohe im dorsalen Teil .......................

8. Kleinster radio-volarer Durchmesser der distalen Gelenkflache in volaren Teil. . . . . . . . . . . . . . . . . . . . . .

9. Dorso-volarer Durchmesser der proximalen Gelenkflache . . .

10. Radio-ulnarer Durchmesser der proximalen Gelenkflähe am dorsalen Rand . . . . . . . . . . . . . . . . . . . . . . . . .

11. Rartio-ulnarer Durchnesser der proximalen Gelenkflaiche am rolaren Rank. . . . . . . . . . . . . . . . . . . .

12. GröBter proximo-distaler Durchmesser der rad inlen Gelenkfläche . .

13. Geradinige Entfernung des zugespitzten dorsalen rom zugespitzten volaren Encle der radialen Gelenkflache . . . . . . . . . . . .

14. Dorso-volarer Durchmesser der ulmaren Gelenkflüehe . . . . . .

15. Proximo-distaler Durchmeser der ulnaren Gelenktläche. . . . .

n) Capitatum.

1. Größter Durchmesser . . . . . . . . . . . . . . . . . . . .

2. Dorso-volarer Durchmesser im distalen Peil (geradinige Entfemung ler Mitte des dorsalen Randes der distalen Celenkfluche vom vorspringendsten Punkt des distalen Teiles der Volarflache) . . . .

3. Dorso-volarer Durchmesser im unaren distalen Teil (geradlinige Entfernung der distalen, dorsalen, uharen spitze rom vorsprinrendsten Punkte der rolaren Flache) . . . . . . . . . . . . .

4. Dorso-volarer Durchmesser in der Mitte les Capitatun. . . . .

5. Gröbter dorso-volarer Durchmesser des Capitatum . . . . . . .

(i. Proxino-distaler Durehmesser (Entfernung der Mitte dor proximalen Flishe des Capitatum von der Mitte der distalen Gelenkflache) .

7. Geradlinge Entfemung der Witte der proximalen Fiache des Capitatum von der distalen, dorsalen, uhnaren Spitze des Capitatum . . . .

8. Radio-nharer Durehmesser in der Witte des distalen Teilos des Capitatum . . . . . . . . . . . . . . . . . . .

$\begin{array}{rrr}\text { links } & \text { rents } & \text { Nr.? } \\ 14.0 & ] 4,1 & 16,9 \\ 8,9 & 9,0 & 12,0 \\ 4,5 & 4,5 & 7,0 \\ 8,9 & 9,0 & 10,2 \\ 5.0 & 5,8 & 6,0 \\ 3,9 & 3,8 & 4,0 \\ 10,0 & 10,1 & 18,0\end{array}$

$17,5 \quad 17.5 \quad 18.0$

14.i) $13,0 \quad 15,5$

$8,9 \quad 8,6 \quad 0,1$

$7.2 \quad 7.3 \quad 9.8$

1.8 $7,0 \quad 7,4$

I.t. 15.614 .9

$9.0 \quad 10.5 \quad 11,1$

$4.8 \quad 4.9 \quad 4.9$

$9,0 \quad 9,0 \quad 9,0$

$6,0 \quad 7,0 \quad 7,8$

$4.5 \quad 4.5 \quad 5.0$

$5,6 \quad 5,5 \quad 6,5$

$12,5 \quad 13,9 \quad 14,0$

- $\quad$ - 8.5

$5.0 \quad 4,9 \quad 6.2$

$22,1 \quad 23,0 \quad 26,0$

$34.5 \quad 14,5 \quad 17,5$

$16,5 \quad 17,0 \quad 79,0$

$12.2 \quad 13,0 \quad 13,7$

$9,9 \quad 10,1 \quad 16,0$

$19,0 \quad 19.1 \quad 21.0$

$2], 8 \quad 21,5 \quad 23,5$

$10,0 \quad 10,6 \quad 11,4$ 
9. Radio-ulnarer Durchmesser im mittleren Teil des Knochens. . .

10. Radio-nlnarer Durchmesser des Capitatum . . . . . . . . . .

11. Dorso-volarer mittlerer Durchmesser der radialen Facette der diwlaten Gelenkfläche

12. Dorso-volarer Durchmenser der mittleren Faette der distalen Gelenktliche.

13. Dorso-volarer Durchmesser der unaren Facette der distalen Gelenkfläche

14. Troßter radio-nlnarer Iurchmesser der radialen Facette der distalen Gelenkflache

15. Größter radio-ulnarer Durchmesser der mittleren Facette der (istalen Gelenkfläche (im dorsalen Teil).

16. Größter madio-ulnarer Durchmesser der ulnaren Facette der distalen Gelenkfläche

17. Dorso-volarer Durchmesser de beiden ibereinander gelagerten distalen Gelenkflachen der radialen Knochenflache (zur Anlagerung an das Os multangulum minus).

18. Größter proximo-distaler Durchnesser der beiden ibereinander gelagerten distalen Gelenkfläeben der radialen Knochenfläche. .

19. Kleinster proximo-distaler Durchmesser derselben Flächen wie bei Nr. 18 . . . . . . . . . . . . . . . . . . .

20. Proximo distaler Dumchmesser der proxinalen Celenkfacette der ulgaren Fläche des Capitatum . . . . . . . . . . . . . . . .

21. Dorso-volarer Durchmesser des proximalen Teiles der alnaren telenkfläche. . . . . . . . . . . . . . . . . . . . . . .

22. Geradlinige Entfernuny der Mitte des proximalen Randes der unaren proximalen Gelenkfläche von der distalen, dorsalen, ulnaren Spitze .

\section{h) Flamatum.}

1. GröBter Durchmesser

2. Dorsal-volarer Durchmesser distal . . . . . . . . . . . . . .

3. Dorso-volarer Durchmesser in der Mitte des Knochcns . . . . .

4. Dorso-volarer Durohmesser proximal . . . . . . . . . . . . .

5. Dorso-volarer Durchmesser im distalen ulnaren Teil, den Hamulus ossis hamati mit einbegriffen . . . . . . . . . . . . . . . . .

6. Proximo-distaler Durchmesser (getadlinige Entfernung der Mitte der distalen Gelenktläche von der Mitte der zugeschärften proximalen Kante) . . . . . . . . . . . . . . .

7. Geradlinige Entfernung der Mitte des Randes der distalen Gelenkfläbe von der Mitte der zugeschirften proximalen Kante . .

8. Geradlinige Entfernung der Mitte des ulnaren Randes der distalen Gelenkfläbhe ron der Mitte der zugeschärten proximalen Kante.

9. Radio-ulnarer Durchmesser am distalen Teil . . . . . . . . . .

10. Radio-ulnarer Durchmesser in der Mitte des Hamatum (die Wittelpunkte der lateralen Flächen verbindend) . . . . . . . . . .

11. Dorso-volarer Durchmesser der Mitte der distalen Gelenkflüche

12. Radio-ulnarer Durchmesser der Mitte der distalen Gelenkfläche.

13. Größter dorso-volarer Durchmesser der proximalen Gelenkfacette der radialen Fläche . . . . . . . . . . . . . . .

14. Proximo-distaler Durohnesser der proximalen Facette der radialen Fläche......................

15. Gröbter dorso-volarer Durchmesser der ulnaren Gelenkfläche . .

16. GröBter proximo-distaler Durchmesser der ulnaren Gelenkfläche .

17. Radio-nlnarer Durchmesser des Hamulus ossis hamati an der Basis

18. Proximo-distaler Durchmesser des Famulus ossis hamati....

\begin{tabular}{|c|c|c|}
\hline \multicolumn{2}{|c|}{ Sr. 1} & 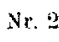 \\
\hline links & rechts & links \\
\hline 11,0 & 10,0 & 13,0 \\
\hline 9,1 & 10,0 & 12.3 \\
\hline 9,0 & 9,0 & $9, \tilde{3}$ \\
\hline 14,0 & 14,0 & 14.0 \\
\hline 4.0 & 3,2 & $4, \pi$ \\
\hline 5,0 & 5.0 & 6.0 \\
\hline 10.9 & 11.0 & 11,5 \\
\hline 2.1$)$ & $1, \overline{3}$ & 50 \\
\hline 13,1 & 13.1 & 10,0 \\
\hline 5,0 & 4,1 & 6.5 \\
\hline 2,2 & 3,0 & 4,5 \\
\hline- & - & 12 \\
\hline 7,2 & 8.0 & 8,0 \\
\hline 17.5 & 17,5 & 19, \\
\hline
\end{tabular}

$22,0 \quad 22,0 \quad 24,5$

$12,0 \quad 10,0 \quad 11,2$

11,0 $12,0 \quad 13,0$

$9,0 \quad 12,0 \quad 10,0$

$19,6 \quad 19,9 \quad 21,0$

$15,0 \quad 15,3 \quad 18,0$

$15,0 \quad 15,0 \quad 17,3$

$15,0 \quad 14,8 \quad 19,0$

$12, \pi) \quad J 3,0 \quad 14,0$

$8,5 \quad 8,0 \quad 9,9$

$9,4 \quad 9,5 \quad 9,0$

$12,1 \quad 12,0 \quad 13,5$

$8,0 \quad 9,0 \quad 9,0$

$7,0 \quad 8,0 \quad 11,0$

$9,0 \quad 9,5 \quad 10,1$

$13,0 \quad 14,0 \quad 18,0$

$5,1 \quad 5,8 \quad 5.1$

$0,5 \quad 10,0 \quad 3,5$ 


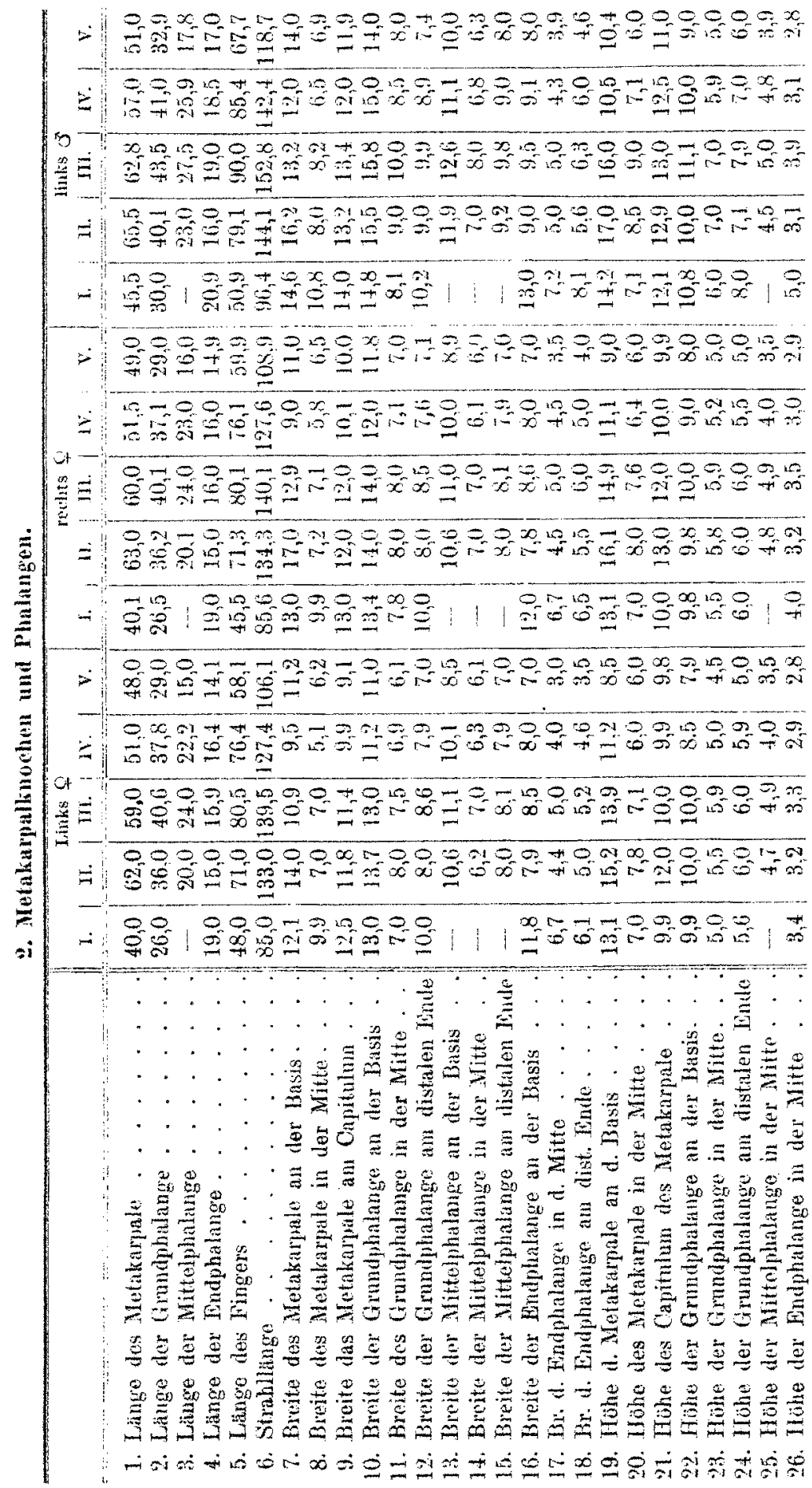


Zum Vergleiche will ich in folgender Tabelle den Längenmaßen der Metakarpalknochen und der Phalangen des Chinesen und der Chinesin diejenigen ron Europäern und Japanern (nach Pfitzner und Adachi) zufügen. Aus den Zahlen von Nr. 1 (links und rechts) ist das arithmetische Mittel genommen.

\begin{tabular}{|c|c|c|c|c|c|c|c|c|c|c|c|c|c|}
\hline & & & & I. & II. & III. & IV. & v. & \multicolumn{5}{|c|}{ Differenz } \\
\hline 1. & Län: & des & Metakarpale & & & & & & & & & & \\
\hline & & & esin) & 40,0 & 62,5 & $\mid 59,5$ & 51,2 & 48,5 & $1, \pm$ & $(0,4)$ & 0,3 & 2,8 & 1,3 \\
\hline ב. & 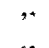 & $\because$ & ". (Europäer) & 41,4 & 62,1 & 59.8 & 54,0 & 50,0, & & & & & \\
\hline 4. & " & $"$ & 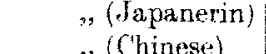 & 40,0 & 58.1 & 56.0 & $\begin{array}{l}50,6 \\
-70\end{array}$ & $\begin{array}{l}46,3 \\
51,0\end{array}$ & & & & & \\
\hline 5 & & $"$ & & $\begin{array}{l}45,5 \\
44,5\end{array}$ & $\begin{array}{l}65,5 \\
65,3\end{array}$ & 62.8 & $\begin{array}{l}57,0 \\
: 56,7\end{array}$ & 40 & $(1,0)$ & () & 0 & $(0,3)$ & 1,6 \\
\hline 6. & & , & "Japan & 41,9 & 62,2 & $\begin{array}{l}102,8 \\
59.3 \\
59,3\end{array}$ & 54,2 & 50,5 & & & & & \\
\hline 7 . & $\because$ & $"$ & Grimelph & & & & & & & & & & \\
\hline & & & & $\mid 26,2$ & 36,1 & 40,3 & 37,4 & 29,0 & & (1) & 00 & & \\
\hline 8. & $\because$ & " &,$($ Eu & 27.7 & 37,0 & 41,2 & 38.8 & 30.6 & & 0.1 & 0.3 & 1.4 & \\
\hline 9 & 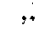 & ", & & 27,1 & 36,0 & 40,4 & 38,4 & 29.9 & & & & & \\
\hline 10. & $"$ & ". & & 30.0 & 40,1 & 43.5 & 41,0 & 32,9 & & (13) & $(0,1)$ & 0 & 60. \\
\hline 11. & ". & ", & , (Europäer) & 29,4 & 38.8 & 43,4 & 41,0 & 32,4 & & $(t, n)$ & $(0,1)$ & 1 & \\
\hline 2. & $\because$ & ,. & .. Japaner) & 28.2 & 37.7 & 42,3 & 40,0 & 31,5 & & & & & \\
\hline 4. & ," & , & r) & - & 20,0 & $24,1)$ & 22,6 & $\begin{array}{l}15,5 \\
18,2\end{array}$ & 12,4 & 3,1 & 3.2 & 2.7 & \\
\hline 15. & .. & , & & - & 22,4 & $2 \pi, 1$ & 25,8 & $\begin{array}{l}18,2 \\
16,6\end{array}$ & & & & & \\
\hline 16. & "י & " & . Chinese & - & $\begin{array}{l}21,0 \\
93,0\end{array}$ & 24.9 & 23,7 & $\begin{array}{l}10, n \\
17,8\end{array}$ & & & & & \\
\hline 17. & .. & $\therefore$ &,$($ Eur & - & $\begin{array}{ll}2,3,0 \\
23,7\end{array}$ & $\begin{array}{l}27,5 \\
28,5\end{array}$ & $\begin{array}{l}25.9 \\
27.2\end{array}$ & 19,2 & & 1.0 & 1.3 & 1.4 & \\
\hline 18. & ". & .. & , (Japaner $)$ & - & 22,2 & 26,7 & 25,3 & {$[7,4$} & & & & & \\
\hline 10. & " & $\therefore$ & Endphala & & & & & & & & & & \\
\hline (1). & & & & 19,0 & 15,0 & 15,9 & 16,2 & 14,5 & & 1.0 & 0,8 & 1,3 & 1,2 \\
\hline 21. & & " & r) & 20,4 & 16,0 & 16,7 & 17,5 & 15,7 & & & & & \\
\hline 3. & & $"$ & anerin) & 19,6 & 10,8 & 16,9 & 17,1 & 15,1 & & & & & \\
\hline 2. & , & ", & nase) & 20,9 & 16,0 & 19,0 & 18,5 & $\begin{array}{l}17,0 \\
173\end{array}$ & 1,7 & 1,7 & $(0,4)$ & 0,6 & 0,3 \\
\hline 4. & & $\because$ & "(Juropaer) & $\left|\begin{array}{l}22,5 \\
21,6\end{array}\right|$ & 18,9 & 17,8 & 18,4 & 16,5 & & & & & \\
\hline
\end{tabular}

Die europäischen Maße ergeben höhere Werte als die chinesischen. Die eingeklammerten Zahlen bedeuten, daß hier beim Chinesen das gröhere Maß vorliegt. Beim Japaner herrscht im allgemeinen eine geringere Länge als beim Chinesen.

Im Anschluß an das Skelett der oberen Extremität des erwachsenen Chinesen lasse ich eine Beschreibung des oberen Extremitätenskelotts des neugeborenen Chinesenkindes folgen. Ich mußte inich auf diesen einen Fall beschränken und weiteren Untersuchungen wird es vorbehalten bleiben, Rassoncigentümlichkeiten am Skelett des neugeborenen Chinesenkindes aufzufinden. Rassendifferenzen sind hier um so schwieriger zu beurteilen, als zu ciner Anthropologie des Nengehorenen nur wenige Ansätze vorhanden sind.

\section{Untersuehtes Material.}

Durch Wendung gewonnenes, ausgetragenes, männliches Chinesenkind mit einem Gasamtgewicht ron $3810 \mathrm{~g}$. Länge des Kindes, gomessen vom Soheitel his zum After, $38,0 \mathrm{~cm}$, Länge der Arme $2.2,3 \mathrm{~cm}$, gemessen vom Ende des Mittelfingers bis zur Extr. acrom. clav., Länge des Beines $20,5 \mathrm{~cm}$, gemessen vom 
Trochanter major bis zur Ferse. Länge der Nabelschnur 65,0 em. Durchmesser der Placenta $20,0 \mathrm{~cm}$, Gewicht des Gehirns nit Pia $437 \mathrm{~g}$; die laterale Affenspalto beiderweits gering entwickelt. Lebergewicht $140 \mathrm{~g}$; Milzgewicht 1.3,5g; Gewicht der Placenta nebst der Nabelschnur $740 \mathrm{~g}$. Das in Alkohol konservierte Kind wurde skelettiert, Perichondrium und Periost wurden entfernt und die einzelnen Knorpel und Knochen wurden gewogen, nachdem sie leicht abgetrocknet worden waren.

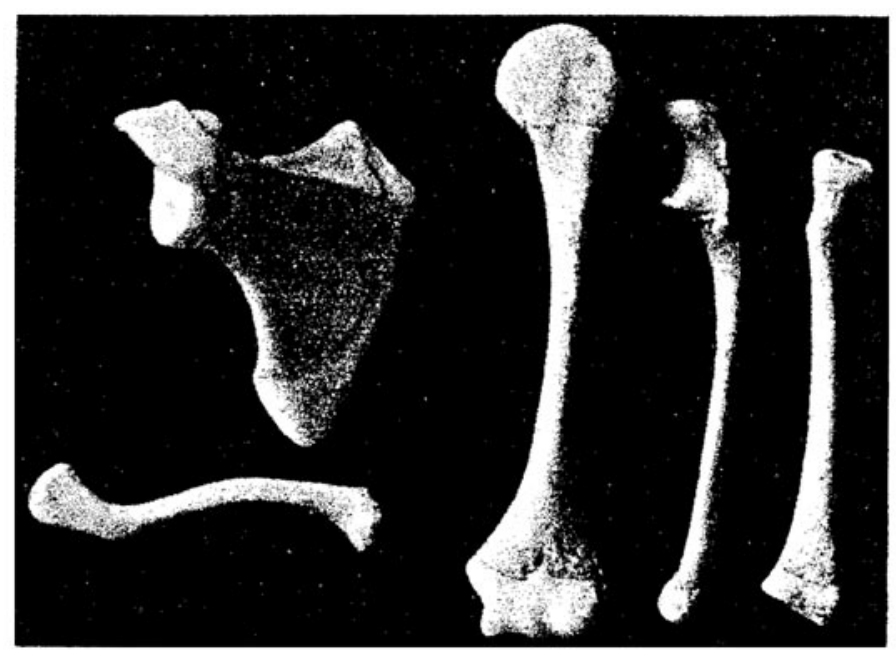

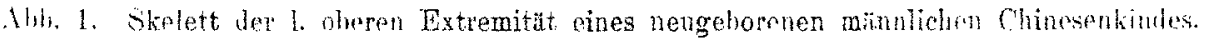

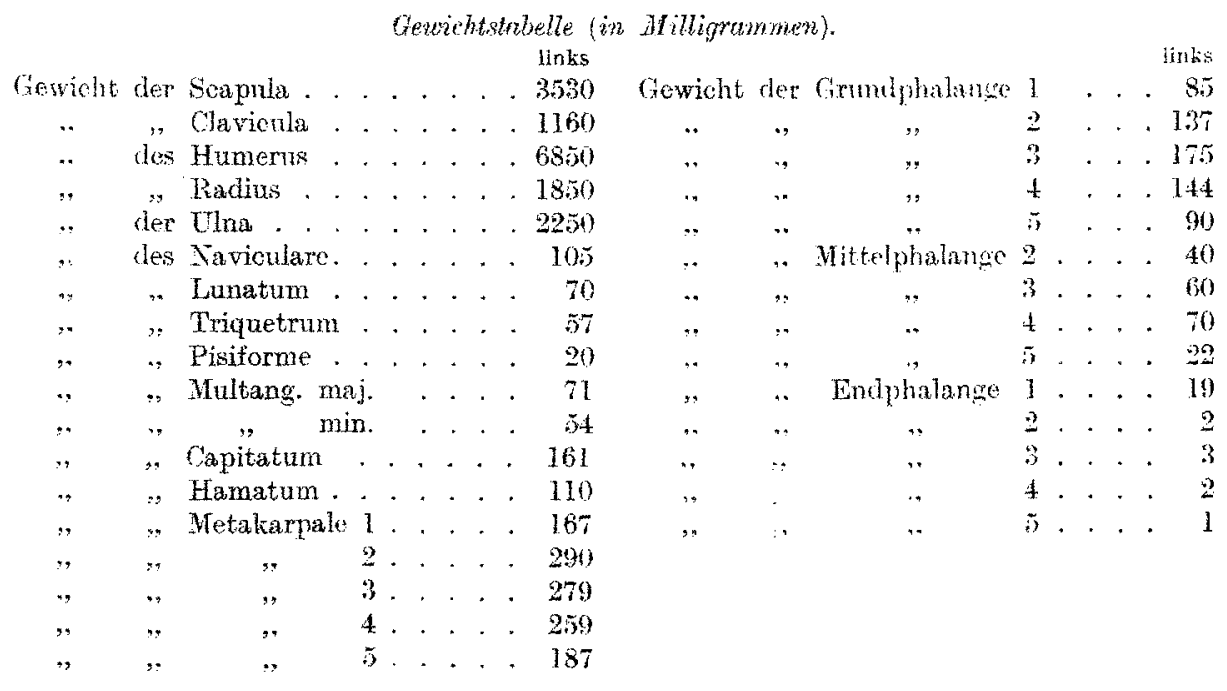

\section{Seapula.}

Vollstindig knorpelig sind an der Scapula der Margo vertehralis, das Acromion, die Cavitas glenoidalis und das Collum seapulae. Der Prozssus coracnideus ist größtenteils knorpelig: er besitzt jectoch an der vorderen und unteren 
Fläche seines nach außen gewandten Horizontalfortsatzes einen 5,0 mm breiten und $4,0 \mathrm{~mm}$ langen (hohen) Knochenkem.

\section{Mabe dex Seapula.}

1. Morphologische Breite der Scapula

2. Morphologische Länge der Scapula

Lange cler scapula

4. Lange des Margo superior . . . . . . . . . . . . . . . . . . . . . . . . 31.0

5. Projektivische Bieite der Fossa infraspinata . . . . . . . . . . . . . . . . 37,0

5a. Morphologische Breite der Fosea infraspinata . . . . . . . . . . . . . . . 39,0

6. Projektivische Breite der Fossa supraspinata . . . . . . . . . . . . . . . 10,5

6a. Morphologische Breite der Fossa supraspinata . . . . . . . . . . . . . .

6. (1) Kürzester Abstand des Angulus superior von einem moterhalb der spina gelegenen Punkt

7. Länge der Spina scapulae . . . . . . . . . . . . . . . . . . . . . . . . 46,0

ฬ. Entfernung des nach medial vorspringendsten Punktes der knorpeligen Basis spinae vom Ansatz des knorpligen Acromion . . . . . . . . . . . . . . . 35,0

8. (l) Lange der knöchernen Spina scapulae . . . . . . . . . . . . . . . . . 29,2

9. Größte Breite des Acromion . . . . . . . . . . . . . . . . . . . . . . . 9,0

10. Länge des Acromion . . . . . . . . . . . . . . . . . . . . . . 17.0

11. Grobte Länge des Processus coracoidens . . . . . . . . . . . . . . . . . 16,5

12. Länge der Cavitas glenoidalis . . . . . . . . . . . . . . . . . . . . . 13,0

13. Breite der Cavitas glenoidalis . . . . . . . . . . . . . . . . . . . . . 19,0

14. Tiefe der Cavitas glenoidalis . . . . . . . . . . . . . . . . . . . . . 2,5

15. Breitenlägenwinkel der Scapula . . . . . . . . . . . . . . . . . . . . 95

15a. Scapulospinalwinkel . . . . . . . . . . . . . . . . . . . . . . . . . $80^{\circ}$

15b. Winkel, den der Vertebralrand in seinen unteren Dreiviertelu mit der sina scapulae bildet. . . . . . . . . . . . . . . . . . . . . . . $88^{\circ}$

16. Axillospinalwinkel . . . . . . . . . . . . . . . . . . . . . . . . . . $50^{\circ}$

17. Axilloglenoidalwinkel . . . . . . . . . . . . . . . . . . . . . . 145

18. Vertebroglenoidalwinkel . . . , . . . . . . . . . . . . . . . . 7

19. Spinoinfraspinalwinkel . . . . . . . . . . . . . . . . . . . . . . . . . . $691 / 2$

20. Spinosupraspinalwinkel . . . . . . . . . . . . . . . . . . . . . 50

21. Spinoglenoidal winkel . . . . . . . . . . . . . . . . . . . . . . . . . 941/2

2.2. Breite des Knorpelrandes an Angulus sup. modialis . . . . . . . . . . . . 3,5

23. Breite des Knorpelrandes an der Basis spinae . . . . . . . . . . . . . . . 5,5

24. Breite des Knorpelrandes am Angulus inf. . . . . . . . . . . . . . . . . 11,4

26. Dicke des Knorpels am Angulus inf. . . . . . . . . . . . . . . . . . . . 3,1

26. Dicke des Knorpels am Margo vertebr. . . . . . . . . . . . . . . . . . . 1,0

27. Scapularindex. . . . . . . . . . . . . . . . . . . . . . . . . 79,1

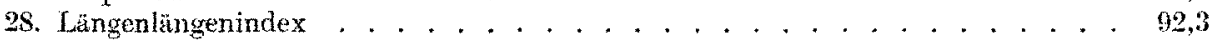

29. Infraspinalindex . . . . . . . . . . . . . . . . . . . . . . I02.7

30. Supraspinalindex . . . . . . . . . . . . . . . . . . . . . . . . . . 29,1

31. Marginalindex . . . . . . . . . . . . . . . . . . . . . . . . . . 83,5

32. Spinalgmbenindex

a) . . . . . . . . . . . . . . . . . . . . 28,3

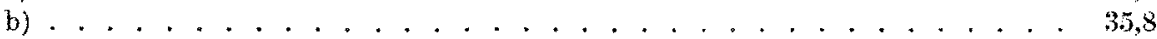

33. Längenbreitenindex der Cavitas glenoidalis . . . . . . . . . . . . . . 69,2

34. Sehnenhobhenindex . . . . . . . . . . . . . . . . . . . . . 19,2

Der Scapularindex beträgt 79,1 ; beim erwachsenen Chinesen schwankt er zwischen 67,7 und 69,2 . Der Spinalgrubenindex ist gering and zeigt damit das für den Menschen typische Merkmal. Die Fossa supraspinata ist im Verhältnis zur Fossa infraspinata wenig ausgebildet. 
Der scapulospinalwinkel beträgt $80^{\circ}$, weicht also wenig von dem des Erwachsenen ab and zeigt ebenfalls typisch menschliche Verhältnisse.

Der Infraspinalindex, von Flowe für den erwachsenen Europäer zu 89,4 angegeben, beträgt hier 102,7, eine Zahl, die der des erwachenen Negers $(100,9$ Flower) sich nähert. Der Margo vertebralis ist in der Gegend der Basis spinae stark geknickt; der Winkel zwischen den unteren Dreivierteln und dem oberen Viertel beträgt $118^{\circ}$.

Der Margo superior besitzt eine $5,0 \mathrm{~mm}$ breite und $2,0 \mathrm{~mm}$ tiefe Incisura scapulae. - Der Margo axill. ist in seinem knöchernen Bereich deutlich nach medial konkav, der gegen den Angulus inf. gerichtete knorpelige Abschnitt dagegen ist nach außen leicht konvex. Dicke des knöchernen Margo axillaris $2,2 \mathrm{~mm}$. Gegen die Mitte der Fossa infraspinata zu wird der Fnochen durchscheinend.

Das knorpelige Acromion ist viereckig, oben konvex, unten konkav. Die Fossa glenoidalis ist birnförmig nach unten zu verbreitert; ihr Längenbreitenindex betrat 69,2 . Der Vertebroglenoidalwinkel ist gering $\left(7^{\circ}\right)$, wathrend er bei den Anthromorphen in Mittel $45^{\circ}$ betrïgt. Der tiefste Punkt der Fossa subscapularis liegt $5,0 \mathrm{~mm}$ unter einer den Angulus sup. med. mit dem Angulus inf. verbindenden Geraden. - Im lateralsten Abschnitt der Fossa supraspinata findet sich ein größeres Foramen nutricium. In der Fossa subscapularis sind zwei Lineae musculares eben angedeutet.

Clavieula.

Mabe der Clavicula.

1. Größte Länge der Clavicula . . . . . . . . . . . . . . . . . . . . . . . 49,5

2. Hobe der Diaphysenkrïmmung. . . . . . . . . . . . . . . . . . . . . . 4, 4

3. Länge der Sehne der Diaphysenkrummung. . . . . . . . . . . . . . . . 32,0

4. Vertikaldurchmesser der Mitte . . . . . . . . . . . . . . . . . . . . . 3,1

5. Sagittaldurchmesser der Mitte . . . . . . . . . . . . . . . . . . . . . 4 4.8

6. Umfang der Mitte . . . . . . . . . . . . . . . . . . . . . . . . . . . 12,0

7. Längendickenindex der Clavicula . . . . . . . . . . . . . . . . . . . 21,2

8. Krümmungsindex der Clsticula . . . . . . . . . . . . . . . . . . . . . 12.5

9. Querschnittsindex der Clavieula . . . . . . . . . . . . . . . . 64,5

10. Claviculohumeralindex . . . . . . . . . . . . . . . . . . . . . . 59,2

Die Extremitas acromialis ist deutlich abgeflacht, so daß obere und untere Fläche einander parallel laufen. Die Extremitas sternalis dagegen ist von vome unten nach hinten oben zu zusammengepreßt. Die von unten hinten nach vome oben verlaufende Achse der sternalen Gelenkfläche ist $9 \mathrm{~mm}$, die darauf senkrecht stehende $6,0 \mathrm{~mm}$ lang. Die langste Achse der akromialen Gelenkfläche ist ebenfalls $9 \mathrm{~mm}$ lang, dorso-volar verlaufend; die kranio-caudale Achse mißt $4 \mathrm{~mm}$. Die Extremitas acromialis ist also von oben nach unten, die Extrem. stemalis von vorne nach hinten zusammengepreBt. Die gröBte Achse des sternalen Gelenkstückes bildet eimen annähernd rechten Winkel mit der gröBten Achse der akromialen Gelenkfläche, ein Verhalten, wie es an der Europäer-Clavieula selten, an der Feuerländer-Clavicula in der Regel sich findet (Martin). Der hintere Rand der Clavieula zeigt an der Grenze der medialen Zweidrittel und des lateralen Drittels eine stark nach hinten gerichtete Knickung. Von dieser aus zieht eine Knochenleiste auf der Unterfläche der Clavicula nach medial. Die ganze Clavicula ist knöchern, nar die beiden Enden sind von einer dünnen Knorpelschicht äberzogen. 
Fimerus.

An Humerus ist nur die Diaphyse knöchern. Die proximale Epiphyse (Caput, Collum, Tuberculum majus et minus) ist bis zu dem zirkulären Collum shirurgorum knorpelig, ebenso die distale Epiphyse (Capitulum, Trochlea, Epicondylus medialis et lateralis). Zwischen dem Tuberculum majus tt minus ist ein breiter, aber seichter Sulcus intertubercularis. Das Caput humeri bildet ein sehr deutliches Ellipsoid; der transversale (anteroposteriore) Durchmesser ist um $2,5 \mathrm{~mm}$ kürzer als der Längsdurchmesser. Der Index des Caputquerschnittes betrïgt 86,1. Der Querschnitt der Diaphysenmitte ist unregelmäßig dreieckig, an den Kanten abgerundet. Der Längendickenindex mit 21,1 zeigt ähnliche Terhältnisse wie beim Erwachsenen (18-23). Der Diaphysenquersehnittsindex heträgt 83,3 , so daB hier ein ziemlich abgerundeter eurybracher Humerus vorliegt. Fom Tuberculum majus erstreckt sich eine zwar wenig herrortretends, aber $29 \mathrm{~mm}$ lange Crista tuberculi majoris bis gegen die Mitte der Diaphyse. Tuberositas deltoidea angedentet. An der distalen Epiphyse ist der knorpelige Epicondylus med. gut ansgeprägt, während der Epicondylus lat. nur schwach rntwickelt ist. Die Trochlea verläuft horizontal, so daß der Kondylodiaphysenwinkel $90^{\circ}$ betragt. Eine Fossa coronoidea ist kaum angedeutet, eine Fowia radialis fehlt. Die Fossa olecrani ist breit und tief, aber viel weniger tief als die Fossa olecrani bei Macacus rhesus. Eine Perforation der Fossa olecrani ist nicht vorhanden: die Dicke des Knochenseptumis beträgt $3,0 \mathrm{~mm}$. Ein Foramen supracondyloideum fehlt. - Etwas unterhalb der, Mitte der medialen Flache res Humerus findet sich ein Foramen nutricium.

Der Torsionswinkel des 1. Humerus beträgt $147^{\circ}$, bei neugeborenen Europäern beträgt er $113,6-135,8^{\circ}$. Legt man den Humerus so auf seine Vorderfläche, daß Trochleartangente und Schaftachse aufeinander senkrecht stehen, so sieht das Caput humeri nach hinten und medial, das knorpelige Tuberculum majus nach rome und lateral; das Tuberculum min. sieht rein nach vorne. Bei Macacus rhesns sieht der Humeruskop viel mehr nach hinten als an dem Humerus des nougeborenen Chinesen.

Mabe des Humerus.

links in mu

1. Grölte Lünge des Humerus . . . . . . . . . . . . . . . . . . . . . . 85.1

2. Canze Lange des Humerns . . . . . . . . . . . . . . . . . . . . . . . 83,5

3. Obere Epiphysenbreite . . . . . . . . . . . . . . . . . . . . . . 19,2

3. (1) Transversaler oberer Durchmesser . . . . . . . . . . . . . . . . . . . 18,0

3. (2) Transversale Dicke an Collum chirurgieum . . . . . . . . . . . . . . 13.0

4. Untere Epiphysenbreite . . . . . . . . . . . . . . . . . . . . . . 200

4a. Crößte Epikondylenbreite . . . . . . . . . . . . . . . . . . . . . . . , 20,0

5. Gröbter Durchmesser der Witte . . . . . . . . . . . . . . . . . . . . . 6,0

f. Kleinster Durchmesser der Mitte . . . . . . . . . . . . . . . . . . . . . 5,0

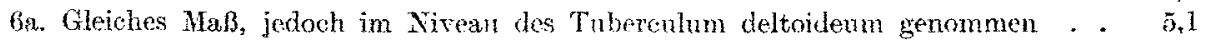

7. Kleinster Umfarg der Diaphyse . . . . . . . . . . . . . . . . . . . . . 18,0

7a. Umfang der Heitte. . . . . . . . . . . . . . . . . . . . . . . . . . 18,0

8. Umfang des Caput... . . . . . . . . . . . . . . . . . . . . 52.0

9. Gröbter transversaler Durchmesser des Caput . . . . . . . . . . . . . . . 15,5

10. CröBter sagittaler Durchmesser des Caput. . . . . . . . . . . . . . . . 18,0

11. Breite dex Trochlea . . . . . . . . . . . . . . . . . . . . . . 9,0

12. Breite des Capitulum , . . . . . . . . . . . . . . . . . . . 6,0 
13. Tiefe der Trochlea . . . . . . . . . . . . . . . . . . . . . . $\$ .6$

14. Breite der Fossa olecrani. . . . . . . . . . . . . . . . . . . . . . . . . 0,5

15. Tiefe der Fossa olecrani . . . . . . . . . . . . . . . . . . . . . . . . . 5,0

16. Kondylodiaphysenwinlkel . . . . . . . . . . . . . . . . . . . . . . . . . $90^{\circ}$

17. Capitodiaphysenwinkel . . . . . . . . . . . . . . . . . . . 40

18. Humerustorsion (konte nir amahernd bestimmt werden) . . . . . . . . 147

19. Diaphysenquerschnitsindex . . . . . . . . . . . . . . . . . . . . . . . 89,9

20. Längendickenindex . . . . . . . . . . . . . . . . . . . . . . . . . . . 21,1

21. Index des Capatquerschnittes . . . . . . . . . . . . . . . . . . . . . . $\$ 6,1$

2. Trochlearepikondylenindex . . . . . . . . . . . . . . . . . . . . . . . . 45,0

\section{Radius.}

Die größte Länge des Radins beträgt $66,0 \mathrm{~mm}$. Die proximale Epiphyse (Capitulum radii) und ebenso die distale sind knorpelig. Der radio-ulnare und der darauf senkrecht stehende Durchmesser des Capitulum betragen $8,0 \mathrm{~mm}$. Die distale knorpelige Epiphyse besitzt einen $12 \mathrm{~mm}$ messenden radio-ulnaren und einen $7 \mathrm{~mm}$ messenden dorso-volaren Durchmesser. Der Radiushals zeigt gegenüber dem Schaft eine nur geringe Abknickung; der Collodiaphysenwinkel mißt $159^{\circ}$. Der Radius ist sehr wenig nach außen gekrümmt, was sich auch ans dern geringen Krümmungsindex $(1,08)$ zu orkennen gibt. Die Crista interowsen ist ziemlich gut ausgeprägt nnd geht proximal in dis: Tuberositas hieipitalis radii über; die letztere liegt also an der Ulnarfläche des Radius; wie stellit einen linsengroßen, ovalen, glatten Höeker dar. Der Tuberositaslagewinkel ist $85^{\circ}$. Im distalen Teil des Radiusschaftes weicht die Crista internssea in zwei Linien auseinander, so daß hier eine ulnare Schaftflache zustande kommt. Die Diaphyse ist auf dem Quersehnitt prismatisch; der Querschnittsindex beträgt 75. Die distale Epiphyse trägt auf der Cavitas glenoidalis zwei durch eine deutliche Knorpelleiste geschiedene Gelenkfacetten. Höhe der knorpeligen distalen Epiphyse radial 6,5, ulnar 3,0 $\mathrm{mm}$; Höhe des knorpeligen Capitulum 2,5-4,0 $\mathrm{mm}$.
Makte.
links mm
1. Gröbte Länge des Radius . . . . . . . . . . . . . . . . . 66,0
2. Physiologische Länge des Radius . . . . . . . . . . . . . . . . . . . . . 61,0
3. Kleinster Umfang des Radins . . . . . . . . . . . . . . . . . . . . . . 13,0
4. Transversaler Durchmesser des Schaftes . . . . . . . . . . . . . . . . . 4,0
5. Sagittaler Durehnesser des Schaftes . . . . . . . . . . . . . . . . . . . 3,0

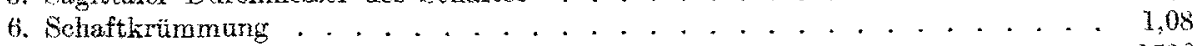
7. Collodiaphysenwinkel. . . . . . . . . . . . . $150^{\circ}$
8. Tuberositaslagewinkel . . . . . . . . . . . . . . . . . . . . . . 85
9. Längendickenindex . . . . . . . . . . . . . . . . . . . . . . . . . . . . 21,3
10. Diaphysenquerschnittsindex . . . . . . . . . . . . . . . . .

\section{Cln:i.}

An cler Uha ist nur die Diaphyse verknöchert; die distale Epiphyse, ebenso wie die proximale mit dem Olecranon und dem Prozessus coronoideus sind knorpelig. Die Differenz zwischen der größten und der physiologischen Länge beträgt $11 \mathrm{~mm}$. Der Längendickenindex ist hoch $(22,4)$, steht also im Gegensatz zu den kleineren Indices der Anthropoiden. Die Ulna ist sowohl gegen den Radius zu als auch nach dorsal konvex gekrümmt. Besonders ausgeprägt ist die dorsale Konvexität. Der Krümmungsindex ist infolgedessen ziemlich hoch $(3,6)$, ein 
primitives Zeichen. Die proximale Epiphyse ist etwas nach einwärts gekrümmt; der Ulnargelenkswinkel beträgt $94^{\circ}$. Der proximale Gelenkkörper ist nicht nach hinten abgekniekt, wie das bei den Anthropomorphen der Fall ist. Die Kuppe des Olecranon zeigt eine sanfte Wölbung; cs fehlt der eckige Vorsprung, wie ihn z. B. Macacus besitzt. Die Breite des Olecranon ist geringer als die Tiefe, und zwar um $2,3 \mathrm{~mm}$. Der Olecranonhöhenindex mit 104,4 ist niedriger als bei niederen Simiiden, höher als bei den Anthropomorphen. Die Incisura semilunaris bildet eine einheitliche ükerknorpelte Gelenkfläche. Die ulnare Gelenkfläche auf dem Processus coronoideus ist viel breiter als die radiale auf demselben Fortsatz. Dureh eine von der Spitze des Processus coronoideus schief nach abwärts und hinten verlaufende Knorpelleiste sind beide Gelenkflachen voneinander geschieden. Der Index der radialen Gelenkhälfte auf dem Processus coronoideus beträgt 66,0. Im Gegensatz zur radialen, völlig isolierten Gelenkhälfte von Macacus, die fast horizontal verläuft, bildet sie hier eine schiefe Ebene. Die Crista interossea ist gut entwickelt; infolgedessen ist der Diaphysenquerschnittsindex niedrig (70). Im proximalen Teil der Ulna dagegen ist der radioulnare Durchmesser kleiner als der dorso-volare; der etwas distal von der proximalen Epiphyse gelegene Teil der Ulna ist daher seitlich zusammengepreßt, platolen. Der Index der Platolenic beträgt 85,7.

\section{Maße.}

links $\mathrm{mm}$

1. Crößte Länge der Ulna . . . . . . . . . . . . . . . . . . 73,5

2. Physiologische Länge der Ulna . . . . . . . . . . . . . . . . 62,5

3. Umfang der Ulna . . . . . . . . . . . . . . . . . . . . . . 14,0

4. Schaftkrümmung von vorne nach hinten . . . . . . . . . . . . . . . 3,6

5. Höhe der Olecranonkuppe . . . . . . . . . . . . . . . . . . . 6,0

6. Breite des Olecranon . . . . . . . . . . . . . . . . . 6, 6,

7. Tiefe des Olecranon . . . . . . . . . . . . . . . . . . . . 9,0

8. Höhe des Olecranon. . . . . . . . . . . . . . . . . 7,0

9. Vordere Breite der radialen Gelenkhälfte auf dem Processus coronoideus . . . 3,3

10. Hintere Breite der radialen Gelenkhälfte auf den Processus coronoideus . . . 5,0

11. Dorso-volarer Durchmesser der Ulna . . . . . . . . . . . . . . . -

12. Transversaler Durchmesser der Ulha . . . . . . . . . . . . . . . . . . . . . 5,0

13. Oberer transversaler Durchmesser der Ulna . . . . . . . . . . . . 6,0

14. Oberer dorso-volarer Durchmesser der Ulna . . . . . . . . . . . . . . 7,0

15. Ulnargelenkswinkel . . . . . . . . . . . . . . . . . . . $94^{\circ}$

16. Größte Breite des Spatium interosseum . . . . . . . . . . . . . 6,0

17. Olecranonwinkel ................... . $81^{\circ}$

18. Längendickenindex . . . . . . . . . . . . . . . . . . . . . . . . . . 22,4

19. Olecranontiefenindex . . . . . . . . . . . . . . . . . . . . . . . . . 134,3

20. Olecranonhöhenindex. . . . . . . . . . . . . . . . . . . . . . . . . . . . . . . 104,4

21. Index der radialen Gelenkhälfte auf dem Processus coronoideus . . . . . . . 66,0

22. Diaphysenquerschnittsindex . . . . . . . . . . . . . . . . . . . . 70,0

23. Index der Platolenie . . . . . . . . . . . . . . . . . . . . . . . . . . . . . . . . . . . 85,7

24. Breiteninder des Spatium interosseum . . . . . . . . . . . 9,6

Das Handskelett.

1. Geradlinige Entfernung des proximal am meisten vorragenden Punktes der proximalen Karpalreihe vom Vorderende des Mittelfingers . . . . . . . . . . . . 68.0

2. Breite der proximalen Karpalreihe (in gerader Linie) . . . . . . . . . . . . 18,0

3. Breite der distalen Karpalreihe (in gerader Linie) . . . . . . . . . . . . . 20,0

4. Proximo-distale Ausdehnung der beiden Karpalreihen in der Mitte der Dorsalseite 13,5 
In der proximalen Karpalreihe liegen drei, in der distalen vier Carpalia. Dazu kommt noch das Os pisiforme. Vom Os centrale ist nichts mehr zu sohen. Alle Karpalelemente sind knorpelig.

\section{Navieulare.}

Das Naviculare ist mit seiner größten Achse $(11 \mathrm{~mm})$ dorso-ulnar radio-volar gestellt. Die proximo-radiale Gelenkfläche ist konvex. In der Mitte des proximalen und distalen Randes zeigt sich eine Einschnürung, so daß eine hantelförnige Gestalt der Naviculare zustande kommt. Die dorso-ulnare Hälfte des Naviculare ist radio-alnar zusammengepreBt; ihre radiale Fläche ist konvex, ibre ulnare durch eine scharfe Knorpelleiste in zwei Gelenkflächen geschieden für das Intermedium und Capitatum. Die volare radiale Hälfte des Naviculare gelenkt distal mit dem Multangulum majus et minus; ein Tuberculum des Naviculare ist bereits vorhanden.

1. Größter Maße des Naviculare. fiuks mm

1. Crobter Durehmesser . . . . . . . . . . . . . . . . 11,0

2. Proximo-distaler Durehmesser der ulnaren Hälfte . . . . . . . . . . 5,5

3. Proximo-distaler Durchmesser in der Mitte . . . . . . . . . . . . . . 4,2

4. Proximo-distaler Durchmesser in der radialen Halfte. . . . . . . . . . . . . 4,9

5. Dorso-volarer Durchmesser in der Mitte der ulnaren Hälfte . . . . . . . 2,5

6. Dorso volarer Durchmesser in der Mitte der radialen Hälfte . . . . . . . 4,3

7. Dorso-ulnarer radio-volarer Durchmesser . . . . . . . . . . . . . . . 10,8

8. Sehnenbreite der distalen konkaven Gelenkflächo für, das Capitatum . . . . 5,0

\section{Lunatum.}

Die radiale und ulnare Fläche des Lunatum sind halbmondförmig und dienen zur Anlagerung des Naviculare und Triquetrum. Die Flàche für das letztere ist größer als für das erstere. Die Dorsalfläche ist klein und unregelmäßig viereckig. Die proximale Fläche ist dorsovolar stark konvex, die distale Flache ist stark konkav und dient zur Aufnahme des Kopfes des Capitatum.

Iabe des Lunatum.

1. GröBter Durohmesser des Lunatum . . . ................... 6,2

2. Dorso volarer Durchmesser . . . . . . . . . . . . . . . . . . . . . 6,0

3. Proximo-distaler Durchmesser . . . . . . . . . . . . . . . . . . . . . . . 3,6

4. Padio-ulnarer Durchmesser an der proximalen Fläche . . . . . . . . . . . . 5,2

5. Radio-ulnarer Durchmesser an der distalen Fläche. . . . . . . . . . . . . . 3,0

\section{Triquetrum.}

Das Triquetrum besitzt 6 Flachen, cine radiale und uhare, eine große dorsale und kleine volare, eine große proximale und ziemlich große distale. Die radiale, zur Anlagerung des Lunatum dienende Gelenkfläche ist halbmondförmig and eben. Die ulnare Fläche ist kreisförmig, sieht zugleich etwas volarwärts und dient dem Pisiforme zur Anlagerung. Die distale, abgerundet dreieckige Gelenkfläche ist groß und lagert sich in eine leichte Konkavität des Hamatum. Die Dorsalfläche ist ebenfalls groß und rechteckig, wobei der radio-uinare Durchmesser größer ist als der proximo-distale. Da die Volarfläche nur klein ist, so hat das Triquetrum ausgesprochene Keilform. 
Yabo des Triquetrum.

1. Crobter Durchmesser des Triquetrum (radio-1ulnar) . . . . . . . . . . . . . i,0

2. Dorso-volarer Durchmesser . . . . . . . . . . . . . . . . . . . . . . . . 4,

3. Proximo-distaler Durchmesser (dorsal) . . . . . . . . . . . . . . . . . . . 42

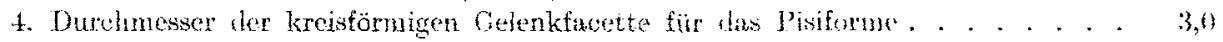

\section{Pisiforme.}

Das Pisiforme ist rundlich und besitat dorsal eine kreisformige chene Celenkfläche.

Mabe des Pisiforme. Iinks min

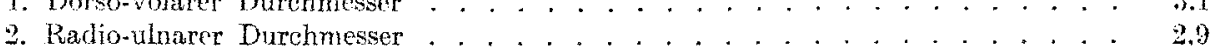

3. Proximo-distaler Durchmesser . . . . . . . . . . . . . . . . . . . . . . . 30

\section{Multangulum majus.}

Das Multangulum majus bmitzt distal eine grobe, wattelfömige Gelenk. fläche, dio herzförmig gentaltet ist. Die Basis ist dorsal, die Spitze volar gewandt. Dic distale Gelenkfläche ist dotso-volar konvex, radio-ulnar konkav. Die Ulnarfläche besitzt zwei Gelenkfacetten, eine kleine dreicekigc für das zweite Metacarpale und cimo löngswak für das Multangulum minus. Der lange Durehmesser der letzteren betragt 5,0, der kurze, senkrecht dazu stehende 2,8 mom. Die proximale Flibhe ist akgerundet drcieckig und dient zur Anlagerung des Naviculare. Der radio-ulnare Durchmesser dieser Gelenkflache heträgt 3,2, der dorso-volare $3,0 \mathrm{~mm}$. Die radiale Fläche des Multang. majus ist abgerundet, viereckig, rauh. and geht volar in einen niedrigen Höcker abber; nharwärtis von diesem befindet sich eine kleine Rinne für den $\mathrm{H}$. fl. carpi radialis. Die viereckige dorsale Fläche geht ulnar und distal in einen der radialen Seite des zweiten Metakarpale angelagerten Fortsatz über.

1. Crößter Durchmesser . . . . . . . . . . . . . . . . . . . . . 8 .

2. Dorso-blarer Durchnesser . . . . . . . . . . . . . . . . . . . . . . . 5.0

3. Proximo-distaler Durchmesser . . . . . . . . . . . . . . . . . . . . . 5,2

4. Gröbter radio-ulnarer Durchmesst'r. . . . . . . . . . . . . . . . . . . . . 6,4

\section{Multangulum minus.}

Das Multangulum minas ist dorso-volar entwickelt. Die proximale Gelenk. fläche ist klein und dreickig. Die distale Gelenkflache int grob, dorsal breiter als volar; sie zeigt einen dorso-volaren Vorsprung, der in eine gleichgerichtete Rinne der Hinterfliche des zweiten Netakarpale paßt. Der radio-ulnare Durchmesser de: distalen Gelenkfliche beträgt in der Mitte 3,3, der borso-volare $5,1 \mathrm{~mm}$. Die ulnare Gelenkfliche ist dreieckig und lagert sich an die radiale rordere Hälfte des Capitatum. Die Dorsalfläche ist victeckig. $3,5 \mathrm{~mm}$ radioulnar, $5,0 \mathrm{~mm}$ proximo-distal ausgedehnt. Die radiale, zur Anlagerung an das Mutangulum majus dienende Gelenkfläehe ist rhombisch und leicht konvex.

1. Dorso-volarer Durchmesser . . . . . . . . . . . . . . . . 6,0

2. Radio-ulnarer Durchmesser . . . . . . . . . . . . . . . . . . . . . 4,0

3, Proximo-distaler Durchmesser . . . . . . . . . . . . . , . 4,0 


\section{Capitatum.}

Day Capitatum besitzt einen stark konvexen Gelenkkopf, der unregelmäBig ungrenzt ist. Die dorsale Gelenkfläche ist dorsal breiter als volar und radio-ulnar (mit $4,2 \mathrm{~mm}$ in der Mitte) geringer entfaltet als dorso-volar (mit $7,0 \mathrm{~mm}$ in der Mitte). Die distale Gelenkfläche ist in eine schmale radiale und breite ulnarc Gelenkfläche geschieden; erstere legt sich der schräg abgestutzten ulnaren Fläche des zweiten Metakarpale an. Die ulnare Gelenkflüche ist dorso-volar nur gering ausgelehnt (vorne 1,4 , hinten $2,6 \mathrm{~mm}$ ), dagegen proximodistal sehr entwickelt $(9,0 \mathrm{~mm})$. Die dorsale Fläche ist in ihren vorderen $Z$ weidritteln rauh. Die radialc Fläche ist viereckig und geht hinten in den Kopf des Capitatum über. Die volare Näche zeigt Rechteckiform und ist schmäler als die dorsale, so daß Keilform zustande kommt.

\section{Make dos Capitatum. links}

1. Dowo-volarer burehmester distal . . . . . . . . . . . . . . . 7,5

2. " " , " proxinil. . . . . . . . . . . . . . . . . . . 4.].

3. Radio-nharer Dunchm d. Mitte. . . . . . . . . . . . . . . . . . . . . . 40

4. Proximodistaler Durchmesser- . . . . . . . . . . . . . . . . . . . . . . 9,8

\section{Hamatum.}

Das Hamatum ist keilformig mit distal gerichteter Basis and proximaler Spitze. Der radio-ulnare Durchmesser der dorsalen Fläche distal beträgt 6,0 , der proximo-distale $8,0 \mathrm{~mm}$. Die distale Gelenkflache ist groß, rechteckig und mit zwei durch eine dorso-volare Knorpelleiste getrennten Vertiefungen zur Aufnahme des 4 . und 5. Netakarpale ausgestattet. Der radioulnare Durchmesser der distalen Fläche beträgt 6,0, der dorsovolare $5,0 \mathrm{~mm}$ : radialwärts wird die distale Gelenkfläche niedriger. Die Ulnarseite des Hamatum zeigt eine nieren. förmige Gelenkfläche mit einem $6,0 \mathrm{~mm}$ langen, proximo-distalen und einem 3,1 mm langen, dorso-volaren Durchmesser. Die radiale Gelenkfläche ist hinten rechteckig, $5 \mathrm{~mm}$ lang und $4 \mathrm{~mm}$ hoch; sie setzt sich dorsal und distal in einen 1,0 mm hohen und $2,0 \mathrm{~m}$ langen Knorpelstreif fort zur Anlagerung an das Capitatum. Volar, distal und ulnarwärts ist ein gut entwickelter, proximo-distal komprinierter Hamulus vorhanden.

Mabe des Hamatum.

1. Dorso-volaper Durchmesser . . . . . . . . . . . . . . . . . . . . . . . 5,0

2. Proximo-distaler Durchmesser . . . . . . . . . . . . . . . . . . . . . . . 8,0

3. Radio-ulnarer Durchmesser (dorsal, distal) . . . . . . . . . . . . . . . . 6,0

\section{Metarearpen und Phalangen.}

Länge der Strahlen und der Finger.

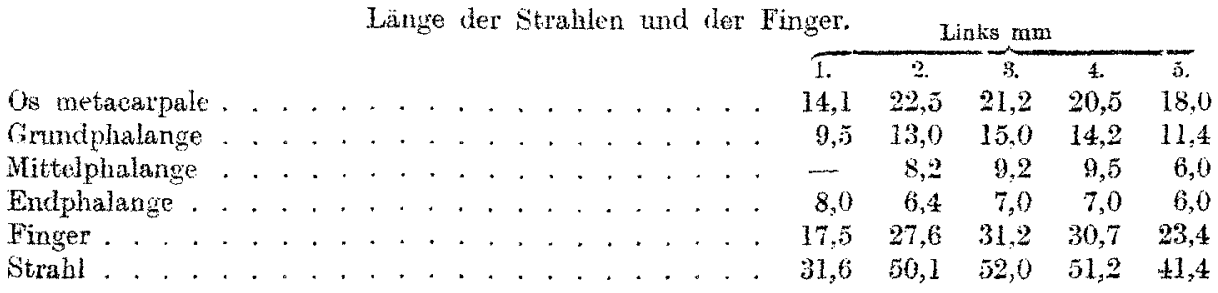




\begin{tabular}{|c|c|c|c|c|c|c|c|c|c|c|c|c|}
\hline & & & & & & & & & & kks in & & \\
\hline & & & & & & & & 1. & 2. & $\because$ & 4. & 5. \\
\hline Breite & des & Metakarpalo an der Basis & & & & & . & 4,6 & 6,0 & 4,0 & 4,5 &, \pm 6 \\
\hline, & ", & $\because \quad$ in der Mitte. & & . & & . & . & 3.7 & 3,10 & 3,0 & 2,7 & 3,0 \\
\hline ., & , & , am Capitulum & $\cdot$ & . & . & . & . & 5,0 & 4,0 & 4,0 & 4.5 & 4,5 \\
\hline$\because$ & der & Crundphalange an der Basis & $s$. & . & . & . & . & 6.0 & 5,0 & 6.5 & 5,6 & 5,9 \\
\hline , & $\because$ & $\quad, \quad$ in der Nitte & & . . & . & . & . & 3,7 & 4,0 & 4,0 & 4,0 & 3,0 \\
\hline$\therefore$ & , & " am Ende . & & . & . & . & . & 4,4 & 4,0 & 4,5 & $4, \pi$ & 4,0 \\
\hline .. & 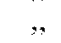 & Mittelphalange an der Basis & & . . & . & . & . & - & 5,0 & 5,0 & 5,0 & 3,9 \\
\hline ., & $\because$ & ". in der Mitte & & . & . & . & . & - & 3.8 & 4,0 & 4,0 & 8,1 \\
\hline$;$ & , & " am distalen & Ende & . & . & . & . & - & 4,0 & 4,1 & 4,3 & 3,1 \\
\hline ., & . & Endphalange an der Basis & . . & . & . & . & . & 50 & 4.5 & 3,4 & 3.5 & $\$, 1$ \\
\hline ," & , &,$\quad$ in der Mitte. & . & . & . & . & , & $: 3,2$ & 2.0 & 2,1 & 2,0 & 1,5 \\
\hline & 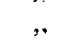 &,$\quad$ an der Spitze & . & . & . & . & . & 3,0 & 2.1 & $2, \tilde{5}$ & 2,3 & 1,7 \\
\hline Höhe & de's & Metakarpale an der Basis. & . & . & . & . & . & 5,0 & $b, 0$ & 5,0 &, \pm 0 & 4,0 \\
\hline " &. & , in der Mitte. & . & . & . & . & & 3.4 & 3,0 & 3,4 & 3,0 & 3,0 \\
\hline$\therefore$ & & am Capitulun & . & . & . & . & & 5,0 & 4,3 & 5,1 & 5,9 & 5,0 \\
\hline$\therefore$ & der & Grundphalange an der Basis & . & . & . & . & &, \pm 0 & 3,8 & 4,2 & 4,0 & 4,0 \\
\hline ., & ., & , in der Mitte & . & . & . & . & . & 2.2 & 2,1 & 2.4 & 2,2 & 2,0 \\
\hline$\therefore$ & $"$ & ., am Ende. & . & . . & . & - $\cdot$ & . & 3,0 & 2.8 & 3,0 & 3,1 & 3,0 \\
\hline :, & & Mittelphalange an der Basis & . & . & . & . & . & - & 3,8 & 3,5 & 3,5 & $3,0 \mathrm{~s}$ \\
\hline &, & ., in der Mitte & . & . & . & . & . & - & 2,0 & 2.1 & 2,0 & 2,0 \\
\hline & n & am Ende. . & & . & . & . & & - & 2,0 & 21 , & 2,1 & 1,6 \\
\hline , & 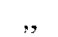 & Endphalange an der Basis & & & . & . & & 3,0 & 2,2 & 2,4 & 2,0 & 2,0 \\
\hline " & , &,$\quad$ in der Mitte & & & . & . & & 2,0 & $1, \overline{5}$ & 1,5 & 1,1 & 1,0 \\
\hline & ", & am Ende . &. & . & & . & & $0, \overline{5}$ & 0,8 & 1,6 & 1,2 & 1.0 \\
\hline
\end{tabular}

\section{B. Untere Extremität.}

\section{Becken.}

\section{Untersuchtes Material.}

1. Becken eines 30 jährigen Chinesen (Präpariersaalleiche). Die zugehörigen Femora sind beim Femur unter $\mathrm{Nr} .3$ and 4 aufgeführt.

2. Becken eines männlichen Chinesen (ausgegraben in Shanghai).

3. Os coxae eines männlichen Chinesen (Präpariersaalleiche).

4. Becken einer an Phthise verstorbenen 25jährigen Chinesin (Präpariersaal. leiche).

5. Becken eines $3810 \mathrm{~g}$ schweren neugeborenen männlichen (hinesenkindes.

Die Beckenhöhe schwankt beim Chinesen $g$ zwischen 206 and $219 \mathrm{~mm}$ und beträgt im Mittel 212,5. Bei der Chinesenfrau beträgt sio $178 \mathrm{~mm}$. Als Differenz zwischen der mittleren Beckenhöhe beim Manne und der Beckenhöhe bei der Frau ergeben sich 34,5 mm. Bezüglich der Beckenhöhe herrscht somit eine deutliche sexuelle Differenz. Die Beckenhöhe beim Europäer ist im Mittel größer $(220 \mathrm{~mm}$ ) als beim Chinesen; das Becken der Chinesin ist um $19 \mathrm{~mm}$ niedriger als das der Europäerin (197 mm). Bei Japanerinnen und Australierinnen beträgt die Beckenhöhe etwas mehr ( $182 \mathrm{~mm}$ ), bei Andamaninnen ist sie am geringsten (167 mm nach Garson). Somit ist nur das Becken der letzteren noch niedriger als das der Chinesin. Die Differenzen der Beckenhöhe beim Mann und Weib betragen bei Europäern 23, bei Australiern 20 , bei Japanern $18 \mathrm{~mm}$ (Verneau, Seharlau und Kaganei). 
Die Beckenbreite mißt beim Chinesen im Mittel $272 \mathrm{~mm}$, bei der Chinesin $245 \mathrm{~mm}$. Die Differenz ist $27 \mathrm{~mm}$. Fär den Europäer 3 betrïgt die Beckenbreite 279, das Europäer $\subseteq 266 \mathrm{~mm}$. Die Beckenbreite bei der Chinesin ist noch geringer als bei der Japanerin $(252 \mathrm{~mm})$ und der Australierin (217 mm). Das Becken der Europäerin ist um $21 \mathrm{~mm}$ breiter als das der Chinesin.

Der Höhenbreitenindex, mit einem Mittel von 75,8 beim Chinestu or, int etwas gröBer als der des Europäers mit 73,8. Beim Chinesen $\mathrm{s}$ beträgt der Index 72,6, bei der Europäerin 77,6. Der Höhenbreitenindex beider Gesehlechter im Verhaitnis zueinander nähert sich beim Chinesen mehr dem der Feucrlander $(077,0, \leqslant 71,9)$ als dem der Europäer.

Der Breitenhohenindex beträgt bein Chinexen ${ }^{7}$ im Mittel 131, $\pi$, beim Chinesen $\subseteq 137,6$, beim Europäer o 126,6, beim Europäer $\& 136,9$. Das weibliche Becken ist mithin relativ breiter und niedriger als das minnliche Becken, eine allen Rassen zukommende sexuelle Differenzierung.

Bezüglich der Beckentiefe stelle ich die Masse beim Chinosen neben diejenigen anderer Rassen:

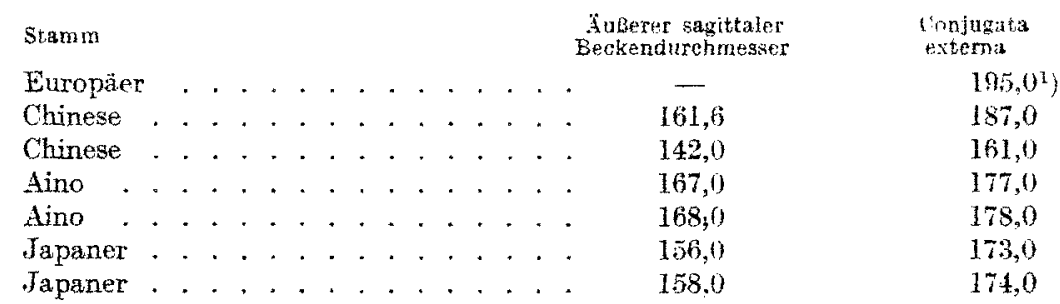

Während bei Ainos und Japanern bezüglich des äuBeren sagittalen Durchmessers (der äuBeren Beckentiefe) und der Conjugata externa nur geringe sexuelle Differenzen bestehen, sind dieselben am chinesischen Becken groß und zwar sind umgekehrt die Maße beim Weibe kleiner als beim Mann. Diese Differenz rührt daher, daß nicht nur die absoluten Maße beim Weibe kleiner, sondern da $B$ auch die Processus spinosi kürzer sind und da $B$ das Kreuzbein nach hinten weniger Konvex ist als beim Manne.

Am männlichen Becken (Nr. 2) ist der vordere Teil der Crista ossis ilei stark nach einwärts gebogen; diese Einwärtsbiegung wird noch verstärkt durch einen im Bereich der größten Beckenbreite gelegenen grobzackigen mächtigen Knochenvorsprung (für den Ursprung des vorderen Teiles des M. glutaeus medius und der Fascie dieses Muskels sowie des M. tensor fasciae latae), so daß das Becken an dieser Stelle $21 \mathrm{~mm}$ dick ist, während die Dicke an der gleichen Stelle bei dem. anderen männlichen Becken nur $15 \mathrm{~mm}$ beträgt. Durch die stärkere Einwärtskrümmung der Crista erfährt auch die Fossa iliaca eine starke Krümmung. Trotz (Ler gröBeren Beckenbreite (bei Nr. 2) ist daher die obere Spinalbreite um $31 \mathrm{~mm}$ geringer als beim männlichen Becken Nr. 1. Auch beim Weibe ist der vordere Teil der Crista ossis ilei kräftig nach einwärts gebogen; die vordere obere Spinalhreite beträgt hier nur $204 \mathrm{~mm}$, während sie beim Europäerweib Werte von $230-259 \mathrm{~mm}$ besitzt. Die hintere obere Spinalbreite beträgt beim Chinesen ${ }^{x}$ im Mittel $62 \mathrm{~mm}$. Beim Chinesen $q$ ist sie infolge des breiten Kreuzbeines viel

1) An der Lebenden genommen. 
gröker $(81 \mathrm{~mm})$. Sic nähert sich für das Chinesen $\leq$ derjenigen der Japanerin (83,0 Kuganei) und der Senoifrau 180,0 Martin), während sie für die Europäerin zu $74 \mathrm{~mm}$ angegeben wird. Die Indices aus der vorderen Spinalbreite und der

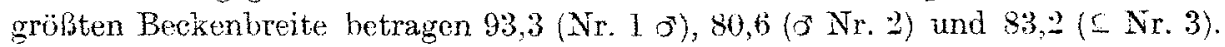
Die Indices aus der hinteren Spinalbreite und der größten Beckenbreite betragen $25,1^{-}(5 \mathrm{Nr} .1), 20,4(5 \mathrm{Nr} .2) 33,0$ (5 Nr. 3).

Der Darmbeinindex ist trotz der Kleinheit des Beckens des Chinesen $\subseteq$ gröBer als bei den kräftigen männlichen Chinesenbeckon. Für das \& beträgt er 147,3 , für den 5 im Mittel 140,2 . Daraus ergibt sich, dals die Darmbeinschaufel beim Woibe breiter und niedriger ist als beim Manne, ein Verhalten, das für alle untersuchten Menschenrassen gilt.

Die Tiefe der Fossa iliaca (Maß 11) miBt im Durchschnitt beim Chinesen o $7,8 \mathrm{~mm}$, beim Weibe $5,7 \mathrm{~mm}$. Es herrscht also auch hier eine sexuelle Differenz. Xhnliche Zahlen finden sich bei den Japanern und Ainos (Kogrnei) und den Senois (Martin). Alle Darmbeinschaufeln zeigen, gegen das Licht gehalten, cine dünne, durchscheinende Stelle, die beim Darmbein Nr. 4 sehr klein ist.

Der Neignuguinkel der Darmbeinschaufel wurde auf zeichnerischem Wege aus der größten Beckenbreite, der Darmbeinhöhe und dem Querdurchmesser des Beckeneinganges berechnet. In der beigegebenen Tabelle ist der äuboro Winkel angegeben. Der innere stumpfe Winkel beträgt beim Chinesen $s$ im Nittel $123,5^{\circ}$;er ist kleiner als beim Europäer, wo ihn Murtin zu $126^{\circ}$ angibt. Beim Chinesen $\subseteq$ ist er etwas gröBer (1 $\left.28^{\circ}\right)$. Das aus allen drei Becken berechnete arithmetische Mittel ergibt 125. Eine Rassendifferenz ist aus diesen Winkel nicht ersichtlich.

Setzt man den Querdurchmesser des Beckeneinganges mit der gröBten Beckenbreite in Beziehung (Breitenindex des Beckens), so ergibt sich für den Chinesen 5 49,2, für das Chinesen $\subseteq 46,9$. Bei anderen Rassen schwankt der Breitenindex zwischen 43,8 und 47,4 beim Manne, zwisehen 48,0 und 51,7 beim Weibe. Er ist also bei der Chinesin ausnahmsweise kleiner als beim Chineson.

Der Sagittaldurchmesser des Beckeneinganges mibt beim Chinesen im Mittel 112, bei der Frau $97 \mathrm{~mm}$. Der Querdurchmesser des Beckeneinganges beträgt beim o 134 , beim $\subseteq 115 \mathrm{~mm}$. Es wird daher der Beckeneingang im allgemeinen eine querovale Form besitzen. Die Breitentiefenausdehnung des Beckeneinganges wird durch den Beckeneingangsindex ausgedrückt. Derselbe zeigt beim Chinesen o im Mittel einen Wert von 83,5, während er für den Europäer von verschiedenen Autoren zu 77,0-84,4 angegeben wird. Bei der Chinesin beträgt er 84,3. Für das europäische $\&$ schwankt der Beckeneingangsindex nach den versebiedenen Autoren zwischen 79 und 85,9. Alle drei Chinesenbecken besitzen einen kleineren Beckeneingangsindex als 89,9 ; sie sind mithin platypellisch. Auf die Geräumigkeit des kleinen Beckens hat die Krümmung des Kreuzbeines einen groBen EinfluB. Beim Chinesen $\$$ (Nr. 1) ist das Kreuzbein auf seiner vorderen Fläche stark konkav gekrümmt; beim Weibe dagegen und noch mehr am münnlichen Becken Nr. 2 ist die Vorderfläche des Freuzbeines fast flach; dadurch wird das kleine Becken der Chinesin weniger geräumig als bei der Europäerin.

Die Konturform des Beckeneinganges wird durch den Beckeneingangsindex nur unvollstündig ausgedrückt; es erübrigt daher, über dieselbe einige Bemerkungen zu 
machen. Beim Chinesen $\%$ ist, wie die Abbildung meiner zusammenfassenden früheron Arbeit zeigt, die querovale Form des Beckeneinganges gut ausgeprägt. Das Promontorium des platten Os sacrum springt sehr wenig vor und der Querdurchmesser des Beckeneinganges ist an seinen Enden von den Articulationes ossis sacri stark nach vorn gerückt. Die Linea terminalis läuft in ihrem vorderen Teil sehr gering konkav gekrümmt gegen die Symphyse. Ein ähnliches Verhalten zeigt das männliche Becken Nr. 2. Hier springt infolge des noch platteren Kreuzbeines das Promontorium noch weniger nach vorn vor. Die Enden des Quer. durchmessers des Beckeneingangs sind ebenfalls gegen die Mitte der Linea arcuata gerückt, so daß auch beim Manne (Nr. 2) das Queroval deutich zu erkennen ist. Am Becken des Mannes Nr. I dagegen springt das Promontorium weiter vor, der Querdurchmesser des Beckeneingangs liegt näher gegen dio Articulatio sacroiliaca zu, so dab die Konturform des Beckeneingangs mehr in der sagittalen tohse entfaltet ist als bei den beiden anderen Becken. Die Linea arcuata verjüngt sich nach vorn zu, gegen die symphyse konkav verlaufend und eine stärkere Feilform bildend als an den beiden anderen Becken. Bei allen chinesischen Breken liegt der Kreuzungspunkt der sagittalen und der transversalen Achse dex Beekeneingangs hinter dem Schnittpunkt der beiden schiefen Durchmesser. Besonders weit liegt die Querachse des Beckens Nr. I (ot) hinter dem Sohnittpunkt der schiefen Durchmesser, ein Verhalten, wie es sich auch beim Ainomann findet.

Bezüglich der für den Geburtsmechanismus wichtigen Conjugatae entnehme ich aus Martin, "Lehrbuch der Anthropologie" foigende Tabelle und füge die? Maßse beim chinesen bei:

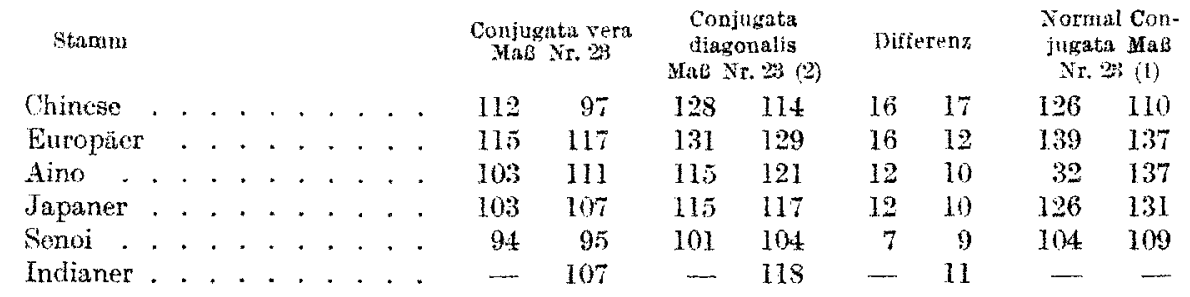

Der sagittale Durchmesser des Beckeneingangs, die Conjugata vera, ist bei der Chinesin um $20 \mathrm{~mm}$ kürzer als bei der Europäerin; sie kommt am meisten der der Senoifrau gleich. Entsprechend sind auch der untere sagittale Durchmesser des Beckens (Conjugata diagonalis) und die Normalconjugata der Chinesin um 16 bzw. $27 \mathrm{~mm}$ kürzer als bei der Europäerin, die, vorausgesetzt, daß der Kopf des Kindes anderer Rassen nicht erheblich kleiner ist, die für die Geburt günstigsten Verhältnisse aufweist.

Die Symphysenhöhe beträgt im Wittel beim chinesischen Mann $37,5 \mathrm{~mm}$, bei der Frau 35 mm; beim Europäer ist sie höher ( 43 beim Mann, 39 beim Weib). Die Symphysenhöhe nähert sich der der tino und Japaner (37 resp. 34).

Die seilliche Höhe des kleinen Beckens mißt beim chinesischen Wann im Wittel 91,4 , ist also geringer als beim Aino $\left(0^{n}\right)$ und Japaner $\left({ }^{\top}\right)$, wo sie 105 und $104 \mathrm{~mm}$ beträgt. Bei der Chinesin ist die seitliche Höhe sehr gering $(78 \mathrm{~mm})$, verhält sich also ähnlich wie die der Senoi (Tumer, Martin). Beim Aino- und Japanerweib 
ist die seitliche Höhe des kleinon Beckens um 19 mm größer. Eine sexuelle Differenz ist beim Chinesen bez. der seitlichen Höhe deutlich vorhanden $(13,4 \mathrm{~mm})$.

Das Foramen obturatorium ist beim Mann Nr. 1 annähernd viereckig mit einem dorsalen. langen und kurzen, ventralen Rand sowie fast gleich langen Rändem cranial und caudal. Von der Mitte des dorsalen, oranialen und ventralen Randes ragt je eine ziemlich kräftige Knochenspitze ins Foramen obturatorium; auf der rechten Seite sind diese Zacken jedoch nur angedeutet. Sie dienen vermutlich dem M. obturatorius externus zum Ursprung. Das Foramen obtoratorium des Mannes Nr. 2 ist birnförmig, wobei der verjüngte Teil caudalund dorsalwärts sieht. Beim Weibe ist diese Offnung abgestumpft dreieckig. Der Längenbreitenindex des Foramen obturatum beträgt beim Chinesen (j) im Nittel 66,6, beim Weibe 65,2. Beim Europäer ist er umgekehrt beim Weibe gröber als beim Manne $(68,0$ und 61,4$)$. Die Breite der Symphysengegend ist beim Manne viel bedeutender $(50,6 \mathrm{im}$ Mittel) als beim Weibe $(40,0 \mathrm{~mm})$, was wohl mit der stärkeren Entwicklung der Adduktoren im Znsammenhang steht.

Auch hinsichtlich des Beckenausganges herrschen beim Chinesen Geschlechtsunterschiede. Der sagittale Durchmesser des Beckenausganges beträgt bei o im Mittel 102, beim $\subseteq 104 \mathrm{~mm}$. Der Querdurchmesser des Beckenausganges ist beim o größer $(115 \mathrm{~mm})$ als beim $\&(102 \mathrm{~mm})$. Beim Europäer $\subseteq$ sehwankt der Querdurchmesser des Beckenausganges zwischen 100 und $128 \mathrm{~mm}$; beim Europäer $\sigma^{x}$ verhält er sich wie beim (thinesen $\sigma^{2}(115 \mathrm{~mm})$. Der Kleinbeckenraum besitzt bei der Chinesin einen deutlich querovalen Beckeneingang, da der sagittale Durchmesser um $18 \mathrm{~mm}$ kürzer ist als der transversale. Nach unten nimmt der sagittale Durchmesser etwas zu (um $7 \mathrm{~mm}$ ), so daß der Beckenzylinder nach unten in sagittaler Richtung sich etwas erweitert. Der transversale Durchmesser dagegen nimmt nach unten zu sehr ab; er ist um $13 \mathrm{~mm}$ kleiner als der Querdurchmesser des Beckeneingangs; dadurch werden Quer- und Sagittaldurchmesser des Beckenausgangi fast gleich groß, sodaß letzter fast kreisrunde Form erhält. Durch die Abnahme des Querdurchmessers nach unten zu wird der Kleinbeckenraum trichterförmig verengert. - Beim Chinesen $\jmath^{3}$ ist der Beckeneingang in beiden Fällen ein deutliches Qucroval, da bei Nr. I der Querdurchmesser um 25, bei $\mathrm{Nr} .2 \mathrm{um} 19 \mathrm{~mm}$ größer ist als der sagittale. Durch das vorspringende Promontorium bei Nr. 1 ist der Beckeneingang hier zugleich herzförmig, was bei Nr. 2 durch den Mangel des Promontoriums nicht der Fall ist. Auch der Beckenausgang ist in beiden Fallen beim 3 ein Queroval, da der Querdurehmesser bei Nr. 1 um 15, bei Nr. 2 um $11 \mathrm{~mm}$ größer ist als der sagittale. Nach unten zu nehmen jedoch sagittaler und transversaler Durchmesser beider Becken bedeutend $\mathrm{ab}$, so daß deP Kleinbeckenzylinder des Chinesen os einen nach unten verengten Trichter mit querovalem Beckenausgang darstellt.

Der gerade Durchmesser der Beckenmite (= Beckenweite), der von der Mitte der Hinterfläche der Symphyse sich erstreckt, beträgt beim Chinesen or Nr. 1 12.2, bei Nr. 2 102, beim Weibe nur $98 \mathrm{~mm}$. Bei der Europierin miBt er $120 \mathrm{~mm}$.

Die Breite der Beckenenge betrïgt beim Chinesen o im Mittel $96 \mathrm{~mm}$, beim Weibe $84 \mathrm{~mm}$. Da für die Europäerin 99, für die Tapanerin und das Ainoweib 100 und für das Senoiweib, dessen Becken ungefähr gleiche Dimensionen wie das der Chinesin besitzt, $104 \mathrm{~mm}$ als MrBe für die Becken gelten, so haben wir 
es bei dem vorliegenden Becken der Chinesin offenbar mit einem gleichmäßig rerengten pathologischen Becken zu tun.

Der Beckenausgangsindex beträgt beim Mann im Mittel 88, 6; beim Weibe ist er gröher als beim Manne (101,9). Für die Japanerin weist er einen Wert vón 95,5 auf. Der Index der Beckenenge betrïgt im Mittel 106,3 beim Manne, 123,8 beim Weibe. Der untere Schambeinwinkel ist beim Chinesenweib gröBer $\left(87^{\circ}\right)$ als beim Mann ( $72^{\circ}$ im Mittel); hei Europäern (Mann) beträgt er im Mittel $60^{\circ}$, beim Weibe $74^{\circ}$. Die Winkelschenkel verlanfen beim Mame geradlinig, beim Weibe ist an der Ventralfläche des unteren Schambeinastes eine ventralgerichtete, starke konvexe Krümmung vorhanden.

Die Beckenneigung, die Neigung der Conjugata vera zur Horizontalen beträgt für den Chinesen $3^{\circ} 65^{\circ}$, für das Weib $70^{\circ}$. Sie steht in der Mitte zwischen den für Japaner $\left(64^{\circ}\right)$ und Senois $\left(71-72^{\circ}\right)$ angegehenen Werten.

Der von der Conjugata vera und der Forderfläche der beiden exsten Sakralwirbel gebildete Angulus sacropelvicus beträgt für den Mann Nr. $196^{\circ}$.

Eine sulcus praeauricularis ist an allen Becken ausgebildet, besonders stark beim Mann Nr. 1 und beim Weibe. Bei $\mathrm{Nr} .4\left(0^{\circ}\right)$ ist er schwächer, aber breiter und greift auf die dorsale Seite der Spina iliaca posterior inferior über, hier schief nach medial und etwas nach aufwärts verlaufend. Am

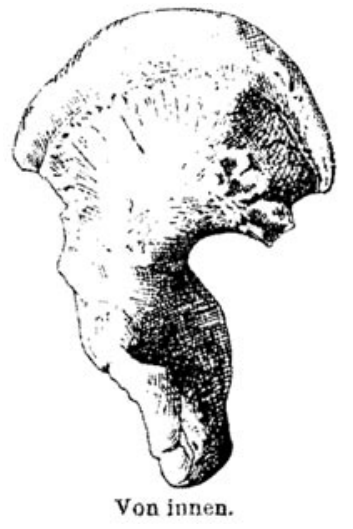

Ab3. 2. Hüftbein eines neneborenen münulichen Chinesenkindes.

Kleinbeckenanteil des Darmbeines reicht er bei Nr. 4 fast bis zum hinteren Ende der Linea areuata. An den übrigen Becken ist er kürzer. Der Suleus praeauricularis findet sich auch bei Japanern, Javanen und Grönländern.

Die Fossa acetabuli ist beim Chinesen og grober als bei der Frau. Einen schr breiten knorpeligen Pfannenanteil besitzt das männliche Becken Nr. 2. Die Tiefe der Hüftgelenkspfanne beträgt beim Wanne im Mittel 27,5 , beim $\subseteq 24 \mathrm{~mm}$.

Im AnschluB an das Becken des Erwachsenen gebe ich eine Beschreibung des Beckens eines neugeborenen männlichen Chinesenkindes. Nähere Angaben über Cröße des Kindes siehe bei der oberen Extremitat des Neugeborenen. Nach Abzug des Perichondriums und des Periostes beträgt das Gewicht des rechten Hüft. beins 8510 , das des linken $8400 \mathrm{mg}$.

Das Darmbein besteht aus einem knorpeligen proximalen und einem knöchernen distalen Abschnitt. Die knorpelige Epiphyse ist an der Spina il. ant. sup. 4,0, in der Mitte 8,0 und hinten 5,0 mm hoch. Die Dicke des Knorpels beträgt etwas hinter der Spina il. ant. sup. 4,0, in der Mitte 2,5 und etwas vor der Spina il. post. sup. 4,5 mm. Der knöcherne Anteil des Os ilei ist in der Mitte und außen $25 \mathrm{~mm}$, innen $30 \mathrm{~mm}$ hoch, da sich der Knochen auf der Innenflache weiter nach abwärts erstrekt. Die dickste Stelle des Darmbeins in der Nähe der knorpeligon 
Pfanne mißt $8,1 \mathrm{~mm}$. Im Bereich des vorderen Teiles der Facies aurieul. ist das Darmbein $5,5 \mathrm{~mm}$ dick. Der obere Teil des knöchernen Abschnittes des Darmbeines ist durchscheinend. Die Spina il. ant. sup., inf. und post. sup. sind knorpelig; nur die Spina il. post. inf. ist knöchern. Die Pfanne und ihre Limgebung besteht größtenteils aus Knorpel. Der hinter der Pfanne und über dex knorpeligen Spina ischiadica befindliche Knorpel hat eine Breite von $10 \mathrm{~mm}$. In der Fossa acetabuli sind zwei Knochenkeme, ein gröBerer unterer, in der hinteren, unteren Hälfte der Fossa acetabuli gelegener und in der Incisura acetabuli nach hinten und unten ziehender, dem Sitzbein angehörender Knochenkern und ein kleinerer, oberer, dem Ileum angehöriger Kern. Der in der Pfanne gelegene Abschnitt. des Kernes des Sitzbeines mißt von vorne nach hinten 3.0, von oben nach unten $6,0 \mathrm{~mm}$. Der Knochenkern des Sitzbeines ist außen wenger entfaltet als innen: or geht auBen von der hinteren, oberen Umrahmung des Foramen oht. gegen die Spina isehiadica $z u$, die er aber nicht erreicht, 5,0 mm entfernt ron ihr endigenr. Auf der medialen Seite ist der Kern des Sitzbeins $17,0 \mathrm{~mm}$ hoch; seine gröbto Breite beträgt $10,0 \mathrm{~mm}$. Er erreicht den unterhalb der Spina ischiadica gelegenen hinteren Rand des kleinen Beckens nicht. Der Knochenkem des Sitrobeins ist vorn konkav, entsprechend dem hinteren Rand des Foramen obturatum, hinton und oben konvex und spitzt sich nach abwirts zu. Gröle Dicke des Sitzbeinkernes $6,0 \mathrm{~mm}$. Der Knochenkern des Schambeines ist außen 15 , innen $13 \mathrm{~mm}$ lang. Er begrenzt den vorderen und etwas den unteren Teil des Foramen obtur. Der Schambeinkamm ist knorpelig. Der Schambeinkern hat eine mediale und eine obere und untere laterale Fläche. Vom Tuberculum pubicum bis zum Tuber ossin ischii befindet sich eine in der Mitte 5 mm hohe Knorpelmasse. Dicke des Knorpels an dieser Stelle $3,5 \mathrm{~mm}$. Die Mitte des hinteren Randes der Symphyse ist rom medialen Knochenkernrand $3 \mathrm{~mm}$ entfernt. Gegenüber der Pfanne befindet. sich auf der Innenfläche des Hüftbeines ein breiter, von vorn nach hinten sich crstreckender Knorpelstreifen, der sich nach unten und vorn gegen das Foramen obtur. fortsetzt, hinten gegen die Spina ischiadica zieht und von da nach abwärts in das knorpelige Tuber ossis ischii übergeht. Maße des Beckens des Neugeborenen siehe Tabelle.

1. Beckenhöhe . . . . . . . . . 207 20

2. Größte Beckenbreite. . . . . . . . 270

3. Anßerer sagittaler Beckendurchmesser . . . . 163

3. Dasselbe Maß, aber projektivisch zur Höhe .

3b. Diamètre antero-postérieur maximum . . .

3. (1) Conjugata externa . . . . . . . . 187

4. Hüfbeintiefe . . . . . . . . . . . . . . . . 160

5. Vordere obere Spinalbreite des Beckens . . . 252

5. (1) Vordere untere Spinalbreite des Beckens. . 194

$\begin{array}{rrrrr} & & & \text { Xengeh, } \\ N_{r .1} & \text { Nr. } 2 & \text { Nr. } & \text { Nr.t } & \text { Ar, } \\ 0 & 0 & 5 & 5 & 5 \\ 207 & 206 & 178 & 219 & 63,7 \\ 270 & 274 & 245 & - & 81,0 \\ 163 & 160 & 142 & - & 48,0 \\ 159,5 & 156 & 141 & - & 40,0 \\ 167 & 168 & 148 & - & 48,0 \\ 187 & - & 161 & - & 54,5 \\ 160 & 155 & 150 & - & 51,1 \\ 252 & 221 & 204 & - & 77,0 \\ 194 & 199 & 165 & - & 62,0 \\ 68 & 56 & 31 & - & 27,0 \\ 132 & 143 & 113 & - & 37,0\end{array}$

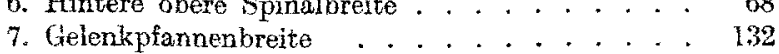

7a. Geradlinige Entfernung der Punkte am Hinterrande der Pfanne voneinander an derjenigen Stelle, an welcher Os ilium und Os ischium zu. sammentreffen ..........

7. (1) Unterpfamenbreite . . . . . . . 200 $\begin{array}{lll}209 & 162 & - \\ 142 & 112 & -\quad 33,0\end{array}$ 
8. Breite zwischen den Spina ischiadicas . . . .

9. Darmbeinhöhe. . . . . . . . . . . . . . .

10. Höne der Dambeinschaufel . . . . . . .

laa. Pon einem Punkte der Linea arcuata, der in der Hälfte zwischen der Art. sacroiliata and lem Endpunkte des Querdurchmessers des Beckeneinganges gelegen ist, bis zu dem glcichen Punkte wic (it. (1). . . . . . . . . . . . .

11. Tiefe der Fossa liaca . . . . . . . . , . . .

11a. Die Ebene wird bestinnt dureh rlit vorderen und hinteren höchsten Endpunkte der Crista bei flach liegender Darmbeinschanfel . . . . . . . . .

12. Darmbeinbreite , . . . . . . . . . . . . .

13. Breite der Darmbeinschaufel . . . . . . . . .
14. Acetabular-Symphysenbreite . . . . . . . .

15. Sitzbeinhöhe ,. . . . . . . . . . . . . .

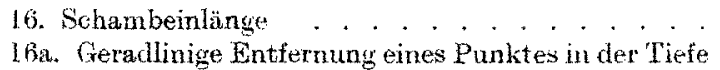
der Celenkpfanne, der am Oberrande der rauhen Fläche vecemiaber der Eminentia iliopectinea gelegen ist, von der Mitte der Symphyo' . . . .

17. Symphysenhöhe . . . . . . . . . . . . .

18. Breite der Symphysengegend . . . . . . . .

19. Sitzbeinlange. . . . . . . . . . . . . . . .

21. Breite des Foramen obturatorimm . . . . . .

22. CröBter Durchmesser der Gelenkpfanne . . . .

23. Sagittaler Durchmesser des Beckentinganyes. .

23. (1) Normalconjugata . . . . . . . . . . . Beckens . . . . . . . . . . . . . . . . .

24. Querdurchmesser des Reckeneinganges . . .

25. Schiefer Durchmesser des Beckeneinganges. . .

26. Sagittaler Durchmesser des Beckenausgangs . .

27. Querdurchmesser des Beckenausgangs . . .

27a. Gleiches MaB, jedoch von der Mitte der Tubera ischiadica ausgehend . . . . . . . . . .

27b. Gleiohes MaB am AuBenrande der Tubera ischiadica genommen . . . . . . . . . . . . . . .

28. Seitliche Höhe des kl. Beckens . . . . . . .
29. Vordere Höhe des Beckens. . . . . . . . . .

30. Wahre Höhe des kl. Beckens. . . . . . . . .

31. GröBte Breite der Incisura ischiadica... . . .

32. Höhe der Incisura ischiadica . . . . . . .

33. Unterer Schambeinwinkel . . . . . . . . . .

34. Neigungswinkel der Darmbeinschaulel (äußerer Winkel) . . . . . . . . . . . . . . .

34. (1) Differenzwinkel der Darm beinsohaufeln (eigentlicher Winkel) . . . . . . . . . . . . .

34. (2) Erganzungswinkel . . . . . . . . . . . .

35. Beokenneigungswinkel . . . . . . . . . . . .

36. Sakralneigungswinkel . . . . . . . . . . . .

$\begin{array}{rcccc}\text { Nr. } & \text { Nr. } & \text { Nr.3 } & \text { Nr.t } & \text { Nengeb. } \\ j & \gamma^{*} & 5 & 3 & 5 \\ 98 & 94 & 84 & -5 & 26,0 \\ 125 & 123 & 115 & 135 & 41,0 \\ 102 & 107 & 0.5 & 110 & 30.7\end{array}$

$\begin{array}{rrrrr}91,5 & 78 & 79 & 101.5 & 30,0 \\ 0.8 & 9.2 & 5,7 & 7.5 & 2.5\end{array}$

$\begin{array}{rrrrr}18 & 20,5 & 20 & 15 & 2,5 \\ 150 & 155 & 140 & 142 & 44,5 \\ 101,5 & 98 & 84 & 95 & 27,4 \\ 114 & 123 & 103 & - & 34,0 \\ 89 & 83 & 71 & 89 & 23,1 \\ 89,5 & 91,5 & 73 & 82 & 24,3\end{array}$

\begin{tabular}{|c|c|c|c|c|}
\hline 79 & 87 & i1 & $\ldots$ & 23,0 \\
\hline 43 & 36,5 & 35 & $3 i 3$ & 10,5 \\
\hline 47,8 & 53,5 & 40 & - & 12,0 \\
\hline 95 & 91 & 75 & 90,5 & 29,0 \\
\hline 49 & 53 & 46 & 93 & 16,0 \\
\hline 37 & 36 & 30 & 30 & 10,0 \\
\hline 55 & $5 i$ & $48 . \tilde{5}$ & 57 & 17.5 \\
\hline 109 & 11.3 & 97 & $\ldots$ & 36,1 \\
\hline 134 & 118 & 110 & $\cdots$ & 34.0 \\
\hline 125 & 131 & 114 & - & 37,1 \\
\hline 134 & 134 & 115 & $\ldots$ & 39,0 \\
\hline 129 & 122 & 114 & - & 39,2 \\
\hline 100 & 104 & 104 & - & 26,5 \\
\hline 115 & 115 & 102 & - & 18,0 \\
\hline 127 & 139 & 122 & - & 25,0 \\
\hline 147,5 & 156 & 130 & - & 30,3 \\
\hline 94 & 94 & 78 & 86 & 28,0 \\
\hline $10^{4}$ & 95 & $\$ 6$ & - & 33,0 \\
\hline 135 & 118 & 115 & 135 & 35,0 \\
\hline 50 & 54 & 51 & 63 & 14,0 \\
\hline 39 & 40 & 33 & 35 & 8,0 \\
\hline $74^{\circ}$ & $70^{\circ}$ & $97^{\circ}$ & - & $333^{\circ}$ \\
\hline$\tilde{5} 8^{\circ}$ & $55^{\circ}$ & $52^{\circ}$ & - & $59^{\circ}$ \\
\hline $93^{\circ}$ & $78^{c}$ & $82 \%$ & - & $107^{\circ}$ \\
\hline $43,5^{=}$ & $51^{\circ}$ & $49^{\circ}$ & $\ldots$ & $36,5^{\circ}$ \\
\hline $65,5^{\circ}$ & $65^{\circ}$ & $70^{\circ}$ & - & $77,5^{\circ}$ \\
\hline $47,5^{\circ}$ & $40^{\circ}$ & $46^{\circ}$ & - & $70,5^{\circ}$ \\
\hline
\end{tabular}




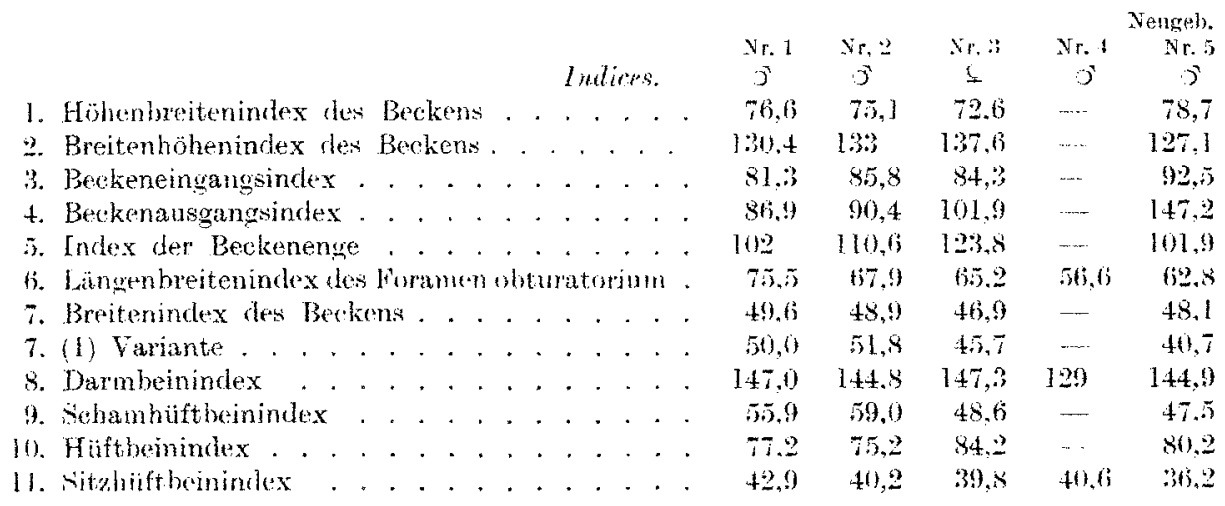

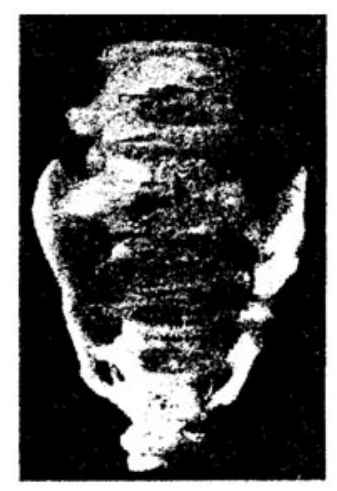

Nhin. 3.

Vin ventral.

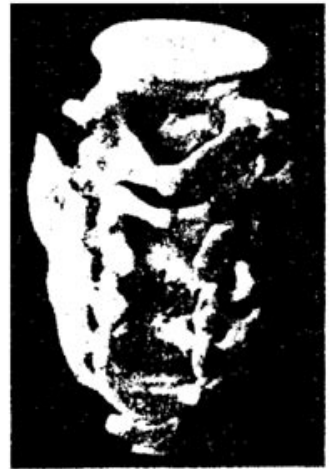

Abis. 4 .

Abh, 3 u. 4. Krenzb+in nines nengeborenen mämblichen Chinesenkindes.

\section{Femur.}

\section{Untersuehtes Material.}

$\mathrm{Nr} .1$ und 2. Zwei vollstandig erhaltene Femora eines ca. 25jährigen Chinesenweibes (Präpariersaalleiche).

$\mathrm{Nr} .3$ und 4. Zwei vollstandig erhaltene Fomora eines ca. 30 juhrigen Chinesen (Pripariersaalleiche).

Nr. 5. Ein $405 \mathrm{~mm}$ langes Femur, dem der gröbte Teil des Collum und das Caput fehlen.

Nr. 6. $385 \mathrm{~mm}$ langes Femur, dem der Trochanter major, der Condylus med. und der äuBere Abschnitt des Condylus lateralis fehlen.

Nr. 7. Ein $395 \mathrm{mam}$ langes Femur, dem der hintere Teil des Trochanter major sowic der innere und äuBere Abschnit des Condylus med. fehlen.

Nr. 8. Ein $355 \mathrm{~mm}$ langes Femurstuick, dem die distale Epiphyse and von der proximalen Caput et Collum fehlen.

Nr. 9. Ein $367 \mathrm{~mm}$ langes Fermurstück, dem der Trochanter major et minor sowie die distale Epiphyse fehlen. Das Collum und der änBere Teil des Caput sind stark arrodiert. 
Nr. 10. Ein $372 \mathrm{~mm}$ langes Fernurstuck, dem Caput et Collum sowie ein tangentiales Stück des Condylus lat. fehlen.

Nir. 11. Ein $353 \mathrm{~mm}$ langes Stück, dem die distale Epiphyse fehlt. Caput und Trochanter major sind stark arrodiert.

Nr. 12. Ein $320 \mathrm{~mm}$ langes Femurstück, dem die distale Epiphyse fehlt.

Nr. 13. Fin 297 mim langes Femurstück. dem Caput, Collum und distale Epiphyse fehlen.

Nr. 14. Ein $283 \mathrm{~mm}$ langes Stück, dem der distale Abschnitt fehlt. Das Caput ist an der Hinterflache arrodiert.

Nr. 15. Ein 282 mm langes Femurstück. dem die distale Epiphyse, ein Teil des Caput, des Trochanter major und minor fehlen.

Nr. 16. Ein 230 mm-langes Femurstuck, dem der distale Teil and der froximale bis auf den Trochanter minor fehlen.

Nr. 17. Ein ebensolches 201 inm langes Stïck.

Nr. 18. Ein $215 \mathrm{~mm}$ langes Femurstïck, dem die distale Halfte fehlt. Caput, Trochanter major and minor sind arrodiert.

Nr. 19. Ein proximales Femurstiuk von $164 \mathrm{~mm}$ Länge. Caput und Trochanter major sind arrodiert.

Nr. 20. Ein proximales Femurstück von $129 \mathrm{~mm}$ Länge. Caput und Trochanter major sind etwas arrodiert.

Nr. 21. Ein 328 mm langes Femurstuck, dessen proxinaler Abschnitt fehlt.

Nr. 22. Ein 312 mm langes Femurstuck, dem die proximale Eyiphyse fehlt. Von der distalen Epiphyse ist nur der Condylus med. gröitenteils erhalten.

Nr. 23. Ein $314 \mathrm{~mm}$ langes Fenurstück, dem die proximale Epiphyse fehlt. Die beiden Condylen sind vorn arrodiert.

Nr. 24. Ein $275 \mathrm{~mm}$ langes Femurstük, dem die proximale Epiphyse fehlt. AuBerdem ist der gröBte Teil des medialen Condylus und ein kleines Stüdk des lateralen zerstört.

Nr. 25. Ein $167 \mathrm{~mm}$ langes distales Stück, dem der laterale Condylus fehlt.

Die aus zwei Femora, zwei Humeri, zwei Radï und Ulnae berechnete Körpergröße beträgt für das Weib $150,2 \mathrm{~cm}$; die aus zwei Humeri, einem Radius, einer Ulna und zwei Femora berechnete Körpergröbe beträgt für den Mann $163,7 \mathrm{~cm}$.

Im Verhältnis zu deutsehen Femora sind alle Knochen schiank; nur das Wemur Nr. 5 erscheint etwas plumper. Die Muskelursprünge und Insertionen treten bald deutlicher, bald weniger deutlich hervor. Die Maßtabelle soll vorausgestellt werden, da das Folgende Bezug auf dieselbe hat; sie ist nach Martin "Lehrbuch der Anthropologie" geordnet, enthält aber an einigen Stellen Einfügungen. Die ganze Länge des Femur beträgt beim Weib im Mittel 388,2, beim Mann $450,5 \mathrm{~mm}$, mit einer sexuellen Differenz von $62,3 \mathrm{~mm}$. Die ganze Länge des Femur in natülicher Stellung ergibt beim 5 ein beiderseitiges Mittel von 383,5 , beim $5^{7}$ von $445,5 \mathrm{~mm}$ mit einer fast gleichen sexuellen Differenz $(62,0 \mathrm{~mm})$. Das rechte Femur ist beim $\mathrm{o}$ um 4,5 ( $\mathrm{MaB}$ 1) und 3 ( $\mathrm{MaB}$ 2) $\mathrm{mm}$ größer als das linke, während das Femur des Mannes, die Diaphysenlange ausgenommen, das gewöhnliche Verhalten zeigt und links lïnger als rechts ist (um $6 \mathrm{~mm}$ bzw. $3 \mathrm{~mm}, \mathrm{MaB} 1 \mathrm{bzw} .2)$. Im Verhältnis zur ganzen mittleren Länge des männlichen Femur in natürlicher Stellung beträgt die des $586.5 \%$. 
Die aus 6 Zahlen berechnete Diaphysenlänge heträgt $333 \mathrm{~mm}$. Beim $\mathrm{s}$ ist die Diaphysenlänge rechts um $4,0 \mathrm{~mm}$, beim ₹ um $5,0 \mathrm{~mm}$ größer als links, so daß die bilaterale Asymmetrie der Femora auf Rechnung der verschieden langen Diaphysen zu setzen ist. Die sexuelle Differenz der mittleren Diaphysenlänge des Mannes $(364,5 \mathrm{~mm})$ und der des Weibes $(307 \mathrm{~mm})$ beträgt $57,5 \mathrm{~mm}$. Dic absolut größere Länge der männlichen Femora ist also hauptsächlich in der gröBeren Diaphysenentwicklung zu suchen, während die Differenz zwischen der mittleren Diaphysenlänge und der mittleren ganzen Länge des Femur in natürlicher Stellung bei beiden Geschlechtem nicht wehr versohieden ist, beim 4 76,5, heim o $71,5 \mathrm{~mm}$ beträgt.

Der Umfang der Diaphysenmitte schwankt zwischen 61,0 und 92,5 mm und beträgt im Nittel (aus 21 Zahlen) $75,5 \mathrm{~mm}$. Beim 5 (Nr. 3 and 4) sind die Umfänge der beiden Diaphysenmitten gleich $(79,5)$, beim $\mathrm{C}$ ( $\mathrm{Nr}$. 1 und 2) ist der Umfang der rechten Diaphysenmitte $(66,3 \mathrm{~mm})$ um $0,5 \mathrm{~mm}$ kleiner als der linke $(67,0 \mathrm{~mm})$. Der aus dem Umfang der Mitte und der ganzen Länge des Femur in natürlicher Stellung berechnete Längendickenindex beträgt in. Mittel (aus 4 Zahlen) 17,4, zwischen 17,2 und 17,6 mm schwankend. Einen :ihnlich geringen Index besitzen nach Lehmann- Yitsche auch die Schwaben und Alemannen, wo er für das $\subseteq 17,8$, für den 318,8 beträgt; jedoch ist bei diesen die ganze Länge des Femur in natürlicher Stellung größer $(403 \mathrm{~mm}$ bein 4 . and $464 \mathrm{~mm}$ beim $\mathrm{s}$ ) als beim Chinesen $(383,5 \mathrm{~mm}$ beim $\subseteq$ und $445,5 \mathrm{~mm}$ beim 2). Soularure gibt für das mongoloide 5 den viel höheren Index von 21.3 an. Der Längendickenindex zeigt beim Chinesen nur eine ganz geringe sexuelle Differenz. Die aus dem Umfang der Diaphysenmitte und den Diaphysenlängen (5) und 5a) berechneten Indices ergeben (aus 6 Zahlen) Indices von 22,3 (Index $b$ der Tabelle) und 21,7 (Index c).

Der Robusticitätsindex, im Mittel (aus 4 Zahlen) 11,2 betragend, ist entgegen der Regel beim Manne etwas geringer als beim Weibe. Die Femora des Chinesen (Nr. 1, 2, 3, 4) sind also noch graziler als die des Negers, bei dem der Robusticitätsindex 11,8 beträgt. Im Gegensatz $z u$ diesen niederen Indices steht der des Japaners mit 13,1. Unter den Anthropomorphen hat Hylobates den kleinsten Robusticitätsindex $(10,8)$. Über die Form der Diaphysenmitte geben die auf beigefügter Tafel dargestellten 24 Umrißzeichnungen eine Vorstellung. Zum Vergleich ist in Nr. 25 ein deutsches Femur dargestellt. Die CmriBzeichnungen des Diaphysenquerschnittes sind im allgemeinen birnförmig und ähneln in den meisten Fällen denen der Feuerländer (Martin). Die gröBte Achse liegt in sagittaler Richtung. In einigen Fällen ist der Querschnitt annähernd dreieckig und einmal annähernd ein Längsoval (Nr. 16). In Nr. 22 und 23 stellt die Linea aspera eine $4 \mathrm{bzw} .6 \mathrm{~mm}$ breite glatte Fläche dar, die zwei seitliche Kanten besitzt. Der sagittale Durchmesser der Diaphysenmitte schwankt zwischen 22 und $33 \mathrm{~mm}$ mit einem Mittel (aus 22 Zahlen) ron 26,4 mm. Der zwischen 20 und $27 \mathrm{~mm}$ schwankende transversale Durchmesser beträgt im Mittel (aus 22 Zahlen) 22,6 $\mathrm{mm}$. Der Index des Diaphysenquerschnittes der Mitte (Index pilastricus) schwankt zwischen 104,4 and 129,4 und beträgt im Mittel (aus 22 Zahlen) 116,6. Die niederen Indices sind indessen die selteneren, und nur fünfmal ist der Index geringer als 110. Reiht man den gefundenen 
mittleren Pilasterindex in der Rassenskala ein, so wärde er zwisehen den der Negritos (116, Bello) und den der Uraustralier (116,9 Hepburn) zu stellen sein. Der Index pilastricus des Chinesen steht im Gegensatz zu dem des Japaners, bei dem er sehr niedrig ist (100 nach Koganei). Wie bei anderen Rassen ist beim

L. $\subseteq$

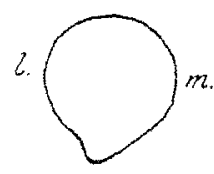

I
R. 5

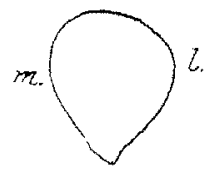

?
L. $)^{\pi}$

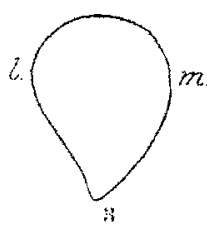

$R . \sigma^{x}$

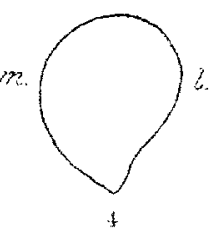

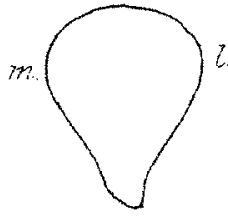

5

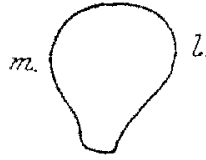

[1]

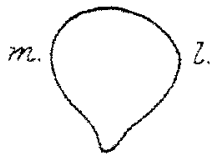

I-1

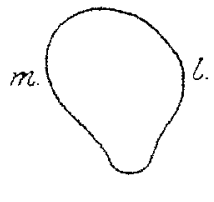

6i
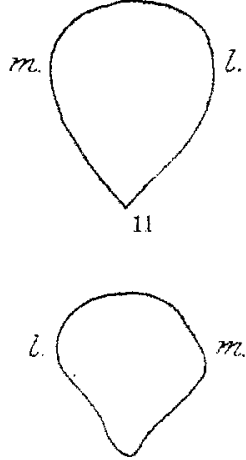

1.)

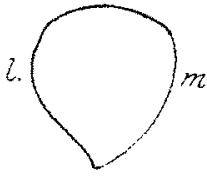

$\ddot{\imath}$

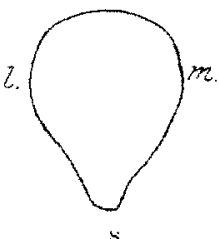

is

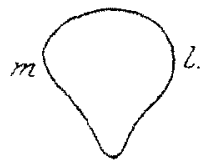

(1)

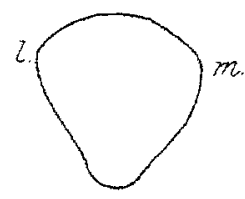

12

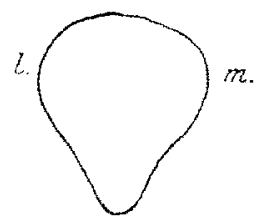

1:3

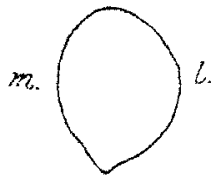

11;

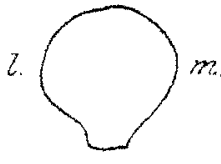

17

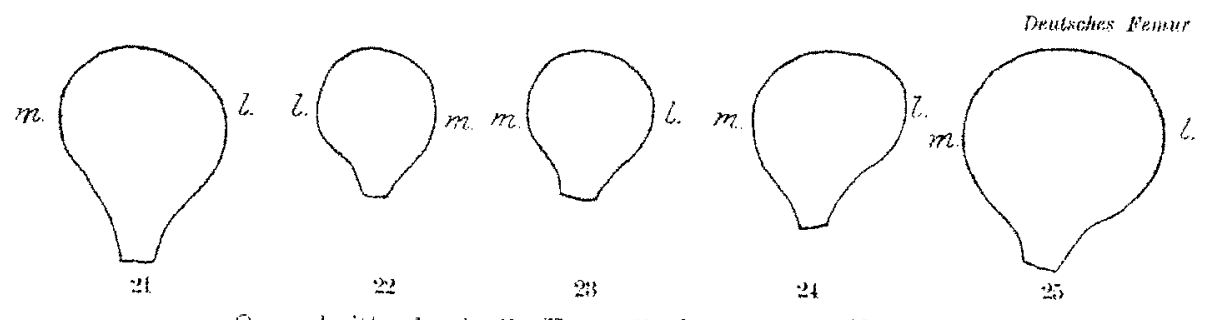

Quersehnitfo durch die Femurdiaphysenuitte (Chinese).

Weib der mittlere Pilasterindex $(110,5)$ geringer als beim Yann $(127,2)$. Da der Index pilastricus keinen zuverlässigen Ausdruck für die Stärke des Pilasters gibt, so soll der Indexberechnung folgendes ergänzend zugefügt werden:

1. Einen leichten, nur von der lateralen Seite her erkennbaren Pilaster besitzt das Femur Nr. 16. Obwohl die Linea asp. femoris nur ganz gering ent. 
Mabe des

\begin{tabular}{|c|c|c|c|c|c|c|c|c|c|}
\hline & $\begin{array}{c}c \\
1 . . \\
1 . \\
\end{array}$ & $\begin{aligned} & c \\
&(r, j) \\
&-2\end{aligned}$ & $\stackrel{3}{a .)}$ & $\begin{array}{c}9 \\
(\mathrm{r}) \\
4 .\end{array}$ & $\therefore$ & 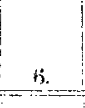 & 7. & 8 & $\therefore$ \\
\hline \multicolumn{10}{|l|}{ Femur. } \\
\hline 1. Gribte binge lis Femur . . . . . & 386 & 300.3 & $45 \%, 5$ & 447,5 & - & - & - & ... & - \\
\hline 2. Gauze Lunge in maturlicher Stellung. & 382 & 385 & 447 & +44 & - & - & - & - & - \\
\hline 3. Ge. Troclianterenlängre $\ldots \ldots \ldots$ & 367 & $3 \div 1$ & $42 y$ & 428 & 408 & -- & -- & - & - \\
\hline 4. Trochanterenlingo in natirlicher Stellung & 354 & 3.57 & 418 & $41 \bar{i}$ & 396 & - & - & - & - \\
\hline $\begin{array}{l}\text { 5. Diaphysenlange des Femur . . . . . . } \\
\text { 5a. Abstand des Tuh. lineae obliquae ron der }\end{array}$ & 305 & 309 & 362 & 367 & 338 & - & - & - & - \\
\hline Wittr ler linm intercondyloidea ant. & 393 & 392 & 375 & 3,0 & $35:$ & $\cdots$ & 328 & - & - \\
\hline 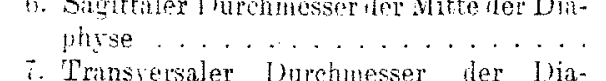 & 22,9 & 23 & 28 & 28 & 31 & 26 & 25 & 31 & 23 \\
\hline 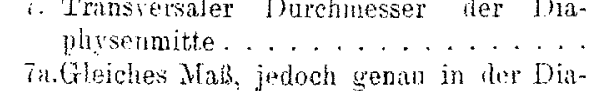 & 21 & 80.5 & 22 & 22 & 25 & 21 & 23 & 24 & 20 \\
\hline 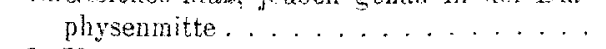 & 21 & 20,3 & 22 & 23 & $2+, 5$ & - & 22.5 & -- & - \\
\hline 8. Tmftung der Diaphysenmitte . . . . & $6 i \bar{T}$ & 99,5 & 78,5 & 38,5 & $8 i$ & 75 & $7+, 5$ & $8 i$ & 68,5 \\
\hline 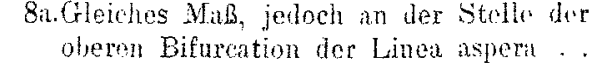 & 68 & 67 & 79 & 79,5 & 83 & $7 \bar{c}$ & 80 & 45,5 & 70 \\
\hline 9. Ohere transvers. Diaphysendurchmesser & 23 & $29, \sqrt{3}$ & 28 & 31,5 & 33 & 26.5 & 30 & 31 & 27 \\
\hline 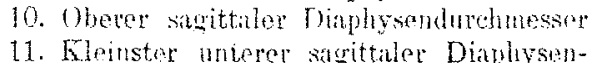 & 18,5 & 17 & 23 & 21,0 & 25 & 20 & 22 & 26 & $1 i$ \\
\hline 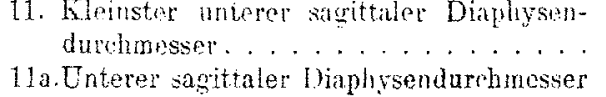 & 25,1 & 25 & 28,4 & 27,5 & 31 & 29,1 & 26,5 & - & $27, \tilde{7}$ \\
\hline 3 cm oberhall for Linea intercondyloidea & $2: 3$ & 23 & 25 & 25 & 32 & 28 & 25,5 & -- & 25 \\
\hline 12. Euterer transers. Diaphysendurhuesser & 50 & 47 & 45 & 45 & 55 & - & 50 & - & - \\
\hline 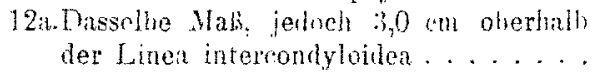 & 36 & $3 t$ & 31 & 33 & 41 & -. & 42 & 39 & 30 \\
\hline 13. Obere Epiphysenlinge. . . . . . . . & 84 & 81 & 91 & 97 & $-\ldots$ & - & 84,5 & - & 80 \\
\hline 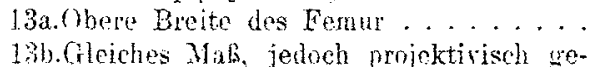 & 80 & 79 & 94 & 93 & - & - & 80 & - & $\ldots$ \\
\hline & 56 & 54 & 66 & 66 & - & $\ldots$ & -. & $\cdots$ & - \\
\hline 13c.Linge von Collum und Caprat . . . . . & 67 & 67 & 72 & 73 & - & - & - & $\cdots-$ & - \\
\hline 14. Collambinge & 63,5 & 63 & 78 & 75 & - & -- & 70 & - & ti1 \\
\hline 15. Vertikaler Durchnesser des Collum & 27,8 & 27,3 & 35 & 34,5 & - & 27 & 28,5 & - & 28 \\
\hline 16. Sagittaler Durchnesser des Collum. & 20 & $21, \overline{1}$ & 27 & 27,5 & - & 24 & 24 & $\cdots$ & 21 \\
\hline 17. Emfang des Collum . . . . . . . . & 81 & 83 & $10 \%$ & 103 & - & 83 & 85,5 & -.-- & 81 \\
\hline 18. Vertikaler Durchnesser des Femurkopfes & 39 & 39 & 47 & 48 & - & 40 & 39 & $\cdots$ & 3!) \\
\hline 19. Trausrers. Durdmesser des Femurkopfes & 4) & t0) & 45 & 49 & - & - & - & $\cdots$ & 39 \\
\hline 20. Vmfang ties Femurkoptes. . . . . . . . & 121 & 222,5 & 150 & $1+6$ & $\cdots$ & - & - & $\cdots$ & -. \\
\hline 21. Epikondylenbreite . & 70 & 60 & 78 & 78 & $c a .80$ & - & - & - & - \\
\hline 22. Dicke des Condylus lat. . . . . & $5 \overrightarrow{7}$ & 56 & 60 & 50 & 61,5 & - & - & - & - \\
\hline 23. Gröste Linge des Conlylus lat. . . & 56.5 & 56,7 & 60,9 & 60 & 132 & - & - & - & - \\
\hline 24. Gröite Lange des Condylus med. . . & 53 & 53 & 61,9 & 60 & 192 & - & - & -- & \\
\hline 25. Hijhe des Condylus lat. . . . . . . & 30 & 31 & 33,2 & 32 & 32,9 & - & - & .... & \\
\hline 26. Ë̈h & 30,1 & 31,5 & 32,3 & 32,5 & 33 & - & -- & - & $\ldots$ \\
\hline 77. Krimmung der Diaphyse . . . . . . & 8 & - & - & - & - & - & - & - & - \\
\hline $\begin{array}{l}27 \mathrm{a} . \ldots \ldots \ldots \ldots \ldots \ldots \\
\quad \text { Winkel. }\end{array}$ & 53 & 54 & 55 & 55 & - & - & - & - & - \\
\hline 28. Torsionswinkel & $11^{\circ}$ & $14^{\circ}$ & $45^{\circ}$ & $+5)^{\circ}-(-1)$ & - & - & -1 & - & $128^{\circ}$ \\
\hline 9. Kollodiap & $128^{\circ}$ & $136, \pi^{2}$ & $132^{\circ}$ & $128^{\circ}$ & - & - & $132^{\circ}$ & - & $138^{\circ}$ \\
\hline $\cos 2 \cos 20$ & $10^{\circ}$ & $14^{\circ}$ & $10^{\circ}$ & $10^{\circ}$ & $9^{\circ}$ & - & $-\bar{c}$ & - & $30^{\circ}$ \\
\hline 31. Rotationswinkel & $48^{\circ}$ & $41,2^{\circ}$ & $44^{\circ}$ & $45^{\circ}$ & -- & 47,50 & $47^{\circ}$ & - & \\
\hline
\end{tabular}


Fenur.

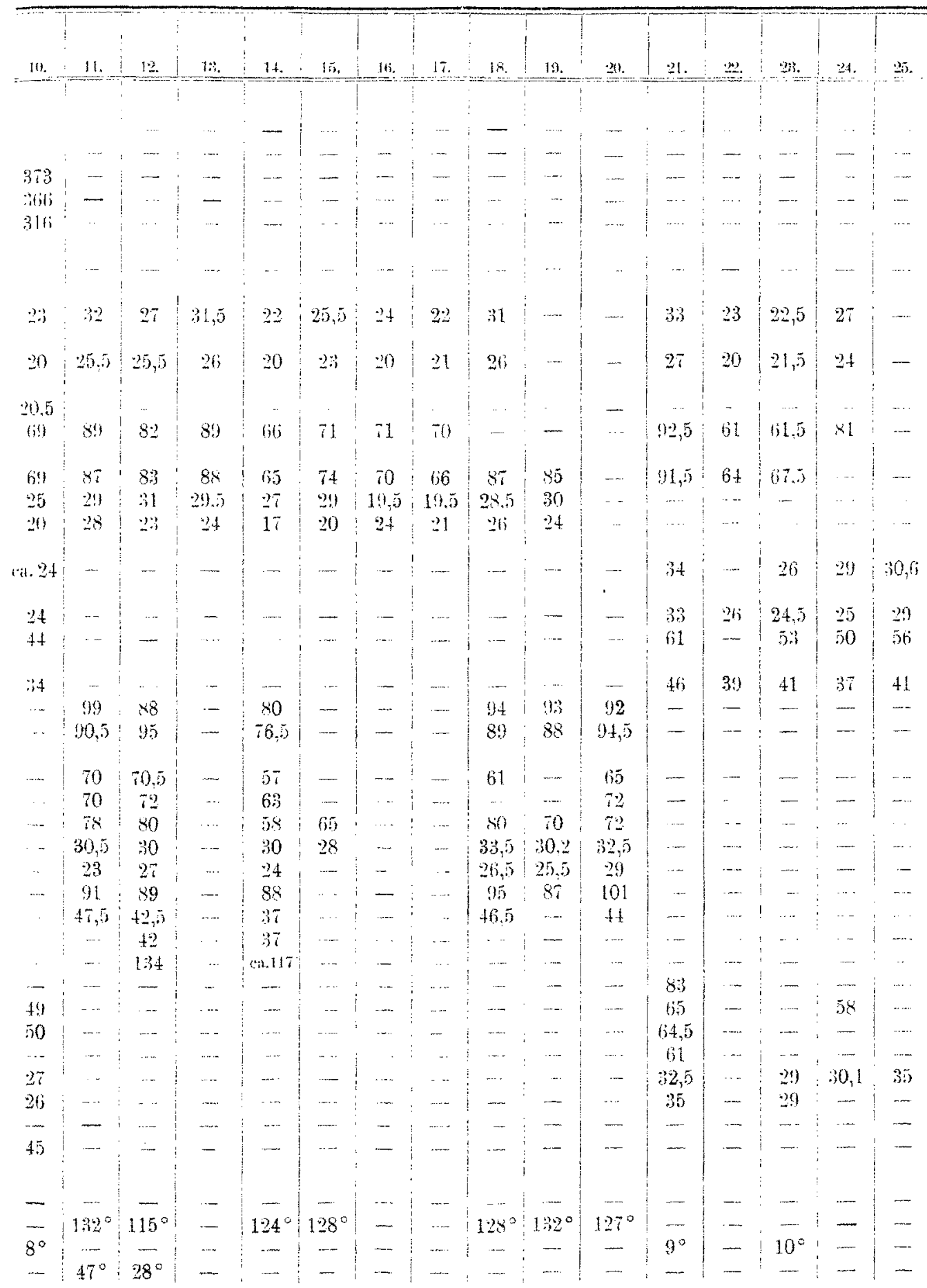




\begin{tabular}{|c|c|c|c|c|c|c|c|c|c|}
\hline Indices & $\begin{array}{l}\text { (5) } \\
\text { (i.) } \\
1 .\end{array}$ & $\begin{array}{l}0 \\
(\mathbf{s}) \\
2\end{array}$ & $\begin{array}{l}\frac{5}{(1 .)} \\
3 .\end{array}$ & $\overrightarrow{3}$. & 5 & is. & 7. & 8. & is \\
\hline 1. Lungendickenindex & & & & & & & & & \\
\hline a) $\frac{[8] \cdot 100}{[2]}$ & 17,5 & 17,2 & 17,5 & 17,6 & - & - & $-\infty$ & - & - \\
\hline b) $\frac{[8] \cdot 100}{[5]}$ & 21,9 & 21,5 & 21,6 & 21,3 & 25,7 & -. & $\ldots$ & ... & $\cdots$ \\
\hline$\frac{[8] \cdot 100}{[5 a]}$ & $20, \bar{i}$ & 20,0 & 20,9 & 21,2 & $2+\pi$ & & 22,7 & $\cdots$ & $\cdots$ \\
\hline - Robusticitätsindex & 11,4 & 11,2 & 11,1 & 11,2 & - & -1 & - & $-\infty$ & - \\
\hline 3. I & 104 & 112,1 & 127,2 & 127,2 & 12,4 & 123,8 & 108,6 & 129,1 & 115 \\
\hline 4. Index des & 68.5 & 57,6 & 82,1 & 68,2 & 75.7 & 75,4 & 73,3 & $8:, 8$ & 61,8 \\
\hline 5. Sugittalindex der un & 109,1 & 108,6 & 104,1 & 98,2 & 100 & $111, \%$ & 106 & -1 & $119, \pi$ \\
\hline 5a. Index ans $\frac{[11 a] \cdot 100}{[6]} \ldots \ldots$ & 100 & 100 & 89,2 & 89,2 & 103,2 & 107,6 & 102 & - & 108.1 \\
\hline $\begin{array}{l}\text { 6. Transrersalindex der unteren Diaphysen- } \\
\text { hälfte } \ldots \ldots \ldots \ldots \ldots \ldots \ldots\end{array}$ & 238 & 299,2 & 204,5 & 204,5 & 220 & - & 213 & - & - \\
\hline Ga.Lndex aus $\frac{[12 a] \cdot 100}{[7]} \cdots \ldots \ldots$ & 171,4 & 175,6 & 140,9 & 150,0 & 164 & - & $18:, 6$ & 162.5 & 180 \\
\hline 7. Index poplitens ... & 50,2 & 53,1 & 63.1 & 61,1 & 56,3 & - & 53 & $\ldots$ & - \\
\hline Fit. $\frac{[11 a] \cdot 100}{[12 a]}$ & 63,8 & 63,8 & 80,6 & 75,7 & 78 & - & 60,7 & $\ldots$ & 69,4 \\
\hline 8. Index des Collu & $\pi 1,9$ & 78,7 & 77,1 & 79,7 & - & 88,8 & 84,2 & - & 75 \\
\hline & 102,5 & 102,5 & 1002,1 & & - & - & - & -. & 100 \\
\hline Capat. & 20,6 & 20,5 & 21,2 & 21,8 & - & - & - & - & - \\
\hline & 16,6 & 16,3 & 17,4 & 16,8 & $\cdots$ & - & - & - & - \\
\hline $\mathrm{E}$ & $81, \pm$ & 80,0 & 76,9 & 75,6 & 76,8 & - & - & - & - \\
\hline$T^{\top}$ & 30 & 29,2 & 28,2 & 28,2 & 31,2 & - & - & - & - \\
\hline längenindex . . . & 21,6 & 21 & 20,8 & 21 & 22,7 & -- & - & - & - \\
\hline . & 106 & 106,9 & 98,3 & 100 & 10 & - & - & - & $\ldots$ \\
\hline 6. Hohenbreitenindex des Condylus lateralis & & 53,5 & 55,3 & $5+2$ & 53,3 & $1-$ & - & - & - \\
\hline
\end{tabular}

wickelt ist (siehe Abb. 16 auf der Tafel der Querschnitte durch die Diaphysen. mitte), ist der Index pilastricus doch hoch (120), weil die Diaphyse seitlich stark komprimiert ist, so daß der Sagittaldurchmesser sehr lang $(24,0 \mathrm{~mm})$ wird.

2. Einen von beiden Seiten her crkennbaren, aber gering ausgebildeten Pilaster besitzen die Femora Nr. 1, 2, 6, 7, 9, 10, 12, 14, 15. 17, 22 and 23 .

3. Einen starken Pilaster haben die Femora $\mathrm{Nr} .3,4,5,8,11,13,18,21$. Die Linea asp. femoris ist bis dorthin, wo sie proximal und distal in die beiden Labien auseinanderwicht, 55-165 $\mathrm{mm}$ und im Mittel (aus 17 Zahlen) 106,1 mm lang. Aus den Querschnitten der Diaphysenmitten kann man annähernd auch auf die Ausbildang des M. vastus medialis et lateralis schließen. Die laterale (dorsolaterale) Fläche der Diaphyse ist in den meisten Fällen leicht konkar (Fossa pilastrica extema), selten eben; sie dient zum Ursprung des M. vastus lat. Die mediale, zum Crsprung des Vastus med. dienende Flache dagegen ist meist leicht konvex. Der proximale Abschnitt des Vastus intermedius ruft unter der Linea intertrochanterica an manchen kräftigen Femora eine starke Vertiefung hervor. Dieselbe ist besonders an den männlichen Femora (3 und 7) ausgesprochen, bei denen sich auch eine sehr kräftige rauhe Linea 


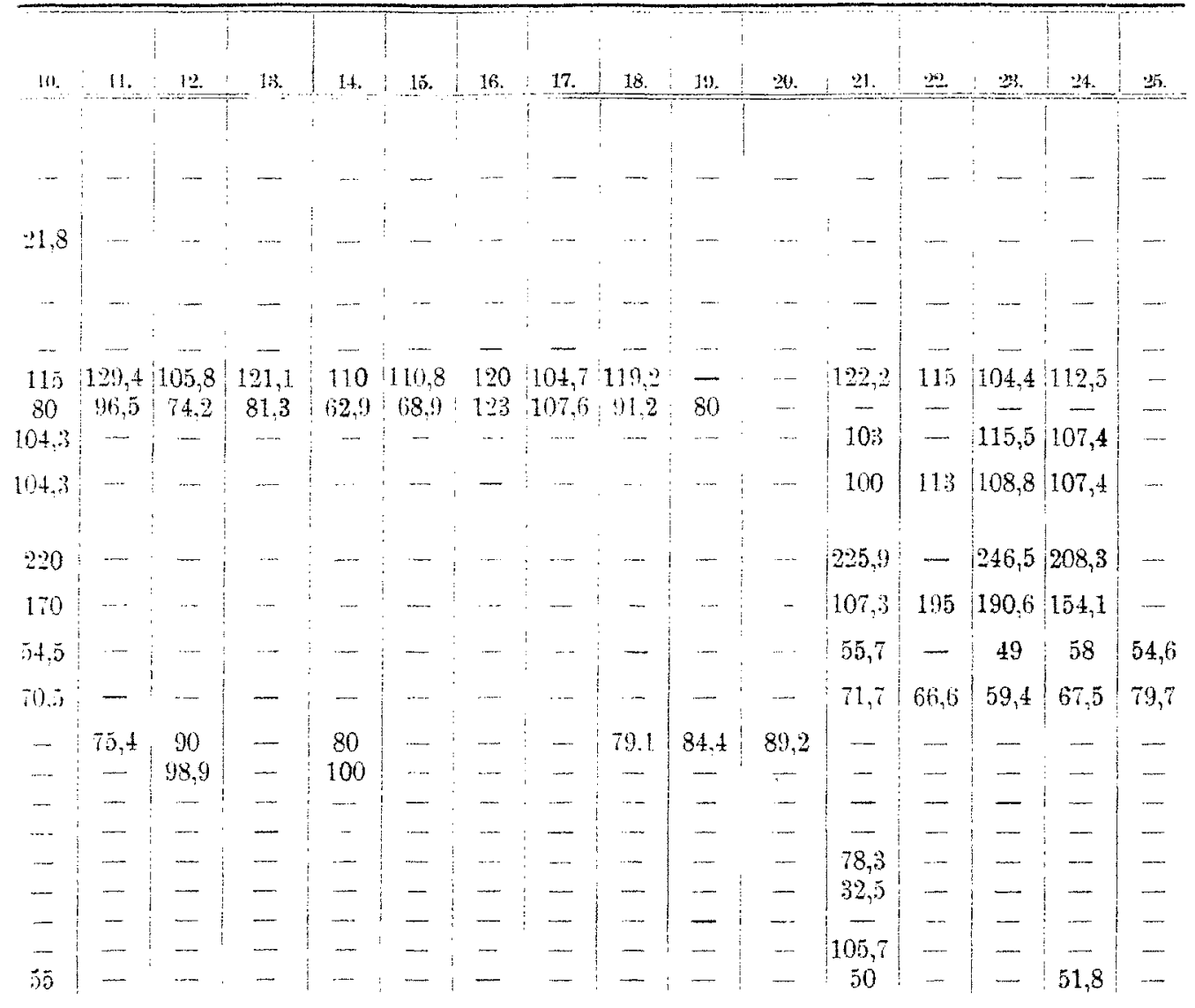

intertrochanterica findet. Dieses grubenförmig vertiefte Feld zerfällt, was besonders am Femur Nr. 4 zu sehen ist, in eine lat. unter der Insertion des M. glutaeus minimus gelegene, kleinere, dem proximalen Ursprung des MI vastus lat. dienende und in eine med. gröbere und tiefere, zum Ursprung des proximalen Teiles des M. vastus intermedius dienende Fläche. Gehen wir zu den Verhältnissen des proximalen T'eiles der Diaphyse über, so finden wir, daß der obere transversale Diaphysendurchmesser zwischen 19,5 und $33 \mathrm{~mm}$ schwankt und im Nittel (aus 19 Zahlen) 28,0 mm beträgt. Der obere sagittale Diaphysendurchmesser schwankt zwischen 17 und $28 \mathrm{~mm}$ und beträgt im Mittel (aus 19 Zahlen) $21,9 \mathrm{~mm}$. Im Mittel ist also der transversale obere Durchmesser um $6,1 \mathrm{~mm}$ größer als der sagittale, so daB sich im allgemeinen eine querovale Form des proximalen $\mathrm{Ab}$ schnittes der Diaphyse ergibt. Die Abb. auf Seite 532 (2.-5. Reihe) geben die Umrisse von 19 chinesischen Femora im proximalen Diaphysenteil. Der Index des oberen Diaphysenquerschnittes, der Index platymericus, der den queren und sagittalen Durchmesser in Verbindung setzt, beträgt im Mittel (aus 17 Zahlen) 75,3. Der Index schwankt zwischen 57,6 und 96,5. In diese Zahlen sind die beiden hohen Indices von Nr. 16 und 17 nicht mit eingerechnet; sie weisen Werte von 
123 und 107,6 auf. Einen ähnlichen Index platymericus wie das chinesiseb: Femur im allgemeinen $(75,3)$ besitzen die Japaner und neolithischen Franzosen $(75,1)$. Von 19 Femora sind 8 hyperplatymer (mit einem Index von 57,6-74,2), 7 platymer (mit einem Index von $75,4-83,8$ ), 2 eurymer (mit Indices von 91,2 und 96,5) und stenomer (mit Indices von 107,6 und 123). In allgemeinen ist also das chinesische Femur platymer. Diese Platymerie ist mit ziemlich hohem Pilasterindex verknüpft, wie dies Martin auch für die Feuerländer fand. Stark platymer sind namentlich die Femora des $\&$ (Nr. 1 und 2, siche Tafel). Diese Platymerie wird nicht nur durch den kleinen sagittalen und gowBen transversalen Durchmesser hervorgerufen, sondern auch durch eine rom distalen Teil des Trochanter major ab beginnende, etwa $80,0 \mathrm{~mm}$ lange Ausbuchtung der lateralen Kante des Femur, die erst gegen die Diaphysenmitte zu verstreicht. Auf der Hinterseite (Dorsalseite) dieser stumpfen Kante befindet sich beim $\$$ beiderseits (Nr. I und 2) eino $70 \mathrm{~mm}$ lange und in der Mitte $6 \mathrm{~mm}$ breite Fossil hypotrochanterica, die mit Rauhigkeiten in der Tiefe versehen ist und dem Ursprung des Vastus lat. dient. Nach oben geht die Fossa hypotrochanterica in die niedere ca. $25 \mathrm{~mm}$ lange und in der Mitte $3 \mathrm{~mm}$ breite Tuberositas glutaealis über. Durch diese starke Fossa hypotrochanterica wird der Angulus lat. des oberen Drittels der Diaphyse stark nach außen vorgebuchtet, ein Verhalten, wie es Martin für das Feuerländerfemur abbildet. Am männlichen Femur (Nr. 3) und 4) fehlt dieser stark vorgehuchtete Angulus lat. and die Fossa hypotrochante. rica. An ihrer Stelle befindet sich eine 63,0 $\mathrm{mm}$ lange und in der Mitte $6 \mathrm{~mm}$ breite, rauhe Fläche, die nach abwärts in die Linea aspera femoris übergeht und zum Ursprung des M. vastus lateralis dient.

Der Torsionswinkel beträgt im Nittel (aus 4 Zahlen) $8^{\circ} 6^{\prime}$. Für den Schweizer gibt Martin $8^{\circ}$ an. Beim Weibe ist der Torsionswinkel bedeutend größer $\left(14^{\circ}\right.$ und $11^{\circ}$ ) als beim Mann $\left(5^{\circ}\right.$ and $\left.8^{\circ}\right)$.

Die Krümmung der Diaphyse, d. h. die höchste Erhebung der vorderen Fläche der Diaphyse über die Horizontalebene, wobei die Hinterfläche der Kondylen und der Trochanter major an dieser angelagert sind, schwankt zwischen 45 und $55 \mathrm{~mm}$ und ist beim Mann etwas größer als beim Weib. Das aus 5 Zahlen berechnete Mittel beträgt $52,4 \mathrm{~mm}$. Beim Weib liegt die höchste Stelle der Krümmung der vorderen Diaphysenfläche ungefähr $50 \mathrm{~mm}$ oberhalb des Knorpelrandes dor Facies patellaris, beim Mann etwa in der Mitte der Diaphyse. Beim Weib nimmt die Diaphysenkrümmung nach abwärts kontinuierlich zu, was mit der beim Weib verhältnismäBig gröBeren distalen Epiphysenlänge zusammenhängt. Setzt man z. B. die Länge des 1 . Femur des Mannes (Ma 2) gleich der des Weibes (382,0 mm), so würde sich für diese Länge eine projektivische Länge des Condylus lat. von nur $51,2 \mathrm{~mm}$ ergeben, während die letztere beim Weib links $57 \mathrm{~mm}$ beträgt. Im Verhältnis zur Femurlänge besitzt also das Weib eine gröBere Kondylenlänge. Bei seitlicher Betrachtung der vorderen Fläche der Diaphyse ergibt sich, daB beim Weib dieselbe in ihren unteren $Z$ weidritteln ziemlich gerade verläuft, während das proximale Drittel nach oben abgeknickt ist. Beim Mann zeigt die Vorderfläche der Diaphyse einen gleichmäBigen, in der Mitte am höchsten Bogen.

Der Condylodiaphysenwinkel schwankt zwisehen $8^{\circ}$ und $14^{\circ}$ und beträgt im Mittel (aus 8 Zahlen) $10^{\circ}$. 
Der follorliaphysenwiok l schwank zwischen $115^{\circ}$ und $138^{\circ}$ und beträgt im Mittel (aus 13 Zahlen) $128^{\circ} 5^{\prime}$. In der Rassentabelle würde dieser Winkel zwischen Japaner (128 $2^{\prime}$ nach Koyanei) und Malayen $\left(129^{\circ}\right.$ Bello) kommen. Der beirlerseitige Nittelwort des Collodiaphysenwinkels ergibt eine sexuelle Differenz; für das Weib beträgt er $127^{\circ} 2^{\prime}$, für den Mann $130^{\circ}$. Das Femur Nr. 12 hat einen besonders kleinen Winkel $\left(115^{\circ}\right)$, ähnlich Homo Neandertalensis (mit $160^{\circ}$ im Mittel nach Boule). Dieser: niedere Winkel ist nicht mit Stenomerie verknüpft (Index $74,2 \mathrm{~mm}$ ).

Der im Bereich des proximalen Teils der Diaphyse liegende Trochanter minor ist im allgemeinen weder so weit axial gestellt wie beim Feuerlander, noch so weit medial wie beim Senoi (Martin). Nur das Fenur Nr. 14 (und in geringerem Grad das rechte Femur des Weibes zeigen ein ahnliches Verhalten wie das Fenerländerfemur mit steiler Stellung der Crista intertrochanterica. In den meisten Fillen springt dor Trochanter minor etwas mehr nach medial vor als beim Europäer, was mit der Platymerie des proximalen Diaphysenteiles im Zusammenhang stehen dürfte, da die Torsion, wenigstens beim Mann, eine nur geringe ist. Wihrend also bei dem auf die Vorderflache gelagerten deutschen Femur die Kuppe des Trochanter minor meist bis zum medialen Knochenrand reicht, springt sie beim Chinosen noch ctwas mehr nach innen vor. Bei dorsaler Lagerung der proximalen Epiphyse ist bei Nr. 14 der Trochanter minor wie beim Feuerlander rersteckt und berührt die Horizontalebene. Bei einigen anderen Femora sind in dieser Lage die Trochanteren mehr von der Tischplatte entfernt als ebenso gelagerte deutsche Femora. Im Gegensatz zu obiger Behauptung, daß der nach innen gelagerte Trochanter minor mit der Platymerie zusammenhinge, stehen die 4 Fälle von eury - und stenomerem Typus, die die gleiche Stellung des Trochanter minor aufweisen (Nr. 11, 16, 17 und 18). Auch steht damit der Fall $14 \mathrm{im}$ Widerspruch, wo ein sehr kleiner platymerer Index $(62,9)$ mit einer axialen Stellung des Trochanter minor verknüpft ist.

Am Trochanter major sind die Muskelfacetten für den M. glutaeus med. et minimus deutheh entwickelt; die Fossa trochanterica ist tief. Dagegen ist die Crista intertroohanterica sehr niedrig, einen flachen Wulst darstellend, ännlich wie beim Senoi und Neandertaler. Der etwas oberhalb der Nitte der Crista intertrochanterica sitzende Höcker für die Insertion des M. quadratus femoris ist in fast allen Fällen deutlich zu sehen.

Das Verhalten der Linea asp. am proximalen Teil des Fenur. ist ähnlich dem, das Martin für den Feuerländer beschreibt und abbildet. Das Labium med. geht ziemlich hoch oben von der Linea aspera ab und wendet sich ea. $25 \mathrm{~mm}$ unter dem Trochanter minor nach oben, med. und vorne, nur in einzelnen Fällen die Linca intertrochanterica erreichend. In keinem Falle geht die mediale Lippe, wie es Henle für den Europäer angibt, zum Trochanter minor. Von diesem distal fortgesetzten Teil der Linea intertrochanterica entspringt der M. vastus med. Die rom Trochanter minor nach abwärts. ziehende Linea pectinea ist beim 0 $26 \mathrm{~mm}$ lang und vereinigt sich mit dem distalen Ende der Linea intertrochanterica ziemlich hoch oben. Die Insertionsstellen für den Adductor brevis et minimus sind sehr gering ausgeprägt. Der proximale, auf der Vorderfläche des Knochens liegende Teil der Linea intertrochanterica bildet mit der Diaphysenachse einen 
Winkel ron 1; - $40^{\circ}$. Der kleine Winkel von $15^{\circ}$ und die damit im Zusanmenhang stehende sehr steile Stellung der Linea intertrochanterica kornmt z. T. wahrscheinlich durch den geringen Collodiaphysenwinkel (1150) zustande. Das Mittel (aus 8 Zahlen) ergibt einen Winkel von $28^{\circ} 4^{\prime}$. Derselbe ist also geringer als beim Europäer $\left(36^{\circ}-45^{\circ}\right)$, gröBer als beim Neandertaler $\left(22^{\circ}\right)$.

Vom proximalen Abschnitt des Labium lat. ist hervorzuheben, daß Tuberositas glutaealis, Trochanter tertius und Fossa hypotrochanterica vorkommen.

Eine Tuberositas glutaealis findet sich von diesen Vorkommnissen am hänfigsten (14 mal). Sie kann $22-65 \mathrm{~mm}$ lang und bis zu $9,0 \mathrm{~mm}$ breit sein. Das rechte Femur des $\&$ zeigt oberhalb der kräftigen Fossa hypotrochanterica eine niedere, $25 \mathrm{~mm}$ lange und $3 \mathrm{~mm}$ breite Tuberositas glutaealis. Sehr mächtig ist dieselbe bei $\mathrm{Nr}$. 5 , wo sie $55 \mathrm{~mm}$ lang und $9 \mathrm{~mm}$ breit ist; sie erstreckt sich nach oben und etwas nach lateral, um sich am hinteren und unteren Rand des Trochanter major zu verlieren. In einigen Fällen ist sie kaum angedeutet oder überhaupt nicht vorhanden. Ein Trochanter III. findet sich nur in einem Falle. Er ist $35 \mathrm{~mm}$ lang und $10 \mathrm{~mm}$ breit. Seine distale Halfte wird niedrig und geht in das Labium lat. über. Höhe $3 \mathrm{~mm}$. Zwischen diesem Trochanter tertius und dem minor befindet sich eine breite Vertiefung, die weiter distal und medial von der Linea pectinea begrenzt wird.

Eine Fossa hypotrochanterica ist 5 mal vorhanden. Beim Weibe (Nr. 1 und 2) ist sie beiderseits sehr ausgeprägt. Das kräftige Femur Nr. 11 besitzt eine $82 \mathrm{~mm}$ lange und $6 \mathrm{~mm}$ breite Fossa hypotrochanterica, aber keine Tuberositas glutaealis. Nr. 7 besitzt eine schwache Tub. glut. und eine schwache Fossa hypotrochanterica. Dem Femur Nr. 18 fehlt die Tuberositas glutaealis. Die Fossa hypotrochanterica ist $55 \mathrm{~mm}$ lang und $5 \mathrm{~mm}$ breit. Die abere Epiphysenlänge schwankt zwischen 80 und $99 \mathrm{~mm}$ und beträgt im Mittel (aus 12 Zahlen) 88,6 mm. Vergleicht man die Epiphysenlänge des $c$ mit der des 0 , so ergibt sich eine sexuelle Differenz von $11,5 \mathrm{~mm}$ (Epiphysenlänge des 5 im Mittel 82,5, des j 94,0 mm). Die Bajuvaren besitzen eine größere Epiph ysenlängc (99 $\mathrm{mm})$.

Vergleicht man die obere Epiphysenbreite (Maß 13a) mit der größten Trochanterenlänge (3), so ergibt sich die relativ geringe Ausbildung der proximalen Epiphyse im Vergleich zu der des Homo Neandertalensis. Der die Trochanterenlänge mit der oberen Epiphysenbreite in Beziehung setzende Index ergibt für das $\&$ ein beiderseitiges Mittel von 46,4 , für den 5 von 45,8. Das aus diesen Zahlen berechnete Mittel von 46,1 ist also viel größer als bei Homo Neandertalensis, für den Klaatsch einen Index von 40,0 und 40,3 angibt. Homo Neandertalensis besitzt dementsprechend eine breite Epiphyse, während die EpiphysenentwickIung des Chinesen innerhalb die Variationsbreite des rezenten Menschen fällt. Für den Badener beträgt der Index $44-50$.

Die Collumlänge schwankt zwischen 58 und $80 \mathrm{~mm}$ und beträgt im Mittel (aus 13 Zahlen) 70,3 nm. Für den Index der Collumlänge ergeben sich die Zahlen 16,3-17,4 mit einem Mittel (aus 4 Zahlen) von 16,8. Dieser Index schlieBt sich in der Rassenreihe an die Patagonier (16,7) an. Die Japaner besitzen einen höheren Index $(17,4)$. Der Index der Collumlänge zeigt beim Chinesen eine sexuelle Differenz, beim $\subseteq 16,4$, beim $; 17,1$ betragend. Der Femurhals 
ist also auch hier wie bei anderen Rassen beim $\subseteq$ kürzer als beim 5 . Der vertikale Durchmesser des Collum schwankt zwischen 27 und $35 \mathrm{~mm}$ und beträgt im Mittel (aus 14 Zahlen) 30,2 mm. Der sagittale Durchmesser schwankt zwischen 20 und $29 \mathrm{~mm}$ und beträgt im Mittel (aus 13 Zahlen) $24,6 \mathrm{~mm}$. Die mittlere Differenz beider Durehmesser beträgt demnach $5,6 \mathrm{~mm}$, d. h. das Collum ist von vorn nach hinten abgeplattet. Der Index des Collumquerschnittes schwankt zwischen 71 und 90 und beträgt im Mittel (aus 13 Zahlen) 81, ist also größer als bei Negern $(80,1)$. Besonders abgeplattet ist das Collum des 1 . Femur des $\subseteq$ Nr. 1, so daB hier der Index auf 71,9 sinkt. Der Umfang des Collum, zwischen 81 und $103 \mathrm{~mm}$ schwankend, betrügt im Mittel (aus 13 Zahlen) $90,2 \mathrm{~mm}$. Der aus beiden Seiten sich ergebende mittlere Collumumfang betrügt beim $\subseteq 82,0$, beim $\Im 103 \mathrm{~mm}$; das Collum des $\Im$ besitzt also einen $21 \mathrm{~mm}$ größeren Umfang als das des 5 .

Der vertikale Durchmesser des Femurkopfes schwankt zwischen 37 und $48 \mathrm{~mm}$ und beträgt im Mittel (aus 12 Zahlen) 42,3 mm. Der transversale Durchmesser schwankt $z$ wischen 37 und $49 \mathrm{~mm}$ und beträgt im Mittel (aus 7 Zahien) $42.1 \mathrm{~mm}$. In 2 von 7 Fällen sind vertikaler und sagittaler Durchmesser gleich groB, so daß der Gelenkkopf Kugelform hat, in einem Fall ist der trans. versale Durchmesser um $0,5 \mathrm{~mm}$ kleiner als der sagittale und in 4 Fallen ist der transversale Durchmesser um 1,0 mm größer als der sagittale. Beim Europäer pflegt umgekehrt der vertikale Durchmesser der gröBere zu sein. Vertikaler und transversaler Durchmesser des Femurkopfes (beiderseitiges Mittel) sind beim o un $8,5 \mathrm{~mm}$ kleiner als beim 5 . Der Index des Caputquerschniltes schwankt zwischen 39,8 und 102,5 and beträgt in Mittel (aus 7 Zahlen) 101,1. Nur in einem Fall ist er kleiner als 100, was bei den Bajuvaren die Pegel ist, in 2 Fällen ist er 100 und in 4 Fällen ist er größer als $100, d$. h. das Caput ist breiter als hoch, was auch Bumüller bei Negern und Lustig beim Aurignac-Menschen und bei Australiern fand.

Der Robustizitätsindex des Caput schwankt zwischen 20,5 und 21,8 und beträgt im Mittel (aus 4 Zahlen) 21. Beim 5 ist er etwas kleiner $(20,5)$ als beim o $(21,5)$. Im Verhältnis zum Neger $(19,7)$ ist der Robustizitätsindex beim Chinesen größer, während er im Verhältnis zum Japaner (22) geringer ist. Der Lmfang des Femurkoples, zwischen 117 und $150 \mathrm{~mm}$ schwankend, beträgt im Wittel (aus 6 Zahlen) 132,1 mm. Was die Fovea capitis anlangt, so ist dieselbe am rechten Femur des of seicht; äber ihr befindet sich eine ebenfalls seichte, halbmondförmige Grube. Die Fovea capitis des 1. Femur des $\&$ ist etwas tiefer. Das Femur des 3 dagegen besitzt eine tiefe, von vorn nach hinten aus. gedehnte, vorn zugespitzt endende Fovea capitis. For derselben liegt ein flacher Eindruck. Die Fovea liegt beim $o$ mehr als bei dem $\rho$ in der ventralen Kugelhälfte. Sehr groB ist die Fovea capitis am Femur Nr. 20; die sagittale Ausdehnung beträgt hier 22, die vertikale $14 \mathrm{~mm}$. Die Grube ist an der tielsten Stelle 5,0 $\mathrm{mm}$ tief. Der hintere obere und untere Rand der Grube sind stark aufgeworfen.

Vom lateralen vorderen Rand des Caput femoris erstreekt sich beim 3 ein nach außen zngespitzter Abschnitt der Gelenlyfäche in einer Länge yon $10,0 \mathrm{~mm}$ auf die med. Hälfte des oberen Randes des Collum femoris. Auch beim $Q$ greift die Gelenkfläche des Femurkopfes auf den Hals über, jedoch liegt hier diese 
Stelle weiter hinten. Diesen Gelenkfortsatz finde ich aber auch an deutsehen Femora. $O b$ dieses Verhaiten mit dem prähistorischer Rassen identisch ist, kann ich nicht entscheiden.

An der distalen Epipylise füllt sofort, besonders hochgradig beim $s$, der plötzliche Übergang der Diaphyse in die distale Epiphyse auf. Dieses Verhalten findet sich auch bei Homo Neandertalensis und bei den Senoi (Martin). An den Femora des c ist jener Cebergang der Diaphyse in die distale Epiphyse nicht so plötzlich als beim 5 , aber irn Verhältnis zu einem deutschen Femur immer noch recht deutlich. Bevor ich auf die Ursache jener plötzlichen Verbreiterung eingehe, die auf einer absolut größeren Epicondylenbreite oder auf der Schmatheit der Diaphyse beruhen kann, sollen einige darauf bezügliche Wabe angegeben werden.

Die distale Epicondylenbreite schwankt zwischen 70 und $83 \mathrm{~mm}$ und beträgt im Mittel (aus 6 Zahlen) $76,5 \mathrm{~mm}$. Sie ist also im allgemeinen geringer als beim Europäer (79,7-80,9). Die Epicondylenbreite ist beim Weibe um $8,0 \mathrm{~mm}$ kleiner als beim Vann; bei den Alemannen ist dieser sexuelle Unterschied etwas größer $(9,4 \mathrm{~mm})$.

Berechnet man die distale Epicondylenbreite im Verhältnis zur Diaphysenbreite, den Epricondylendiaphysenbreitenindex, so ergibt sich für den Chinesen ein Mittel (aus 6 Zahlen) von 29,8 . Dieser Index ist also um ein geringes größer als bei den Senoi (Martin, 29,6, aus 4 Zahlen). Für den Europäer berechnete Bumiuller diesen Index zu 34,4. Das Femur des Chinesen zeigt also im Verhältnis zu seiner geringen Diaphysenbreite eine große Epicondylenbreite. Der Index von 29,8 fällt auBerhalb die europäische Variationsbreite. Beim männlichen Chinesen ist der Index noch geringer, nur 28,2 betragend, während er beim Europäer zwisehen 30,7 und 37,5 schwankt. Die Epicondylenbreite ist aber nur im Verhältnis zur geringen Diaphysenbreite bedeutend. Denn erstere beträgt im Vittel 76,5 , während sich für den Europäer ein Mittel ron $80,3 \mathrm{~mm}$ ergibt. Beim Neandertalmenschen dagegen beträgt dic Epicondylenbreite $87 \mathrm{~mm}$, bei Spy $90,0 \mathrm{~mm}$. Leider finde ich für den Neandertaler den Epicondylendiaphysenbreitenindex nicht angegeben. Die Ähnlichkeit des Chinesen- und Neandertalfemur ist also nur eine äußerliche; beim Neandertaler ist die distale Epiphyse absolut breiter, während beim Chinesen die distale Epiphyse nur so verbreitert erscheint, weil die Diaphyse eine so geringe Breitenentwicklung zeigt. Aber auch aus anderen Verhältniszahlen ergeben sich diese nur dem Anscheine nach gleichen Bildungen des Chinesen- und Neandertal. femur. Vergleichen wir die distale Epiphysenbreite mit der Klatschsehen Trochanterenlänge (gleich Entfernung der Spitze des Trochanter major vom distal vorragendsten Punkt des Condylus lat.), so ergeben sich für das Chinesenfemur folgende Zahlen:

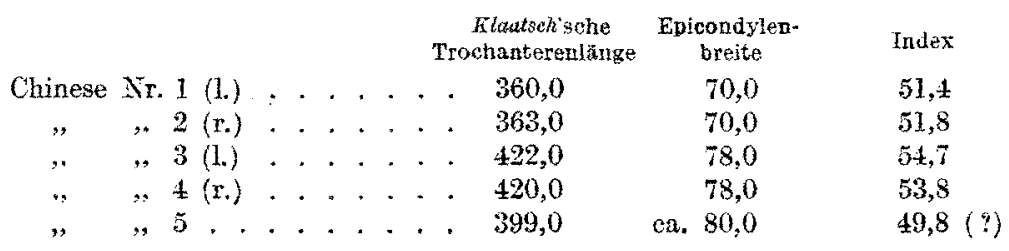


Wegen Beschädigung der Epicondylen ist der Index Nr. 5 nicht ganz richtig. Aus 5 Zahlen ergibt sich für den Chinesen ein Trochanterenlängenepicondylenbreitenindex von 52,2. In der Klantsch'schen Tabelle würde dieser Index 7wischen den der Japaner $(50,0)$ und der Malayen $(53,9)$ kommen, während sich für den Neandertal. und Spymenschen nur Indices von 48,7 und 45,5 ergeben, $d$. beim Chinesen ist die Trochanterenlunge mit einer geringen, beim Neandertaler mit einer großen Epicondylenbreite verbunden. Noch besser erhellt der Unterschied heider Bildungen, wenn wir (mit $M(a r t i n)$ die Epicondylenbreite mit einen $2,0 \mathrm{~cm}$ oberhalb der vorderen Kniegelenksgrenze parallel zu ersterer genommenen Breitenmab des distalen Diaphysenendes vergleichen. Für das männliche Femur heträgt diese Breite des distalen Diaphysenendes links 35,0 , rechts $37,0 \mathrm{~mm}$. Dic Differenzen dieser Maße und der Epicondylenbreiten betragen 43,0 bzw. $41.0 \mathrm{~mm}$, während nach Klaatsch diese Differenz bei 5 Europäerfemora nur $25,0-30,0$, bein Neandertaler- und Spymenschen dagegen $38,0-40,0 \mathrm{~mm}$ beträgt. Setzt man statt der absoluten Make die Indices, die die distale Epiphysen. hroite und den Quesdurchmesser des distalen Diaphysenendes in Beziehung \%ueinander bringen, so exhält man für das Femur des Mannes Indices von 44,3 bav. 47,4 mit einem Mittel von 46,1 . Dieser Index ist mithin noch geringer, als ihn Wrrtir für die Senui angibt (Nittel 50,5). Der Neandertaler und Spy dagegen besitzen Indices von 55,2-5,5,6. Mithin ist der Ubergang zwischen dem distalen Diaphysenende und der Epiphyse beim Chinesen (Mann) noch unvermittelter als beim Senoi und Neandertaler. Ebenso erseheint beim Weib die distale Epiphyse im Verhältnis zur Diaphyse breit, wenn auch nicht in dem ausgesprochenen MaBe als beim Mann.

Setzt man mit Bumüller an Stelle der Trochanterenlänge die Epicondylenbreite mit der Diaphysenlänge in Verbindung (Epicondylendiaphysenlängenindex), so ergibt sich für den Mann (Nr. 3 und 4) ein beiderseitiges Mittel von 20,9, das auch der männliche Senoi besitzt (Martin). Es ist also die distale Epiphysenbreite im Verhältnis zur Diaphysenlänge relativ gering. Die größte Länge des Condylus lateralis beträgt im Mittel (aus 7 Zahlen) $58,6 \mathrm{~mm}$. Die Projektionslänge betrïgt im Mittel (aus 8 Zahlen) $58,2 \mathrm{~mm}$. Der zwischen 57,6 und 81,4 schwankende Condylenindex besitzt ein Wittel (aus 6 Zahlen) von 78,2; er ist also etwas kleiner als bei Bayern $(78,9)$. Beim Weib dagegen beträgt der mittlere Condylenindex 80,7 , so dab hier der Condylus lateralis länger erseheint als beim Europäer. Fast alle lateralen Condylen besitzen eine starke Abflachung der Standfluche, was besonders beim Weib ausgeprägt ist. Von der lateralen Seite her betrachtet bildet der AuBenrand des Condylus lateralis eine flache Ellipse, ganz ähnlich wie es Martin für den Senoi beschreibt. Vergleicht man die projektivische Länge des Condylus lateralis mit der Klaatschschen Trochan. terenlänge, so ergeben sich Indices, die zwischen 63,1 und 75,0 schwanken. Das Mittel aus 6 Zahlen beträgt 68,2, während bei Martin für die 4 Senoifemora sich ein Wittel von 68,7 ergibt. Der Neandertaler- und Spymensch dagegen besitzen viel kleinere Indices $(56,9-60,4)$, so daß hier im Verhältnis zur Knochenlänge die am meisten verlängerten lateralen Condylen bestehen. Nur beim Weib ist dieser Index gering $(63,1)$, so daß, was sich auch aus dem Condylenindex ergibt, der Condylus lateralis relativ länger ist als beim Europäer. 
Die Breite des Condylus lateralis, gemessen hinter dem Epicondylus, betrïgt beim Weibe 20,0, beim Manne im Mittel 22,5 mm. Das Mittel aus 7 Zahlen eryibt $20,9 \mathrm{~mm}$.

Die Breite des Condylus medialis, ebenso gemessen, schwankt zwischen 20,0 und $25,2 \mathrm{~mm}$ mit einem Mittel (aus 6 Zahlen) von $21,9 \mathrm{~mm}$. In 5 von 6 Fallen ist der Condylus medialis um 1-2 mm breiter als der Condylus lateralis: in dem anderen Falle sind medialer und lateraler Condylus gleich breit. Dic ïberwiegende Breite des Condylus medialis über die des Condylus lateralis. erinnert an den Neandertalmenschen. Vergleicht man noch die grofite Läng' les Condylus medialis mit der Klaatsch'schen Trochanterenlänge, so schwanken die Indices zwisehen 64,4 und 70,0 mit einem Nittel (aus :) Zahlen) von 6i,7. Auch der aus der größten Trochanterenlänge (Naß3 3) und der gröBten Länge des Condylus medialis gewonnene mittlere Index (aus 6 Zahlen) be. trägt 67,7, während sich für den Neandertaler, Spy und Le Moustier ein. Mittel von nur 62,6 ergibt. Der Index des Chinesen steht äber dem des Neandertalers, erreicht aber noch nicht die untere Grenze des Index bei Australiern (mit 68,8, Lustig). Im Verhältnis zur Trochanterenlänge ist also der Condylus medialis beim Chinesen länger als beim Australier und Europäer.

Die Facies praepatellaris der distalen Epiphyse reicht nicht so weit nach aufwärts, wie es Martin für den Senoi beschreibt. Bein Weibe fällt der obere Rand der Facies praepat. sehr steil von lateral nach medial ab; beim Manne dagegen bildet er einen proximalkonvexen, fast horizontal verlaufenden, nach medial ganz sanft abfallenden Bogen, ahnlich wie es sich am Neandertalfemur findet. Die Patellargrube ist beim Weibe ziemlich, beim Manne etwas weniger tief: im allgemeinen aber ist sie tiefer als an deutsehen Femora. Die hintere Hälfte des Condylus lat. und med. ist stärker konvex gekrümmt und der Knorpelüberzug reicht weiter nach auf- und vorwärts als an deutschen Femora. Virchow fand dieses Verhalten auch am. Jakunfemur und es dürfte dasselbe auch beim Chinesen mit der Hockfunktion im Zusammenhang stehen. Die durch die Vorderränder der Menisci hervorgerufenen Impressionen der Knorpelränder an den Condylen sind nur ganz gering ausgeprägt.

Die Fossa intercondyloidea ist im allgemeinen schmäler als beim Europäer. So beträgt z. B. ihre Breite an den Femora des Mannes 20, an denen des Weibes $18 \mathrm{~mm}$, während sie an mehreren deutschen Femora 23-24 mm mißt. Sehr stark ausgeprïgt und abgegrenzt sind die Ursprungsgruben für die Ligg. cruciata. Proximal und etwas medial vom Oberrande der Hinterfläche des Condylus med. hefindet sich fast überall eine deutlich ausgeprägte, ziemlich große, dreieckige Fläche, die mit ihrer Spitze an dem kräftigen Tuberculum supracondyloideum mediale endet. Daumenbreit ist diese mit der Hockfunktion in Zusammenhang gebrachte Fläche an dem Femur Nr. 21. Die Grube für das Lig. collaterale fibulare ist an den meisten Femora sehr deutlich; flacher ist diejenige für das Lig. collaterale tibiale.

Das Planum popliteum ist beim Weibe lateral schärfer als medial begrenzt; beim Manne sind beide Begrenzungsleisten scharf. Das Planum popliteum des Weibes ist ziemlich schief nach medial und abwärts geneigt, so daB der distale Diaphysenabschnitt medial einen viel kürzeren Sagittaldurchmesser erhält als 
lateral. Beim Manne ist das Planum popliteum sehr wenig nach medial geneigt und leicht konkav. Diese letztere Eigenschaft besitzt auch das Planum popliteum des Weibes.

Der Index poplitew schwnkt zwisehen 29 und 63,1 und betrugt im Mittel (aus 11 Zahlen) 55,3, wenn man den sagittalen und transfersalen Durchmesser $19,0 \mathrm{~mm}$ oberhalh der Condylengelenkflache miBt. Nimmt man dicse Durchmesser $30,0 \mathrm{~mm}$ proximal von aler Condylengelenkfläche, so erhält man höhere Zahlen $(60,7-80,6)$ und ein ans 13 Zahlen berechnetes Mittel ergibt 69, während nach Bumialler der mittlere Index popliteus für den Europaier 79,0 beträgt. Beim Weibe ist dex Index becleutend geringer als beim Manne.

In AnschluB an die Beschreihung des Femur des Erwachsenen gebe ich eine MaBtabelle des Femur des Vetgeborenen, von dem oben lie vordere Hxtremität behandelt wurde. Tch gebe die Tabelle separiert, da in manchen Fallen

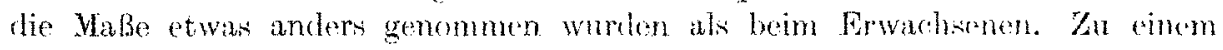
Vergleich mit anderen Rasisen liegt zit wenig Material vor.

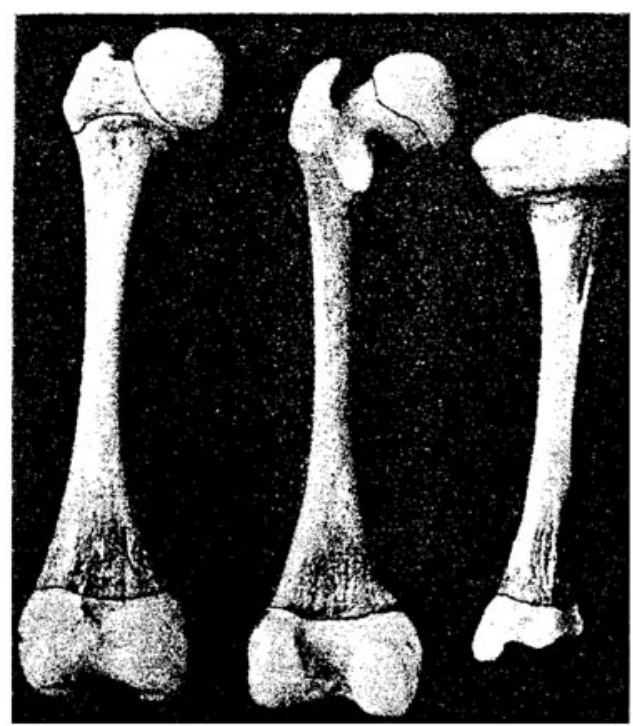

r. femur von yorne l. femurvon hinten r. tibia von hinten atnes neugeborenen männlicbun Chinesentindes.

Abb. 5 .

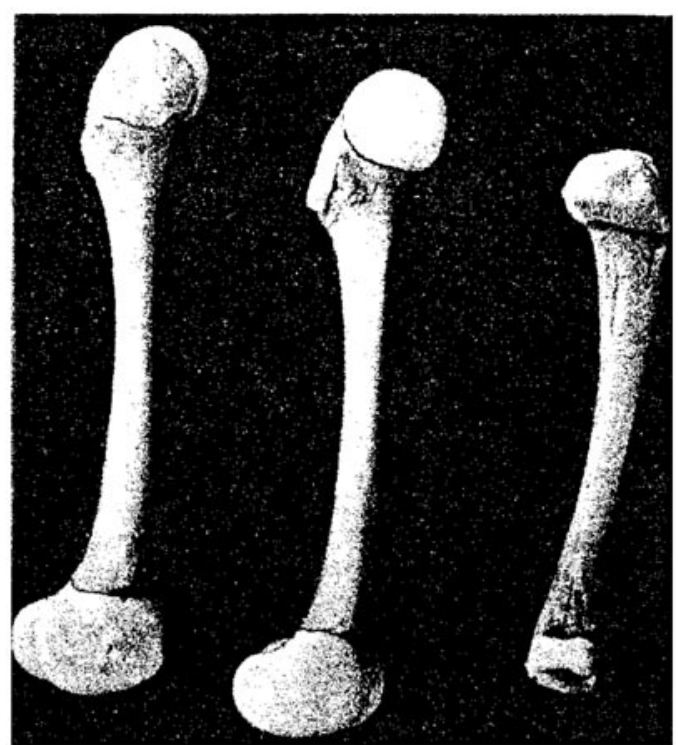

r. femur vou lateral l. temur von medial r. tibia von lateral eines neugeborenten männliehen chinesenkindes.

Abb. 6 .
Femur les Yungebormen (mänmlich).

links rechtik

$103,5 \quad 103,1$

$103,0 \quad 103,0$

$100,7 \quad 100,5$

3. Größte Trochanterenlange . . . . . . . . . . . . . . . . . . . .

3a. Abstand des Oberrandes des Trochanter maj. von der Mitte des Seitenrandes der Gelenkflache des Condylus extern. . . . . . . . . . . . 99,8 99,5

4. Trochanterenlänge in natiorlicher Stellung . . . . . . . . . . . . . . . . 100,5 100,5

5. Diaphysenlange des Femur . . . . . . . . . . . . . . . . . . . . $74,9 \quad 74,0$

5a. Abstand des Tuberoulum linea obl. sup. von der Witte der finea intercondyloidea anterior. . . . . . . . . . . . . . . . . . . . . . . Zeitseitr. f. al guse Ant. T, Abt. Bu. at.
$84,0 \quad 87,0$ 
5b. Gerałe Länge der knöchernen Diaphyse außen . . . . . . . . . .

linkis rechts

5e. Gerade Iänüe der knöchernen Diaphyse vorne . . . . . , . . . .

6. Hagittaler Durchmesser der Diaphysenmitte. . . . . . . . . . . .

i. Transversaler Durchmesser der Diaphysenmitt.

8. Umfanc ker Diaphysenmitte

9. Oberer transversaler Diaphysendurchmesser, gonommen $10 \mathrm{~mm}$ unter dem Trochanter minor, parallel zum Collum fem.

Da. Oberer transversaler Durchmesser der knöchernen Diaphyse an dev Knorpelknochentrenze

9h. Oherer transversaler Diaphysendurchmesser if $\mathrm{mm}$ fistal von dir un. teren Knorpelgrenze des Trochanter minor . . . . . . . . . . . .

10. Oborer sagittaler Diaphysendurohmesser . . . . . . . . . . . . .

10a. Oberes sagitaler Diaphysendurchmesser im vireau von ga gem. .

10b. Oberer sasrittaler Diaphysendurchmesser im Niveau von $9 \mathrm{~b}$ rem.

11. Kleinster unterer sagittaler. Diaphysendurchmesser an dor Knorpelknowengrenze . . . . . . . . . . . . . . . . . . . . . . .

I la. Kleinster unterer sagitaler Diaphysendurehmesser $10 \mathrm{~mm}$ oberhalb drr Knorpelknochengrenze . . . . . . . . . . . . . . . . . . . . . .

12. Unterer transversaler Diaphysendurchmesser (im Xiveau von l1) .

12a. Unterer transwersaler Diaphysendurehnesser (im Yiveau von (la)

13. Obere Epiphysenlange (ohne Pudesicht anf knorpeligen und knothernen Anteil) . . . . . . . . . . . . . . . . . . . . . . .

13a. Obere Breite des Eemur . . . . . . . . . . . . . . . . . . .

13b. Obere Breite des Femur, projektiviseh genommen . . . . . . . . .

13c. Länge von Collum und capub. . . . . . . . . . . . . . . . .

14. Collumlänge . . . . . . . . . . . . . . . . . . . . . . .

15. Vertikaler Durchmesser des Collum . . . . . . . . . . . . . . . .

16. Sagittaler Durchmesser des Collum . . . . . . . . . . . . . . .

17. Umfang des Collum . . . . . . . . . . . . . . . . . . .

18. Vertikaler Durchmesser des Fumurkopfes . . . . . . . . . . . . .

19. Transversaler oder sagittaler Durchmesser des Femurkopfes . . .

20. Umfang des Femurkopfes . . . . . . . . . . . . . . . . . . . .

21. Epikondylenbreite . : . . . . . . . . . . . . . . . . . . . . . .

22. Dicke bzw. projektivische Lange des Condylus lateralis . . . . . . .

23. Größte Länge des Condylus lateralis . . . . . . . . . . . . . . . .

24. Größte Lïnge des Condvlus medialis . . . . . . . . . . . . . . .

25. Hôhe des Condylus lateralis . . . . . . . . . . . . . . . . . . .

26. Höhe des Condylus medialis . . . . . . . . . . . . . . . . . . .

27. Krümung der Diaphyse . . . . . . . . . . . . . . . . . . . . .

28. Torsionswinkel . . . . . . . . . . . . . . . . . . . . . . . . .

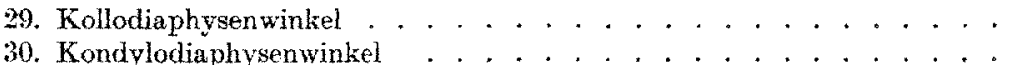

31. Rotationswinkel des Collum . . . . . . . . . . . . . . . . . . $23^{\circ}$

\section{Indices.}

1. Längendickenindex:

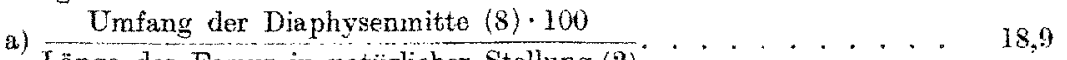

b) $\frac{\text { Umfang der Diaphysenmitte }(8) \cdot 100}{\text { Diaphysenlange }(5)}$ 
4. Index des oberen Diaphysenquerschnittes (Index platymer.) links rechts
a) $\frac{\text { Oberer sagittaler Diaphysendurchmesser }(10 \mathrm{a}) \cdot 100}{\text { Oberer transversaler Diaphysendurehmesser }(9 \mathrm{a})}$
b) $\frac{\text { Oberer sagittaler Diaphysendurchmesser }(10 \mathrm{~b}) \cdot 100}{\text { Oberer transversaler Diaphysendurchmesser }(9 \mathrm{~b})}$

5. Sagittalindex der unteren Diaphysenhalfte. . . . . . . . . 163,5

$5 \mathrm{a}$. Aus den Maßen $11 \mathrm{a}$ und $6 \ldots . . . . . . . .154,5$

เริธิธา 1

6. Transversalindex der unteren Diaphysenhälfte . . . . . . . . . .

6a. Transversalindex der unteren Diaphysenhaifte aus den Maben La und 7

853,3

$2903,218.7$

7. Index popliteus

$42, \pm \quad 42,8$

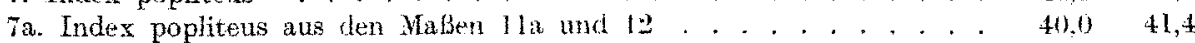

8. Index des Collumquersehnittes . . . . . . . . . . . . . . 88,4 $87 . \mathrm{I}$

9. Index des Caputquerschnittes . . . . . . . . . . . . . . . $10,1100,0$

10. Pobustizitatsindex des Caput . . . . . . . . . . . . . . $31, \overline{3}$ 32,0

11. Index der Collumlange . . . . . . . . . . . . . . . . . . . . . 15,5150

12. Kondylenindex . . . . . . . . . . . . . . . . . . . . 82,0 82,0

13. Epikondylendiaphysenbreitenindex. . . . . . . . . . . . . . . . . 22.4 23,4)

14. Epikondylendiaphysentängenindex . . . . . . . . . . . . . . . . . $31,7 \quad 30,6$

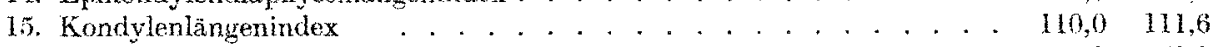

16. Höhenbreitenindex des condylus lateralis . . . . . . . . . . . . $59,3 \quad 59,3$

17. Krümmungsindex .................... . . . . . 000

Gewicht des Femur in Milligrammen ${ }^{1}$ ) . . . . . . . . 1420014320

\section{Patella.}

\section{Tntersuehtes Material.}

1. Linke und rechte Patella einer 25 jährigen, an Ph thise verstorbenen Chinesin (Präpariersaalleiche).

2. Linke und rechte Patella eines 30 jährigen, an Gangraena pedum verstorbenen Chinesen (Prüpariersaalleiche).

Mabe der Patellu.

1. Grußste Höhe der Patella
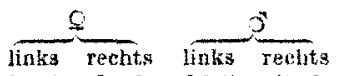

This reets Mittel

2. Größte Breite der Patella

$\begin{array}{lllll}37,5 & 37,2 & 38,5 & 37,8 & 37,7 \\ 39,1 & 30,2 & 40,0 & 39,0 & 39,2\end{array}$

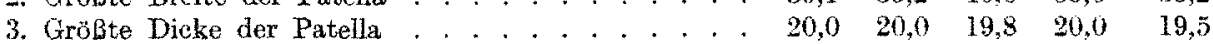

4. Höhe der Facies articularis patellae ....... $\begin{array}{llllll}27,0 & 27,0 & 31,0 & 30,0 & 28,7\end{array}$

$\begin{array}{lllllll}5 . & \text { Breite der medialen Gelenkfacette. . . . . . . . . } & 20,0 & 19,0 & 16,2 & 17,2 & 18.1\end{array}$

6. Breite der lat. Gelenkfacette . . . . . . . . . . . $\begin{array}{cccccc}22,5 & 23,4 & 25,6 & 24,5 & 24,0\end{array}$

$\begin{array}{lllllll}\text { 7. Größte Tiefe der lat. Gelenkfacette . . . . . . . . } & 2,0 & 2,5 & 1,5 & 2,0 & 2,0\end{array}$

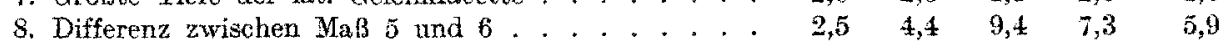

Indices:

Hohenindex der Patella (aus ganzer Femur- und Tibia-

lange ) . . . . . . . . . . .

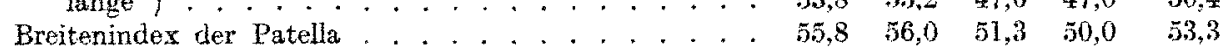

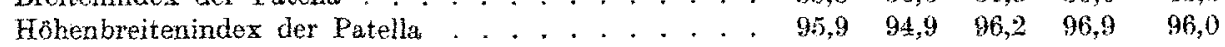

Winkel, den med. und lat. Facette miteinander bilden. $130^{\circ} \quad 125^{\circ} 130^{\circ} 129^{\circ} 128^{\circ} 5^{\prime}$

Gewicht der Patella in Milligrammen ....... 712073501130011120922

Die Form der Patella ist breit herzformig; die Spitze ist gut entwickelt, die Basis vorn abgeschrägt. Die gröbte Höhe der Patella besitzt ein Mittel von $37,7 \mathrm{~mm}$, das beim Europäer $41,2 \mathrm{~mm}$ beträgt. Die mittlere gröBte Breite

1) Die in Alkohol konservierten Femora, deren Periost und Perichondrium entfernt war, wurden lejcht abgetrocknet und gewogen. 
beträgt $39,2 \mathrm{~mm}$ beim Chinesen, 42,4 beim Europäer. Vergleicht man Höhe und Breite der Patella miteinander, so findet man, daß die Patella im Durchschnitt $1,6 \mathrm{rmm}$ breiter als hoch ist. Der Höhenbreitenindex hat ein Nittel von 96,0 . Beim Weib ist der Höhenbreitenindex etwas geringer als beim Mann. Für den Furopäer wird er zu 97,1 angegeben. Der aus der ganzen Länge von Femur und Tibia berechnete Höhenindex der Patella ergibt für das Weib 53,5, für den Wann 47,3 (Vittel 50,4). Der mittlere Breitenindex betrigt $5,5,9$. für das Weib 50,6, für den Mann (Mittel) 33,3.

Ver die beiden Facetten der Facies artienl tronnende Kamm ist stumpt. Der Winkel, den die laterale mit der medialen Facette bildet, schwankt zwischen 125 und $130^{\circ}$. In allen 4 Fällen ist das laterale Feld der Facies articul. patellae herleutend größer als das mediale. Das beruht nicht nur auf der größeren Breite res lateralen Gelenkflächenabschnittes, sondem auch darauf, daß dorelbe nach unten und auken stärker ausgedehnt ist als meist bein Europizer. Dio untere Begrenzang der Facies lat. bildet so einen nach abwäts gerichteten konvexen Bogen. Die Breitendifferenz der inneren und äuBeren Gelenkfläche schwankt zwischen 2,5 und $9,4 \mathrm{~mm}$. Die mittlere Breite der medialen Facette betrïgt $18,1 \mathrm{~mm}$ (beim Europüer 19,4), die der lateralen Facette $24.0 \mathrm{~mm}$ (heim Europäter $24,8 \mathrm{~mm})$. Die Höhe der Facies art. schwankt zwimehen 27 und $31 \mathrm{~mm}$ mit. einern Wittel ron 28,7 , das sich dem des Europäers mit 28,5 mm nähort. Dia laterale Gelenkflache ist im Zusammenhang mit der Hockfunktion ziemlich. stark ausgeböhlt, und zwar beim Weibe starker als bęim Manne. Die größte Tiefe betragt 2,5 $\mathrm{mm}$ (Weib). Auf der lateralen Flähe sind besonders beim Weibu 7wei Querleisten ausgeprägt, dic dicselbe in drei üborcinander liegende Facetten trennt. Die kleinere mediale Golenkflache besitzt ungefuhr in ihrer Mitte cine beim Weibe wieder stärker als beim Mann ausgeprägte proximodistal verlaufende Leiste, durch die die mediale Gelenkflüche in einen medial gehöhlten und einen lateral konvexen Abschnitt zerlegt wird.

\section{Tibia.}

\section{Untersuchtes Material.}

1. Linke und rechte Tibia einer 25 jährigen Chinesin (Präpariersaalleiche, Nr. 1 und 2). Tibien völlig echalten; jedoch ist die rechte Tibia im mittleren Diaphysendrittel durch eine tuberkulöse Periostitis verdickt (in der Mal3tabelle mit einem Stern bezeichnet).

2. I.inke and rechte Tibia eines 30 jährigen Chinesen, Präpariersaalleiche (an Gangraena pedum gestorben).

3. Linke Tibia, vermutlich eines Mannes, der infolge Fußgelenkstuberkulose operiert wurde. Tibia hochgradig porös und daher sehr leicht.

Die ganze Länge der Tibia schwankt zwischen 314,5 und $361,5 \mathrm{~mm}$ (Differeny. $47 \mathrm{~mm}$ ) bei einer mittleren ganzen Länge von $356,2 \mathrm{~mm}$ für den Mann und $315 \mathrm{~mm}$ für das Weib. Die sexuelle Differenz beträgt $41,2 \mathrm{~mm}$. Dräckt man die Länge der Tibia des Weibes in Prozenten der Länge der Tibia des Mannes aus, so ergibt sich für das Weib 88,4 . Die größte Länge der Tibia beträgt im Mittel für das Weib $318,7 \mathrm{~mm}$, für den Mann $360,5 \mathrm{~mm}$. Zieht man von der ganzen Länge den Gelenkflächenabstand $a b$, so ergibt sich eine mittlere Länge des Malleolus 
medialis von $16,4 \mathrm{~mm}$. Der Gelenkflächenabstand (2a) beträgt im Wittel $323,6 \mathrm{~mm}$. während die Condyloastragallänge etwas geringer ist (321.6). Der erstere wurde gemessen als Abstand des Mittelpunktes der Facies artic. des Condylus lat. von dem am wenigsten rorstehenden Punkt der unteren Gelenkfläche (am fibularen Rand). Dieses mit dem Tasterzirkel gefundene Maß ergab sich als gröBer als die Condyloastragallänge, weil (Nr. 3 und 4 ausgenommen) der Condylus lat. höher steht als der mediale. Die rechte Tibia des Mannes (Nr. 4) zeigt beide Mabe gleich groß, während die linke das gewöhnhiche Verhalten aufweist und eine gegenüber dem Gelenkflächenabstand gröbere Condyloastragallänge besitzt.

Die größte proximale Epiphysentreits beträgt beim Weibe 65,2, beim Manne 72,8 $\mathrm{mm}$ mit einer sexuellen Differenz $\vee$ $7,6 \mathrm{~mm}$. Bei den Ainos ergeben sich Zahlen von $67,4 \mathrm{im}$ weiblichen und $73,7 \mathrm{~mm}$ im männlichen Geschlecht (Differenz $6,3 \mathrm{~mm}$ ). Für Schweizer gibt Martin bei einer Tibialänge von $365 \mathrm{~mm}$ cine proximale Epiphysenbreite von $72,7 \mathrm{~mm}$ an. Fast dieselbe Epiphysenbreite besitzt die Tibia des Chinesen (Mann; $72.8 \mathrm{~mm}$ aus drei Zahlen), wobei jedoch $z$ u bericksichtigen ist, daß die mittlere ganze Tibialänge nur $356,2 \mathrm{~mm}$ beträgt, so daß sich im VerhäItnis zur Länge für den Chinesen eine größere proximale Epiphyse ergibt.

Die größte distale Epiphysenlreite schwankt zwischen 40,0 und $45,1 \mathrm{~mm}$ und beträgt im Mittel (aus fünf Zahlen) $43,0 \mathrm{~mm}$. Das Weib besitzt cine Epiphysenbreite von $40,3 \mathrm{~mm}$, der Mann von $44,9 \mathrm{~mm}$ mit einer sexuellen Differenz von $4,6 \mathrm{~mm}$. Die distale Epiphysenbreite nähert sich den von Martin für den Senoi gefundenen Zahlen: 40,5 mm für das Weib, $43,5 \mathrm{~mm}$ für den Mann und ist geringer als bei den Ainos und Japanern, so daß die untere Epiphyse diesen gegenüber graziler erscheint.

Der Sagitialdurchmesser der Hitte schwankt zwischen 22,0 und 26,5 $\mathrm{mm}$ mit einem Mittel von $24,3 \mathrm{~mm}$. Der mittlere transversale Durchmesser beträgt $19,8 \mathrm{~mm}$. Daraus ergibt sich ein Querschnittsindex der Mitte von 81,4. Der aus dem sagittalen und transversalen Durchmesser der Diaphysenmitte und der ganzen Länge der Tibia berechnete Index der Massigkeit schwankt zwischen 11,8 und 14,5 (Mittel 13). Für die Tibia Nr. 3 ergibt sich ein größerer Robustizitätsindex, weil sie periostistisch verdickt ist. Der aus denselben Zahlen und der Condyloastragallänge berechnete Index ergibt ein Mittel von 13,8. Der kleinste Umfang schwankt zwisehen 60,5 und $68,0 \mathrm{~mm}$; er ist kleiner als beim Europäer (o 63, o $75 \mathrm{~mm}$ ). Der aus dem kleinsten Umfang und der ganzen Tibialänge berechnete Längendickenindex besitzt ein Gesamtmittel von 18,8, beim $\$ 19,2$, beim 518,5 betragend. Die gröBere Zahl beim 5 ist pathologisch. Fitr die Mongoloiden gibt Soularure allerdings höhere Zahlen $(21,3)$ an.

Das Foramen nutricium ist vom lateralen Höcker der Eminentia intercondyloidea beim o $102 \mathrm{~mm}$, beim o (Nr. 3 und 4) $129 \mathrm{~mm}$ entfernt. Der sayittale Durchmesser im Niveau des Foramen nutricum hat ein Nittel von $27,9 \mathrm{~mm}$, ist also um 3,6 mm gröBer als der der Mitte. Dagegen sind die transversalen Durchmesser der beiden Höhen fast gleich $(19,9$ und $19,8 \mathrm{~mm})$. Der Index cnemicus sehwankt $z$ wischen 69,2 und 74,7 mit einem Mittel von 71,1 . In 2 Fallen besteht Meso-, in 3 Fällen Euryknemie. In allen Fällen ist eine mehr oder minder konvexe hintere Fläche vorhanden. Vergleicht man die S. 532, 1. Reihe abgebildeten 
Querschnitte mit den Querschnittstypen Hrdlickas, so findet man, daß Nr. 5 der beim erwachsenen Europäer am häufigsten vorkommenden Form (1) entspricht, dic die Gestalt eines gleichseitigen Dreiecks hat. Form 4 ist beim Manne Nr. 3 und $\neq$ vorhanden, indem die hintere Fläche der Tibia durch eine vertikale Leiste in einen lateralen und medialen Abschnitt zerlegt wird. So erhält die Tibia auf dem Querschnitt der Mitte 4 Seiten. Dabei ist die laterale Fläche der Tibia, besonders im oberen Drittel der Diaphyse, stark ausgehöhlt. Beim

1.

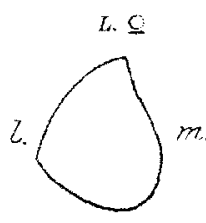

1

L. S

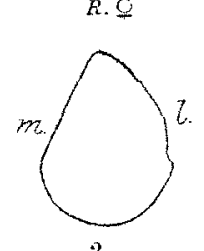

g

R.

2

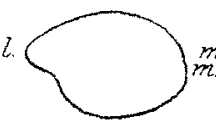

$R$

s.

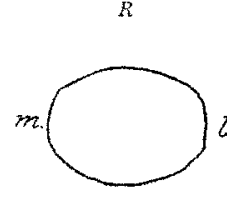

6

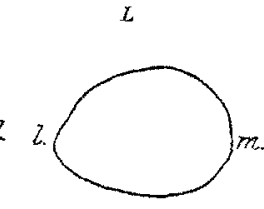

7

4.

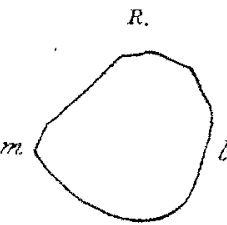

11
I.

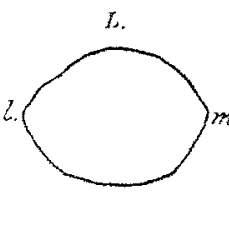

12

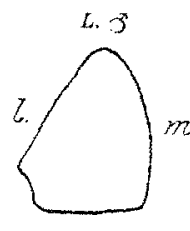

3

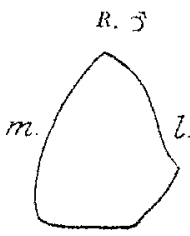

1. 5

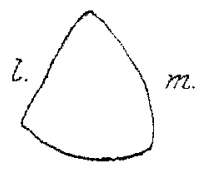

5

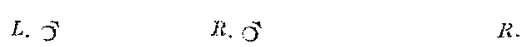

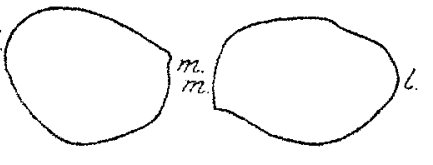

4

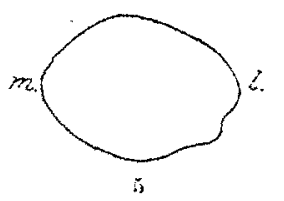

IR

la

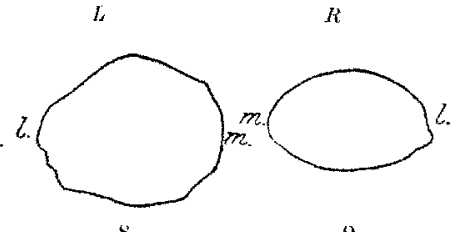

9

10

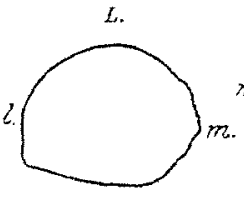

13

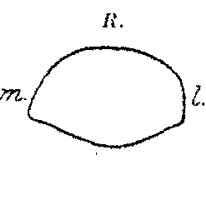

14

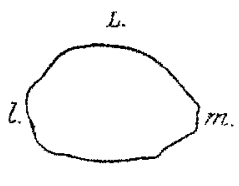

15

5.

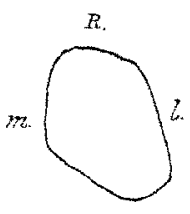

16

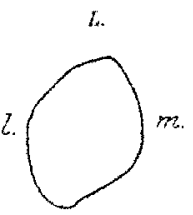

13

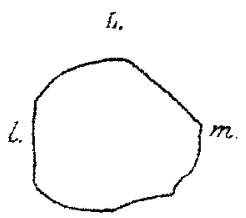

18

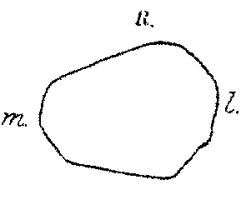

19

1. Umrilzeichnungen der Tibiadiaphysenmitte (Chinese). 2.--5. Querschnitte durch den proximalen Teil der Femurdiaphyse (Chinese). 20-30 $\mathrm{mm}$ distal ron der Basis des Trochanter minor. Die Querschnitte verlanfen nicht parallel der Richtung des Schenkelhalses, sondern horizontal. An einigen Femora ist eine dentliche Fossa bypotrochatiterica za sehen. $3 / 3$ der natül. Größe. 
Tibia.

\begin{tabular}{|c|c|c|c|c|c|c|}
\hline & & & & $\sigma$ & 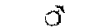 & \\
\hline & $\begin{array}{c}\text { L. } \\
\text { Nr.1 }\end{array}$ & $\begin{array}{c}\mathrm{r} \\
\mathrm{Nr} \cdot 2\end{array}$ & $\begin{array}{l}1 . \\
\text { Nron }\end{array}$ & $\begin{array}{c}\text { r. } \\
\text { Nr. } 4 \\
\end{array}$ & $\begin{array}{c}1 . \\
\mathrm{N}_{\mathrm{r}, 5} \\
\end{array}$ & Mittel \\
\hline Maße: & & & & & & \\
\hline 1. Ganze Länge der Tibia & 314.5 & 315,5 & 361.5 & 360,5 & 348,0 & 340,0 \\
\hline 1a. Größte Länge der Tibia & 319,0 & 318,5 & 365,5 & 365,0 & 351,0 & 343,8 \\
\hline Ib. Länge der Tibia... & 306,5 & $305, \tilde{5}$ & 358,0 & 356,0 & 338,5 & 333,5 \\
\hline 2. Condyloastragallänge der Tibia & 295,0 & 295,0 & 345,0 & 348,0 & 330,0 & 321,6 \\
\hline 2a. Gelenkflächenabstand . . . . . & 300,0 & 300,0 & 343,0 & 343,0 & 332.0 & 323,6 \\
\hline $\begin{array}{l}\text { 3. Größte proximale Epiphysenbreite } \\
\text { der Tibia . . . . . . . } \\
\text { 4. GröBter sayittaler Durchnesser der }\end{array}$ & 65,0 & 65,5 & 73,0 & $i \pm .0$ & 71,5 & 69,8 \\
\hline & 37,5 & $37, \pm$ & 43,0 & 42,0 & 37,0 & 39,4 \\
\hline $\begin{array}{l}\text { ser der Tibia im Niveau der Tube- } \\
\text { rositas . - . . . . . } \\
\text { 6. Größte distale Epiphysenbreite der }\end{array}$ & 44,0 & $4 \overline{5}, 0$ & 45,8 & $4 \pi, 5$ & 44,5 & 45,0 \\
\hline .......... & 40,6 & 40,0 & 45,1 & $4.5,0$ & 44,5 & 43,0 \\
\hline $\begin{array}{l}\text { 7. Sagittaler Durchmesser der distalen } \\
\text { Epiphyse }\end{array}$ & 33,0 & $33 \%$ & 35,5 & $35 \%$ & 370 & 248 \\
\hline 8. Sagittaler, d. h. größter Durchmes & (3), & 0 & (1), & 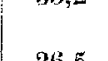 & 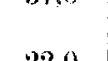 & 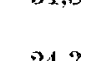 \\
\hline & 22,5 & $\left.25,8^{1}\right)$ & 25,0 & 26,5 & 22,0 & 24,3 \\
\hline & 26,0 & 27,0 & 29,4 & 29,4 & 28,1 & 27,9 \\
\hline $\begin{array}{l}\text { terhalb des Foramen nutricium } \\
\text { 9. Transversaler Durchmesser der }\end{array}$ & 23,4 & $\left.26,2^{1}\right)$ & 28,0 & 29,0 & 24,0 & 20,1 \\
\hline Mitte $\cdot$ & 18,1 & $\left.20,0^{1}\right\}$ & 20,5 & 21.0 & 19,4 & 19,8 \\
\hline $\begin{array}{l}\text { 9a. Cleiches } M a B \text {, jedoch im Niveau } \\
\text { des Foramen nutricium genommen }\end{array}$ & 18,0 & 19,0 & 20,5 & 21,0 & 21.0 & 19,9 \\
\hline $\begin{array}{l}\text { 9b. Gleiches MaB, jedoch } 3-4 \mathrm{~cm} \text { un- } \\
\text { terhalb des Foramen nutricium ge- } \\
\text { nommen }\end{array}$ & 17,0 & 18,9 & 20,4 & 21,0 & 20,5 & 19,6 \\
\hline $\begin{array}{l}\text { 10. Umfang der Diaphyse (in der Mitte) } \\
\text { 10a. Gleiches Maß, jedoch in Nivead }\end{array}$ & 68,0 & $\left.70,0^{1}\right\}$ & 73,0 & 74,0 & 68,0 & 69.6 \\
\hline des Foramen nutricium . . . . & 70,0 & $\left.73,5^{1}\right)$ & 80,0 & 80,0 & 80,0 & 76,7 \\
\hline 10b. Kleinster Unfang der Diaphyse & 60,5 & 61,0 & 68,0 & 68,0 & 62,0 & 63,9 \\
\hline 1. Krümmung der Tibia . . . . . & 2,2 & 3,5 & 3,4 & 3,0 & 2,0 & 2,8 \\
\hline 11a. Sehnenlange. . . . . & 197,0 & 187,0 & 195,0 & 195,13 & 234,0 & 201,6 \\
\hline ionswinkel & $2: 3^{\circ} 3^{\prime}$ & $23^{\circ}$ & $11^{\circ}$ & $12^{\circ}$ & $19^{\circ}$ & $17^{\circ} 7^{\prime}$ \\
\hline 13. Inklina & $18^{\circ}$ & $19^{\circ}$ & $7 \tilde{z}^{\prime}$ & $8^{\circ}$ & $13^{\circ} \tilde{5}^{\prime}$ & $132^{\prime}$ \\
\hline 13a. Biaxialer Winkel & 55 & $4^{\circ}$ & $3^{\circ} 5^{\prime}$ & $4^{3}$ & 505 & 45 \\
\hline $\begin{array}{l}\text { 14. Torsion der Tibia }, \ldots . . \\
\text { Indices: }\end{array}$ & $9^{\circ}$ & $15^{\circ}$ & $18^{\circ} 5^{\prime}$ & $10^{\circ}$ & $35^{\circ}$ & $17^{\circ} 5^{\prime}$ \\
\hline Lndex des Querschnittes der Mitte & 80,4 & 77 & 82, & 79 & 88,1 & 81,4 \\
\hline . . . . . . . & 69 , & 70 & 6 & 71 & 74,7 & 71,1 \\
\hline Längendickenindex . . . . . . . & 19,2 & 19,3 & 18,8 & 18,9 & 17,8 & 18,5 \\
\hline & & & & & & 130 \\
\hline $\begin{array}{l}\text { a) aus ganzer Länge (1) } \\
\text { b) aus Kondyloastragallänge }\end{array}$ & 13,8 & $\begin{array}{l}\left.14,0^{1}\right\} \\
15,5\end{array}$ & $\begin{array}{l}12,0 \\
13,2\end{array}$ & $\begin{array}{l}11,2 \\
13,8\end{array}$ & $\begin{array}{l}11,8 \\
12,9\end{array}$ & $\begin{array}{l}13,0 \\
13,8\end{array}$ \\
\hline ümmungsindex & 1,1 & 1,9 & 1,7 & 1.5 & 0,8 & 1,4 \\
\hline ewicht der & 1000 & & 99000 & 204100 & $75000^{2}$ & 167325 \\
\hline
\end{tabular}

1) Periostitisch verdickt.

2) Sehr porös und nicht ins Wittel mit berech net. 
Weibe (Nr. 1 und 2) ist der innere Winkel vorwischt, so dar mediale und hintere Fläche abgerundet incinander übergehen (Form 5). Der platykneme Typus fehlt. Die Crista interossea ist in allen Fallen gut ausgeyrägt, besonders beim Mann, wo sie etwas vor und unterhalb der Articulatio tibiofibul. sup. beginnend geracle distalwärts verläuft und fast bis zum Ende der distalen Epiphyse zu verfolgen ist. Vor der Crista interossea und oberhalb der Diaphysenmitte ist die Facies lat. tibiae beim Weibe geringer, beim Nanne stark ausgehölt. Tnterhalb der Diaphysenmitte ist die Facies lat. leicht konvex. Die Facies medialis ist keim $s$ leicht konvex oder (bei $\mathrm{Nr}$. 5) eben. Beim Manne (Nr. 3 und 4) befindet sich unterhalb der Diaphysenmitte dicht vor der medialen Kante beiderseits cine $40,0 \mathrm{~mm}$ lange und $5,0 \mathrm{~mm}$ breite Vertiefung.

Fossa intereondylica anterior et posterior und Linea poplitea sind gut aus. geprägt.

Von der Seite betrachtet findet man, daB die hintere Fläche der Tibia dex ganzen Länge nach leicht kunkav ist. Die distale Schienbeinhälfte verläuft gerade, wïhrend die proximale leicht nach hinten gewandt, retroflekticrt ist. Die Crista tibiae anterior ist zumeist scharfkantig. Der Retroversionswinkel ist beim Weibe

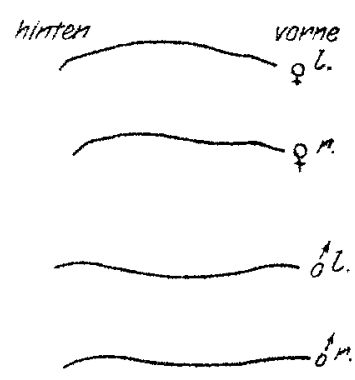
viel größer als beim Mann, was auch schon bei Betrachtung von der Seite hervorgeht. Er beträgt beim Weibe $23^{\circ} 2^{\prime}$, beim Mam (Nr. 3 und 4 ) $11^{\circ} \overline{5}^{\prime}$, ist also bei letzterem um die Hälfte kleiner. Der aus fünf Zahlen gewonnene mittlere Retroversionswinkel beträgt $17^{\circ} 7^{\prime}$.

Für den Inlilinationswinkel ergibt sich $18^{\circ} 5^{\prime}$ beim Weibe, $7^{3} 7^{\prime}$ beim Manne (Nr. 3 und 4). Das aus fünf Zahlen gewonnene Mittel beträgt $13^{\circ} 2^{\prime}$; mittlerer biaxialer Winkel $4^{\circ}, 5^{\prime}$. Retroversionswinkel und Inklinationswinkel sind also größer als beim rezenten Europäer und zusammen mit der proximalen Retroflexion als altertümliche Befunde zu betrachten.

Die Gelenkflüche des Condylus lateralis ist beim Manne (Nr. 3 und 4) in sagittaler Richtung deutlich konkav, wie beistehende Abbildungen zeigen. Spannt man in dieser Richtung über dem Mittelpunkt der Facies artioul. lat. einen Faden aus und sucht mit einem vertikalen Stäbchen die tiefste Stellung der Krümmung auf, so crgeben sich linsk für die Krünmung 2 , , , rechts $2,0 \mathrm{~mm}$ bei ciner Sehnenlänge von 41,5 bzw. $39,5 \mathrm{~mm}$. Beim Weibe dagegen ist die laterale Gelenkfläche leicht konvex und bei Nr. 5, wo ein eingetrockneter Knorpelüberzug vorhanden ist, elsen.

Beim Weibe ist der Condylus med. mit seiner Facies art. stark nach hinten, medial und abwärts geneigt, so dab er viel tiefer liegt als der Condylus lat. Legt man die Tibia mit ihrer vorderen Fläche auf das Meßbrett, so da B ihre Längsachse mit der Längsrichtung des Brettes zusammenfällt und das Querbrett die höchste Stelle der Eminentia intercondylica berührt, so ist der Mittelpunkt des hinteren Randes des Condylus med. von der Kante des Querbrettes entfernt:

\begin{tabular}{|c|c|c|c|c|c|}
\hline \multirow{3}{*}{ Win don } & \multicolumn{2}{|c|}{$\underline{0}$} & \multicolumn{2}{|r|}{2} & \multirow[b]{2}{*}{ links } \\
\hline & $\begin{array}{l}\text { links } \\
18.0\end{array}$ & $\begin{array}{l}\text { rechts } \\
17\end{array}$ & links & $\begin{array}{c}\text { reents } \\
110\end{array}$ & \\
\hline & 13,5 & 13,0 & 10,0 & 10,0 & $10,0 \mathrm{~mm}$ \\
\hline
\end{tabular}


Der Hinterrand der lateralen Gelenkfläche biegt bei allen Tibien nach hinten und abwärts um; beim Mann (Nr. 3 und 4) ist diese auf der Hinterfläche des Condylus lat. liegende Gelenkfacette $10,0 \mathrm{~mm}$ proximo-distal ausgedehnt. Sie liegt medial und oberhalb der Facies articul. fibul. und besitzt eine halbmond. förmige Cestalt. Beim Weib ist diese überhingende mit der Hockfunktion im Zusammenhang stehende Gelenkfacette kleiner.

Am Vorderrande der distalen Tibiaepiphyse ist zur Verbindung mit dem Talus nur in geringem Grade eine Gelenkfacette beim Weibe entwickelt; dabei ist die fibulare Facette etwas größer als die tibiale. Beim Mann ist nur die fibulare Facette ausgebildet. Sie ist $9,0 \mathrm{~mm}$ breit und in der Nitte $3,1 \mathrm{~mm}$ hoch. Der prosimale Abschnitt des Talushalses besitzt beim Weib beiderseits eine kleine, mediane, 4,0 mm breite und lange Gelenkflüche, die nach hinten und aufwärts in die Facies art. sup. übergeht. Dagegen ist eine fibulare Gelenkflüche am Talushalse nur ganz gering ausgeprägt. Ganz ähnlich verhält es sich beim Manne.

Die Torsion der Tibia beträgt beim Weibe im Mittel $12^{\circ}$, beim Manne $14^{\circ} 2^{\prime}$. Bei Nr. 5 ist dagegen der Torsionswinkel sehr groß $\left(35^{\circ}\right)$; der Condylus med. erscheint weit nach hinten und innen gedreht. Die Tuberositas tibiac ist dabei in allen Fallen in der Sagittalebene genau nach rorn gerichtet.

\section{Fibula.}

\section{Untersuchtes Material.}

1. Linke und rechte Fibula einer 25 jährigen an Phthise verstorbenen Chinesin (Präpariersaalleiche).

2. Linke und rechte Fibula eines 30 jährigen an Gangrän verstorbenen Chinesen (Präpariersaalleiche).

3. Linke Fibula, vermutlich eines Mannes, der infolge Fußgelenkstuberkulose operiert wurde. Fibula hochgradig porös und daher sehr leicht.

\section{Fibula.}

Wake:

1. Gröbte Länge der Fibula ....... .

2. Gröbter Durchmesser der Mitte. . . .

3. Fleinster Durchmesser der Mitte . .

4. Umfang der Mitte . . . . . . . . . .

4a. Kleinster CTmfang . . . . . . . . .

Intices:

Index des Diaphysenquerschnites der Mitto

Längendickenindex . . . . . . . . . . .

Robustizitatsindex (aus dern Durchmesser)

Robustizitatsindex (aus dem Umfans der

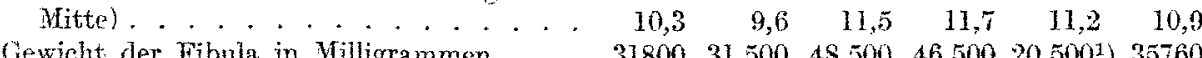

Die Diaphyse besitzt beim Weibe (Nr. 1 und 2) beiderseits drei ziemlich ausgeprägte Kanten, denen drei Flächen entsprechen, eine laterale, mediale und hintere. Die schärfste, zum Ursprung des M. ext. dig. longus dienende Kante

1) Sehr porös, 
ist nach vorn gewandt. Sie beginnt ca. $48,0 \mathrm{~mm}$ unterhalb des proximalen Endes des Capitulum fibulae und ist anfangs niedrig, wird aber raseh höher und verläuft als scharfe Leiste fast gerade nach abwärts, sich vier Finger breit oberhalb der Spitze des Malleolus lat. in einen lat. und med. Gabelast teilend, die eine leicht. konkave, etwas nach lateral sehende Fläche zwischen sich fassen. Beim Mann zeigt die Crista anterior dasselbe Verhalten, nur entwickelt sie sich hier erst am Beginn des mittleren Drittels der Diaphyse. Am stärksten ist sie im proximalen Abschnitt der Diaphysenhälfte entfaltet.

Die laterale Kante der 1. Fibula des Weibes heginnt zwei Finger breit unter dem Capitulum fibulae; sie ist in der unteren Hälfte des proximalen Drittels rauh und mit einer hinter ihr liegenden, gleichfalls rauhen, $40,0 \mathrm{~mm}$ langen und $3,0 \mathrm{~mm}$ breiten Rinne versehen. Im mittleren Drittel der Fibula ist die laterale Kante stumpf und geht vom unteren Drittel ab auf die hintere Flache über, etwas oberhalb des Malleolus lat. sich verlierend. Das proximale und distale Drittel der lateralen Kante sind verhältmismäßig am schärfsten. An der rechten Fibula des Weibes liegt unmittelbar vor dem proximalen Drittel der lateralen Kante eine ca. $65,0 \mathrm{~mm}$ lange, rauhe Knochenstelle für den Ursprung des $\mathbf{M}$. peronaeus longus. Beim Manne beginnt die laterale Kante sehon am untersten lat. Teil des Capitulum fibulae, verläuft stumpf im proximalen Drittel abwärto, rundet sich im mittleren Diaphysendrittel sehr $a b$, so daß die laterale Fläche der Fibula ohne Kante in die hintere übergeht, wird im distalen Drittel wieder höher und ist am schärfsten in der unteren Hälfte des distalen Drittels ausgeprägt. Sie verschwindet unmittelbar oberhalb der hinteren Fläche des Malleolus lat. Auf der hinteren Fläche der Fibula befindet sich medial von der proximalen Halfte der lateralen Kante eine 125,0 mm lange und 2,0-3,0 $\mathrm{mm}$ breite, rauhe Stelle für den M. peronaeus longus. Auf der linken Seite ist die laterale Kante beim Mann in den oberen Zweidritteln wenig ausgeprägt, desgleichen die Ur. sprungsstelle für den letztgenannten Muskel.

Die mediale Kante ist beim Weib ca. $195,0 \mathrm{~mm}$ lang; sie beginnt unmittelbar unter dem Capitulum fibulae, hier mit dem proximalen Teil der Crista interossea zusammenflieBend. Im proximalen Drittel ist die med. Kante niedrig und wird erst in mittleren Drittel etwas höher. Am Beginn des distalen Drittels wendet sie sich nach rom und schlieBt sich der hier niedrig werdenden Crista interossea an. Beim Mann ist rechts die mediale Kante im proximalen Drittel ziemlich flach und begrenzt von hinten her eine tiefe Konkavität für den Ursprung des $M$. tibialis posticus. Im mittleren Drittel ist die mediale Kante scharf, die hintere Grenze für die Ursprungsvertiefung des M. flexor hallucis longus bildend. Etwa von der Mitte der medialen Kante erstreckt sich eine Leiste schief nach aufwärts und vorn, hier in die Crista interossea übergehend and die beiden rinnenförmig vurtieften Ursprungsfelder des M. tib. post. und M. fl. hall. longus voneinander trennend. Vom Beginne des distalen Drittels ab wendet sich die mediale Kante nach vom und verschmilzt mit der weit distal reichenden Crista interossea. Auf der linken Seite ist beim Manne die mediale Kante nur auf das mittlere Drittel der Fibula beschränkt, hier aber stark ausgeprägt. Das untere Ende der Kante wendet sich gleichfalls nach vorn, um mit der Crista interossea zu verschmelzen.

In allen Fällen ist als vierte Kante eine Crista interossea entwickelt. Beim 
Weibe verläut sie medial ron der vorderen Kante und parallel mit ihr. Sie beginnt schon anmittelbar anter dem Capitulum und ist in der unteren Hälfte dos proximalen Drittels sehr schart. Im mittleren Drittel der Fibula trennt sie die mediale Fläche derselben in oinc vordere und hintere. Vom Beginn des unteren Drittels ab wird die Crista interossea flach und verschwindet einige Zentimeter oberhalb der Syndesmisis tibio-fibularis. Beim Manne ist die Crista interossea schärfer ausgeprägt. Etwas unterhalb des Capitulum fibulae beginnend, wird site im proximalen Drittel kehr scharf; sie bleibt aber anch im mittleren und distalen Drittel eine scharfe Kante, die im mittleren Teil der Fibula die mediale Fabhe derselben in eine vordere and hintere rimnenartige Fäche zerlegt. Etwas oberhalb der distalen Celenkverbindung verliert sich die Crista interossea Die Fibula Nr. 5 ist ebenfall, dreikantig; besonders scharf ist die Crista anterior; im übrigen ist sie periostitisch verändert.

An der medialen Seite des Halleol. Wat. bufindet sich eine dreiseitig begrenzte, proximo-distal leicht konvext Gelentfluche für den Talus. Unterhalb und hinter derselben ist in allen Fällen eine ticfe Bandgrube. Lat. von letzterer liegt der beim Mann stärker als beim Weibe ausgeprägte Sulcus malleolaris für die Peronaeussehne. Sehr stark ist diese Rinne bei Nr. 5 ausgebildet. Beim Manue (Nr. 3 und 4) findet sich am vorderen oberen Winkel der Facies articularis malleol. eine kleine Gelenkfläche, die einer am lat. vorderen 'Teil der distalen Tibiatepiphyse liegenden Gelenkfläche entspricht. Beide Gelenkfacetten sind halbmondförmig, und diejenige der Tibia ist $10 \mathrm{~mm}$ lang (von, vorn nach hinten gemessen) und an ihrer höchsten Stelle $4,0 \mathrm{~mm}$ hoch. Beim Weibe sind diese Facetten wur gering ausgeprägt. Häufig finden sich dieselben bei Negern und Australiern. Die Spitze des Malleolus lat. ragt beim Manne $n$ m $7,0 \mathrm{~mm}$, heim Weibe um $10,0 \mathrm{~mm}$ weiter nach abwärts als die des Malleolus med. Die proximale Epiphyse ist annähernd viereckig, die Facies art. in allen Fullen leicht konkay. Apex capituli klein.

Die größte Länge der Fibula schwankt zwischen 309 und $356 \mathrm{~mm}$, beim Weibe 310 , beim Manne $349,3 \mathrm{~mm}$ betragend (Differenz $39.3 \mathrm{~mm}$ ). In allen Fallen ist die größte Länge der Tibia bedeutender als die der Fibula und zwar um 7,5 bis 14,0 mm. Der gröpte, im Wittel 12,4 mm betragende Dhmhmesser sehwankt zwischen 10,4 und $14,0 \mathrm{~mm}$, während sich für den kleinsten Durchmesser 8-11,2 (im Mittel 9,8) mm ergeben. Der Diaphysenguerschnittsindex schwankt zwischen zwischen 74,1 und 85,4 (Yittel 78,6). Der Crmfang der Witte hat ein Mittel von 36,4, der kleinste Umfang von $30,5 \mathrm{~mm}$. Der Längendickenindex beträgt 8,5 bi 9,7 (Wittel 9,1 ), der aus dem größten und kleinsten Durchmesser der Mitte und der größten Länge berechnete Massigkeitzindex 6,6. Berechnet man den Massigkeitsindex aus dem Umfang der Mitte und der größten Länge, so ergeben sich zwischen 9,6 und 11,7 schwankende Zahlen (Mittel 10,9). Das letztere ist also am ein geringes größer als bei Feuerländern $(10,7)$.

Die Fibula des Weibes Ferlauft ganz gerade, einen infantilen und primitiven Typus repräsentierend, wie er sich auch bei Weddas, Feuerländern und Senois findet. Die des Mannes (Nr. 3 und 4) ist dagegen ganz leicht nach hinten konvex gekrümmt und noch etwas stärker diejenige von Nr. 5 .

Betrachtet man die Unterschenkelknochen yon der Seite, so sieht man, 
daB beim Weib die Fibula in gerader Pichtung von hinten oben nach vorn unten verläuft unter spitzwinkliger Kreuzung der Längsachse der Tibia. Beim Manne (Nr. 3 und 4) ist diese Kreuzung beider Knochen noch viel stärker ausgesprochen (Klaatschs mongoloider Typus). Am geringsten ist dieser spitze Winkel bei $\mathrm{Nr} .5$, wo auch die Fibula den fortgeschrittensten (am stärksten konkav nach vorn gekrümmten) Zustand aufweist.

Das Spatium interosseum ist beim Mann (Nr. 3 und 4) weit; die breiteste Stelle mißt $24,0 \mathrm{~mm}$, während sie beim Weib nur $11,0 \mathrm{~mm}$ betrügt.

\section{Fußskelett.}

\section{Untersuchtes Material.}

1. Linkes und rechtes, vollständig erhaltenes Fußskelett einer 25 jührigen an Phthise verstorbenen Chinesin (Präpariersaalleiche).

2. Linkes und rechtes, vollständig erhaltenes Fubskelett eines 30 jährigen an Gangraena pedum verstorbenen Chinesen (Präpariersaalleiche).

T'ulus.

Waße:

1. Länge des Talu

1a. Größte Länge des Talus

1b. Ganze Länge des Talus. . . . . . . . . . .

2. Breite des Talus . . . . . . . . . . . .

2a. Getadinige Entfernung der unteren Spitze der Facies mall. lat. vom Tub. med. proc. tali. post.

2b. GröBte Breite der 3 Gelenkflächen der Trochlea. .

3. Höhe des Talus. . . . . . . . . . . . .

3a. Projekt. Entfernung des höchsten Punktes des med. Randes der Fac. art. sup. von dem am meisten rorstehenden Punkt des Caput unten . . . . . . .

3b. . . . . . . . . . . . . .

4. Länge der Trochlea tali. . . . . . . . . . .

5. Breite der Trochlea tali. . . . . . . . . . . . . .

5. (1) Hintere Trocbleabreite . . . . . . . . . . . .

5. (2) Vordere Troehleabreite . . . . . . . . . . . .

6. Höhe der Trochlea . . . . . . . . . . . .

7. Canze Breite der Facies art. mall. lat. . . . . . .

7a. Projekt. Breite der Facies art. mall. lat. . . . . .
s. Lange des Collum und Caput tali. . . . . . . .

9. Länge des Caput tali. . . . . . . . . . . . . .

10. Breite des Caput tali. . . . . . . . . . . . .

11. Höhe des Caput tali. . . . . . . . . . . . . . .

12. Länge der Facies art. calcanea pasterior. . . . . .

13. GröBte Breite der Facies art. caleanea posterior . . .

13a. Breite in der Mitte der Länge gemessen . . . . .

14. Tiefe der Facies art. calcanea posterior . . . . . .

15. Ablenkungswinkel der Facies art. calcenea post. . .

16. Ablenkungswinkel des Collum tali. . . . . . . . .

17. Torsionswinkel des Caput . . . . . . . . . . . .

17a. Winkel, den die mittlere Längskurve der Facies art. nav. mit der Horizontalebene bildet, auf welcher der Talus in normaler Lage aufliegt, , . . . . . .

\begin{tabular}{|c|c|c|c|c|}
\hline \multicolumn{2}{|c|}{ 오 } & \multicolumn{2}{|c|}{8} & \multirow{2}{*}{ Mittel } \\
\hline$n k s$ & reehts & links & rechits & \\
\hline 46,5 & 47,0 & 32,0 & 53,0 & 49,6 \\
\hline 49,0 & 49,1 & 55,0 & 54,9 & 52,0 \\
\hline 46,0 & 46,0 & 51,0 & 52,0 & 48,7 \\
\hline 35,5 & 35,5 & 39,9 & 39,0 & 37,5 \\
\hline 35,0 & $3+0$ & 39,5 & 38,0 & 36,6 \\
\hline 40,0 & 40,0 & 43,0 & 42,5 & 41,4 \\
\hline 29,0 & 29,0 & 28,5 & 29,0 & 28,9 \\
\hline
\end{tabular}

$\begin{array}{lllll}29,0 & 29,0 & 29,5 & 30,2 & 29,4\end{array}$

$\begin{array}{lllll}25,0) & 24,0 & 22,5 & 23,5 & 23,7\end{array}$

$30,0 \quad 29,5 \quad 32,5 \quad 32,0 \quad 31,0$

$25,0 \quad 25,0 \quad 29,0 \quad 29,0 \quad 27,0$

$20,0 \quad 19,0 \quad 24,9 \quad 25,0 \quad 22,0$

$26,0 \quad 27,0 \quad 29,5 \quad 30,0 \quad 28,1$

$\begin{array}{rrrrr}9,0 & 9,0 & 6,0 & 6,0 & 7,5\end{array}$

$\begin{array}{lllll}23,5 & 23,5 & 20,0 & 19,9 & 21,7\end{array}$

$23,0 \quad 23,0 \quad 19,0 \quad 19,0 \quad 21,0$

$\begin{array}{lllll}18,5 & 18,5 & 25,1 & 25,5 & 21,9\end{array}$

$28,0 \quad 28,0 \quad 33,0 \quad 32,0 \quad 30,2$

$\begin{array}{lllll}19,0 & 19,3 & 24,3 & 24,0 & 21,7\end{array}$

$\begin{array}{lllll}8,5 & 9,0 & 10,0 & 10,0 & 9,4\end{array}$

$28,2 \quad 28,0 \quad 30,5 \quad 31,0 \quad 29,4$

$19,0 \quad 18,6 \quad 22,5 \quad 22,0 \quad 20,5$

$\begin{array}{lllll}18,0 & 18,0 & 21,0 & 21,0 & 19,5\end{array}$

$\begin{array}{lllll}5.5 & 5.2 & 6.8 & 6,1 & 5,9\end{array}$

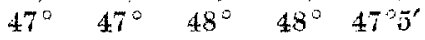

$20^{\circ} \quad 23^{\circ} \quad 21^{\circ} \quad 21^{\circ} \quad 21^{\circ} 2^{\prime}$

$49^{\circ} \quad 44^{\circ} \quad 51^{\circ} \quad 51^{\circ} \quad 48^{\circ} 7^{\prime}$

$44^{\circ} \quad 42^{\circ} 5^{\prime} \quad 45^{\circ} 5^{\prime} \quad 47^{\circ} \quad 44^{\circ} 7^{\prime}$ 


\section{Indices:}

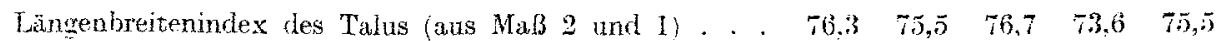

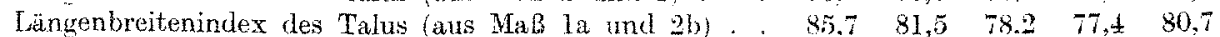

Längenhöhenindex (aus Maß 3 und 1 ) . . . . . . . . $62.6 \quad 61,7 \quad 54,8 \quad 54,7 \quad 58,4$

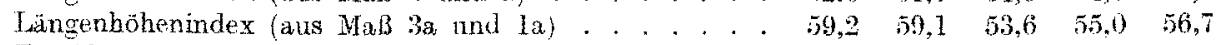

Trochleabreitenindex . . . . . . . . . . . . . . . . $76 \begin{array}{lllll}76,9 & 70,4 & 81,3 & 83,3 & 77,9\end{array}$

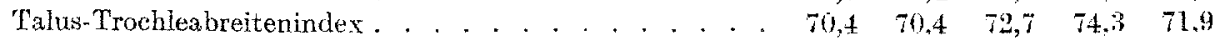

Trochleaindex (Längenbreitenindex)

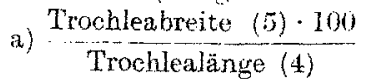
$83,3 \quad 84,7 \quad 89,2 \quad 90,6 \quad 86,9$

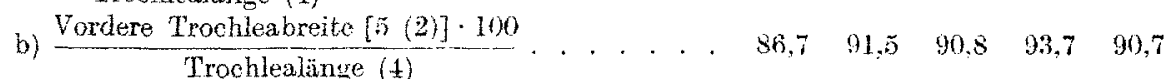

Wolbungsindex der Trocblea (Lüngenhöhenindex).

Indices zur Charakterisierung der Breitenentwicklangr dor Facies art. mall. lat.
a) Ganze Breite d. Facies art. mall. lat. (7) $\cdot 100$
Talusbreite (2)
b) Projekt. Breite der Facies art. mall. lat. (7a) 100
$67.4 \quad 66,4 \quad 73,8 \quad 70,9 \quad 69,6$
$\begin{array}{lllll}19,5 & 18,6 & 22.8 & 19.7 & 20,0\end{array}$
Collumtahisindex . . . . . . . . . . .
$39,3 \quad 39,4 \quad 48.3 \quad 48.4 \quad 43.9$
raputindices:
a) $\frac{\text { Breite des Caput tali }(10) \cdot 100}{\text { Länge des Caput tali }(9)}$
b) $\frac{\text { Länge des Caput tali (9) } \cdot 100}{\text { Talusiange (1) }}$.
$67,8 \quad 69,6 \quad 73,6 \quad 75,0 \quad 71,5$
c) $\frac{\text { Hohe des Caput tali (11) } 100}{\text { Länge des Caput tali }(9)}$
$60.2 \quad 50,6 \quad 63.3 .5 \quad 60.4 \quad 60.9$
$30,3 \quad 32.1 \quad 30,3 \quad 31.2 \quad 30,0$

Die Länge des Talus, d. h. die projektivische Entfernung des Sulcus m. fl. hall. longi vom entferntesten Punkt der Facies art. nav. schwankt zwischen 46,5 und $53,0 \mathrm{~mm}$ und besitzt ein Mittel ron $49,6 \mathrm{~mm}$. Der Talus des Mannes ist im Nittel um $5,8 \mathrm{~mm}$ länger als der des Weibes. Die Breite des Talus beträgt beim Weibe $35,5 \mathrm{~mm}$, beim Manne $39,4 \mathrm{~mm}$ (Differenz 3,9 , Nittel $37,5 \mathrm{~mm}$ ). Im Mittel ist der Talus um 12,1 mm länger als breit. Der Längenbreitenindex des Talus schwankt zwischen 73,6 und 76,7 (Mittel 75,5). Er fält also ganz in die Variationsbreite des rezenten Menschen, jedoch ist der Talus im Verhältnis zu seiner Breite länger als beim Europäer, für den ein Längenbreitenindex von ca. 80 angegeben wird. Die größere Länge beruht hauptsächlich auf dem proximo-distal ausgedehnteren Hals. Berechnet man mit Volkov den Längenbreitenindex aus dem Maß $1 a$ und $2 b$, der größten Länge und der größten Breite, so ergibt sich ein Mittel von 80,7. Bedeutend breiter ist der Talus bei Spy und La Quina (87,3 und 92,1). Reiht man den erstgenannten Längenbreitenindex in die Rassentabelle ein, so kommt er noch vor den der Birmanen (77,8, Poniatonoki). Der aus dor größten Länge und Breite berechnete Index $(80,7)$ reiht den Talus des Chinesen zwischen den des Japaners $(77,2)$ und der Negritos $(84,7)$ ein.

Im Mittel ist der Talus $28,9 \mathrm{~mm}$ hoch. Der Längenhöhenindex des Talus schwanht zwischen 54,7 und 62,6 (Mittel 58,4). Der Längenhöhenindex weist 
eine sehr deutliche sexuelle Differenz auf. Beim Weibe beträgt er 62,1 , beim Nanne 54,7 (Differenz 7,4); demgemäß ist der Talus des letzteren langyestreckt und niedrig. Berechnet man den Längenhöhenindex aus den Maßen 3 a und $1 \mathrm{a}$, $s 0$ ergeben sich $z$ wischen 53,6 und 59,2 schwankende Zahlen mit einem Wittel ron $\mathbf{5 6}, \vec{i}$, das nicht ganz den Längenhöhenindex des Japaners (57.3) erreicht. Auch an diesen Zahien fällt die sexuelle Differenz auf. Die Abflachung des Talus des Mamnes ergibt sich besonders bei Betrachtung von der medialen Seite, indem sich der mediale Rand der Trochlea tali im Verhältnis zu dem des Weibes nux gering konvex erweist. Ein gesondertes $O$ s trigonum fehlt überall. Die Trochlea tali besitzt verschiedene, von der des Europäers etwas abweichende Eigenschaften. Die eben erwähnte Abflachung des Talus des Mannes ist hauptkächlich auf die geringere Konvexität der Trochlea in sagittaler Richtung zurückzuführen. Beim Weibe ist dieselbe stärker als beim Nanne und beim Europäer. Es nähert sich daher die Trochleawölbung beim Weibe den Verhältnissen bei Japanern und Australiern, bei denen einer größeren Konvexität auch eine größere Beweglichkeit entspricht. In allen 4 Fällen zeigt ferner die Trochlea eine stärker" rinnenförmige Vertiefung in sagittaler Richtung als beim Europäer. Beim Weibe steht der fibulare Rand der Trochlea höher als der tibiale, während für den Mamn das Umgekehrte gilt. Die Längsachse der Trochlea und diejenige des Talushalses bilden einen stumpfen, medialwärtis offenen Winkel. In allen 4 Füllen ist die Trochlea nach hinten stark verschmülert, besonders beim Weib. Die Seitenränder der Trochlea sind ziemlich scharf. Nur die hintere, Hülfte des lateralen Seitenrandes geht abgerundet in die fibulare Gelenkfliche über. Die mediale, ler Trochlea angehörige Gelenkfläche greift zungenförmig auf den medialen und proxinalen Teil des Halses über. Die Facies art. mall. med. ist beim Weibe in proximodistaler Pichtung ausgesprochen konkax, während sie beim Manne mehr aben ist. Die Facies mall. lat. ist in dorso-plantarer Richtung konkav, proximo-distal konvex, und zwar beim Weibe stärker als beim Mann. Dic untere Spitze des Processus lat. sieht etwas mehr nach auswärts als beim Europätr. Vor der Trochlea befindet sich auf dem Collum beim Weibe eine tiefere, beim Manne eine flachere und größere Grube. Vor dieser liegt gegen den fibularen Collumrand zu beim Manne eine breitere, beim Weibe eine schmälere quergerichtete Gelenkfacette (ca. $8 \mathrm{~mm}$ breit and $5 \mathrm{~mm}$ lang), die mit dem vorderen unteren Tibialrand artikuliert.

Der von der Längsachse der Facies art. post. und der sagittalen Achse des ganzen Talus gebildete Ablenkungsuinkel schwankt zwischen 47 und $48^{\circ}$ (Mittel $\left.47^{\circ} \tilde{5}^{\prime}\right)$. Derselbe ist also etwas kleiner als bei Tibetanem $\left(48^{\circ} 6^{\prime}\right)$, wahrend er beim Europäer noch kleiner ist $\left(39^{\circ} 6^{\prime}\right)$. Die Facies art. post. ist $28-31 \mathrm{~mm}$ lang (Mittel 29,4) und im Mittel $20,5 \mathrm{~mm}$ breit. Der zwischen 66,4 und 73,8 schwankende Lüngenbreitenindex besitzt ein Mittel von 69,6 , ist also so groß wie beim Europäer (69 und 70). Beim Australier dagegen ist die Breite eine geringere. Die Facies art. post, zeigt gegenüber der des Deutschen lateral und vorn bei beiden Geschlechtern, besonders aber beim Manne, eine Verschmälerung, so daß bei diesem die Gelenkfläche annähernd Birnform erhält. Der mediale hintere Abschnitt des Facies art. calc. post. zeigt besonders beim Manne einen stark ausgeprïgten Processus tali posterior lat. Der lat, vordere Abschnitt 
der Facies art, calc, post. geht in eine frontal gestellte, ziemlich große, halbunonförmige Gelenkfläche über, die nach medial einen langen, queren Facettenstreifen entsendet. Beide Facetten sind gelenkig hinter dem lat. Abschnitt des Sinis tarsi mit dom distalen dorsalen Teil des Calcaneus verbunden. Beim Europäer fincle ich diese beiden frontalen Facetten nur angedeutet.

Die Facies art. med. ist beim Manne 22, beim Weibe $16 \mathrm{~mm}$ lang und bei heirlen $6.10,0 \mathrm{~mm}$ breit. Beim Deutschen zeigt sich diese Celenkflache viel länger
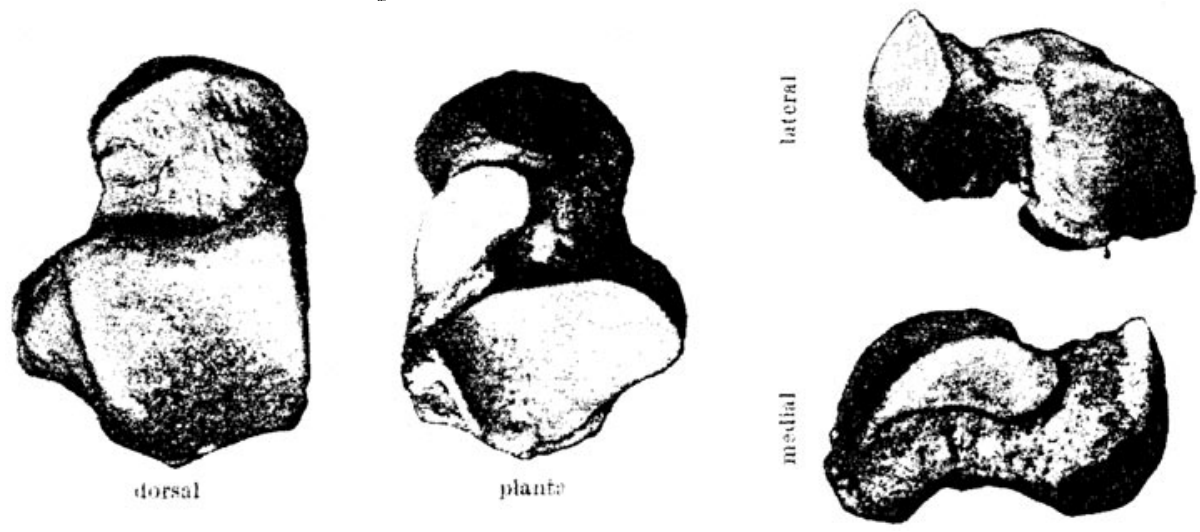

Abb. i. Linkm Talns eines 30 juluigen Chinesen.

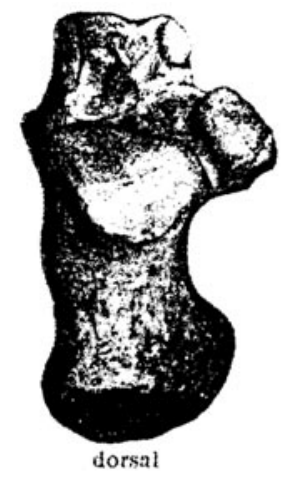

vines 30 juhrigon

Clinesen

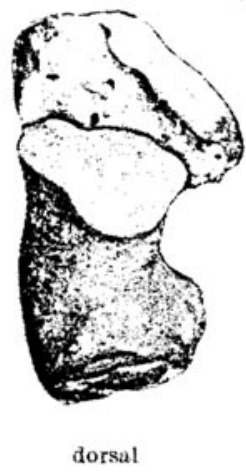

Abb. 8. Links. Calcaneus (ines Teutsebun

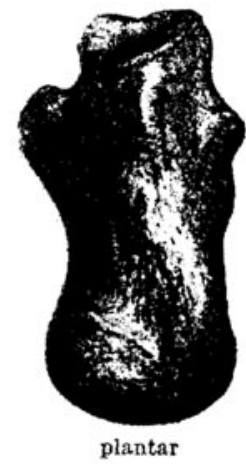

eines 30 juhrigen

Chinesen

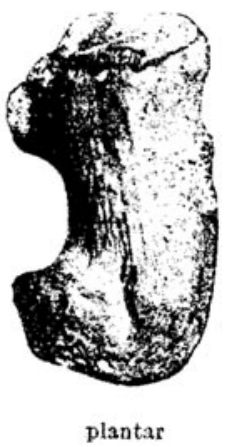

anes Deutschert.

und im Verhältnis zur Länge schmaler. Bæim Manns ist diese Gelenkfläche annähernd bohnenförmig, in ihrer proximalen Hälfte dentlich konkav, in ihrer distalen eben oder ganz leiht konvex. Bein Weibe ist diese, ein kurzes Oval bildende Fläche leicht konvex. Im medialen vorderen Abschnitt geht die Facies art. med. in die Facies art. navicul. über, während beim Deutschen sich eine Trennung dieser beiden Gelenkflächen durch eine breite, rauhe Rinne findet.

Die Länge des Talushalses (MaB S) schwankt zwischen 18,5 and 25,5 mm (im Mittel 21,9). Er ist beim Manne etwas länger als beim Europäter und betrügt 
$39,4 \%$ der ganzen Taluslänge. Die Ablenkung des Talushalses nach medial beträgt im Nittel $21^{\circ} 2^{\prime}$, ist also so groß wie beim Tibetaner $\left(21^{\circ} 1^{\prime}\right.$ nach Poniatowski). Auch an deutschen Füßen finde ich einen ähnlichen großen Ablenkungswinkel, der jedenfalls nichts Primitives besitzt, während er beim Australier 25 und beim Orang $30^{\circ}$ beträgt und hier mit der Greiffußbildung im Zusammenhang steht.

Der Torsionswinkel des Caput tali beträgt im Mittel $48^{\circ} 7^{\prime}$, beim Japaner $48^{\circ} 3^{\prime}$; er ist also gröBer als beim Furopäer $\left(43^{\circ} 3^{\prime}\right.$ nach Atachi) und hat sich weit rom dusgangspunkt entfernt.

Der Torsionswinkel 17 (a) sehwankt zwischen $42^{\circ} 5^{\prime}$ und $47^{\circ}$ und besitzt cin Nittel von $44^{\prime} 7^{\prime}$. Für den Europäer gibt ihn Volkow zu $40^{\circ}$ an.

Wripe:

1. Cirobte Lainge hes Calcanens

1a. Canze Lange des Calcanens

2. Mittlere Breite des Calcaneus . . . . . . .

3. Kleinste Breite des Corpus calcanei. . . .

t. Höhe des Calcanens . . . . . . . . .

5. Länge des Corpus caleanei . . . . . .

6. Breite des Sustentaculum tali. . . . . .

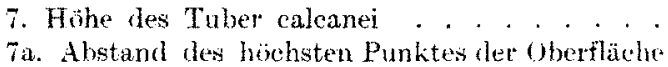
des Tuber rom entsprechenden Punkt der Enterfliache . . . . . . . .

8. Breite des Tuber caleanei . . . . . . .

8a. Breite in Niveau der beilen Processus tub. calc. . . . . . . . . . . . .

9. Länge der Facies art post. calc. . . . . . .

11. Breite der Facies art. post. cale. . . . . . .

11. Höhe der Facies art. post. calc. . . . . . .

12. Crößte Breite der Facies articul. cuboidea. .

13. Höhe der Facies art. cuboidea . . . . . . .

14. Ablenkungswinkel der Facies articul. post. ealcanei . . . . . . . . .

15. Talocalcaneuswinkel .

Indices:

Längenbreitenindex:
a) $\frac{\text { Mittlere Breite des Cale. (2) } 100}{\text { gröBte Länge des Calcaneus (1) }}$
b) $\frac{\text { Kleinste Breite des Corpus cale. (3) } 100}{\text { GröBte Länge des Calcaneus (1) }}$

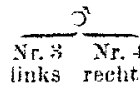

links rechts rochits

links revits

$69,0) \quad 68.13$

$63,0 \quad 63,0$

$37.3 \quad 37.0$

$21,5 \quad 21,9$

$32.1 \quad 32,1)$

$48,6 \quad 47,0$

$11,011,0$

$38,5 \quad 38.7$

$36,2,35.1$

$24,8 \quad 23,7$

$25,5 \quad 25,0$

$26,0 \quad 26,0$

$19.5 \quad 19.0$

$5,0 \quad 5,0$

$22,5 \quad 23,5$

$15,5 \quad 15,1)$

$43^{\circ} 45^{\circ}$

$-4^{\circ}-2^{\circ}$

3 :
54,0

54.0

54,0

$34.44 .4 \quad 38.5 \quad 29.6$

$30,1 \quad 30,5 \quad 26,2 \quad 27,4$

$28,0 \quad 23,0 \quad 21,0 \quad 21,1$

$\begin{array}{rrrr}6,0 & 6,0 & 5,0 & 5,5\end{array}$

$26,0 \quad 26,0 \quad 22,0 \quad 24.0$

$29,0 \quad 23,0 \quad 20,0 \quad 19,2$

$31,1 \quad 32,2 \quad 30,7 \quad 30,8 \quad 35,3 \quad 32,0$

$34,1 \quad 34,8 \quad 32,7 \quad 32,8 \quad 37,4 \quad 34,4$

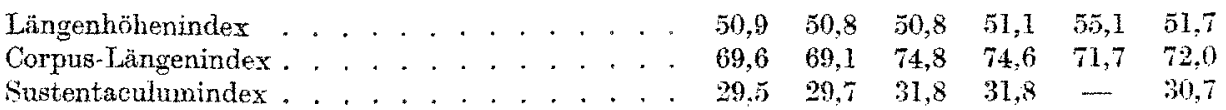

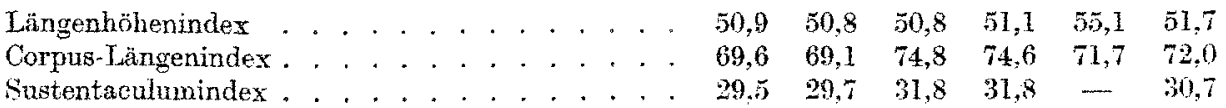

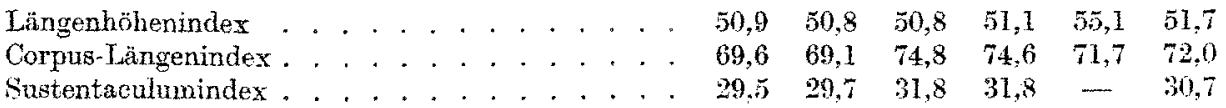

Tuberindices:
a) Breite des Tuber calc. (8) 100
64,4
$61,2 \quad 66,2$
64,4
57,1
62,7
b) $\frac{\text { Höhe des Tuber cale. (7) } \cdot 100}{\text { GröBte Länge des Calcaneus (1) }}$ 
Indices der Facies art. post. calc.:

\begin{tabular}{|c|c|c|c|c|c|}
\hline \multicolumn{2}{|c|}{$\underline{0}$} & \multicolumn{2}{|c|}{$3^{\pi}$} & & \\
\hline $\begin{array}{l}\overline{\Delta r .1} \\
\text { links }\end{array}$ & $\begin{array}{l}\text { NF. } 2 \\
\text { rechts }\end{array}$ & $\begin{array}{l}\text { Nr. } \\
\text { links }\end{array}$ & $\begin{array}{c}\text { S. } \\
\text { rechts }\end{array}$ & $\begin{array}{l}\text { Nr.s } \\
\text { rechts }\end{array}$ & Mittel \\
\hline 75,0 & 73,3 & 76,4 & 75,4 & 80,1 & 76,0 \\
\hline 21,1 & 19,2 & 19,9 & 19,7 & 19,1 & 19.8 \\
\hline 68,9 & 63,8 & $88, \tilde{5}$ & 88,5 & 90,9 & 80,1 \\
\hline
\end{tabular}
a) Breite der Facies art. post. (10) 100
Länge der Facies art. post. (9)
b) Höhe der Facies art. post. (11) 100
Länge der Facies art. post. (9)
Höhenbreitenindex der Facies art. cuboidea . . .

Die gröBte Länge des Calcaneus schwankt zwischen 68,0 und $81,4 \mathrm{~mm}$ (Mittel 73,5); der des Mannes ist im Durchschintt um 12,7 mm länger als der des Weibes. Die mittlere größte Länge beim Europäer beträgt $80,8 \mathrm{~mm}$. Die mittlere Breite des Calcaneus schwankt zwischen 37,0 und 44,0 mm (Mittel 39,9). Aus der mittleren Breite und grüBten Länge ergibt sich ein Längenbreitenindex von 54,2. Der aus der kleinsten Breite des Corpus calcanei und der ganzen Calcaneuslänge berechnete Längen breitenindex sch wankt $z$ wischen 32,7 und 37,4 (Mittel 34,4 ). Im Mittel ist dieser Index für das $\& \mathbf{3 4 , 4}$, für den Mann 32,7; der Calcaneus ist also bei letzterem etwas länger und schmäler als bei ersterem. Vergleicht man den Calcaneus des chinesischen Mannes mit deutschen Calcanei, so ergibt sich schon bei oberflächlicher Betrachtung, dab letztere kurz und breit, die des Chinesen lang und schmal sind. Kurz ist der Calcaneus Nr. 5, der einen Index von 37,4 besitzt und dem der Tibetaner $(37,6)$ nahe steht. Der lange und schmale Calcaneus des Mannes gehört dem primitiven Typus an.

Die Höhe des Calcaneus schwankt zwischen 32,0 und 38,9 mm (Mittel 35,4). Der aus der Höhe der ganzen Länge des Calcaneus

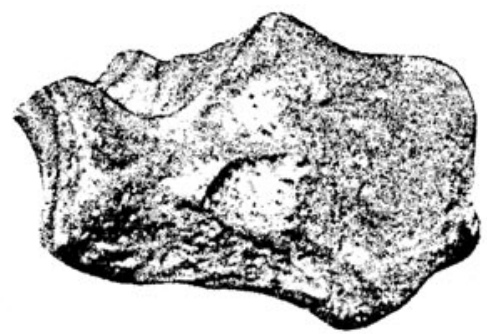
Deutscher

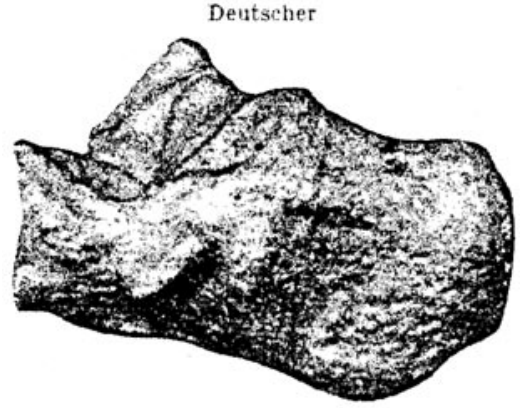

30 jähriger Chinese

Abb. 9. Linker Calcaneus von lateral. berechnete Längenhöhenindex besitzt ein Mittel von 51,7 , ist also so groB wie bei Alemannen. Sieht man jedoch von dem Calcaneus Nr. $5 a b$, der einen auffallend hohen Längenhöhenindex hat, so ergibt sich ein mittlerer Index von 50,9, der zwischen dem der Feuerländer und Tibetaner steht. Der Calcaneus des Chinesen ist also nicht nur länger und schmäler, sondern im allgemeinen auch niedriger als beim Deutschen, was sich ebenfalls schon aus der bloBen Betrachtung ergibt.

Fergleicht man die Länge des Corpus calcanei mit der größten Calcaneus. länge, so ergibt sich ein mittlerer Index von 72 . Beim Manne ist der Calcaneuskörper verhältnismäßig länger $(74,7)$ als beim Weibe $(69,3)$. Die absoluten Zahlen ergeben eine Differenz von $13,2 \mathrm{~mm}$ zugunsten des Mannes.

Das Sustentaculum tali zeigt beim Nanne eine geringere Verkürzung als beim Weibe, so daB sich für ersteren ein Index von 31,8 , für das Weib ein Index von 29,6 ergibt. Der Index des Mannes nähert sich also den Werten bei Tibetanern $(31,7)$ und zeigt in seiner geringeren Reduktion einen primitiven 
Befund. Das Sustentaculum tali ist weiter nach medial ausgeladen als beim Europäer, was nicht nur bei Betrachtung ron der Dorsalseite, sondem besonders von der Plantarseite in die Augen fällt. Von dieser Seite aus sieht man, daß eine von der medialen Ecke der Facies art. cuboidea entlang dem plantaren Rand des Sustentaculum gezogene Linie beim Deutschen mehr der sagittalen, beim Chinesen mehr der transversalen Pichtung zustrebt. Auch ist die mediale Fläche des Substentaculum beim Deutschen mehr vertikal, beim Chinesen mehr horizontal gestellt. Die obere Gelenkfläche des Sustentaculum tali ist beim Manne (Nr. 3 und 4) ein Längsoval (Längsachse 22,0 , Querachse $11,0 \mathrm{~mm}$ ), beim Weibe (Nr. I und 2) mehr kreisförmig (Längsachse 14,1, Querachse 10,5 mm). Bei letzterem ist sie deutlich konkav, ebenso beim Manne, nur zeigt der proximale
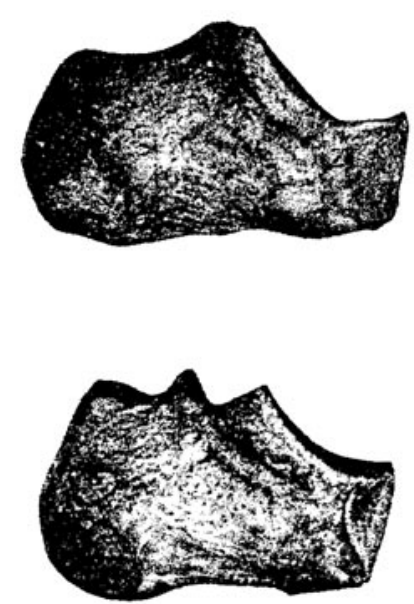

Abb. 10. Oben: L. Calcaneus eines 30 juhrigen Chinesen (medial). Unten: L. Calcaneus eines Deutschen (medial). und mediale Abschnitt der Gelenkfläche bei diesem eine Konvexität. Die Gelenkfläche des Sustentaculum und die ror ihr gelegenen Facies art. ant. sind bei $\mathrm{Nr} .1$ bis 4 vollständig voneinander durch eine tiefe Querrinne getrennt, nur bei Nr. 5 hängen beide Gelenkflächen miteinander zusammen. Die Facies art. ant. ist beim Weibe größer als beim Manne (proximodistaler Durchmesser beim Weibe 11,0, mediolateraler 8,0 , beim Manne 8,0 bzw. $7,0 \mathrm{~mm}$ ). Beim Weibe ist diese Gelenkfläche leicht konvex, beim Manne eben. Die Gelenkfläche auf dem Sustentaculum und die Facies art. ant. bilden beim Chinesen eine größere Konkavität als beim Deutschen. Uberspannt man die Konkavität mit einem Faden und mißt den größten Abstand, so ergeben sich für den Mann 6,2, für das Weib $5,0 \mathrm{~mm}$. Die Rinne für den II. flexor hallucis ist $8,0 \mathrm{~mm}$ breit. Das Sustentaculum tali liegt in derselben Höhe am Calcaneuskörper wie beim Europäer.

Der Index des Tuber ealcanei schwankt zwischen 57,1 und 66,2 (Mittel 62,7), während beim Schweizer das Mittel 65,1 beträgt. Der Processus lat. ist beim Manne stärker entwickelt als beim Weibe, jedoch geringer als beim Europäer. Beim Weibe ist der Processus lat. nur angedeutet. Beim Manne ist die obere Hälfte des Tuber gegen die untere abgeknickt, während sie beim Weibe abgerundet in die letztere übergeht. Die untere Hulfte des Tuber calcanei ist zugleich beim Manne mehr plantarwärts gerichtet als beim Weibe. Distal vom medialen Höcker des Tuber befindet sich beim Europäer eine tiefe Konkavität, die beim Chinesen geringer, bei der Chinesin sehr gering ausgeprägt ist.

Die Facies art. post. calc. ist längsoval. Jedoch ist sie beim Manne und bei Nr. 5 nach medial gegen die sie von der Sustentaculumgelenkfläche trennende Rinne stark ausgezogen, so daß hier die Breite eine bedeutendere wird als distal. So wird bei Nr. 5 der Längenbreitenindex ein sehr großer $(80,1)$, d. h. die Längsachse ist im Verhältnis zur Querachse kurz. Das Mittel aus den 4 übrigen Calcanei ist dagegen geringer $(75,2)$; beim Schweizer beträgt es 76 . Die Facies art. post. ist in sagittaler Richtung viel stärker gewölbt als beim Deutschen, 
so daß der Längenhöhenindex, der für Alemannen und Sehweizer zu 17,2 und 18,6 angegeben wird, zwischen 19,1 und 21,1 schwankt und ein Mittel von 19,8 besitzt. Es nähert sich daher der Längenhöhenindex dem der Birmanen $(20,1)$. Beim Manne besitzt die Facies art. post. in ihrem proximalen Abschnitt noch eine deutliche transversale Konkavität, so daß hier die Sattelgelenkform gut ausgebildet ist. Der größeren Konvexität der Facies calcanei entspricht eine größere Koncaxität des Talus an der entsprechenden Gelenkfläche, was besonders an dem kürzeren Talus des Weibes in die Augen springt. Der stärkeren Krümmung entspricht eine größere Beweglichkeit im unteren Sprunggelenk. Der Ablenkungswinkel der Facies art. post. calc., zwischen 38 und $45^{\circ}$ schwankend, hat ein Mittel von $41^{\circ} 4^{\prime}$ und kommt somit in der Rassentabelle zwischen den der Feuerländer $\left(39^{\circ} 2^{\prime}\right)$ und der Birmanen $\left(44^{\circ} 1^{\prime}\right)$. Beim Europäer ist er größer $\left(47^{\circ} 8^{\prime}\right.$ und $48^{\circ} 4^{\prime}$ ). Die Längsachse der Facies art. post. ist daher weniger von hinten medial nach vorn lateral gerichtet als beim Europäer. Der Ablenkungswinkel am Talus beträgt im Mittel $47^{\circ} 5^{\prime}$, dem der Tibetaner sich nähernd $\left(48^{\circ} 6^{\prime}\right)$. Der aus beiden Winkeln berechnete Talo-calcaneuswinkel ist in allen 4 Fällen negativ, zwischen $-2^{\circ}$ und $-8^{\circ}$ schwankend mit einem Mittel ron $-5^{\circ} 3^{\prime}$. Die Drehung (Rotation) des Calcaneus ist beim Chinesen nicht so weit fortgeschritten als beim Europäer. Während bei den Anthropoiden der Breitendurchmesser der Facies art. cuboidea fast horizontal verläuft, bildet er beim Chinesen mit der Horizontalen einen Winkel von ca. $45-50^{\circ}$, ist also schräg gewandt im Gegensatz zum Europäer, wo er fast senkrecht gestellt ist. Die Gelenkfläche des Fersenbeines mit dem Cuboid ist beim Manne annähernd viereckig mit abgemundeten Ecken; die dorsale Seite ist länger als die plantare, so daß eime Keilform dér Gelenkfläche zustande kommt. Die mediale dorsale Ecke springt weiter vor als an den deutschen Skelet. ten, so daß in der Richtung des Breitendurchmessers der Facies art. cuboidea eine starke Konkavität entsteht, die noch viel stärker beim Weibe ausgeprägt ist und mit den Verhältnissen beim Europäer in einem deutlichen Gegensatz steht. Beim Weib beträgt die größte Tiefe an dieser Stelle 5,0 mm; die mediale und dorsale Ecke ist noch stärker ausgebildet als beim Nann und trägt auf ihrer Dorsalseite die Facies art, ant., die mit ihrer plantaren Flache dachartig weit distalwärts vorspringt, eine Art vorderen Sustentaculums bildend. Beim Weibe ist die Facies art. cuboidea dreieckig, im Verbältnis zur Gelenkfläche des Mannes medial reduziert, was auch durch den Höhenbreitenindex zum Ausdruck kommt (siehe Tabelle). In der Richtung des Höhendurchmessers ist die Facies art. cub. leicht konvex. So findet auch in der Art. calcaneo-cuboidea eine gröbere Beweglichkeit statt als beim. Europäer.

Wie schon beim Talus erwähnt, liegt vor der Facies art. post. eine beim Manne sehr stark ausgeprägte, $14,0 \mathrm{~mm}$ breite und 10, כ $\mathrm{mm}$ lange, vertiefte Gelenkfacette am distalen dorsalen und fibularen Teil des Calcaneus, in die sich die konvexe halbmondförmige, lateral und distal von der Facies art. post. tali gelegene Gelenkfläche legt. Sie ist in allen Fällen vorhanden. An deutschen Skeletten ist sie weniger ausgebildet. Proximal vom unteren Rand der Facies art, cuboidea liegt überall ein Querwulst. Die Tuberachse verläuft von lateral dorsal nach medial plantar. 
Os naviculare.

Mabe:

1. Breite des Os naviculare . . . . . . . . . . . $30,0 \quad 30,0$

2. Höhe des Os naviculare . . . . . . . . . . . . . 21,0 24,5

3. Größte Länge des Facies art. post. . . . . . . . . $23,4 \quad 24.0$

4. Breite des Facies art. post. . . . . . . . . . . $16,8 \quad 17,0$

5. Tiefe des Facies art. post. . . . . . . . . . . $\quad 3,5 \quad 3,5$

6. Crößte Länge der Facies euneiformium . . . . . . $29,0 \quad 28,0$

7. Kleinste Dicke des Os naviculare . . . . . . . . $\quad 8,5 \quad 3.5$

8. Größte Dicke des Os naviculare . . . . . . . . $1 \pm, 0$ 14,0

$\overbrace{1 \text { inks }}^{3} \underbrace{3}_{\text {rechts }}$ Mittel

$40,0 \quad 40,0 \quad 35,0$

$30,5 \quad 31,0 \quad 26,7$

$29,5 \quad 30,1 \quad 26,7$

$25,0 \quad 25,5 \quad 21,1$

$\begin{array}{rrr}7,0 & 7,2 & 5,3\end{array}$

$34,5 \quad 34,2 \quad 31,4$

$\begin{array}{lll}6,9 & 7,0 & 7,7\end{array}$

$19,1 \quad 19,1 \quad 16,5$

\section{Indices:}

Breitenhöhenindex . . . . . . . . . . . . $70,0 \quad 81,6 \quad 76,3 \quad 77,5 \quad 76,3$

Indices der Facies artic. post.
a) Breite der Fabies art. post. (4) 100
b) $\frac{\text { Tiefe der Facies art. post. (5) } 100}{\text { Länge der Facies art. post. (3) }}$
$71,8 \quad 70,8 \quad 84,7 \quad 84,7 \quad 78,0$
c) Länge der Facies art. post. (3) 100
$14,9 \quad 14,6 \quad 23,7 \quad 23,9 \quad 19,3$
$78,0 \quad 80,0 \quad 73,7 \quad 75,2 \quad 76,7$
$96,7 \quad 933,3 \quad 86,2 \quad 85 \% 5 \quad 90,4$ $60,7 \quad 60,7 \quad 36,1 \quad 36,6 \quad 48,5$
Index der Facies art. cuneiformin

Dickenindex
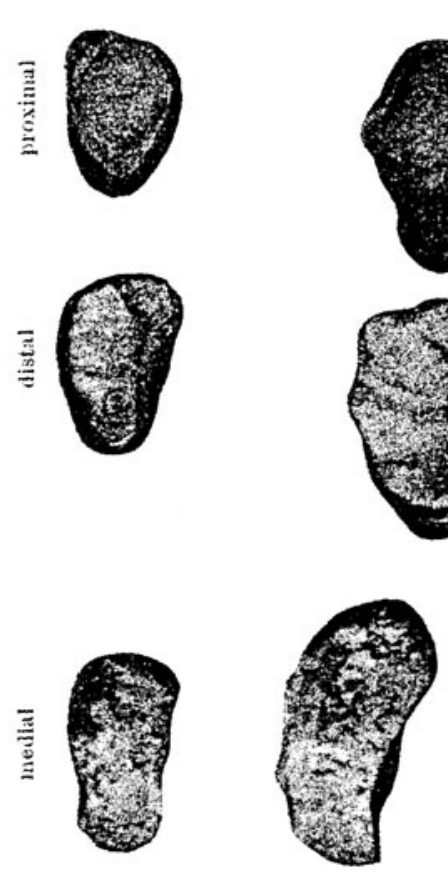

Abb. 11. Naviculare einer 25 juhrigen

Chinesin

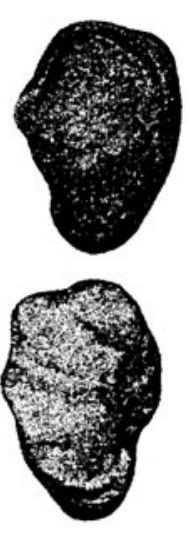

Das Os naviculare besitat im allgemeinen Eiform, die nur beim Mann durch einen plantaren Fortsatz des unteren Randes modifiziert wird. Die Tuberositas ossis navicularis ist beim Weib geringer entwickelt als beim Wann, zeigt jedoch bei letzterem in proximodistaler Richtung und ebenso transversal eine bedeutendere Entfaltung als an einem ungefähr gleichgroßen Fußskelett eines Deutschen. So ist die Tuberositas ossis navicularis distal beim Chinesen 15,0 mm breit, während ich an einem deutschen Fußskelett nur $11,0 \mathrm{~mm}$ finde. Beim Chinesen finden sich lateral vom Plantarabschnitt der Tuberositas ossis navicularie beiderseits eine kräftige, besonders medial scharfbegrenste Rinne, die von medial hinten nach lateral vorn verläuft. Die Tuberositas osais navicularis ragt außerdem beim Mann mehr medial und plantarwärts und ihre Längsachse auf der plantaren Seite ist nicht so schief gestellt als an einem deutschen FuBskelett, so daß dieselbe mehr in die Richtung der Längsachse des ganzen Fußskelettes fällt. Der proximodistale Durchmesser des Oberrandes des Knochens mißt an der Grenze
des Os ouneiforme 1 and 2 beim Weib 15,0 , beim zwischen den Artikulationsflächen des $O_{s}$ cuneiforme 1 und 2 beim Weib 15,0, beim
Mann $15,5 \mathrm{~mm}$, so daB an dieser Stelle das kleine Naviculare des Weibes fast dieselbe 
Ausdehnung erreicht als das fast noch einmal so große Os naviculare des Mannes. Für den Europäer findet Martin an dieser Stelle höhere Zahlen $(18,0-22,0 \mathrm{~mm})$. Auffallend ist die geringe proximodistale Entwicklung am lateralen tbschnitt des Knochens gegenüber der starken Ausbildung medial. An der distalen Gelenkfläche sind die Trennungsleisten für die Gelenkfacetten der drei Keilbeine beim Weib links gering, rechts deutlicher ausgeprägt; beim Mann sind sie ziemlich gut entwickelt. Die gesamte distale Gelenkfläche ist in querer Richtung etwas stärker Konvex als beim Deutschen.

Bezüglich der eben schon hervorgehobenen Dickenentwicklung des Os naviculare am medialen Rande ergibt sich im speziellen, da 8 die Differenz zwischen der kleinsten Dicke des Nariculare (am lateralen Puande) und der gröBten Dicke (am medialen Rande) beim Mann erheblich größer ist als beim Weib, bei letzterem 5,5 , bei ersterem 12,2 mm betragend: beim Mann ist daher der laterale Rand im Verhältnis zum medialen viel geringer entwickelt als beim Weib, ein Charakteristicum primitiver menschlicher Formen. Dementsprechend ist der Dickenindex bei Mann und Weib ein sehr verschiedener; bei ersterem 36.3 , bei letzterem 60,7. Der Dickenindex für das $\subseteq$ ist jedoch wegen Beschädigung des Naviculare am medialen Rande nicht ganz zuverlassig. Während sonst für menschliche Rassen der Dickenindex zwischen 42,1 und 56,4 schwankt, ergibt sich für den Chinesen $s$ ein kleinerer Index als bei Hylobates $(39,3)$. Das aus den vier Zahlen berechnete Mittel ergibt für den Dickenindex 48,5 , ist also etwas größer als beim Neger $(45,0)$. An den deutschen Skeletten ist der mediale Teil des Os naviculare in proximodistaler Richtung geringer entwickelt als beim Chinesen.

Die proximale Gelenkfläche des Os naviculare ist entsprechend der stärkeren Wölbung des Taluskopfes, besonders beim Mann, stärker ausgehöhlt als beim Deutschen, sowohl in querer als auch senkrechter Richtung. Die Facies art. post. erscheint beim Mann birnförmig mit medio-plantar verjüngtem Teil. Etwas lateral von der Mitte des unteren Randes der hinteren Gelenkfläche setzt sich die letztere auf den an seiner Basis $7,0 \mathrm{~mm}$ breiten Processus plantaris fort, wodurch die Höhe des Facies art. post. beim Mann an dieser Stelle um $5,5 \mathrm{~mm}$ vermehrt wird. Beim Weib ist der Processus plantaris gering entwickelt, so daß die Birnform der hinteren Gelenkfläche weniger modifiziert erscheint. Durch den Processus plantaris wird daher die Breite der Facies art. post. beim Mann erheblich vergröBert, was auch für den Längenbreitenindex von EinfluB ist, der dadurch beim Mann höher wird $(84,7)$, während er beim Weib nur 71,3 (Mittel aus beiden Seiten) beträgt. Würde man heim Mann von der Breite der Facies art. post. die Höhe des Processus plantaris in Abzug bringen, so würde sich ein Längenbreitenindex von 67,7 ergeben, der die ovale Form der Facies art. post. deutlich zum Ausdruck bringt.

Die Breite des Os navieulare schwankt zwischen 30 und $40 \mathrm{~mm}$, die Höhe zwischen 21 und $31 \mathrm{~mm}$. Die geringere Höhe beim Weib links rüht von der ge. ringen Ausbildung des Processus plantaris her. Dex mittlere Breitenhöhenindex beträgt 76,3 .

\begin{tabular}{|c|c|c|c|c|c|c|}
\hline & \multirow[t]{2}{*}{ Os euboideum. } & \multicolumn{2}{|c|}{ \% } & \multicolumn{2}{|c|}{$\mathrm{s}^{3}$} & \\
\hline & & Inksis & recht: & links & rewhts & Mitt \\
\hline 1. 1 & & 30,7 & 30,1 & 36,2 & 36 & 33 \\
\hline le Länge des Cuboids & & 10,0 & 10,0 & 17,3 & 17,5 & 13,7 \\
\hline ingenindex $\ldots \ldots$ & & 32,6 & 33,2 & 47.8 & 47,9 & 40,1 \\
\hline
\end{tabular}


E. Kurz:

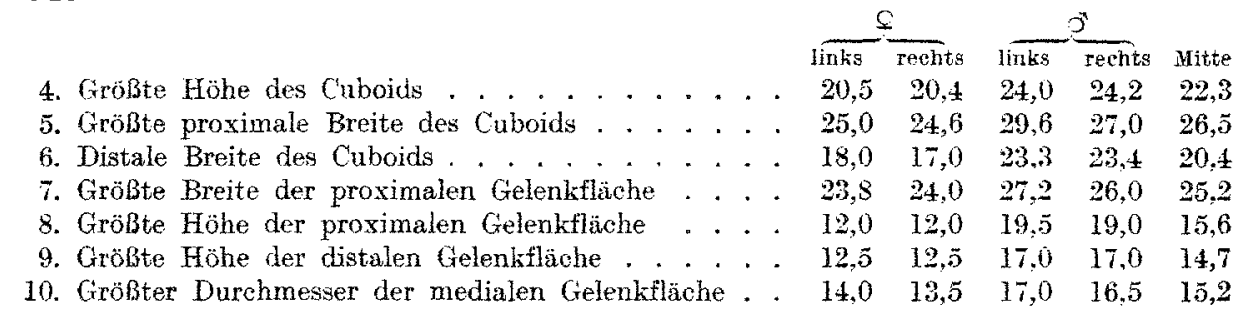

Die mediale Länge des Os cuboideum übertrifft die laterale beim Weib um das Dreifache, beim Mann nur um das Doppelte. Dementsprechend beträgt der Längenindex beim Weib 32,9, beim Mann 47,8. Der laterale Rand ist somit beim Weib proximodistal sehr gering entwickelt, ein primitiver Zustand, wie er auch für die Senoi und Weddas angegeben wird. Proximale und distale Gelenkfläche stoßen lateral beim Weib unter einem Winkel von $55^{\circ} 5^{\prime}$, beim Mann von $39^{\circ} 2^{\prime} z u$ sammen. Die dorsale Fläche des Cuboids zeigt im distalen Abschnitt auf beiden Seiten eine Einschnürung. Die mediale Einschnürung kommt durch den mediodorsalen Vorsprung der distalen Gelenkfläche zustande, die laterale wird durch den von der plantaren Fläche auf den lateralen Rand des Knochens sich erstreckenden Sulcus M. peronaei hervorgerufen. Beim Weib ist diese Einschnürung geringer ausgeprägt.

Die proximale Fläche weist beim Mann einen großen, beim Weib einen geringen Höhendurchmesser auf. Dementsprechend ist das Cuboid des letzteren im proxi. malen Teil sehr niedrig gegenüber dem des Mannes. Der mediale Abschnitt der proximalen Gelenkfläche ist beim Mann stärker. mediolateral konvex und dorsoplantar konkav gewölbt als an deutschen Skeletten. Die größte Tiefe beträgt beim Mann $2,1 \mathrm{~mm}$. Beim Weib ist der mediale Abschnit der proximalen Gelenkfläche nur wenig ausgehöhlt, dagegen in querer Richtung sehr stark konvex gewölbt. Mit der geringen proximo-distalen Entfaltung des lateralen Cuboidrandes hängt es zusammen, daß der laterale Teil der proximalen Gelenkfläche sehr schief nach außen und vorn gewandt ist.

Die distale, annähernd birnförmige Gelenkfläche ist durch eine schwach ausgebildete, dorsoplantare Leiste beim Mann in eine schmälere und höhere mediale und eine breitere und niedrigere laterale Gelenkfacette geschieden. Die erstere ist 18,3 , die letztere $15,0 \mathrm{~mm}$ breit. Beim Weib sind beide Gelenkfacetten ungefähr gleich breit. Die distale Gelenkfläche ist beim Mann dorsoplantar ziemlich stark konkav, namentlich rechts; in stärkerem Maße als an deutschen Skeletten.

Die größte Tiefe beträgt $2,2 \mathrm{~mm}$. Beim Weibe ist jede der beiden distalen Facetten leicht konkav. Auf der lateralen Fläche greift der Sulcus M. peronaei weit nach dorsal. Hinter diesem lateralen Abschnitt der Rinne befindet sich ein in proximo-distaler Richtung 10,0 mm ausgedehnter Knochenwulst, der auf die plantare Fläche des Cuboids übergreift und hier als starker, 23,0 mm langer und $10,0 \mathrm{~mm}$ breiter Vorsprung parallel mit dem Sulcus M. peronaei zieht, an der Grenze der plantaren und medialen Knochenfläche endigend. Auch beim Weibe ist dieser plantare Knochenvorsprung sehr ausgebildet, wenngleich der Sulcus des M. peronaeus weniger tief und breit ist. Die Peronaeussehnenrinne besitzt beim Mann eine Breite ven 10,0 mm. Proximal von dem erwähnten Knochenwulst auf der plantaren Seite zeigen alle Cuboide eine stärkere große Konkavität als sie an deutschen Skeletten sich findet. 
Die mediale Fläche des Cuboids besitzt in allen Fälen eine nierenförmige, beim Weib ebene, beim Mann ganz leicht konkave Gelenkfläche für das Cuneiforme 3. Dadurch, daß der mediale Rand der distalen Gelenkfläche weit nach innen vorspringt, entsteht die oben erwăhnte Einsenkung distal von der medialen Gelenkfläche für das dritte Keilbein.

\section{Maße: \\ Os cuneiforme $I$.}

1. Untere Länge des Cuneiforme I. . . . . . . .

\begin{tabular}{|c|c|c|c|c|c|}
\hline \multicolumn{2}{|c|}{ Q } & & & \\
\hline inks & rechts & & rechts & links & Mittel \\
\hline 23,0 & $2 \mathcal{9}, 1$ & 27,8 & $2 \pi, 5$ & 24,0 & 24,9 \\
\hline 17,0 & 17.0 & 21,1 & 21,2 & 20,0 & 19,3 \\
\hline
\end{tabular}

2. Wittlere Lange des Cuneiforme I. . . . . . . $\quad 17,0 \quad 17,0 \quad 21,1 \quad 21,2 \quad 20,0 \quad 19,3$

3. Ohere Länge (parallel zum Enterrand) $\quad \begin{array}{lllllll}\text {. . } & 18,0 & 18,0 & 22,0 & 22,0 & 21,0 & 20,2\end{array}$

3a. Geradlinige Entfernung des Oberrandes der proximalen Gelenkfläche $v$. dem d. distal. Celenkfläche

4. Proximale Gelenkflächenhöhe . . . . . . .

5. Distale Gelenkflächenhöhe . . . . . . . .

6. Proximale Hölie . . . . . . . . . . .

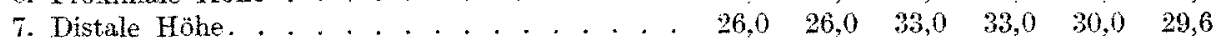

Indives:

Längenhöhenindex des Cuneiforme I.:

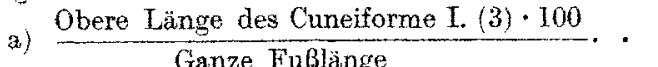
$9,0 \quad 9,0 \quad 9,4 \quad 9,4 \quad-$
b) $\frac{\text { Distale Höhe des Cuneiforme I. (7) } \cdot 100}{\text { Obere Länge des Cuneiforme I. (3) }}$

$20,0 \quad 20,0 \quad 24.1 \quad-\quad 23,0 \quad 21,8$

$17,0 \quad 16,8 \quad 22,3 \quad 22,3 \quad 20,0 \quad 19,7$

$24,0 \quad 23,1 \quad 29,0 \quad-\quad 28,0 \quad 26,0$

$21,1 \quad 21,1 \quad 29,1 \quad 28,9 \quad 23,0 \quad 24,6$

Höhenindex des Cuneiforme I. . . . . . . . $123,2 \quad 123,2 \quad 113,4 \quad 114,2 \quad 130,4 \quad 120,9$

Am Os cuneiforme 1. ist morphologisch die distale Gelenkfläohe arn wichtigsten. Dieselbe ist beim Mann langgestreckt nierenförmig, beim Weib halbmondförmig mit abgerundeten Enden. Der laterale Rand ist beim Mann in der Mitte, entsprechend dem Nierenhilus, stärker nach medial ausgebuchtet als beim Weibe. Die distale Gelenkfläche ist in ihrer größeren dorsalen Hälfte in transversaler und vertikaler Richtung konvex gekrümmt, beim Weib in viel stärkerem Maße noch als beim Mann. Die mediale Hälfte der distalen Gelenkfläche zeigt sich daher medial abgeschrägt, was mit einer stärkeren Abduktion der Großzehe einhergeht. Bei gleicher Orientierung des Cuneiforme I. und Metatarsale I. ist letzterer beim Chinesen mehr nach lateral gewandt als beim Deutschen. Der obere Rand der distalen Gelenkfläche greift zugleich etwas auf die dorso-mediale Fläche des Knochens über, so daß nicht nur die Spreitzung der großen Zehe, sondern auch die Dorsalflexion im Tarsometartarsalgelenk eine größere sein wird als beim Deutschen. Die plantare kleinere Hälfte der distalen Gelenkfläche ist beim Weib ebenfalls konvex, während sich beim Mann in der Mitte eine kleine Telle zeigt. Die proximale, für das Os naviculare bestimmte Celenkfläche des Cuneiforme $T$. ist stärker dorsoplantar und transversal konkay als beim Deutschen Die laterale hintere, für das Cuneiforme II. bestimmte Gelenkfläche ist relativ groß, in dorsoplantarer Pichtung konkav und geht in allen Fälen mit einer ziemlich scharfen Kante in die proximale Gelenkfläche über. Die vordere laterale Gelenkfläche für das Os metatarsale II. ist von der hinteren Gelenkfläche getrennt.

Die Plantarfläche des Os cuneiforme I. zeigt in ihrer proximalen Hälfte beim Mann einen starken umschriebenen Höcker. Die distale Hälfte der Plantarfläche scheint in der Quere geringer entwickelt zu sein als beim Deutschen. 
Waße:

\begin{tabular}{|c|c|c|c|c|c|}
\hline \multicolumn{2}{|c|}{ s: } & \multicolumn{2}{|r|}{5} & & \\
\hline links & $\overline{\text { rechts }}$ & $\operatorname{lnks}$ & $\overline{\text { rechts }}$ & links & Mit \\
\hline 15,0 & 15,0 & 15,5 & 16.0 & 17,3 & 15 \\
\hline 12.0 & 12,8 & 15,9 & 16,1 & 15,0 & 14,4 \\
\hline 8,7 & 9,0 & 13,4 & 13,3 & 12,9 & 11. \\
\hline 12.8 & $12, \tilde{3}$ & 14,5 & 14,9 & 14,0 & 13,7 \\
\hline 18,2 & 18,1 & 20,5 & 22,0 & 21,0 & 20 \\
\hline
\end{tabular}

1. Obere Länge des Cuneiforme II. . . . . . . $\begin{array}{lllllll}15,0 & 15,0 & 15,5 & 16,0 & 17,5 & 15,8\end{array}$

2. Wittlere obere Breite des Cuneiforme II. . . . $12,0 \quad 12,8 \quad 15,9 \quad 16,1 \quad 15,0 \quad 14,4$

3. Distale Breite des Cuneiforme II. . . . . . . $\quad 8,7 \quad 9,0 \quad 13,4 \quad 13,3 \quad 12,9 \quad 11,5$

4. Proximale Breite des Cuneiforme II. . . . . . $\begin{array}{llllll}12,8 & 12,5 & 14,5 & 14,9 & 14,0 & 13,7\end{array}$

5. Hohe des Cuneiforme II. . . . . . . . . . $\quad \begin{array}{llllll}18,2 & 18,1 & 20,5 & 22,0 & 21,0 & 20,0\end{array}$

Indices:

Längenindex des Cuneiforme II. . . . . . . . . . $\begin{array}{ccccccc}7,5 & 7,5 & 6,6 & 6,8 & - & 7,1\end{array}$

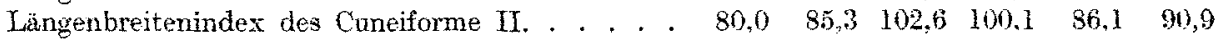

Breitenindex des Cuneiforme II. . . . . . . . . $147,1 \quad 138,9 \quad 108,2 \quad 112,0 \quad 108,5 \quad 122,9$

Das Cuneiforme II. besitzt beim Weibe eine rechteckige, beim Manne eine quadratische Dorsalfläche, wie auch aus den Längen- und BreitenmaBen und dew Längenbreitenindex hervorgeht. Beim Weibe ist ferner noch der distale Teil der Dorsalfläche verschmälert. Die proximale dorsoplantar konkave Gelenkfläche ist beim Manne an der tiefsten Stelle $2,0 \mathrm{~mm}$ tief und scheint damit stärker ausgehöhlt zu sein als an europäischen FuBskeletten. Die distale dreieckige Gelenkfläche ist dorsoplantar und tibiofibular konvex, nur am Cuneiforme III. fast eben. Die mediale Gelenkfläche ist groß, nimmt die ganze dorsale Fläche des Facies med. ein und gibt einen distalen kürzeren und einen proximalen längeren Gelenkflächenfortsatz ab, von denen der letztere die plantare Knochenkante erreicht und dorsoplantar konvex gekrümmt, ist. Die mediale Crelenkfläche scheint größer zu sein als an europäischen Skeletten. Die Facies art. lat. ist in ihrem dorsalen Teil proximodistal stärker entwickelt als bei Deutsehen und dorsoplantar stark ausgehöhlt.

Os Cuneiforme III.

Maße:
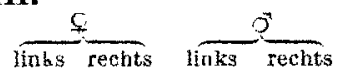

1. Obere Länge des Cuneiforme III. . . . . . . 20,0

$20,0 \quad 20,5$

$24,1 \quad 24,0$

links Mittel

2. Mittlere obere Breite des Cuneiforme III. . . 14,0

14,5

14,0

3. Distale Breite des Cuneiforme III. . . . . . . 12,8
4. Proximale Breite des Cuneiforme III.
.

12,1

$15,0 \quad 14,1 \quad 13,0 \quad 13,4$

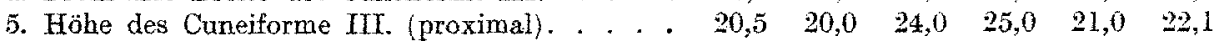

\section{Indices:}

Längenindex des Cuneiforme III. . . . . . . . . $\quad \begin{array}{llllll}10,0 & 10,2 & 10,2 & 10,2 & - & 10.2\end{array}$

Langenbreitenindex des Cuneiforme III. $\quad . \quad . \quad \begin{array}{cccccc}70,0 & 70,3 & 58,1 & 58,3 & 60,3 & 63,4\end{array}$

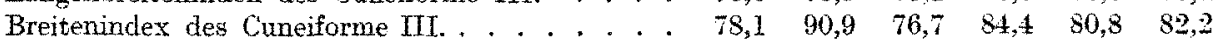

Die Dorsalfläche des Cuneiforme III. ist schmäler als an deutschen Skeletten; der Rücken des Keiles damit weniger quer ausgedehnt. Die proximale Gelenkfläche ist eben. Die mediale Fläche des Knochens besitzt eine proximal annähernd birnförmige, dorsovolar und proximodistal konvex gewölbte Gelenkfläche für das Os cuneiforme II. ; distal befinden sich zwei übereinander liegende halbmondförmige Gelenkflächen für die fibulare Seite des 2. Metatarsale. Auf der lateralen Seite liegen proximal eine nierenförmige Gelenkfläche für das Cuboid und distal eine nur ganz kleine, halbmondförmige Gelenkfläche für die tibiale Seite des 4. Metatarsale. Die distale Fläche ist ganz leicht konkar oder eben. 


\section{Ossa metatarsalia.}

Wie bei anderen Rassen ordnen sich die Ossa metatarsalia der Länge nach in folgende Reihe: $2,3,4,5,1$. Das $O$ s metatarsale 1 ist am kürzesten, wie das auch bei Japanern immer der Fall ist. Die bei Europäern und Japanern im Mittel $3,0 \mathrm{~mm}$ betragende Längendifferenz des Os metatarsale 2 und 3 ist beim Chinesen etwas gröBer $(4,1)$, während für primitive Rassen eine nur geringe Längendifferenz angegeben wird. Die Diaphysen der Ossa metatarsalia sind schlanker und proximale sowie distale Epiphysen schmäler als beim Europäer. Die Corpora der Ossa metatarsalia verschmälern sich in ihrem distalen Teil bei letzteren plötzlich, während sie beim Chinesen mit einem sanft konkaven Bogen in die distalen Epiphysen übergehen.

Die Längsachsen des Os metatarsale I und Cuneiforme 1 bilden beim Chinesen einen stumpfen, nach medial offenen Winkel, während sie beim Europäer in eine Richtung fallen. Namentlich beim Weib sieht man, wie die distale Halfte des Os cuneiforme 1 nach medial scharf abgeknickt ist, so daß die distale Gelenkfläche statt rein nach rorn, wie beim Europäer, nach medial gewandt ist, ein Cberbleibsel der alten Greiffußverhältnisse. Entsprechend der stärkeren Wölbung der distalen Gelenkfläche des Cuneiforme 1 ist auch die Höhlung des Os metatarsale 1 eine größere und gegen den nicht artikulierenden Teil sehärfer abgegrenzt. Das Spatium interosseum 1 ist weiter als beim Europäer.

\section{Phalangen.}

Zum Vergleiche der Längenmaße der Phalangen gebe ich eine Tabelle der Längen der einzelnen Zehenglieder beim Europäer nach Pfitzher und die Mittelmaße beim Chinesen.

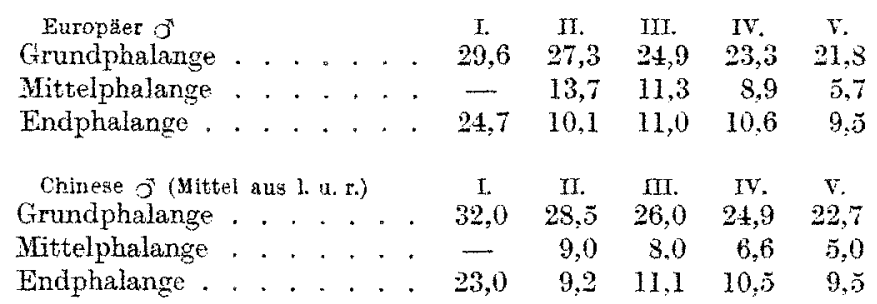

Es ergibt sich aus dieser Tabelle, dab alle Grundphalangen länger und zugleich schlanker sind als an deutschen Skeletten. Die Grundphalangen haben also eine geringere Reduktion erfahren als beim Europäer; auch ist der erste Strahl beim Chinesen länger als beim Europäer. Die proximalen und distalen Epiphysen der Grundphalangen sind schmäler, die Mittelphalangen beim Chinesen kürzer als beim Europäer. Dagegen zeigen die Endphalangen dem Europäer gegenüber nur eine geringe Längendifferenz. Ordnet man die Phalangen der Länge nach, so ergeben sich folgende Reihen:

$$
\begin{aligned}
& \text { Grundphalange , ...... 1,2,3,4,5 } \\
& \text { Mittelphalange . . . . . . }-2,3,4,5 \\
& \text { Endphalange . . . . . . 1, 3, 4, 5, } 2
\end{aligned}
$$

Die Endphalangen sind viel schmäler als beim Europäer; namentlich beim Weib sind sie äuBerst schlant und zugespitzt. An der vierten und fünften Zehe 
sind beim Weib Mittel- und Endphalange miteinander verschmolzen. Beim Mann sind sämtliche Endphalangen selbständig. Die beiden Phalangen der großen Zehe bilden in höherem Grade als bei Deutschen einen lateralwärts offenen Winkel, wie das auch bei Japanem, Feuerländern, Weddas und Senois sich findet.

\section{Der FuB als Ganzes.}

Für die Strahlenlünge gilt als Reihenfolge: $2,1,3,4,5$. Der erste Strahl ist beim Chinesen länger $(118,0 \mathrm{~mm})$ als beim Europäer $(114.5 \mathrm{~mm})$. Vergleicht man die Länge der Fußwurzeln mit der Länge des $0_{s}$ metatarsale 2, so ergibt der Tarsallängenindex für

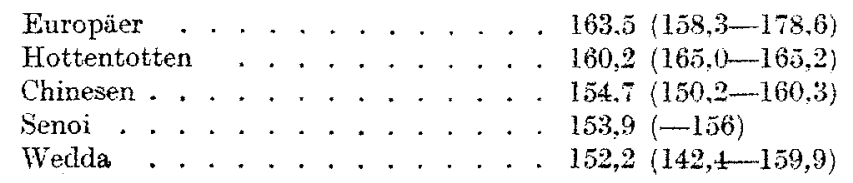

Die Fußwurzel ist also im Verhältnis zum Mittelfuß beim Chinesen wie bei den Senoi und Weddas weniger proximodistal entfaltet als beim Europäer. Bei den Affen ist dieser Index noch geringer, die Fußwurzel also noch kürzer. So sind beim Chinesen noch sehwache Anklänge an die alte Kletterfunktion. des Fußes erhalten.

Der Tarsalbreitenindex schwankt beim Chinesen zwischen 75,9 and 85,9 (Mittel aus vier Zahlen 80,4 ); er ist also ungefähr so groß wie beim Europäer. Bezüglich des Fußgewölbes ist hervorzuheben, daß es geringer ausgeprägt ist, als beim Europäer. Maße des Metatarsus, der Phalangen und des Fußes als Ganzes siehe Tabelle.

\section{Netatarsus.}

1. Lange des Os metatarsale 1

la.

2.

3. Breite des Corpus ossis metat

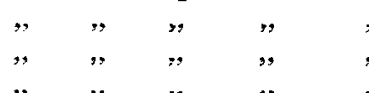

$$
\begin{aligned}
& \text { " }, \quad \text { " " " , }
\end{aligned}
$$

4. Höhe des Corpus ossis metatars.

$$
\begin{array}{llll}
, & \text { " } & , & , \\
, & , & , & , \\
, & \text { " } & \text { " } & ,
\end{array}
$$

5. Breite der Basis des Os metatars.

$$
\begin{array}{ll}
, & 2 \\
, & 3 \\
, & 4 \\
, & 5
\end{array}
$$

\begin{tabular}{|c|c|c|c|c|}
\hline links & rechts & links & rechts & Mittel \\
\hline 55,0 & $\overline{5} 5,0$ & 62,0 & - & 57,3 \\
\hline $53, \overrightarrow{5}$ & 53,0 & 60,1 & - & $\tilde{5} \tilde{ต}, 5$ \\
\hline 65,2 & 650,9 & 74,0 & 73,3 & 69,6 \\
\hline 61,0 & 61,0 & 70,0 & 70,0 & 65,5 \\
\hline 58,0 & 58,0 & 66.5 & 67,1 & 62,4 \\
\hline 57,1 & 57,0 & 65.0 & 66,5 & 61,4 \\
\hline 10,1 & 9.8 & 14,0 & - & 11,3 \\
\hline 6,0 & 6,8 & 8,0 & 8,0 & 7,2 \\
\hline 5,1 & 5,9 & 6.5 & 7,0 & 6.1 \\
\hline 4,9 & 5,9 & 6,8 & 6,9 & 6,1 \\
\hline 7,0 & 8,2 & 9,5 & 10,0 & 8,7 \\
\hline 11,0 & 11,2 & 18,5 & - & 11,9 \\
\hline 7,0 & 6.9 & 8,0 & 8,5 & 7,6 \\
\hline 6,8 & $6, \overline{0}$ & 8.4 & 8,0 & 7,4 \\
\hline 7,0 & 7,4 & 8,2 & 9,5 & 8,0 \\
\hline 6.0 & 6,0 & 7,0 & 7,5 & 6,6 \\
\hline 15,0 & 14,8 & 20,0 & - & 16,6 \\
\hline 13,0 & 13,0 & 15,9 & 15,9 & 14,4 \\
\hline 11,0 & 10,6 & $\{3, \overrightarrow{3}$ & 13,6 & $12, \hat{2}$ \\
\hline 9.0 & 9,5 & 10,5 & 12.0 & 10,2 \\
\hline 16,0 & 16,5 & 21,0 & 21,0 & 18,6 \\
\hline 24,0 & 24,0 & 29,0 & - & 25,7 \\
\hline 17,0 & 18,0 & 22,0 & 21,9 & 19,7 \\
\hline 17,0 & 17,0 & 19,5 & 19,5 & 18,2 \\
\hline
\end{tabular}

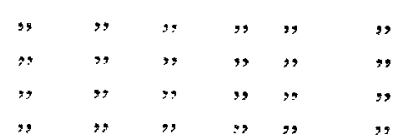

6. Höhe der Basis des Os metatars.
C. Mabe in mu 


\begin{tabular}{|c|c|c|c|c|c|c|c|c|c|c|c|c|}
\hline & & & & & & & & & Mabe & in num & $3^{*}$ & \\
\hline & & & & & & & & links & rechts & $\sqrt{\operatorname{lnks}}$ & $\overline{r e c h t s}$ & Mittel \\
\hline döhe & der & Basis des & Os me & etatars. 4 & & . & & 13,0 & 13,5 & 18,9 & 18,0 & 16,1 \\
\hline & , & & &,$\quad 5$ & & . & . & 10,0 & 11,5 & 16,0 & 16,3 & 13,6 \\
\hline Breite & des & Capitulum & $\mathrm{n}$ ossis & metatars. & 3. 1 & . . & 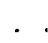 & 16,5 & 15,1 & 22,0 & - & 17,9 \\
\hline$"$ & : &, & $"$ & , & 2 & . & . & 5,0 & 7,0 & 11.0 & 一 & 7.8 \\
\hline , & $"$ & $\because$ & $"$ & $\because$ & 3 & . & . & 5,5 & - & 9,0 & - & 7,2 \\
\hline ", & ", & ", & " & ", & 4 & . & . & 6.0 & - & 9,0 & - & 7,5 \\
\hline ", & $"$ & & , & , & 5 & . & & 6,0 & $\ldots$ & 11,0 & 11,0 & 9,3 \\
\hline Höhe & des & Capitulum & ossis & metatars. & 1. & . & . & 16,0 & 15,5 & 23.1 & - & 17,9 \\
\hline$"$ & $"$ &, & $"$ & , & 2 . & . & . & 10,0 & - & 16,5 & 16.3 & 14,3 \\
\hline :" & : & $n$ & , & , & 3 & & & 11,0 & - & 15,5 & 14,5 & 13,8 \\
\hline ., & ", & " & ", & ,. & 4 & . & . & 11,9 & - & 14.5 & 14.5 & 13,6 \\
\hline$\because$ & $\because$ & $"$, & ", & ," & 5 & . . . & & 10.0 & - & 14,1 & 11,0 & 11,7 \\
\hline agitt: & alkur & rvenlänge & des Ca & pitulum o & ossis & metatars. & 1. & 24,5 & 24,5 & 1 & - & 27,7 \\
\hline & $"$ & & $"$ & $"$ &, & , & 2. & - & - & 21,0 & 25,0 & 23,0 \\
\hline & 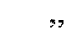 & & & $"$ & , & " & 3. & 19,0 & - & 22,0 & 24,0 & 21,7 \\
\hline & 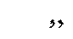 & & & & " & $"$ & 4 . & 18,5 & - & 19,5 & 20,2 & 19,4 \\
\hline & $"$ & & ", & $"$ & , & $"$ & 5 & 13,0 & - & 20,0 & 22,0 & 18,3 \\
\hline
\end{tabular}

Indices:

1. Metatarsaler Beinindex . . . . . . . . $7,8 \quad 7,8 \quad 7, \overline{7}-7,8$

2. Langenindex des Os metatars. 1 . . . . . . 27,5 27,4 26,4 - 27,1

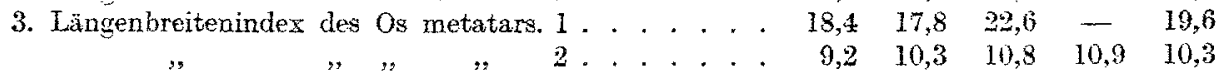

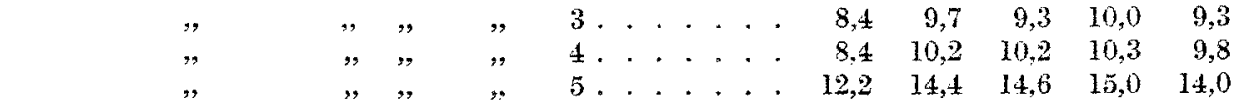

4. Breitenhöhenindex des os metatars. 1 . . . . . $108,9114,3 \quad 96,4-106,5$

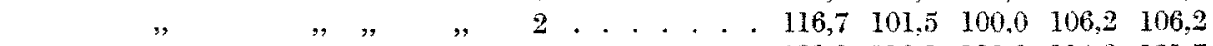

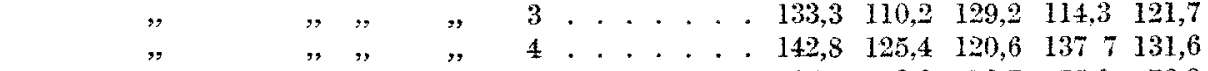

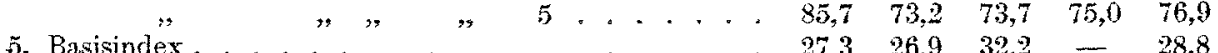

6. Capitulumindex . . . . . . . . . . . . . . . . 30,0 27,4 $35,5=31,0$

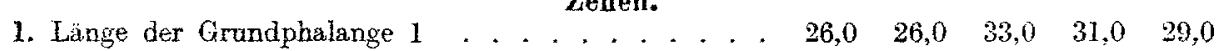

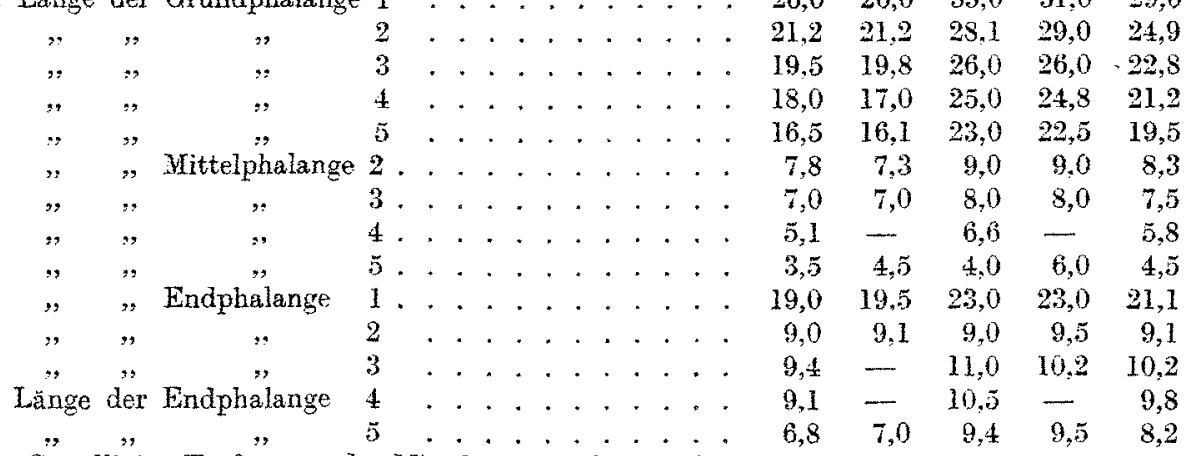

1a. Geradlinige Entfernang dea Mittelpunktes der basalen

Gelenkfläche vom Mittelpunkt der Trochlea:

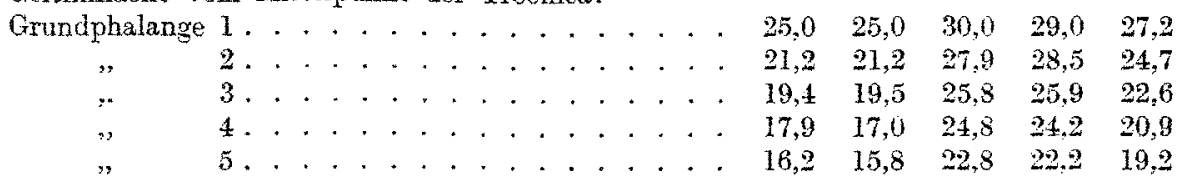


Mittelphalange 2

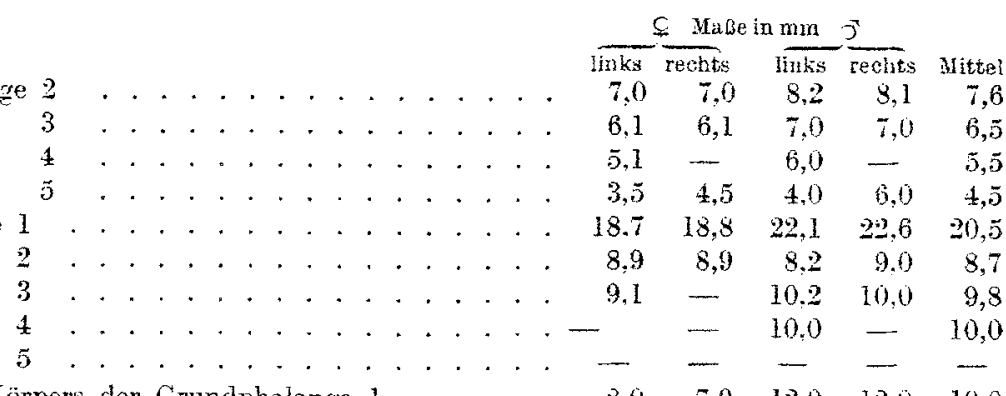

2. Breite des Körpers der Grundphalange 1. . . . . $\begin{array}{cccccc}8,0 & 7,9 & 12,0 & 12.0 & 10,0\end{array}$

Endphalange 1

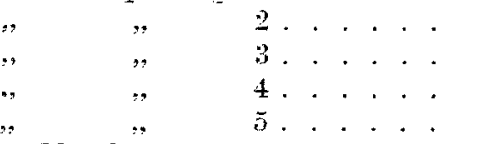

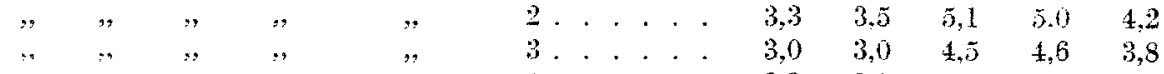

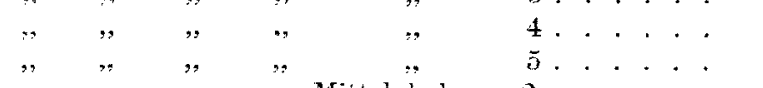

$3,3 \quad 3,2 \quad 4,5 \quad 4,2 \quad 3,8$

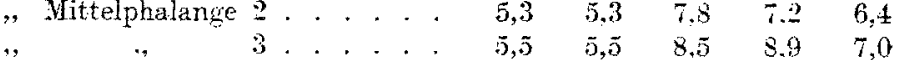

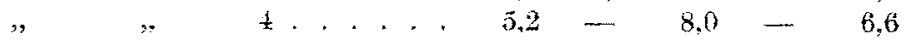

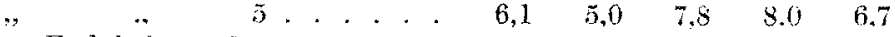

Endphalange 1. . . . . . $6 \begin{array}{lllll}6,0 & 6,0 & 8.8 & 8.9 & 7,4\end{array}$

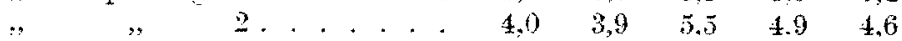

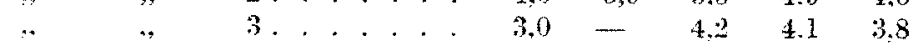

., $\quad$. $\quad 4 . . . . .2,0-4.0-3,0$

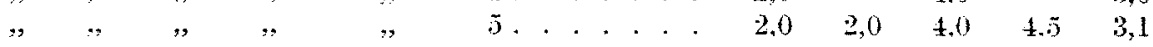

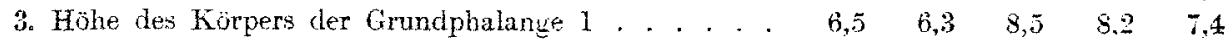

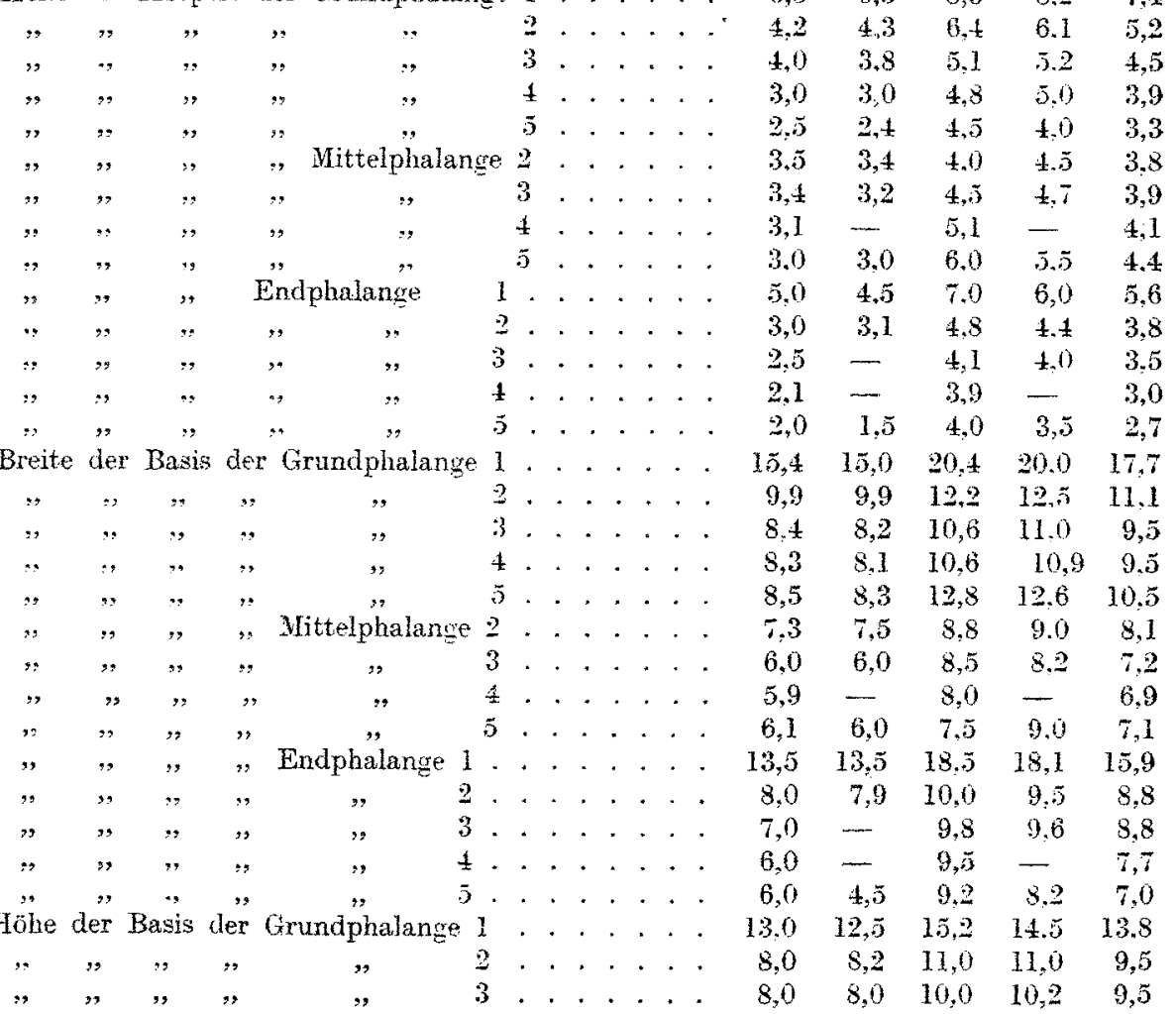




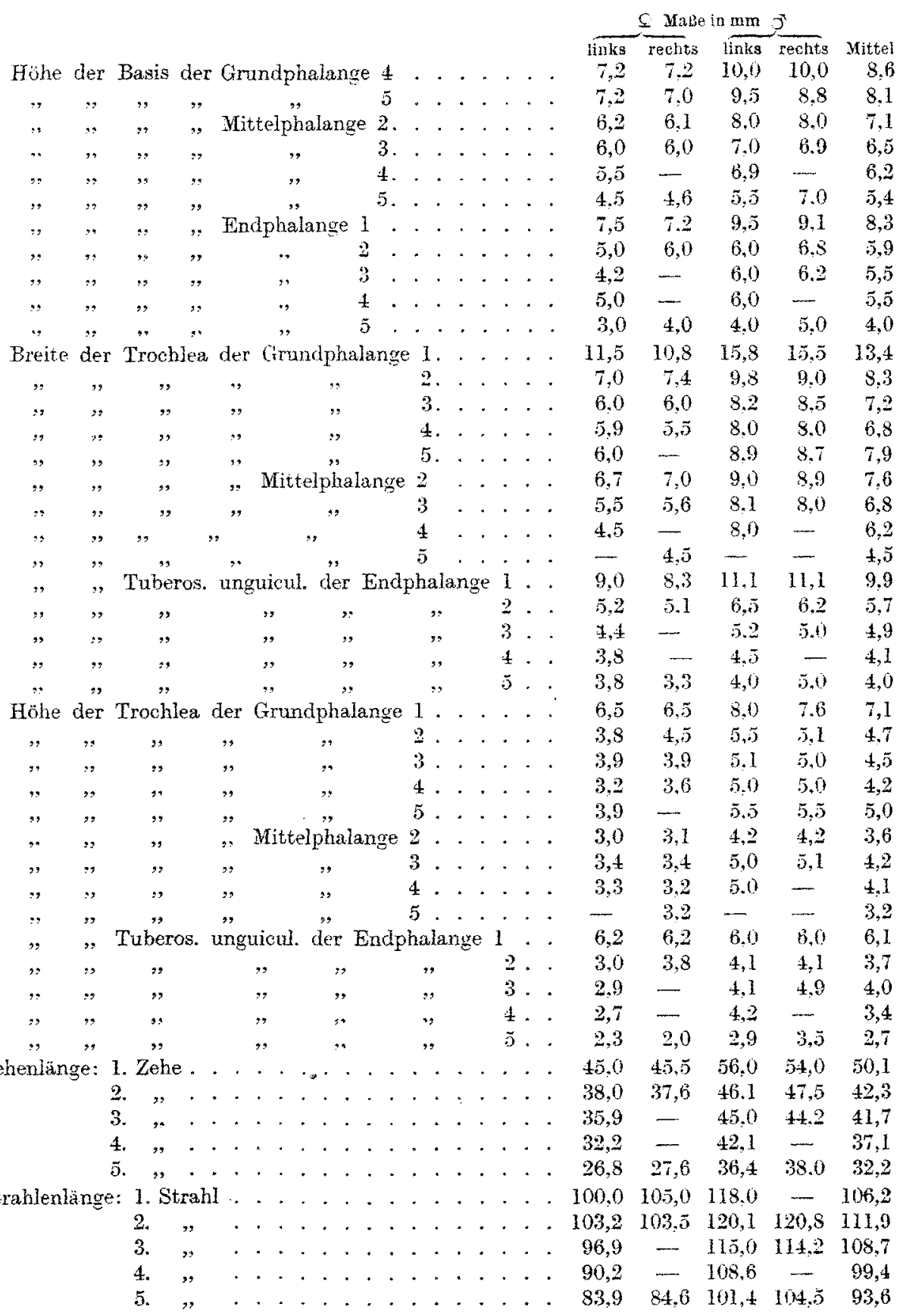

Indices:

Phalanx-Fublängenindex 1. . . . . . . . . . $13,0 \quad 13,0 \quad 14,0 \quad 13,2 \quad 13,3$

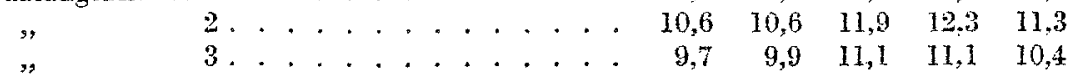




\begin{tabular}{|c|c|c|c|c|c|c|c|c|c|c|c|c|c|}
\hline \multirow{3}{*}{\multicolumn{2}{|c|}{ Phalanx-Fußlängenindex }} & & & & & & & & \multicolumn{2}{|r|}{$\subseteq$} & & \multirow{3}{*}{$\begin{array}{r}\text { Mittel } \\
9,6\end{array}$} \\
\hline & & & & & & & & & $\operatorname{links}$ & $\overline{\text { rechts }}$ & links & reents & \\
\hline & & 4. & & & & . & & & 9,0 & 8.5 & 10,6 & $10, \overline{5}$ & \\
\hline 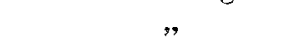 & & 5 & & & & . & . & & 8,2 & 8,0 & 9.8 & 9,6 & 8,9 \\
\hline Chenfußlängenindex & & & & & & . & . & & $22, \overline{0}$ & 22,7 & 23,8 & 23,0 & 23,0 \\
\hline, & 2 & 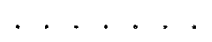 & . & . & & . & . & & 19,0 & 18,7 & 19,6 & 20,2 & 19,4 \\
\hline " & 3 & . . . & . . & . & & . & . & & 17,9 & - & 19,1 & 18,8 & 18,6 \\
\hline ", & 4 & . . . & . . & . & & . & & & 16,1 & - & 17,9 & - & 17,0 \\
\hline , & 5 &..$\quad$. & . & . & . & . & . & & 13,4 & 13,8 & 15,5 & 16,2 & 14,7 \\
\hline Strahlenlängenindex & 1. & . . . . & . & . & . & . & . & & 45,0 & 45,3 & 47,4 & - & 45,9 \\
\hline , & 2 & . . . & . & . & . & . & . & & 36,8 & 36,3 & 38,4 & 39,3 & 37,7 \\
\hline$"$ & 3 & . . . & . & 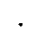 & . & . & . & & 37,0 & - & 39,1 & 38,7 & 38,3 \\
\hline » & 4 &. & . & & . & . & . & & 35,7 & - & 88.8 & - & 37,2 \\
\hline & 5 & & . & & . & . & . & & 31,9 & 32,5 & & 36,4 & 34,2 \\
\hline ängenbreitenindex & der & Grundphalange & 1 & & . & . & . & & 30,8 & 30,4 & 36,4 & 38.7 & 34,1 \\
\hline " & $"$ & ," & $\underline{2}$ & & & . & . & & 15,6 & 16,5 & 18.1 & 17,2 & 16,8 \\
\hline$\because$ & $"$ & , & 3 & & & . & . & & 16,4 & 15,1 & 3 & 17,7 & 16,4 \\
\hline$\%$ & $"$ & $"$ & 4 & & & . & & & 18,3 & 18,8 & 18,0 & 16,9 & 18,0 \\
\hline 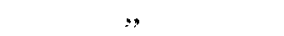 & , & & 5 & & & . & . & & 24,2 & 24,8 & 29,3 & 27,1 & 26,1 \\
\hline$\because$ & 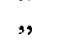 & Mittelphalange & 2 & & & . & & & 67,9 & 72,6 & 36.7 & 80.0 & 76,8 \\
\hline, & , & $-2+2+2-0$ & 3 & & & . & . & & 71,4 & 78,8 & 106,2 & 111,2 & 91,9 \\
\hline$n$ & , & , & 4 & & & . & . & & & - & & $\ldots$ & 111,5 \\
\hline ," & ", & & 5 & & & & & & 74,3 & 111,1 & 195.0 & 133,3 & 153,4 \\
\hline & $"$ & Endphalange 1 & & & & & . & & 31,6 & 30,8 & 38,3 & 38,7 & 34,8 \\
\hline$"$ &, & , $\quad 2$ & & & & & . & & 44,4 & 42,8 & 61,1 & 51,6 & 50,0 \\
\hline & , & 3 & & & & . & . & & 31,9 & - & 38,2 & 40,2 & 36,9 \\
\hline & $"$ & 4 & & & & & . & & 22,0 & - & 38,1 & - & 30,0 \\
\hline & ", & 5 & & & & & . & & 29.4 & 28,6 & 42,5 & 47,4 & 37,0 \\
\hline reitenhöhenindex d & der 1 & Grundphalange & 1 & & & & . & & & 79,7 & 8 & 68,3 & 75,0 \\
\hline & &, & 2 & & & & . & & & 120,8 & & 122,0 & 123,9 \\
\hline & & & 3 & & & & • & & 133,3 & 126,6 & 13,3 & 113,0 & 121,5 \\
\hline & & & 4 & & & & . & & 90,9 & 93,7 & 106,6 & 119,0 & 102,5 \\
\hline & , & 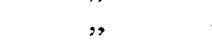 & 5 & & & & • & & 62,5 & 60,0 & 69,2 & 65,6 & 64,3 \\
\hline
\end{tabular}

\section{Tarsus und Fuß als Ganzes.}

1. Länge des Tarsus f . . . . . . . . . . . 98,0 $99,0 \quad 117,0 \quad 117,5 \quad 107,9$

Ia. Zum Cuneiforme 1 . . . . . . . . . . . . $106,0 \quad 106,0 \quad 126,0 \quad 126,0 \quad 116,0$

1b. Zum Cuneiforme 3 . . . . . . . . . . . . $97,0 \quad 95,0 \quad 116,0 \quad 116,5 \quad 106,1$

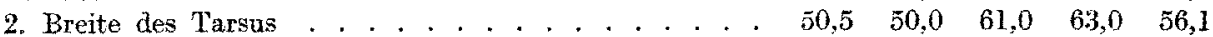

2. (1) Hintere Breite des Tarsus . . . . . . . . . . . $42,0 \quad 43,0 \quad 51,5 \quad 50,0 \quad 46,6$

3. Ganze Fußlänge . . . . . . . . . . . . $200,0 \quad 200,5 \quad 235,0 \quad 235,0 \quad 217,6$

3a. Abstand des am meisten nach hinten vorragenden,

Punktes des Calcaneus von dem distalen Ende der am meisten vorstehenden Zehe, projiziert auf die Längsachse des FuBes . . . . . . . . . . . . 201,0 $199,5 \quad 235,0 \quad 236,0 \quad 217,9$

4. Vordere Fußbreite . . . . . . . . . . . . . $533,0 \quad 52,0 \quad 66,0 \quad 68,0 \quad 59,7$

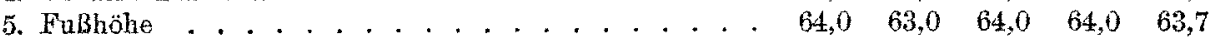

5a. Abstand der Spitze der Malleolus lat. von der Lnter-

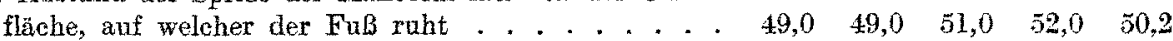

Indices:

Tarsallängenindex:
a) $\frac{\text { Länge des Tarsus }(1) \cdot 100}{\text { Länge d. Os metatars. } 2(2)}$
$\begin{array}{lllll}150,3 & 150,2 & 158,1 & 160,3 & 154,7\end{array}$
b) $\frac{\text { Lange } d \text { Os metatarsale } 1(1) \cdot 100}{\text { Lange des Tarsus }(1)} \ldots \ldots \quad \tilde{56,1} \quad \ldots 5,5 \quad 53,0 \quad-\quad 54,8$ 


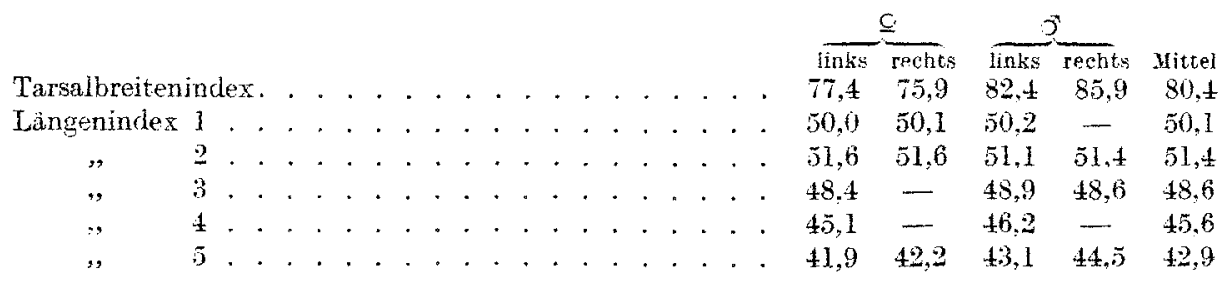

Indices der Skelettproportionen.

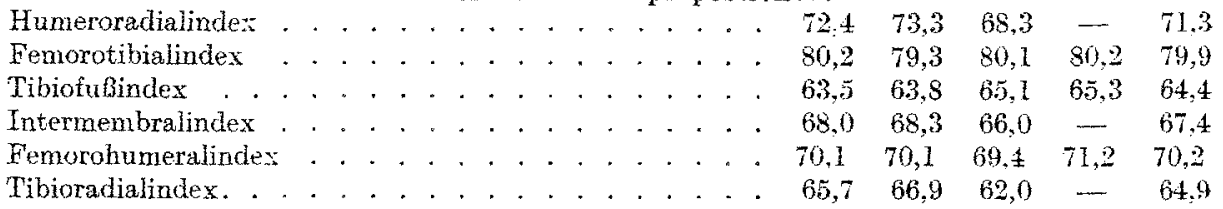

Gewieht der Elemente des Fufskeletts in Millgrammen.

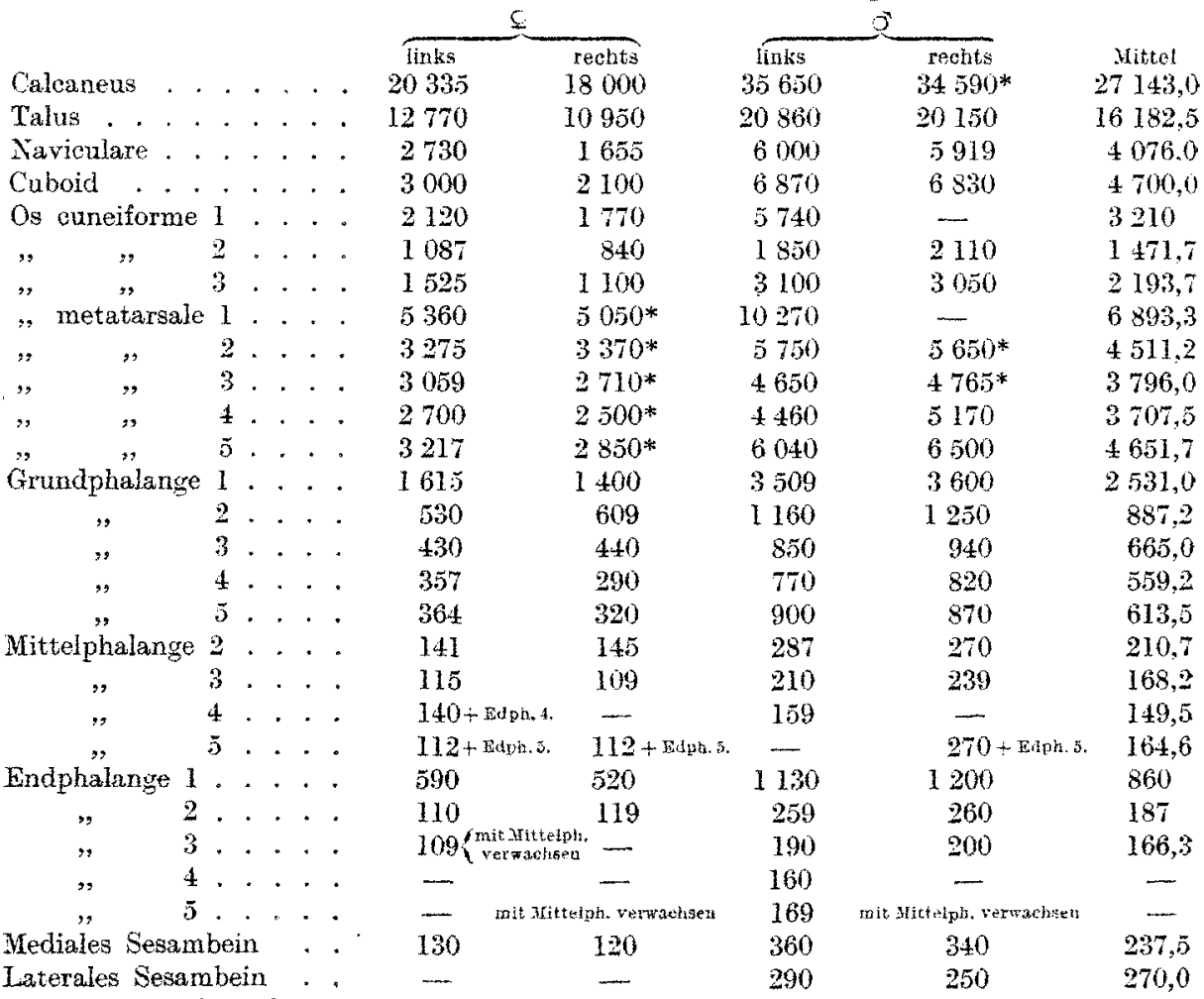

Die mit einem Stern versehenen Zahlen bedeuten, daß der Knochen etwas lädiert war. Beim Weib sind die Knochen der linken Seite infolge ungleicher Präparation etwas fetthaltiger als die der rechten Seite und infolgedessen etwas schwerer. 